\title{
PERFORMANCE TRENDS OF AN AIR-COOLED STEAM CONDENSER UNDER WINDY CONDITIONS
}

by

J. A. van Rooyen

Thesis presented in partial fulfillment of the requirements for the degree of Master of Science in Engineering (Mechanical) at Stellenbosch University

Thesis Supervisor: Prof. D. G. Kröger

March 2007 


\section{DECLARATION}

I, the undersigned, hereby declare that the work contained in this thesis is my own original work and that I have not previously in its entirety or in part submitted it at any university for a degree.

Signature:

Date: 


\section{ABSTRACT}

Air-cooled steam condensers (ACSC's) are increasingly employed to reject heat in modern power plants. Unfortunately these cooling systems become less effective under windy conditions and when ambient temperatures are high. A better understanding of the fundamental airflow patterns about and through such air-cooled condensers is essential if their performance is to be improved under these conditions. For known flow patterns, improved fan designs are possible and flow distortions can be reduced by means of extended surfaces or skirts, windwalls and screens. Spray cooling of the inlet air or the addition of an evaporative cooling system can also be considered for improving performance under extreme conditions.

The present numerical study models the air flow field about and through an air-cooled steam condenser under windy conditions. The performance of the fans is modeled with the aid of a novel numerical approach known as the "actuator disc model". Distorted airflow patterns that significantly reduce fan performance in certain areas and recirculatory flows that entrain hot plume air are found to be the reasons for poor ACSC performance. It is found that the reduction in fan performance is the main reason for the poor ACSC performance while recirculation of hot plume air only reduces performance by a small amount. Significant improvements in ACSC performance are possible under these conditions if a cost effective skirt is added to the periphery of the ACSC while the installation of a screen under the ACSC has very little effect. 


\section{OPSOMMING}

Lugverkoelde stoom kondensors word al hoe meer gebruik om van hitte ontslae te raak in kragstasies. Ongelukkig word hierdie verkoelings-stelsel minder effektief terwyl dit onderhewig is aan winderige toestande en wanneer die atmosfeer se temperatuur hoog is. 'n Beter begrip van die fundamentele lugvloei patroon om en deur die lugverkoelde kondensor is essensieel vir die verbetering van die werkverrigting terwyl dit onderhewig is aan dié toestande. Vir bekende vloei patrone is verbeterde waaier ontwerpe moontlik en die vloei versteurings kan verminder word deur verlengde oppervlaktes of loopvlakke, windwande en windskerms. Sproei verkoeling van die inlaat lug of die byvoeging van 'n verdampingsverkoelings stelsel kan ook oorweeg word vir die verbetering in werkverrigting tydens die uiterste kondisies.

Die huidige numeriese studie modelleer die lugvloei om en deur die lugverkoelde stoom kondensor onder winderige toestande. Die werkverrigting van die waaiers word gemodelleer met behulp van die moderne numeriese benadering wat bekend staan as die "aksie-skyfmodel". Versteurde lugvloei patrone veroorsaak 'n noemenswaardige vermindering in waaier werkverrigting in sekere areas, en die hersirkulerende vloei wat die vasvang van warm pluim lug veroorsaak, word bevind om die redes te wees vir die slegte lugverkoelde stoom kondensor werkverrigting. Daar word bevind dat die vermindering in die waaier werkverrigting die hoofrede is vir die slegte lugverkoelde stoom kondensor werkverrigting, terwyl die hersirkulasie van die warm pluimlug slegs 'n geringe werkverrigting vermindering veroorsaak. Noemenswaardige verbeterings in die lugverkoelde stoom kondensor werkverrigting is moontlik, terwyl dit onderhewig is aan genoemde kondisies as 'n koste effektiewe loopvlak bygevoeg word op die rand van die lugverkoelde kondensor, terwyl die installasie van 'n skerm onder die lugverkoelde kondensor 'n geringe effek het. 


\section{ACKNOWLEDGEMENTS}

I would like to express gratitude towards the following individuals and institutions that made this study possible:

- Prof. D.G. Kröger, my supervisor, for his guidance, motivation and for making this study possible.

- My wife, Karien, for her motivation and encouragement.

- My family, for their support.

- Johan Bredell, for providing the actuator disc model (UDF, $\mathrm{C}^{++}$code) used in this study.

- National Research Foundation (NRF), for their financial support. 


\section{TABLE OF CONTENTS}

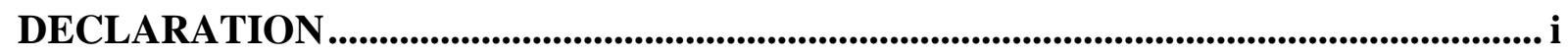

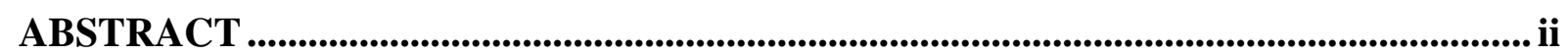

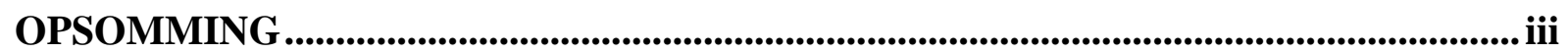

ACKNOWLEDGEMENTS......................................................................................... iv

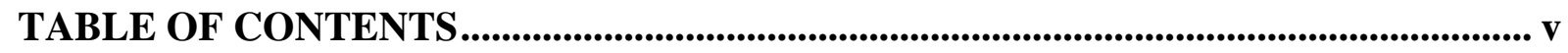

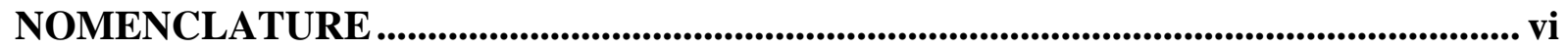

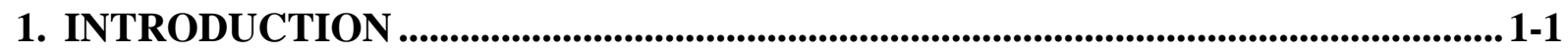

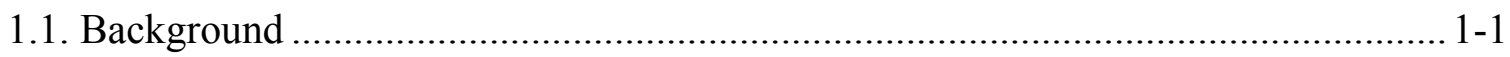

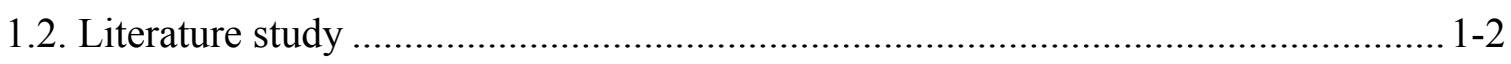

1.3. Outline of report............................................................................................. 1-5

2. PROBLEM STATEMENT AND OBJECTIVES .................................................. 2-1

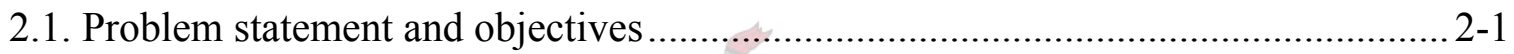

3. NUMERICAL MODELING ............................................................................................ 3-1

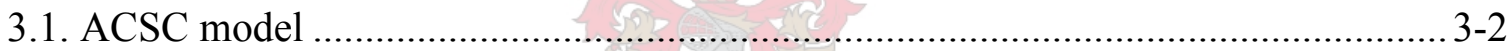

3.2. ACSC fan unit model ...........................................................................................

4. ACSC PERFORMANCE UNDER WINDY CONDITIONS

(WIND IN THE X-DIRECTION) ...............................................................................4 4-1

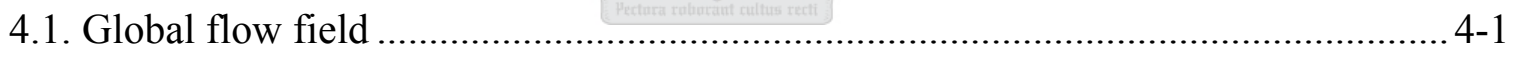

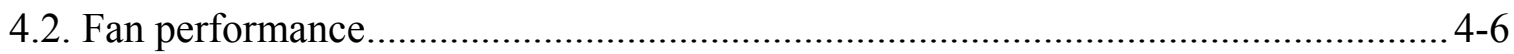

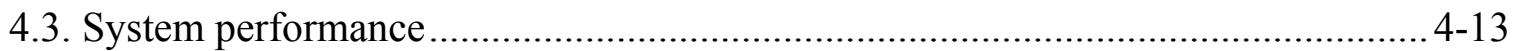

5. ACSC PERFORMANCE UNDER WINDY CONDITIONS

(WIND AT $45^{\circ}$ WITH RESPECT TO X-DIRECTION) ......................................5-1

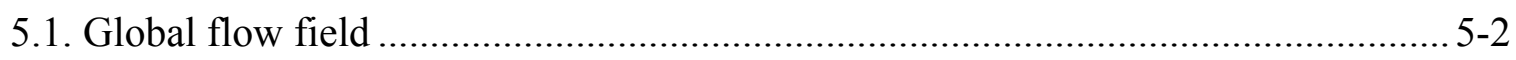

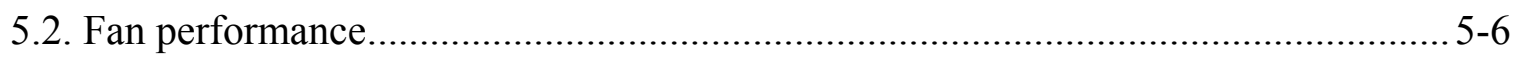

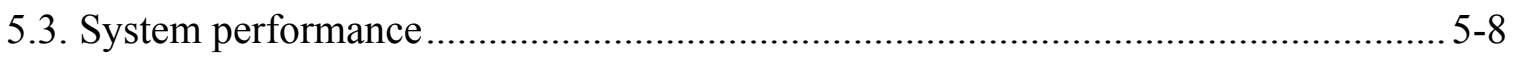

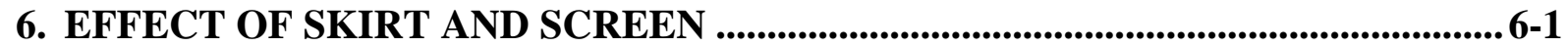

6.1. Effect of skirt width on the upstream fan performance.......................................... 6-1

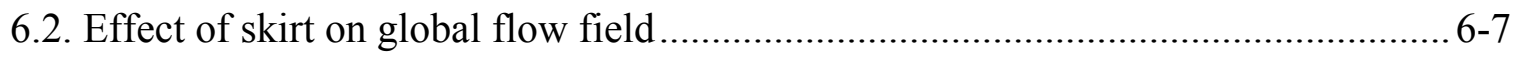

6.2.1. Global flow field with skirt ................................................................ 6-7

6.2.2. Fan performance with skirt ................................................................... 6-10

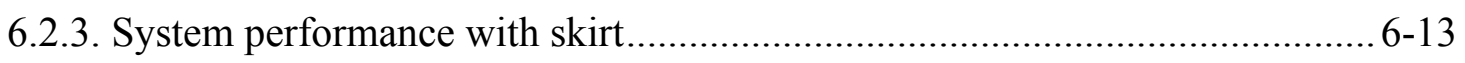

6.3. Effect of screen on the global flow field ............................................................... $6-15$ 


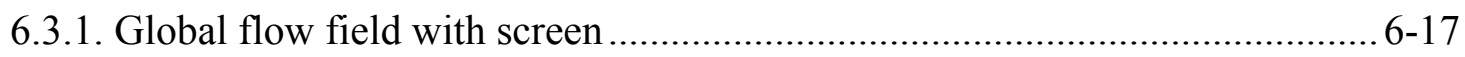

6.3.2. Fan performance with screen ................................................................... 6-18

6.3.3. System performance with screen............................................................. 6-21

7. CONCLUSIONS AND RECOMMENDATIONS ........................................................ 7-1

7.1. Effect of wind on the ACSC performance ......................................................... $7-1$

7.2. Effect of skirt on the ACSC performance ............................................................. $7-2$

7.3. Effect of screen on the ACSC performance .......................................................... $7-4$

7.4. Effect of wind on turbine back pressure ........................................................... $7-4$

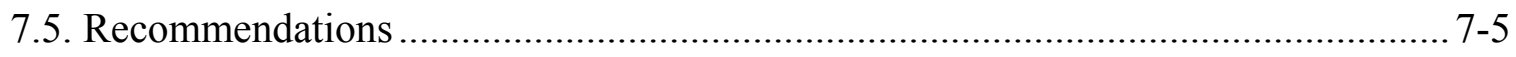

REFERENCES

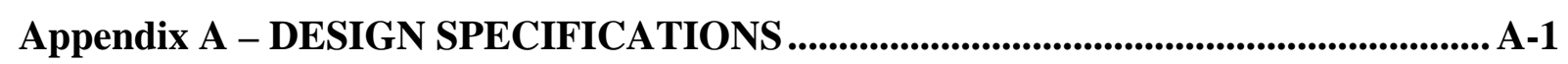

A.1. The thermo-physical properties of the ambient dry air surrounding the ACSC ..... A-1

A.2. Steam condition ......................................................................................... A-1

A.3. Effectiveness of A-frame unit ......................................................................... A-1

Appendix B - FAN SPECIFICATIONS ........................................................................... B-1

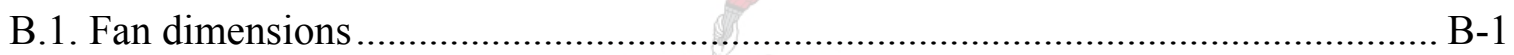

Appendix C - INTERPOLATION SCHEMES ....................................................... C-1

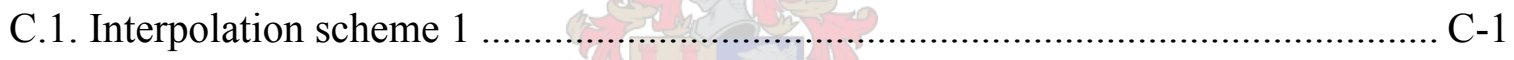

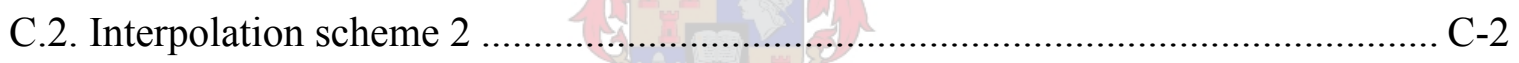

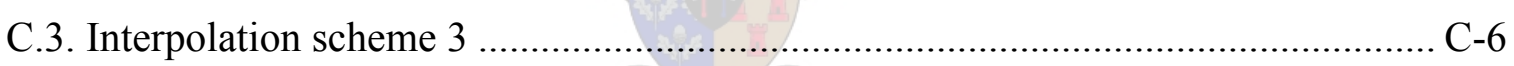

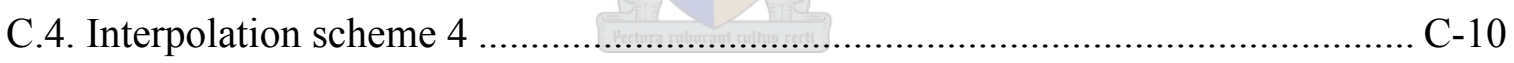

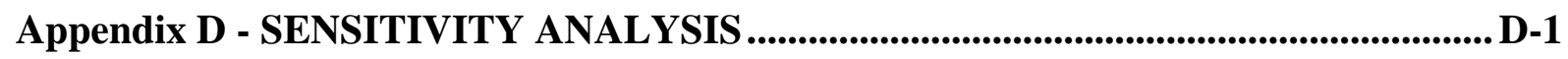

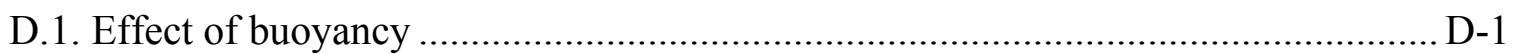

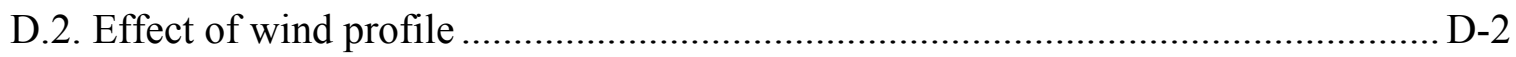

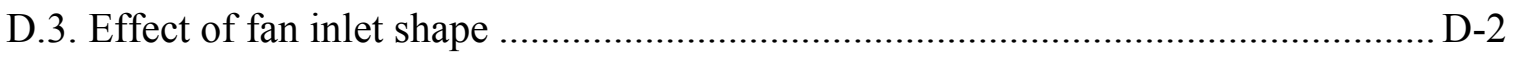

\section{NOMENCLATURE}

\section{Symbols}
A
Area, $\mathrm{m}^{2}$
$\mathrm{b}$
constant
$\mathrm{c}_{\mathrm{p}}$
Specific heat at constant pressure, $\mathrm{J} / \mathrm{kg} \mathrm{K}$
d
Diameter, $m$ 


$\begin{array}{ll}\mathrm{e} & \text { Effectiveness } \\ \mathrm{exp} & \text { Exponential function } \\ \mathrm{F} & \text { Force source term, } \mathrm{N} / \mathrm{m}^{3} \\ \mathrm{~g} & \text { Gravitational acceleration, } \mathrm{m} / \mathrm{s}^{2} \\ \mathrm{H} & \text { Height, } \mathrm{m} \\ \mathrm{i} & \text { Numerical index, } 1,2,3 \ldots \\ \mathrm{j} & \text { Numerical index, } 1,2,3 \ldots \\ \mathrm{K} & \text { Loss coefficient } \\ \mathrm{m} & \text { Mass flow rate, } \mathrm{kg} / \mathrm{s} \\ \mathrm{N} & \text { Rotational speed, } \mathrm{rpm} \\ \mathrm{n} & \text { Number } \\ \mathrm{p} & \text { Pressure, } \mathrm{N} / \mathrm{m}^{2} \\ \mathrm{Q} & \text { Heat transfer rate, } \mathrm{W} \\ \mathrm{T} & \text { Temperature, }{ }^{\circ} \mathrm{C} \text { or } \mathrm{K} \\ \mathrm{U} & \text { Overall heat transfer coefficient, } \mathrm{W} / \mathrm{m}^{2} \mathrm{~K} \\ \mathrm{~V} & \text { Volumetric flow rate, } \mathrm{m}^{3} / \mathrm{s} \\ \mathrm{v} & \text { Velocity, } \mathrm{m} / \mathrm{s} \\ \mathrm{x} & \text { Co-ordinate } \\ \mathrm{y} & \text { Co-ordinate } \\ \mathrm{z} & \text { Co-ordinate } \\ & \end{array}$

\section{Greek symbols}

$\beta_{\mathrm{T}} \quad$ Thermal expansion coefficient, $1 / \mathrm{K}$
$\Delta \quad$ Differential
$\rho \quad$ Density, $\mathrm{kg} / \mathrm{m}^{3}$
$\Sigma \quad$ Summation
$\mu \quad$ Molecular (dynamic) viscosity, $\mathrm{kg} / \mathrm{m} \mathrm{s}$

\section{Subscripts}

$\begin{array}{ll}\text { a } & \text { Air, or ambient } \\ \text { b } & \text { Bellmouth } \\ \text { d } & \text { Design } \\ \text { e } & \text { Effective }\end{array}$




$\begin{array}{ll}\mathrm{f} & \text { Fan } \\ \mathrm{h} & \text { Hub } \\ \mathrm{i} & \text { Inlet } \\ \text { id } & \text { Ideal } \\ \text { ref } & \text { Reference } \\ \text { sc } & \text { Screen } \\ \mathrm{t} & \text { Thermal } \\ \mathrm{v} & \text { Vapor } \\ \mathrm{w} & \text { Water, or wind }\end{array}$




\section{INTRODUCTION}

\subsection{Background}

Air-cooled heat exchangers (ACHEs) are used in systems to reject heat to the atmosphere, which acts as the heat sink. They are typically found in power and chemical plants. Kröger (2004) describes various configurations of air-cooled heat exchangers which are found in practice. An example of a forced draft air-cooled heat exchanger unit is shown schematically in figure 1.1. The air acts as a cooling medium, and is forced through the heat exchanger bundle by means of a fan. The heat exchanger bundle consists of externally finned tubes to increase the contact area between the process fluid and the cooling air.

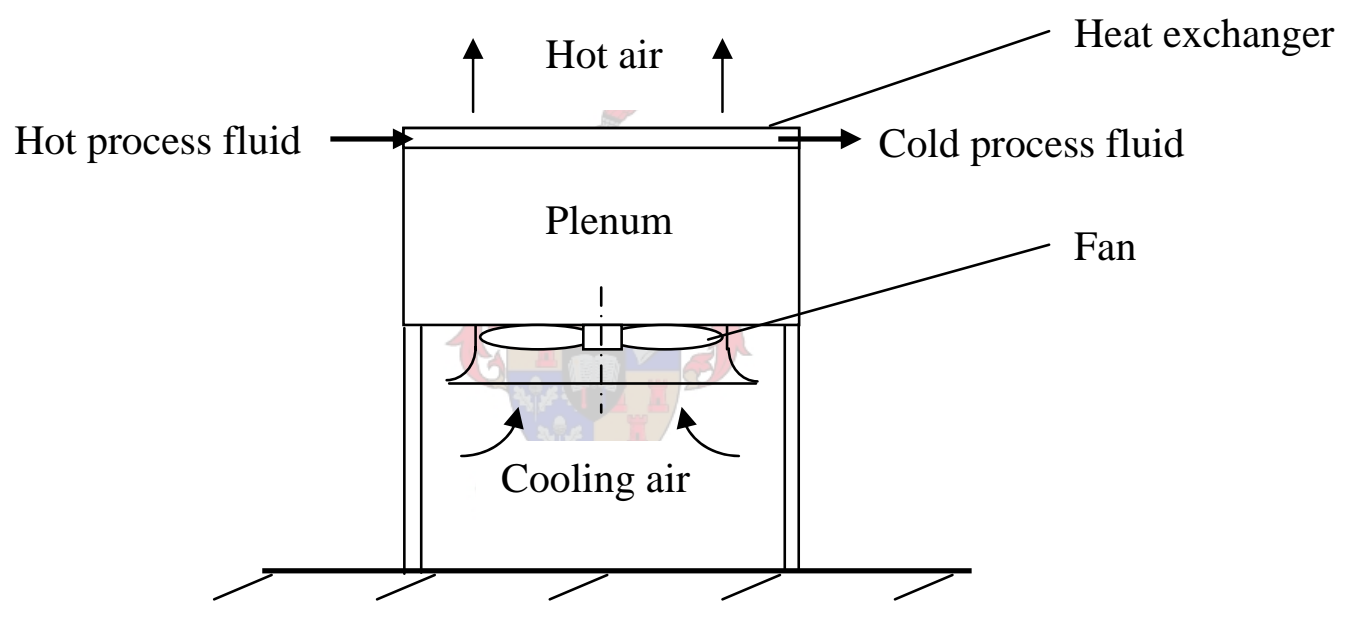

Figure 1.1: Forced draft air-cooled heat exchanger unit.

In a power plant, steam is the process fluid. Heat is rejected from the turbine exhaust steam by means of an air-cooled steam condenser (ACSC). In air-cooled steam condensers, finned tube bundles (heat exchangers) are arranged in the form of an A-frame (figure 1.2) with an apex angle of approximately $60^{\circ}$, thereby reducing the plot area and ensuring drainage of the condensate. Large ACSC's consist of an array of the A-frame or fan units each fitted with an axial flow fan. 


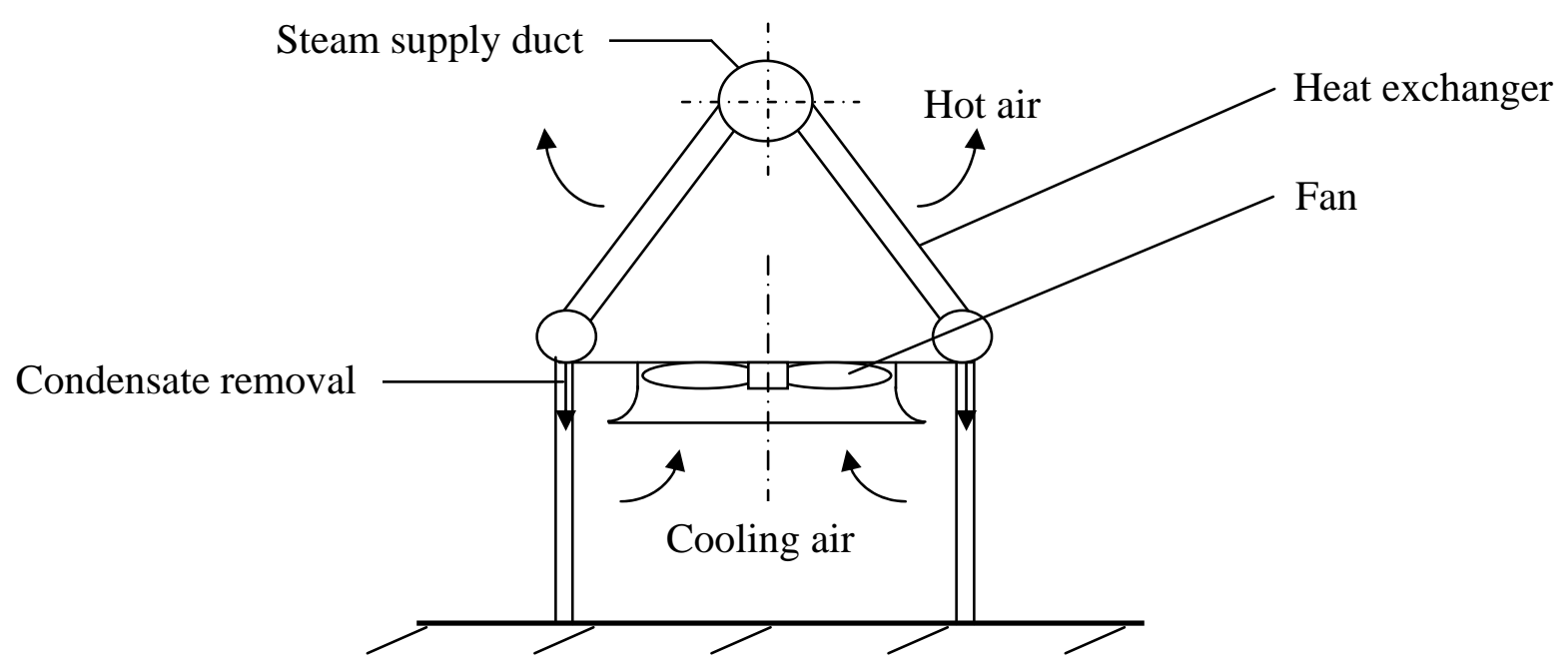

Figure 1.2: A-frame air-cooled steam condenser fan unit.

\subsection{Literature study}

Although it is well known that the performance of ACHE`s and ACSC`s are reduced under windy conditions, very little useful quantitative information concerning this problem is available. A few limited numerical studies have been done to evaluate aspects of the phenomenon.

Van Aarde and Kröger (1990) conducted practical experiments on a full-scale ACSC and they observed that wind had a significant influence on the performance of the particular ACSC. The wind affects the airflow pattern and the static pressure at the inlet to each fan. This in turn affects the volumetric flow rate of the fan. It is evident from this study that wind plays an important role in the performance of an ACSC system.

Goldschagg (1993) found that windy conditions have a negative effect on ACSC performance. This was observed at the world's largest ACSC (Matimba power plant) where the turbine performance was reduced measurably during certain windy conditions and occasional turbine trips occurred under extremely gusty conditions. After extensive experimental and numerical investigations windwalls were added and cladding was removed. Due to the resultant improved air flow pattern into the ACSC, no further trips were experienced and the performance improved significantly (Goldschagg et al.1997). 
Salta and Kröger (1995) conducted laboratory experiments and found that the volumetric effectiveness of a single or multiple fan row ACHE decreases exponentially as the fan deck or platform height is lowered. Their experiments also showed that the volumetric effectiveness of the edge or peripheral fans is always lower than that of the inner fans. Furthermore, their tests also showed that the volumetric effectiveness of the ACHE can be improved by the addition of a walkway or an extension (skirt) of the fan deck or platform.

The negative impact of wind on an ACHE, according to Duvenhage and Kröger (1996), is twofold:

- Hot plume air recirculation occurs when a fraction of the hot buoyant outlet air (plume) is drawn back into the ACHE inlet. This results in an increase in the effective temperature of the cooling air with a corresponding reduction in heat rejection rate.

- Fan performance is reduced (decrease in air mass flow rate through the system) due to distorted inlet air flow conditions.

It is important to note that these two effects are not always coupled. One or the other is usually dominant, depending on the ACHE geometry, wind speed and direction. The present study attempts to quantify the effect that winds have on the performance of an ACSC and to give an indication of the air flow pattern about the ACSC.

An integrated numerical model to predict the global performance of a direct air-cooled power plant is presented by van Staden and Pretorius (1996). They conducted a case study on the Matimba ACSC. Their model not only took into account the effect of the ambient conditions on the ACSC but also the interaction between the steam turbine and the ACSC. Furthermore, they compared their steady state numerical results with data measured on site at the Matimba power plant and revealed good correlation in terms of temperature profiles, velocity distributions and global airflow paths. Due to the relatively simple modeling of the fans the performance characteristics are however unlikely to be very reliable under extreme environmental conditions.

Bredell et al. (2006) numerically investigated the performance of a 2-dimensional forced draft air-cooled steam condenser under windless conditions. The reduction in volumetric effectiveness with a decrease in platform height was successfully modeled and the results were consistent with previous investigations. The numerical flow field showed that the inlet 
flow distortions have a negative effect on the fan flow rate due to a number of factors. The type of fan was also shown to have an effect on the performance of a forced draft ACSC. Furthermore it was shown that the addition of a solid walkway along the edge or periphery of the fan platform or deck significantly improved the performance of the edge fan.

Coetzee and du Toit (2000) conducted a numerical study on the air flow through an ACHE. Despite the many simplifications and assumptions, they claim that numerical modeling (CFD) offers a valuable tool in the performance evaluation of ACHEs. CFD can thus be used to provide useful information concerning ACHE performance under different operating and environmental conditions. Coetzee and du Toit (2004) compared modeling approaches to determine the importance of heat exchanger end-effects. They concluded that an essentially two-dimensional model can be used to represent a heat exchanger bay located near the centre of a large ACHE. They also emphasized the fact that the purpose of their study was not to do a quantitative comparison but rather a qualitative assessment of the importance of end-effects on the operation of an ACHE and that this phenomenon should be investigated in greater depth.

Mehrotra et al. (2003) numerically analyzed the flow about air coolers in a LNG (Liquefied Natural Gas) plant. They observed that the type of skirt (walkway, horizontal or vertical) and the wind direction have a significant impact on the plume's fluid dynamics. The horizontal skirt improves the air cooler performance at all wind speeds and directions, while the vertical skirt reduces plant performance. They also investigated the effect of the horizontal skirt's width, and concluded that as the width was increased to more than $10 \mathrm{ft}$, it resulted in a diminishing return on the performance improvement and a cost increase. Furthermore they also give recommendations on the location of the air cooler with respect to all other equipment (compressors and/or additional bays of air coolers). They do not give information or detail concerning their numerical model.

Meyer (2005) conducted a numerical investigation to determine the effect of the flow distortions on a forced draft air-cooled heat exchanger and concluded that the addition of a walkway improves the volumetric effectiveness of an ACHE. The improvement of the volumetric effectiveness due to the addition of the walkway is more evident at lower platform heights. The removal of certain bell mouth inlets also resulted in an improvement in the volumetric effectiveness of an ACHE system. 
From the above literature study it may be concluded that computational fluid dynamics (CFD) can be effectively employed to investigate the performance of ACHEs (or ACSCs) under windy conditions.

\subsection{Outline of report}

Chapter 2 gives the problem statement and the specific objectives of this study. A more indepth description of the ACSC and the fan unit under consideration in this study is also given.

Chapter 3 provides the information regarding the numerical modeling of the ACSC and the numerical model used to represent the fan in the fan unit model.

Chapters 4 and 5 present the numerical modeling of the ACSC under consideration. The flow field about the ACSC at different wind speeds and directions is discussed, and the effect that wind has on the overall performance of the ACSC.

In chapter 6 the effect of the addition of a skirt or a screen is presented, with the purpose of improving the performance of the ACSC.

In chapter 7 conclusions are drawn and recommendations are made, from the results of this study, for further research. 


\section{PROBLEM STATEMENT AND OBJECTIVES}

\subsection{Problem statement and objectives}

The trend in performance and thermal-flow characteristics about and through the ACSC shown schematically in figures 2.1 and 2.2 under windy conditions will be determined numerically (CFD) with the aid of a commercial fluid dynamic code, FLUENT.

The particular ACSC consists of an array of 6 (rows or streets) $\times 5$ (columns) $=30$ A-frame heat exchanger or fan units as shown in figure 1.2. Fans are numbered according to row number (i) and column (j), i.e. (i,j). Ambient and steam conditions are specified in Appendix A.

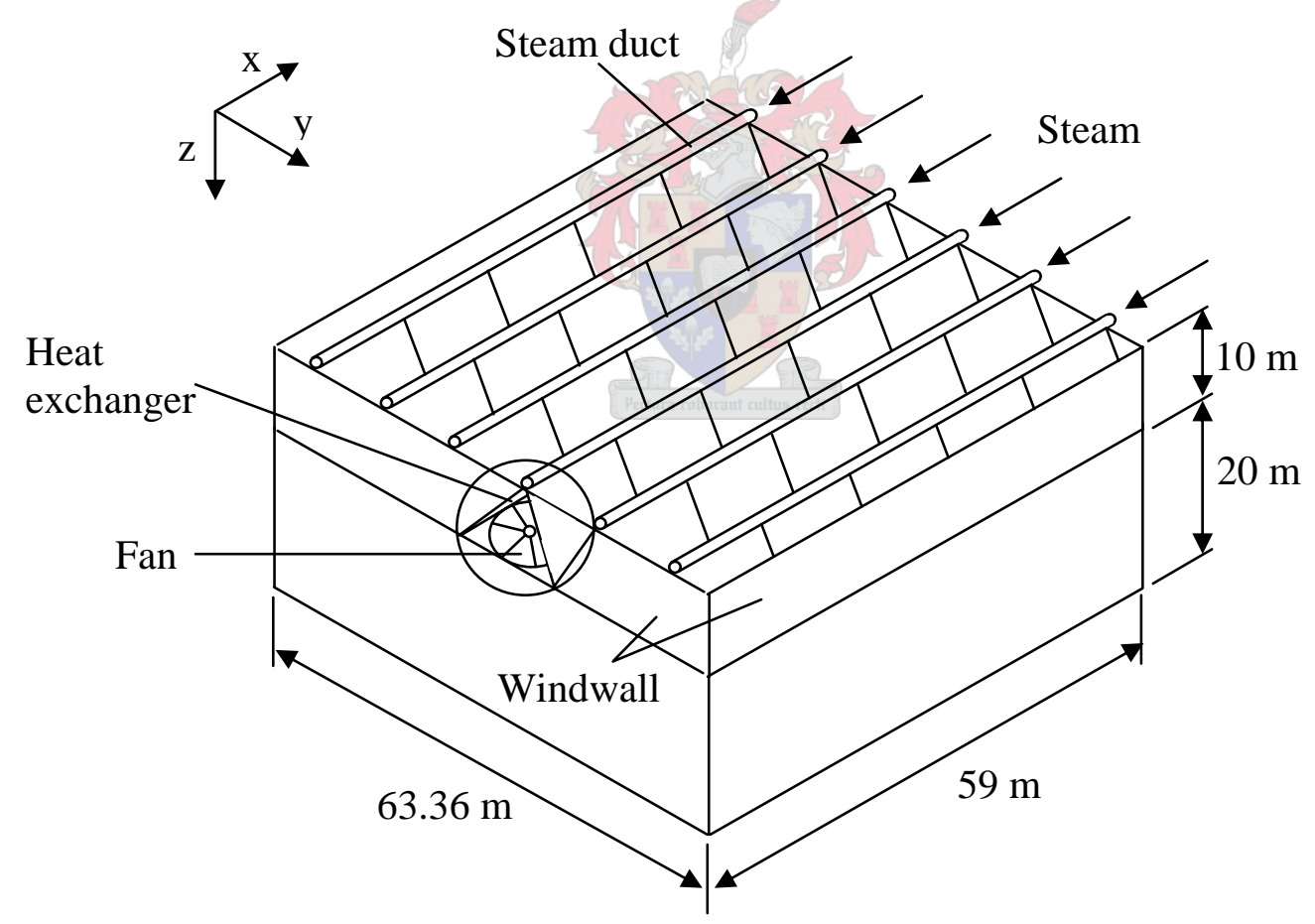

Figure 2.1: ACSC plant consisting of $5 \times 6=30$ A-frame units.

Figure 2.3 shows more detail of an A-frame or a fan unit along the edge or periphery of the ACSC platform. Ambient air at (1) is accelerated towards the platform support at (2). The air then flows from (3), through the fan inlet screen and the fan, into the plenum chamber at (4). The air is heated as it flows from (5) to (6) through the finned tube heat exchanger bundles. The hot air then exits the system at (7). The windwalls along the edge of the ACSC reduce hot 
air recirculation, thus improving the performance of the ACSC. Air and steam properties are given Appendix A. For a more detailed description of the system under consideration and its components see Bredell et al. (2005). The specifications of the fan (axial flow fan) are given in Appendix B.

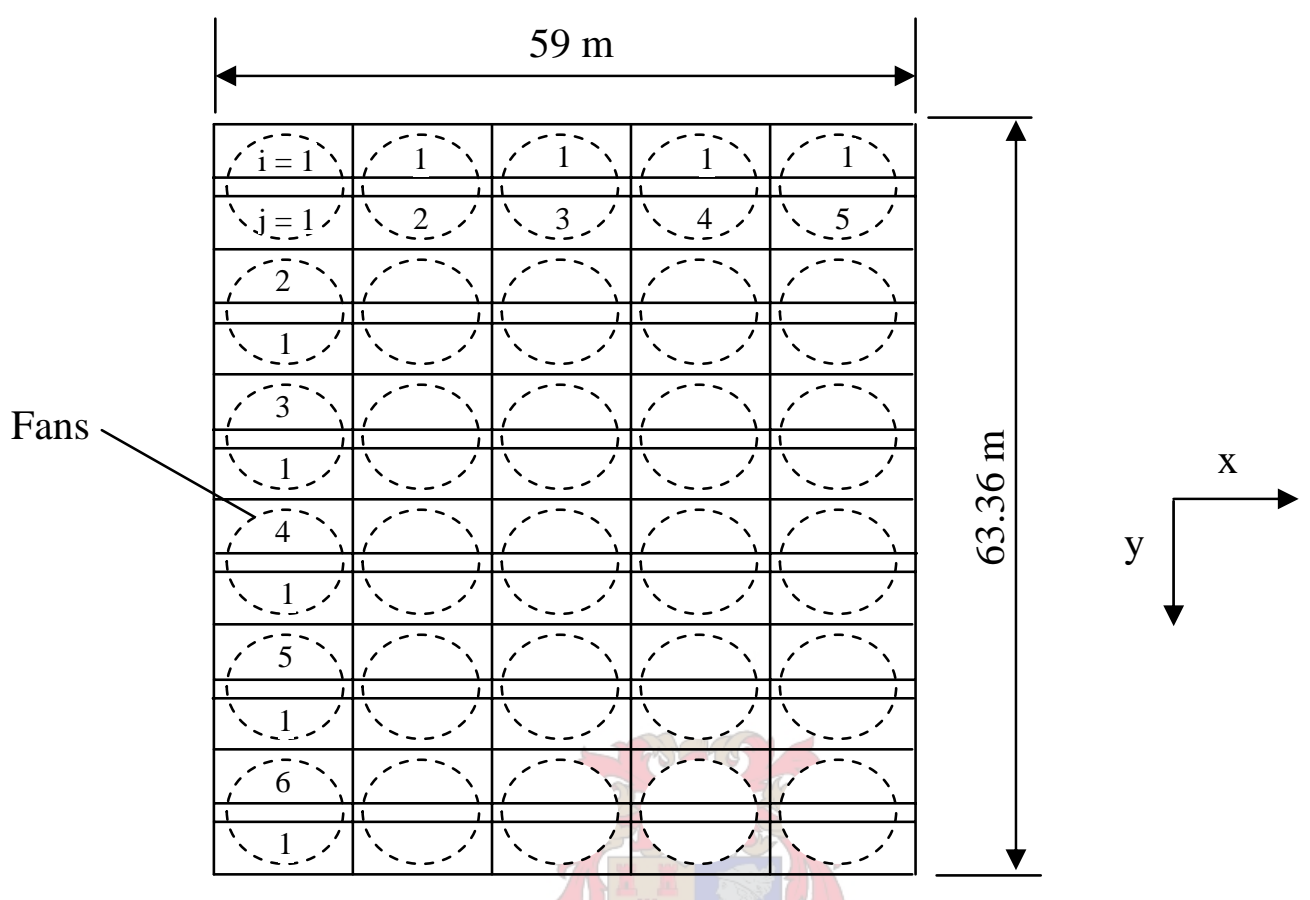

(a)

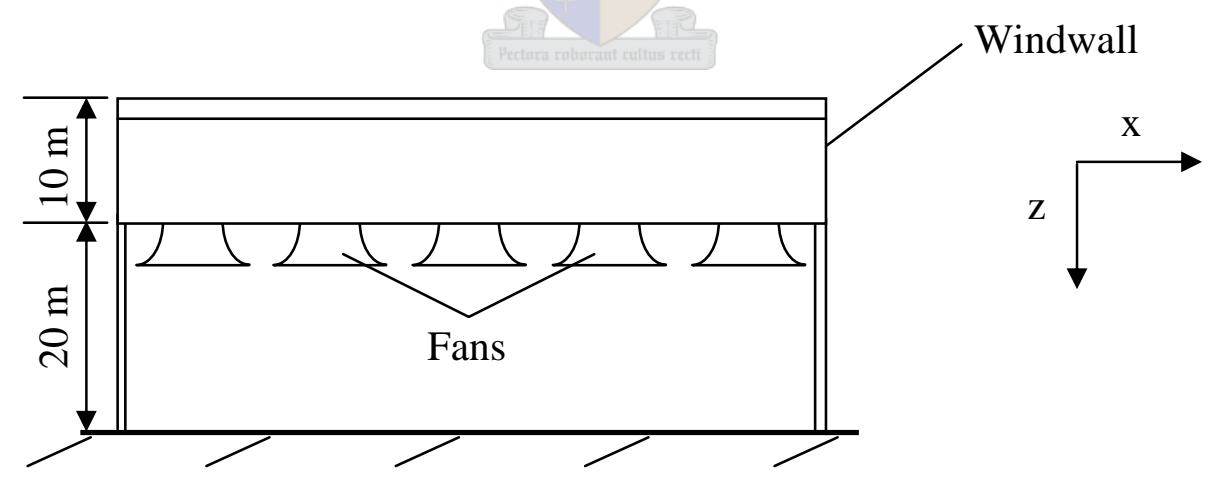

(b)

Figure 2.2: Schematic of ACSC plant consisting of $5 \times 6=30$ A-frame units, (a) Plan, (b) Side elevation. 


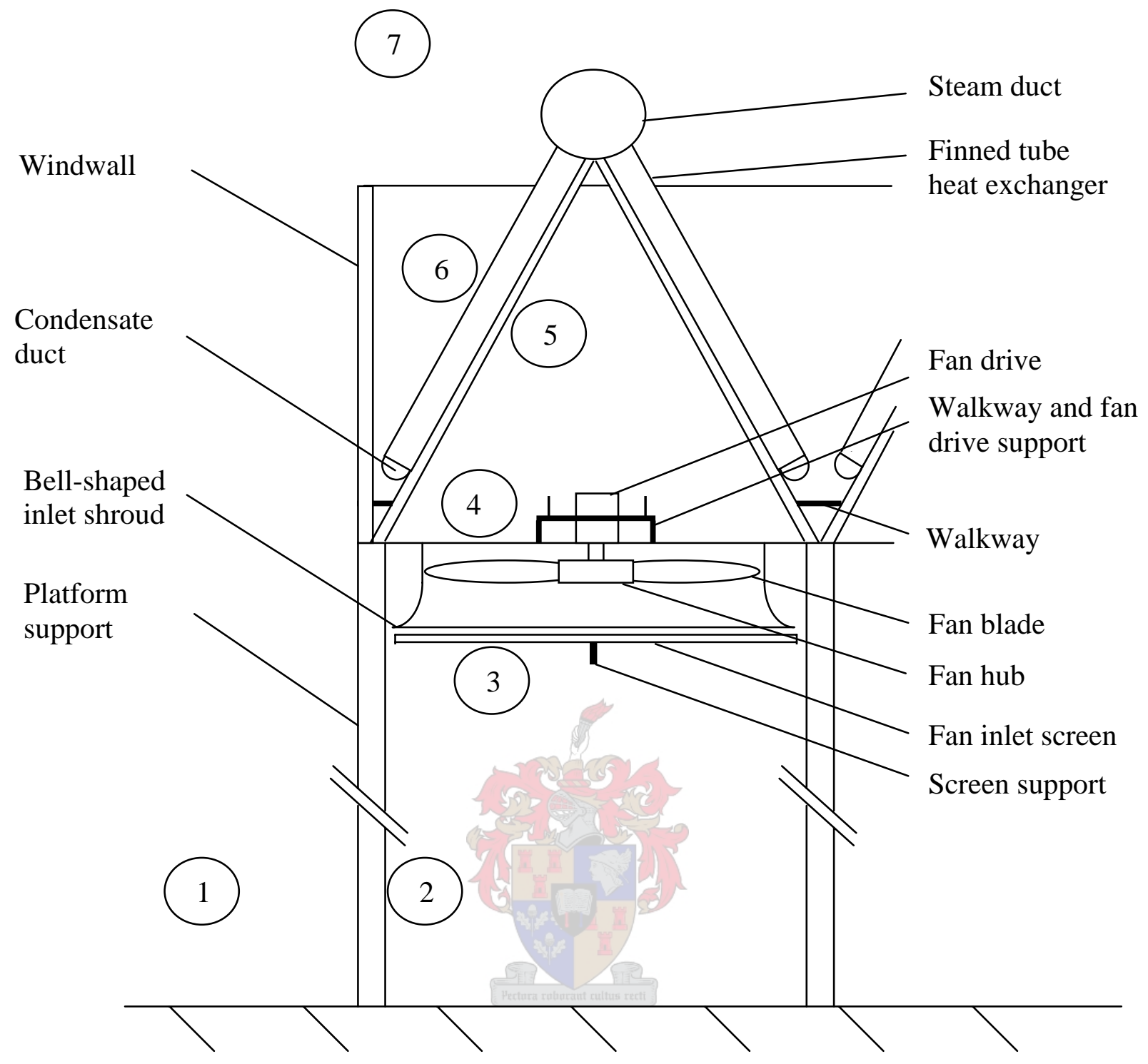

Figure 2.3: A-frame or fan unit along the edge or periphery of an ACSC.

Specific objectives of this investigation are:

- Investigate the ACSC performance at different wind speeds (Positive x-direction and $45^{\circ}$ with respect to the $\mathrm{x}$-direction in a positive $\mathrm{x}$-y direction).

- Evaluate the performance of the ACSC when adding a walkway or a skirt to the plant at different wind speeds (Positive $\mathrm{x}$-direction and $45^{\circ}$ with respect to the $\mathrm{x}$-direction in a positive $\mathrm{x}-\mathrm{y}$-direction). 
- Evaluate the performance of the ACSC when adding a shade net to the plant at different wind speeds (Positive $\mathrm{x}$-direction and $45^{\circ}$ with respect to the $\mathrm{x}$-direction in a positive $\mathrm{x}$-y-direction). 


\section{NUMERICAL MODELING}

The procedure followed in determining the volumetric effectiveness of the ACSC is as follows:

- Solve the global flow field about the ACSC with a simplified global flow field numerical model.

- Use the data from the global flow field numerical model as boundary conditions for the detailed fan unit numerical model, and determine the volume flow rate $\left(\mathrm{V}_{\text {fij }}\right)$ of the specific fan. Each fan has its own numerical model, but only the flow through a selected few fans will be determined (to reduce computational time).

The volumetric effectiveness of a fan is defined as the ratio of the actual air volume flow rate through the fan $\left(V_{f}\right)$ divided by the ideal volume flow through the fan $\left(V_{\text {fid }}\right)$ i.e. that is the case where air flow inlet conditions to the fan are undisturbed.

- By interpolating and extrapolating, the volumetric effectiveness of the fans not modeled is determined approximately.

- The ACSC volumetric effectiveness is determined based on the volumetric effectiveness of the individual fans.

- The thermal effectiveness of the ACSC is determined based on the mass flow rate through each fan and the air inlet temperature at each fan.

As default, the SIMPLE solution algorithm is implemented in FLUENT (6.2.16.), for a steady state solution. The first order upwind differencing scheme is used to ensure stability, and the turbulence is modeled using the k- $\varepsilon$ model, with default model constant settings. Although the validity of this turbulence model may be questioned for application in the present case this was employed by previous researchers in the case of similar types of problems. Using the k- $\varepsilon$ model and following the same numerical procedure as Bredell (2006), his results for a 2-dimensional model consisting of 3 fans were confirmed. Our results for this 2-dimensional 3 fan unit were also found to be in good agreement with the experimental trends reported by Salta and Kröger (1995). In view of this agreement it was not considered to be necessary to evaluate the influence of other turbulence models or fan grid refinement. 


\subsection{ACSC model}

Due to computational limitations, the detailed airflow through the complete ACSC with all 30 fans will not be solved directly. In the global flow field analysis the fans in the ACSC are represented by a simple model consisting of a rectangle as shown in figure 3.1 having a uniform inlet and outlet velocity distribution (also see Appendix D for further details). When buoyancy (non-adiabatic) is taken into account, a constant temperature is also assigned to the uniform velocity boundaries.
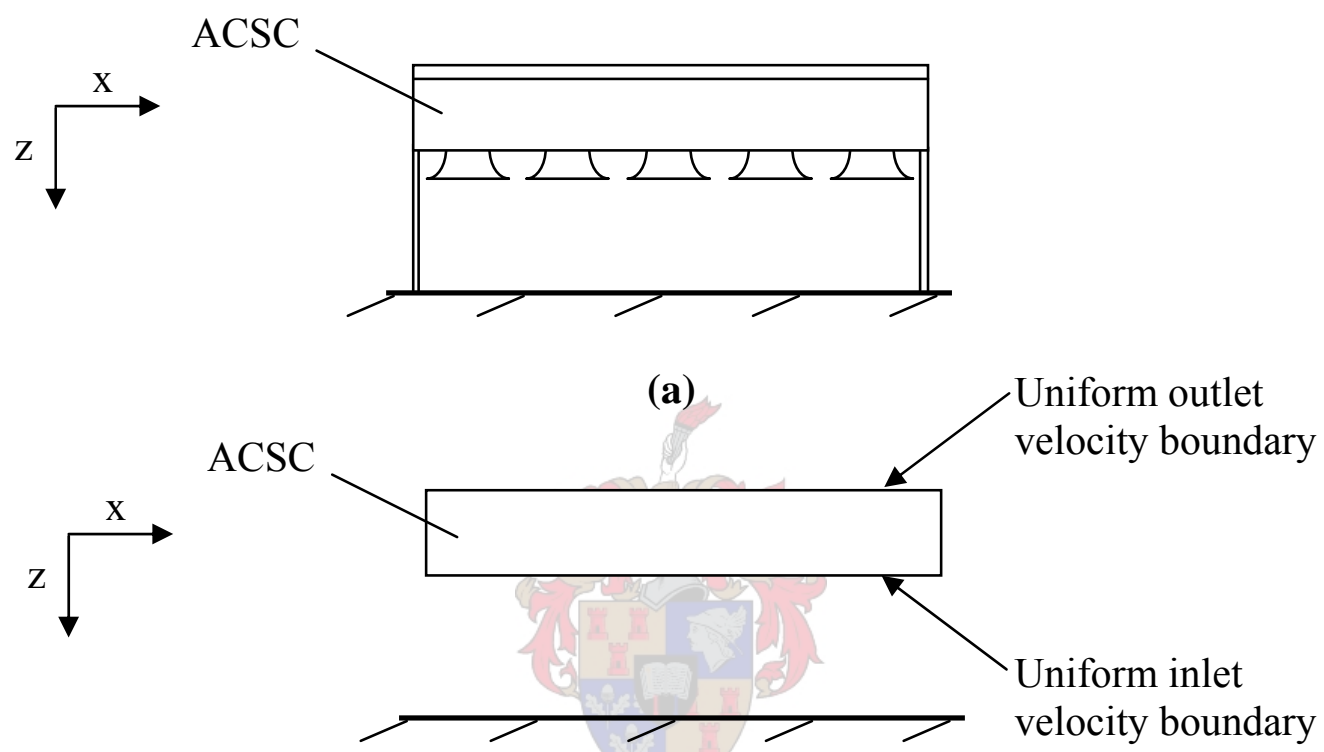

(b)

Figure 3.1: Schematic of ACSC, (a) Side elevation,

(b) Side elevation (simplified numerical model).

Figure 3.2 shows the computational flow domain as well as the boundary conditions for the adiabatic global flow field. In the non-adiabatic case, a constant temperature is assigned to all the velocity boundaries.

The 3-dimensional non-conformal computational grid consists of about $1.5 \times 10^{6}$ hexahedral cells. Since the flow field near the ACSC is of importance, a finer mesh was chosen in this region. The grid interface in figure 3.2 and figure 3.3 shows the transition from the fine mesh near the ACSC to the more coarse mesh. 
A wind velocity distribution is prescribed on the left hand side of the global flow field (refer to Appendix D). The wind speed distribution across a relatively smooth surface is usually expressed as follows:

$\mathrm{v}_{\mathrm{H}}=\mathrm{v}_{\mathrm{ref}}\left(\mathrm{H} / \mathrm{H}_{\mathrm{ref}}\right)^{\mathrm{b}}$

In the present analysis a value of $b=1 / 7$ will be assumed. The influences of other velocity distributions are discussed in Appendix E. It is assumed that the flow is incompressible. Adiabatic and non-adiabatic cases will be solved. In the adiabatic (no heat transfer) cases buoyancy is not taken into account. In the non-adiabatic cases (heat transfer considered) buoyancy is taken into account by means of the Boussinesq model, in which the buoyancy force in the momentum equation is approximated by:

$\mathrm{F}_{\mathrm{z}}=\left(\rho-\rho_{\mathrm{a}}\right) \mathrm{g} \approx \rho_{\mathrm{a}} \beta_{\mathrm{T}}\left(\mathrm{T}-\mathrm{T}_{\mathrm{a}}\right) \mathrm{g}$

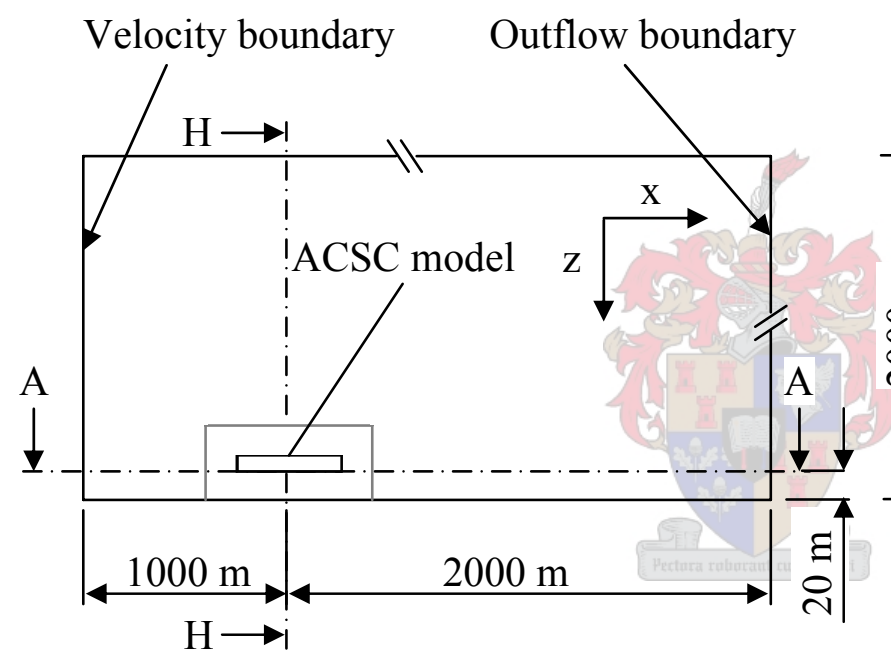

Side elevation

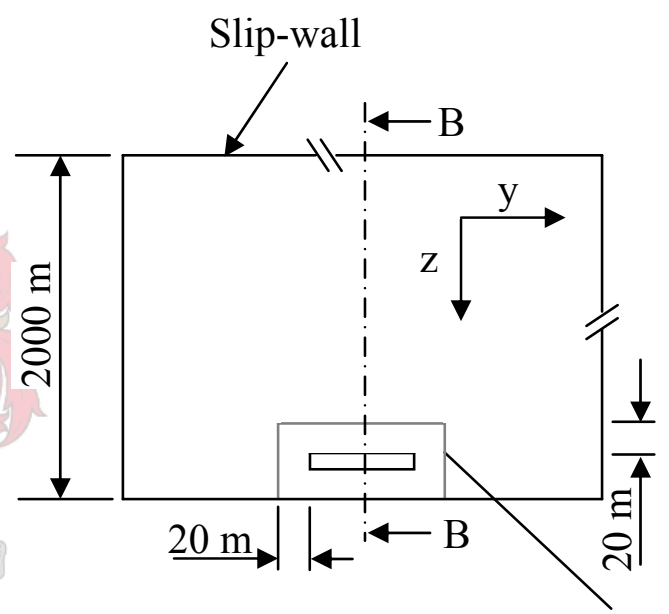

End elevation
Grid interfaces

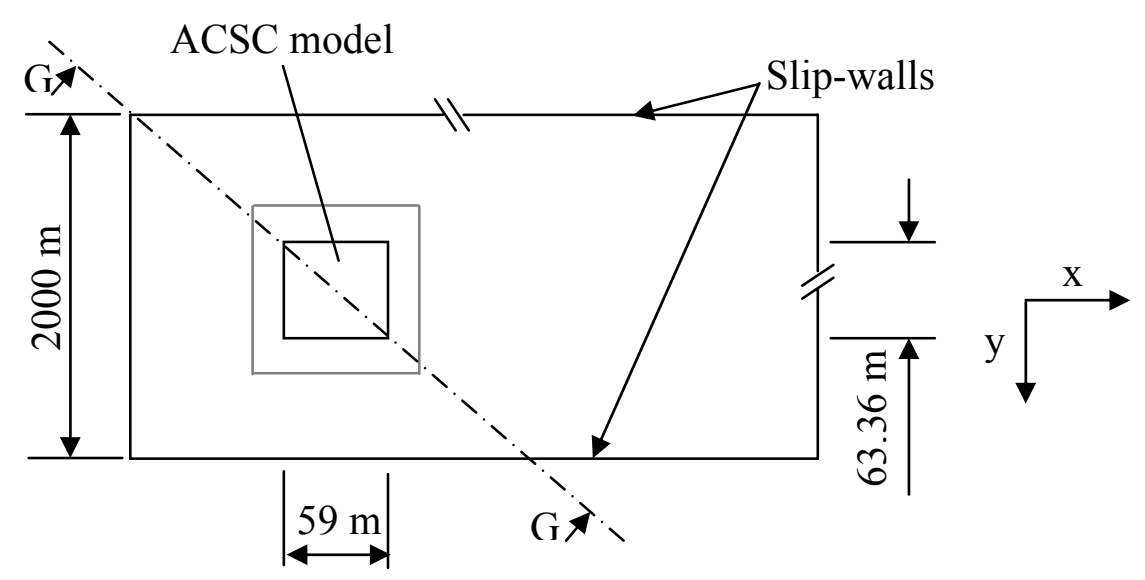

Plan

Figure 3.2: Computational flow domain of the global flow field about the ACSC. 


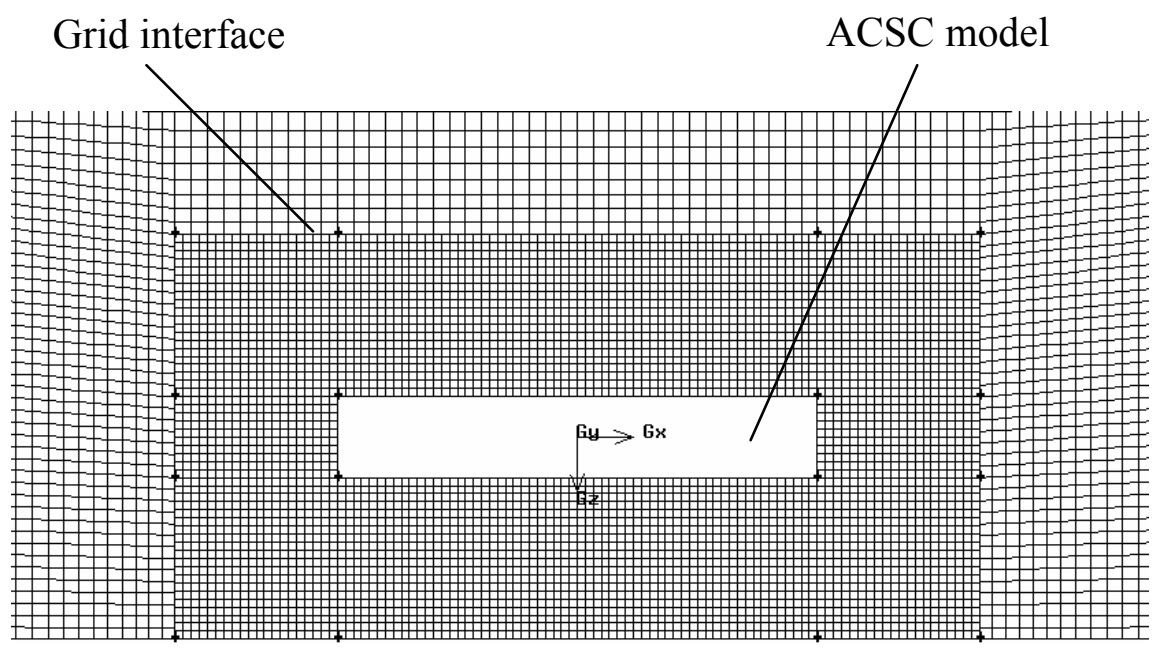

Figure 3.3: Computational grid of the global flow field about the ACSC. Section view B-B (refer to figure 3.2)

\subsection{ACSC fan unit model}

Figure 3.4 shows the actual ACSC fan unit. Obstacles or appurtenances such as supports, beams, inlet screens, electrical fan drives and ducting were not individually modeled in the simplified model of an ACSC fan unit, as shown in figure 3.5. The mechanical energy losses (or corresponding pressure drop) resulting from the obstacles, heat exchanger and outlet losses are taken into account in the heat exchanger model by a viscous and an inertial loss coefficient (see Appendix A). Similar to Bredell et al. (2005) this simplification can be justified, as the purpose of this study is to investigate fan performance and system performance and not the detailed modeling of the flow in the plenum chamber or at the ACSC outlet.

The heat exchanger is represented by a porous media model in FLUENT. The momentum sink terms of the porous media model consist of two parts, namely the viscous resistance and the inertial resistance term. Bredell et al. (2005) found these values to be $1.897 \times 10^{6}$ and 59.1364 respectively. The inertial resistance coefficients in the $\mathrm{x}$-and $\mathrm{y}$-direction are specified to be $1 \times 10^{3}$ times higher than in the $\mathrm{z}$-direction, to restrict the flow in these directions. When buoyancy is taken into account (non-adiabatic) the outlet of the heat exchanger is assumed to have a uniform temperature. 


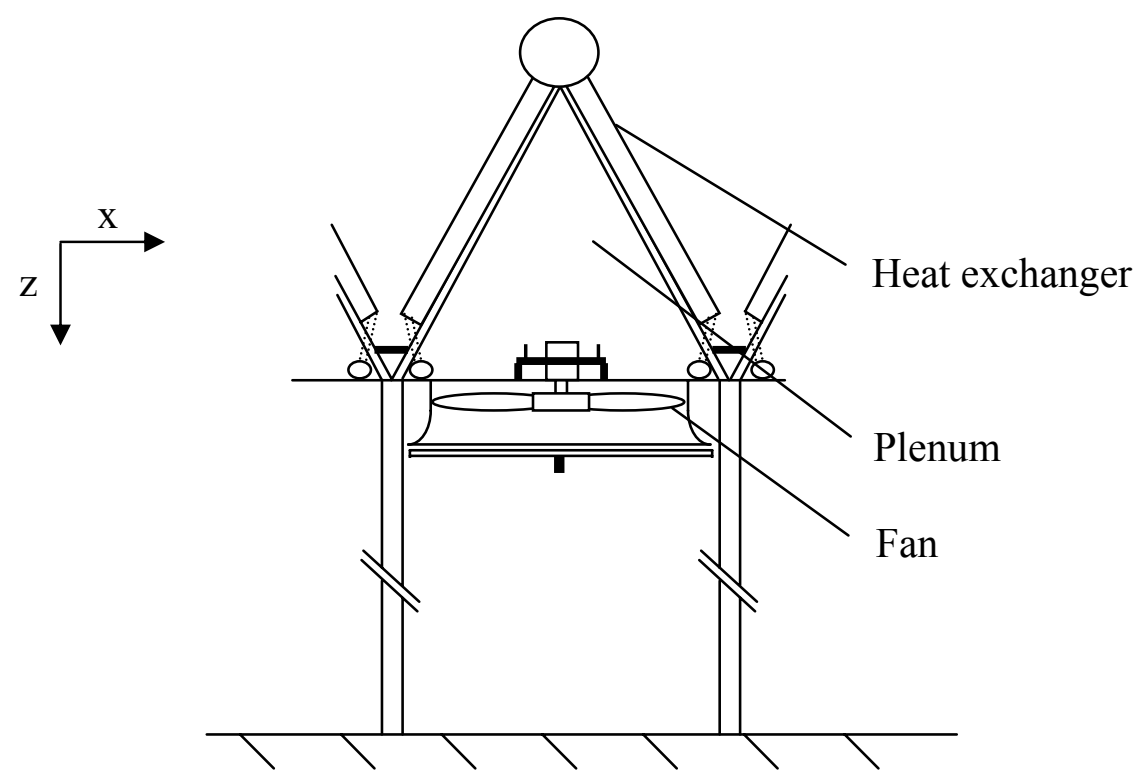

Figure 3.4: Actual ACSC fan unit.

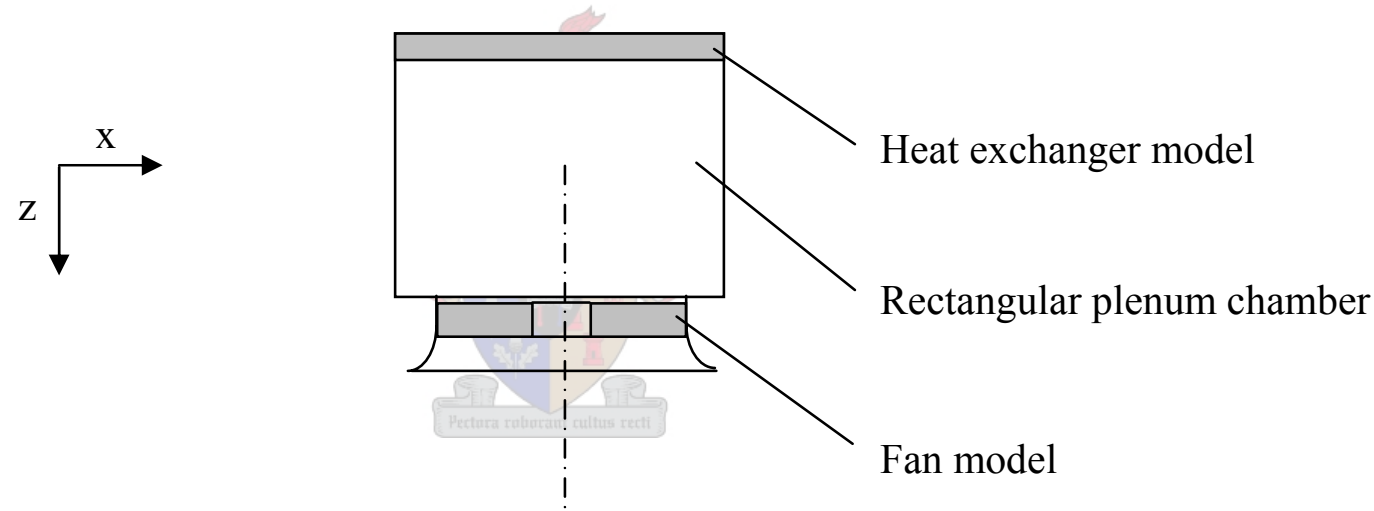

Figure 3.5: Simplified numerical model of an ACSC fan unit.

The advantages and disadvantages of various methods of modeling an axial flow fan are discussed by Bredell et al. (2005). The actuator disc model of Bredell et al. (2005) will be used in this study.

To determine the performance of a particular fan, for example fan(6,1) (see figure 2.2), the latter was represented by the ACSC fan unit model previously shown in figure 3.5 with a flow domain having boundary faces $20 \mathrm{~m}$ from the fan model as shown in figure 3.6. The regions 


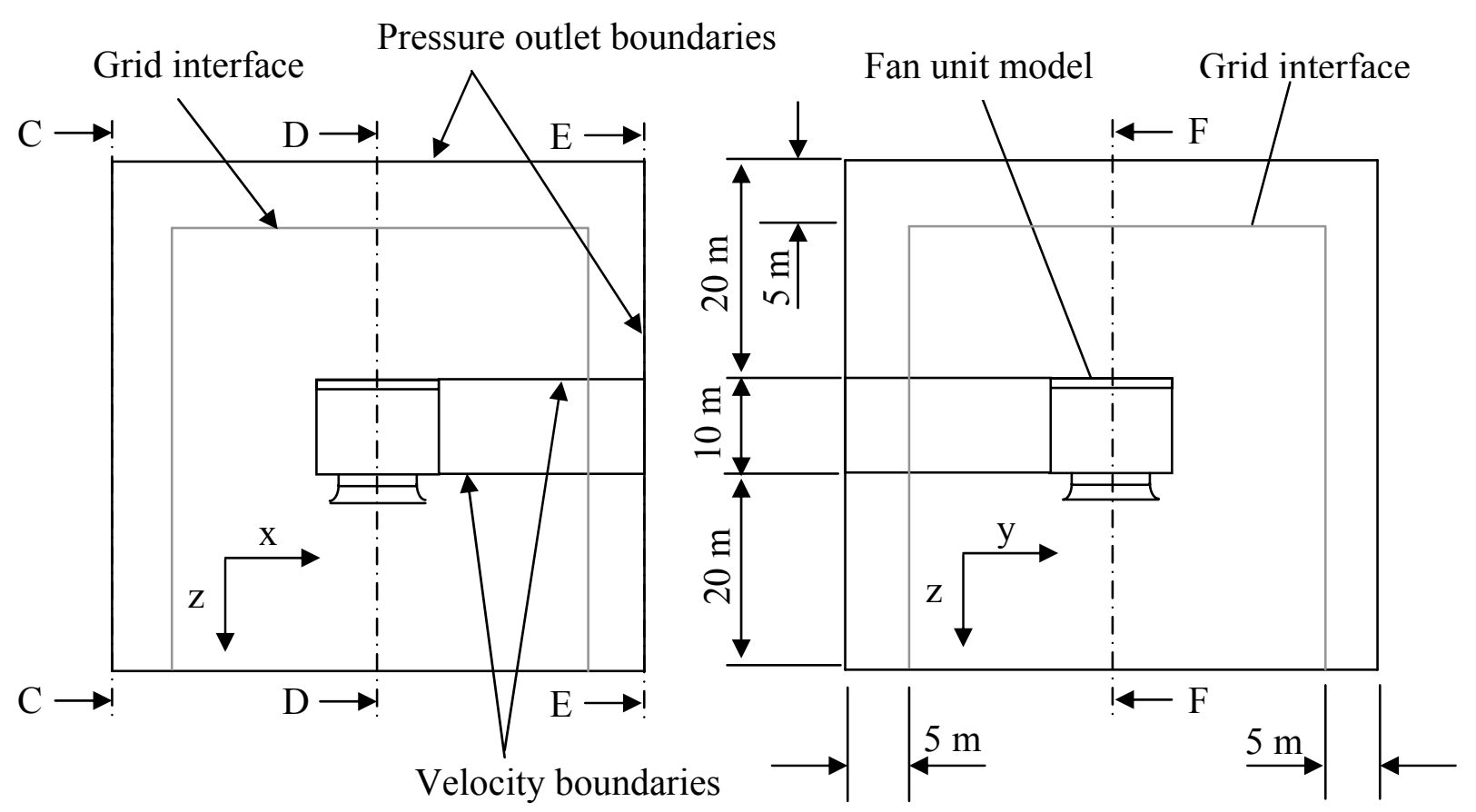

Side elevation

End elevation

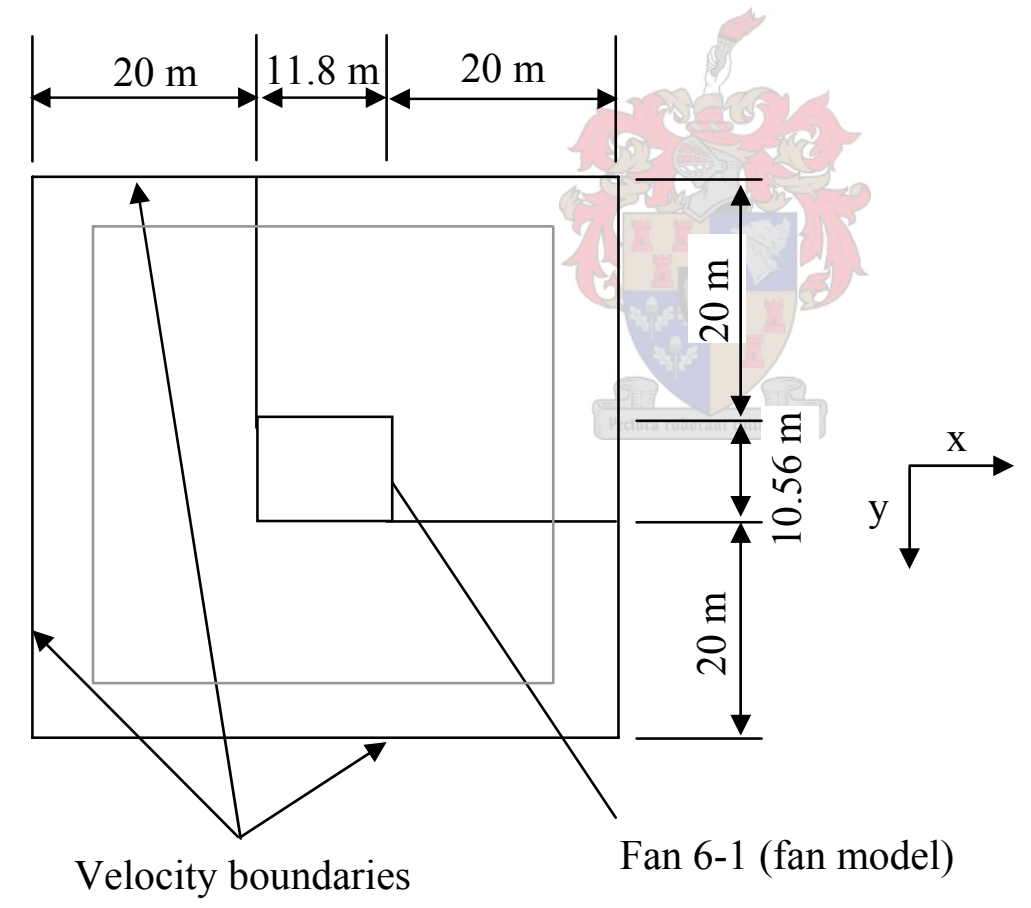

Plan

Figure 3.6: Computational flow domain of fan(6,1).

next to fan $(6,1)$, where there are supposed to be fans, are represented by a uniform inlet and outlet velocity (as assumed for the ACSC numerical model). 
The boundary values are obtained from the global flow field solution. These boundary faces shown in figure 3.6 are also present in the global flow field, but only as faces and not boundary faces. After the global flow field has been solved, the velocity, pressure and temperature (non-adiabatic case) values are exported on these faces respectively, which in turn are imported into the fan model shown in figure 3.6 as fixed boundary values. Then only will the volumetric effectiveness of $\operatorname{fan}(6,1)$ be determined. Similar models are used for the other fans.

The 3-dimensional non-conformal computational grid consists of about $800 \times 10^{3}$ hexahedral cells. The boundary faces are meshed similar to the faces in the global flow field (used to export data). When the volumetric flow rate through a specific fan has to be determined, a relatively fine mesh is required to be able to use the actuator disc model to represent the specific fan. A mesh interface is thus required between the coarse boundaries and the interior of the flow domain. 


\section{ACSC PERFORMANCE UNDER WINDY CONDITIONS \\ (WIND IN THE X-DIRECTION)}

This chapter presents the results of the numerical analysis. It shows the flow field about an ACSC and its performance when the wind blows in the positive $\mathrm{x}$-direction at speeds of $3 \mathrm{~m} / \mathrm{s}, 6 \mathrm{~m} / \mathrm{s}$ and $9 \mathrm{~m} / \mathrm{s}$ at an elevation corresponding to the fan platform height above ground level $(20 \mathrm{~m})$.

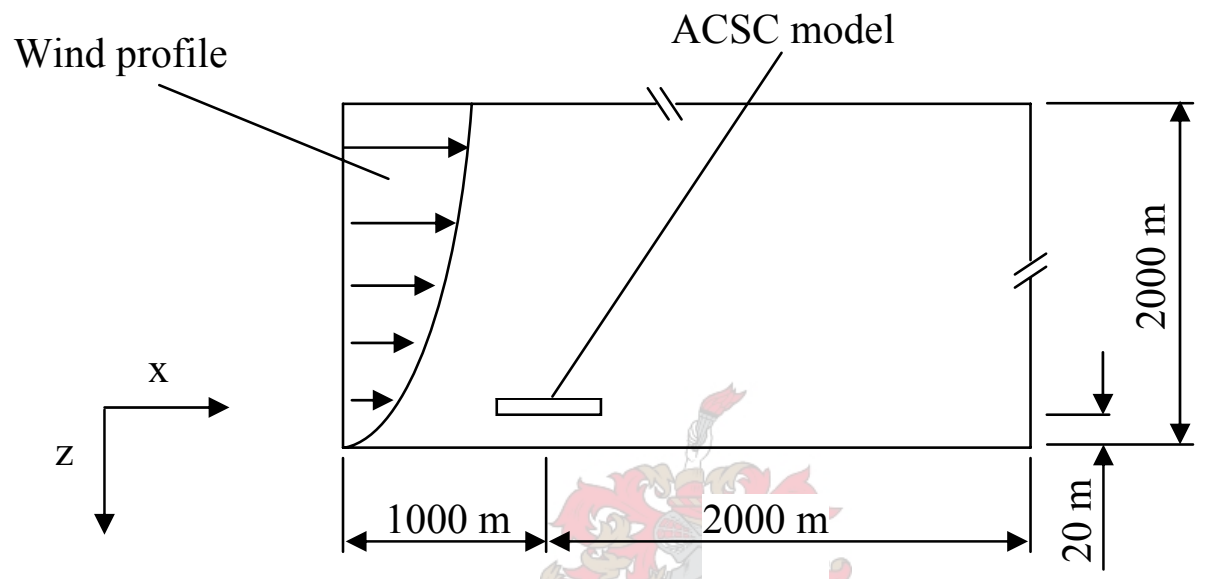

Figure 4.1: Global flow field.

To obtain these results the following procedure was followed:

- Solve the global flow field (refer to figure 3.2).

- Solve the flow field for specified fans (refer to figure 3.6) and determine their volumetric effectiveness.

- Determine the volumetric effectiveness of the remaining fans by interpolation and extrapolation.

- Calculate the volumetric effectiveness of the ACSC.

- Calculate the thermal effectiveness of the ACSC.

\subsection{Global flow field}

Characteristics of the global flow field about the ACSC are shown in the following figures. Figures 4.2 to 4.4 show how the plume is affected by the wind. At a wind speed of $3 \mathrm{~m} / \mathrm{s}$ the 
Figure 4.2: Temperature, $K$, global flow field at a wind speed of $3 \mathrm{~m} / \mathrm{s}$.

Section view B-B (refer to figure 3.2).

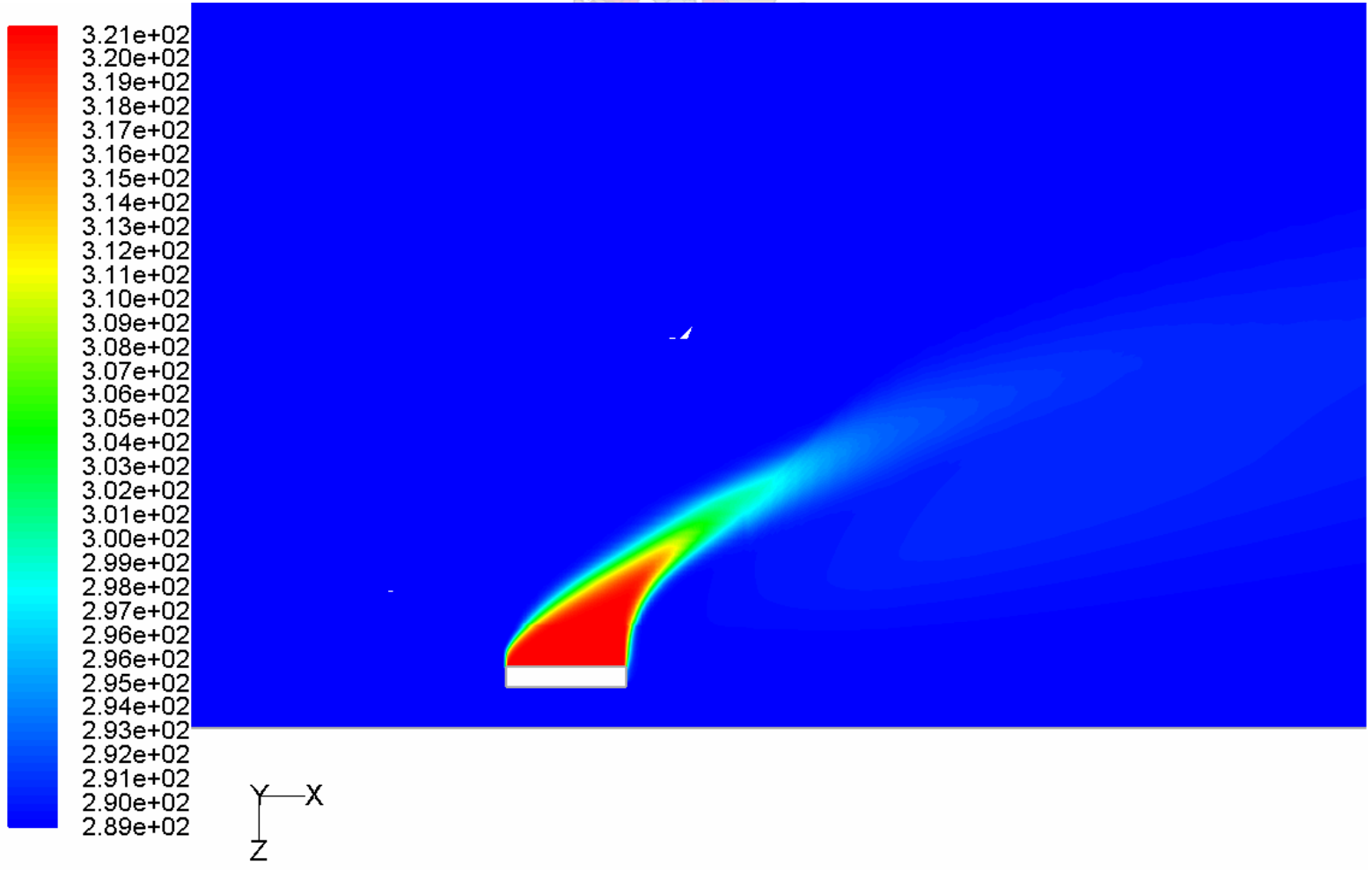

Figure 4.3: Temperature, K, global flow field at a wind speed of $6 \mathrm{~m} / \mathrm{s}$. Section view B-B (refer to figure 3.2). 


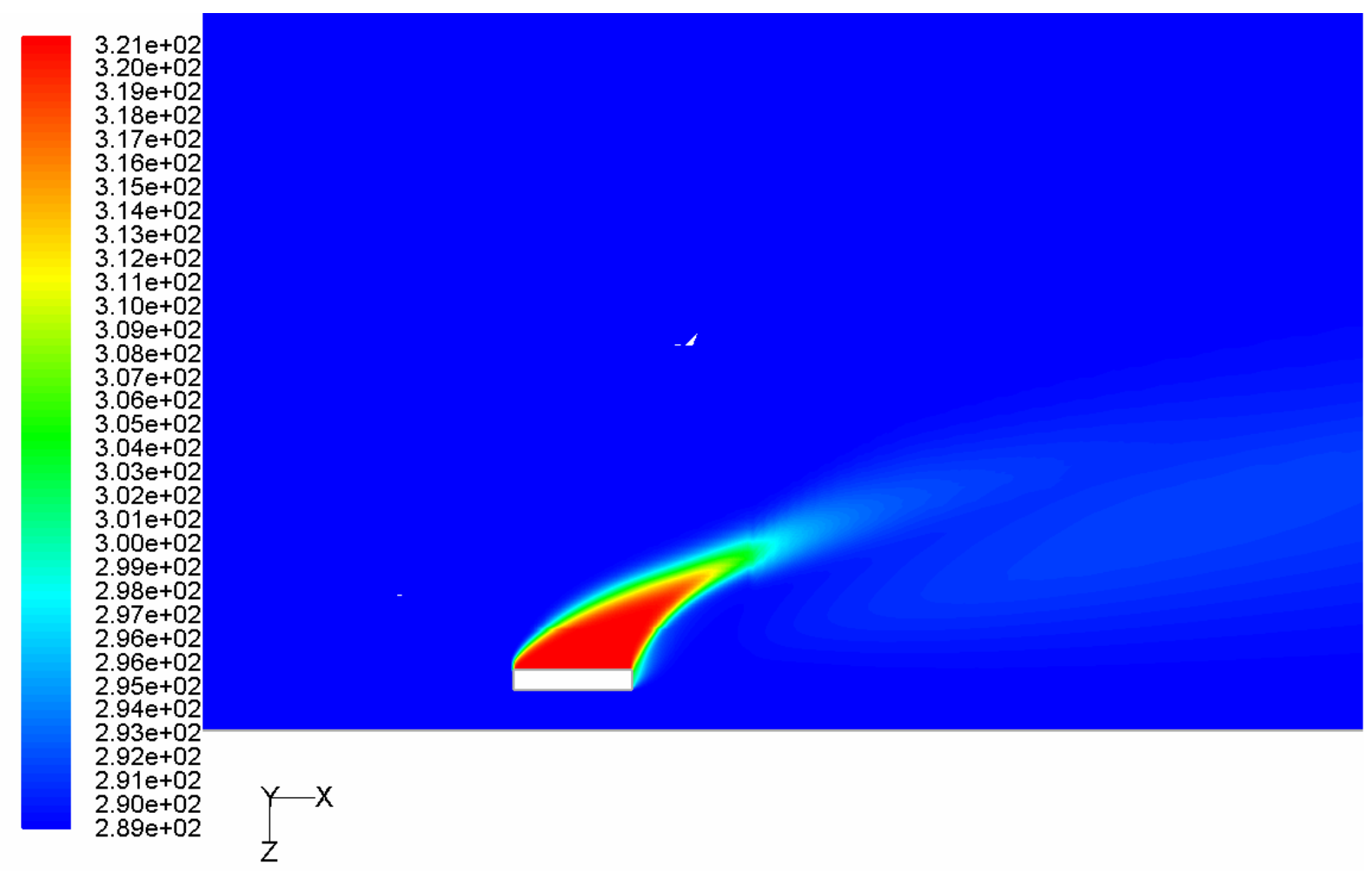

Figure 4.4: Temperature, $K$, global flow field at a wind speed of $9 \mathrm{~m} / \mathrm{s}$.

\section{Section view B-B (refer to figure 3.2).}

plume rise angle (angle between plume and vertical, immediately downstream of the ACSC) is approximately $30^{\circ}, 45^{\circ}$ at $6 \mathrm{~m} / \mathrm{s}$ and $60^{\circ}$ at $9 \mathrm{~m} / \mathrm{s}$. Not withstanding the one seventh power velocity distribution and buoyancy effects, the plume follows an approximately parabolic trend as would be expected from simple momentum considerations.

Figures 4.5 and 4.6 show a vector plot of the flow field about the ACSC at wind speeds of 3 $\mathrm{m} / \mathrm{s}$ and $9 \mathrm{~m} / \mathrm{s}$. These figures show that air flows straight through underneath ACSC and exits downstream of the ACSC.

Figure 4.7 shows that a low pressure region exists at the leading edge, underneath the ACSC. Figure 4.8 shows that this low pressure region is most prominent at rows 3 and 4 (refer to figure 2.2) and decreases towards the sides of the ACSC. 
$1.63 e+01$

$1.57 e+01$

$1.46 \mathrm{e}+01$

$1.41 \mathrm{e}+01$

$1.35 \mathrm{e}+0$

$1.29 \mathrm{e}+0$

$1.24 \mathrm{e}+0$

$18 \mathrm{e}+01$

$1.13 e+0$

$1.07 \mathrm{e}+01$
$1.01 \mathrm{e}+01$

$9.59 \mathrm{e}+00$

$9.03 e+00$

$8.47 \mathrm{e}+00$

$7.91 \mathrm{e}+00$

$7.35 \mathrm{e}+00$

$6.79 \mathrm{e}+00$

$6.23 \mathrm{e}+00$

$5.68 \mathrm{e}+00$

$5.12 \mathrm{e}+00$

$4.56 \mathrm{e}+00$

$4.00 \mathrm{e}+00$

$3.44 \mathrm{e}+00$

$2.88 \mathrm{e}+00$

$2.32 \mathrm{e}+00$

$1.77 \mathrm{e}+00$

$1.21 \mathrm{e}+00$

$6.48 \mathrm{e}-01$

$8.97 \mathrm{e}-02$<smiles>[Z][Y]([Z])[X]</smiles>

Figure 4.5: Vector plot, v, m/s, global flow field about ACSC at a wind speed of $3 \mathrm{~m} / \mathrm{s}$.

Section view B-B (refer to figure 3.2).
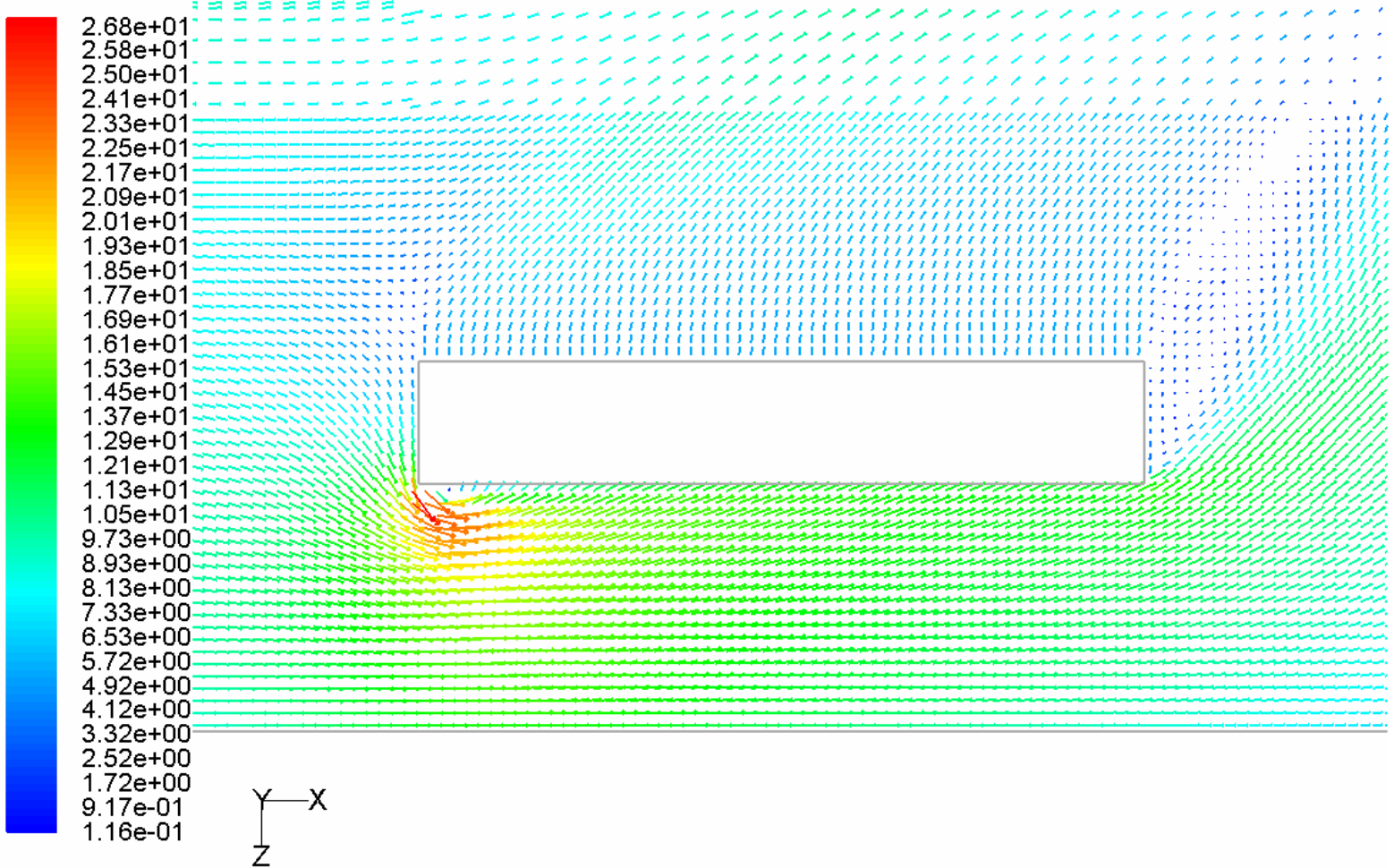

Figure 4.6: Vector plot, v, m/s, global flow field about ACSC at a wind speed of $9 \mathrm{~m} / \mathrm{s}$.

Section view B-B (refer to figure 3.2). 


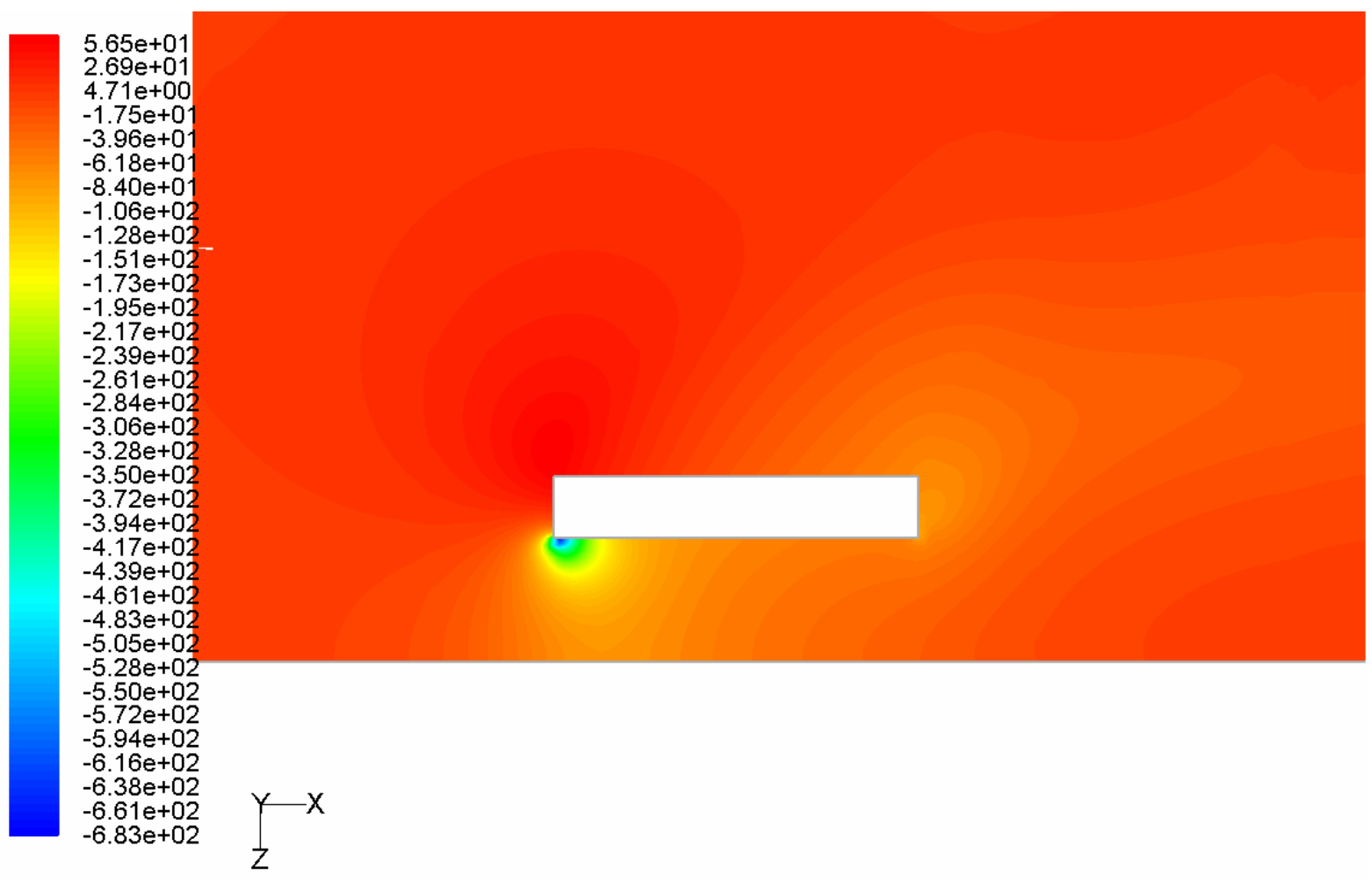

Figure 4.7: Static pressure, $p_{\text {stat }}, N / \mathrm{m}^{2}$, global flow field at a wind speed of $9 \mathrm{~m} / \mathrm{s}$.

Section view B-B (refer to figure 3.2).

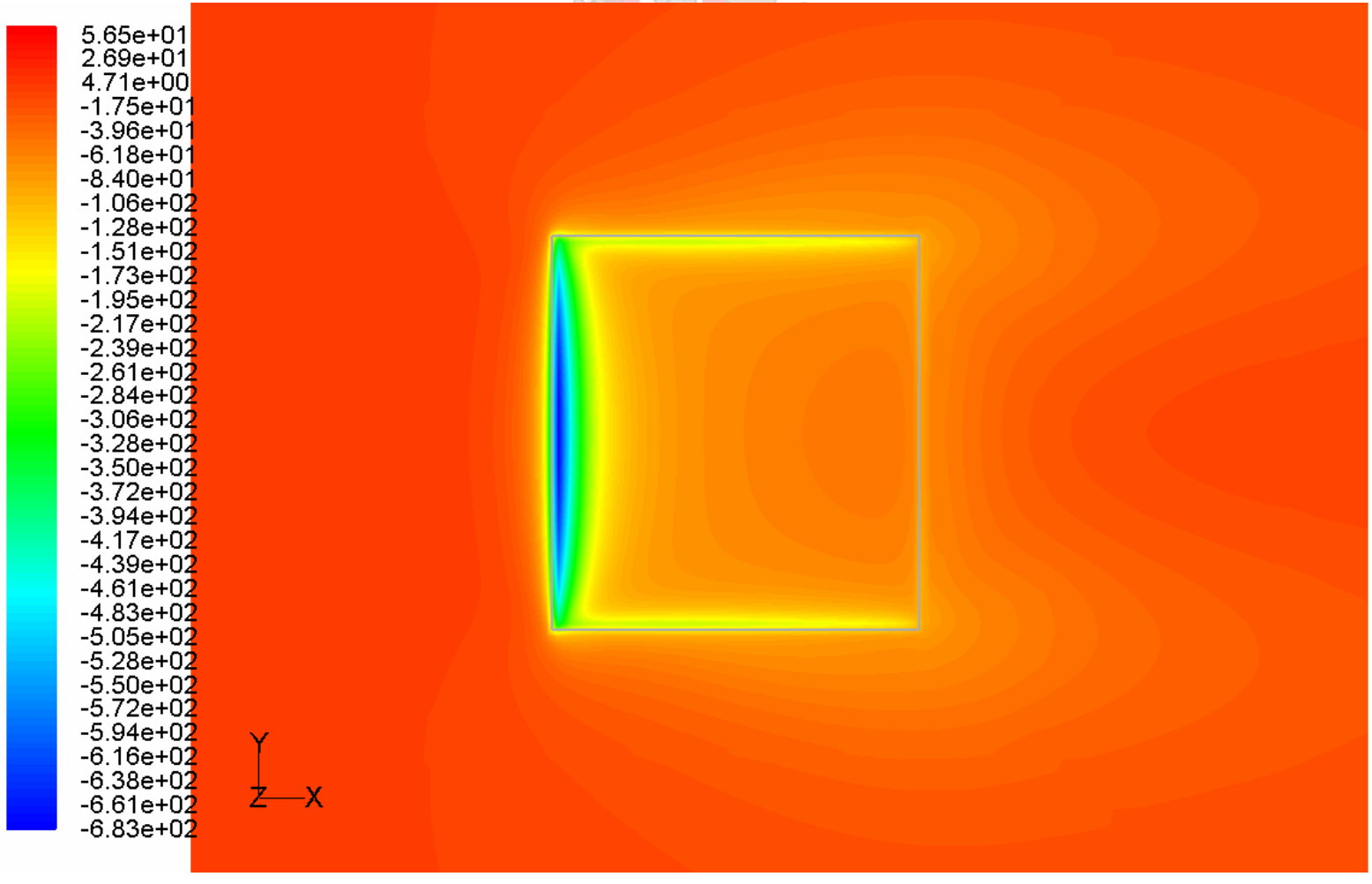

Figure 4.8: Static pressure, $p_{\text {stat, }} \mathrm{N} / \mathrm{m}^{2}$, global flow field at a wind speed of $9 \mathrm{~m} / \mathrm{s}$. Section view A-A (refer to figure 3.2). 


\subsection{Fan performance}

The ACSC has a symmetry plane as shown in figure 4.9, thus only 15 out of the 30 fans (rows 4 to 6 ) have to be numerically analyzed to determine the volumetric effectiveness of the ACSC when the wind blows in the $\mathrm{x}$-direction.

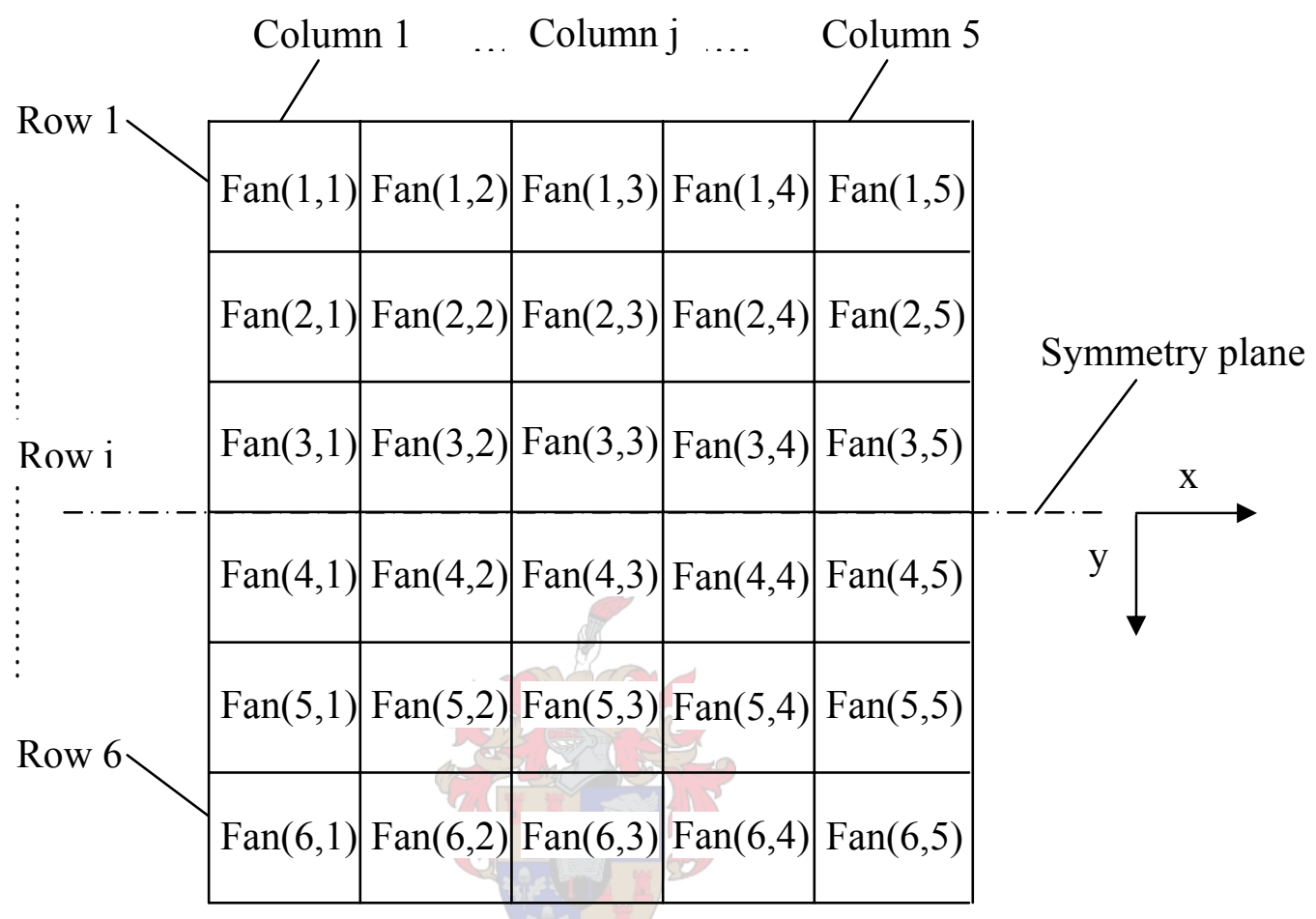

Figure 4.9: Numerical model (ACSC), symmetry plane and fan location.

The volumetric effectiveness of $\operatorname{fan}(4,1), \operatorname{fan}(4,3), \operatorname{fan}(4,5), \operatorname{fan}(5,3), \operatorname{fan}(6,1), \operatorname{fan}(6,3)$ and fan $(6,5)$ are numerically determined at wind speeds of $3 \mathrm{~m} / \mathrm{s}, 6 \mathrm{~m} / \mathrm{s}$ and $9 \mathrm{~m} / \mathrm{s}$ (specified at the fan platform height of $20 \mathrm{~m}$ above the ground).

Figure 4.10 shows that an increase in the wind speed has a significant effect on the volumetric effectiveness of fan $(4,1)$ and to a lesser extent on fan $(6,1)$. The wind effect on the volumetric effectiveness of the remaining fans is considerably less. The wind may actually improve the volumetric effectiveness of some of the fans. $\operatorname{Fan}(4,5)$ is generally not very sensitive to wind and has a volume flow rate that is more than the ideal volume flow rate of $661 \mathrm{~m}^{3} / \mathrm{s}$. The volume flow rate through $\operatorname{fan}(4,3), \operatorname{fan}(5,3)$ and $\operatorname{fan}(6,5)$ also exceeds the ideal. This trend may be ascribed to the relatively high momentum, low distortion of the air entering these fans and reduced pressure on top of the ACSC. 


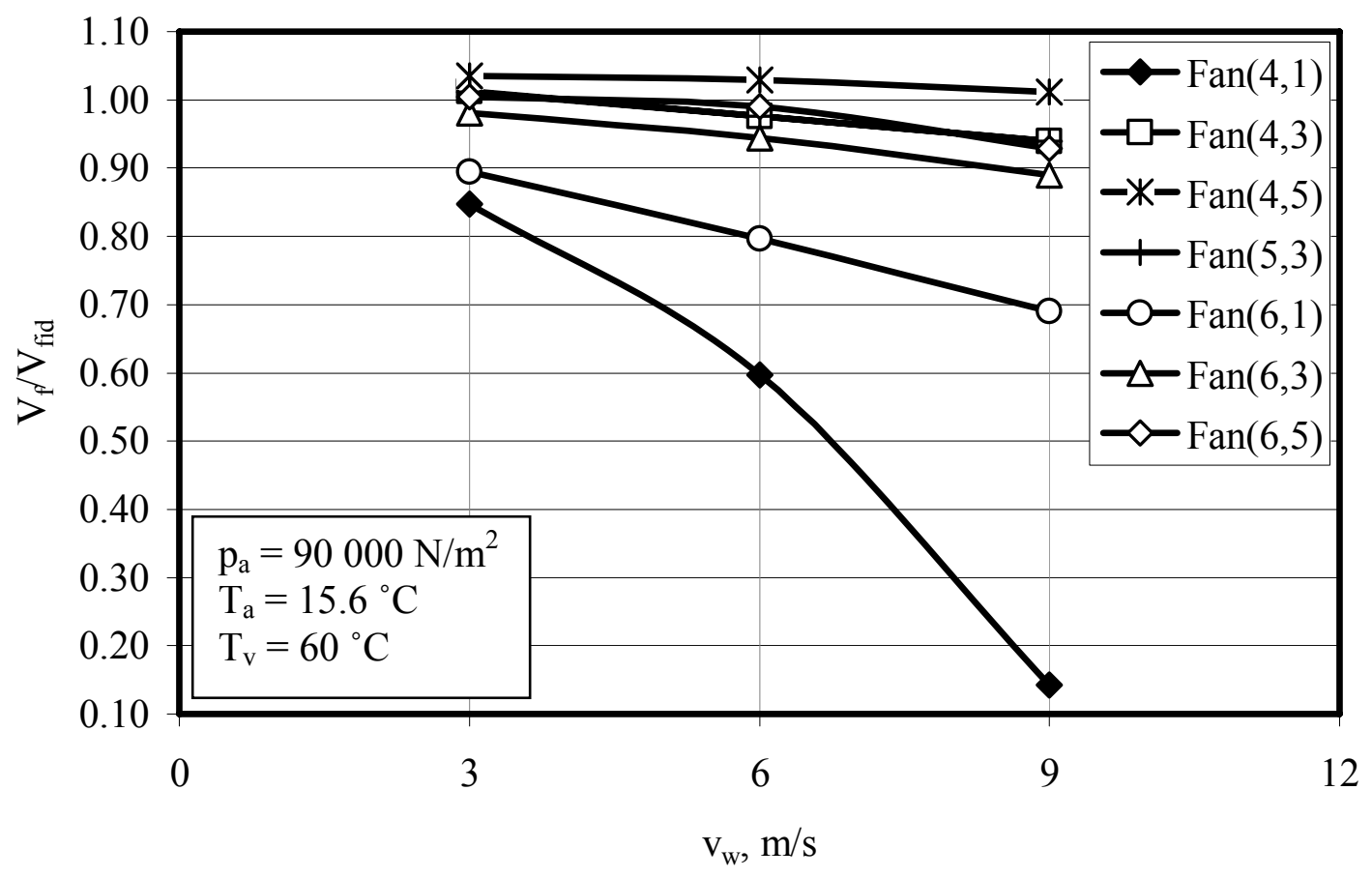

Figure 4.10: Volumetric effectiveness of fans.

It can be concluded that the wind will have the greatest negative effect on the upstream edge fans.

The abovementioned phenomena are illustrated in figures 4.11 and 4.12 for fan $(4,1)$. Due to a low pressure region upstream of fan $(4,1)$, backflow will occur in this region. Furthermore, the distorted airflow pattern at the fan inlet will contribute to its reduced volumetric effectiveness.

The region of low pressure is less under fan $(6,1)$ than $f a n(4,1)$, and this is part of the reason why its performance is superior to that of fan $(4,1)$. As shown in figure 4.14 the low pressure region under fan $(4,3)$ is even less than that of fan $(6,1)$ thus its better performance.

According to Duvenhage and Kröger (1996) the negative effect of the wind on the performance of an air-cooled heat exchanger is twofold:

- Fan performance is reduced (decrease in air mass flow rate through the system) due to distorted inlet flow conditions (pressure and airflow distortions).

- Hot plume air recirculation. This can be expected at the fans on the edge or periphery in the longitudinal direction (direction of wind). 


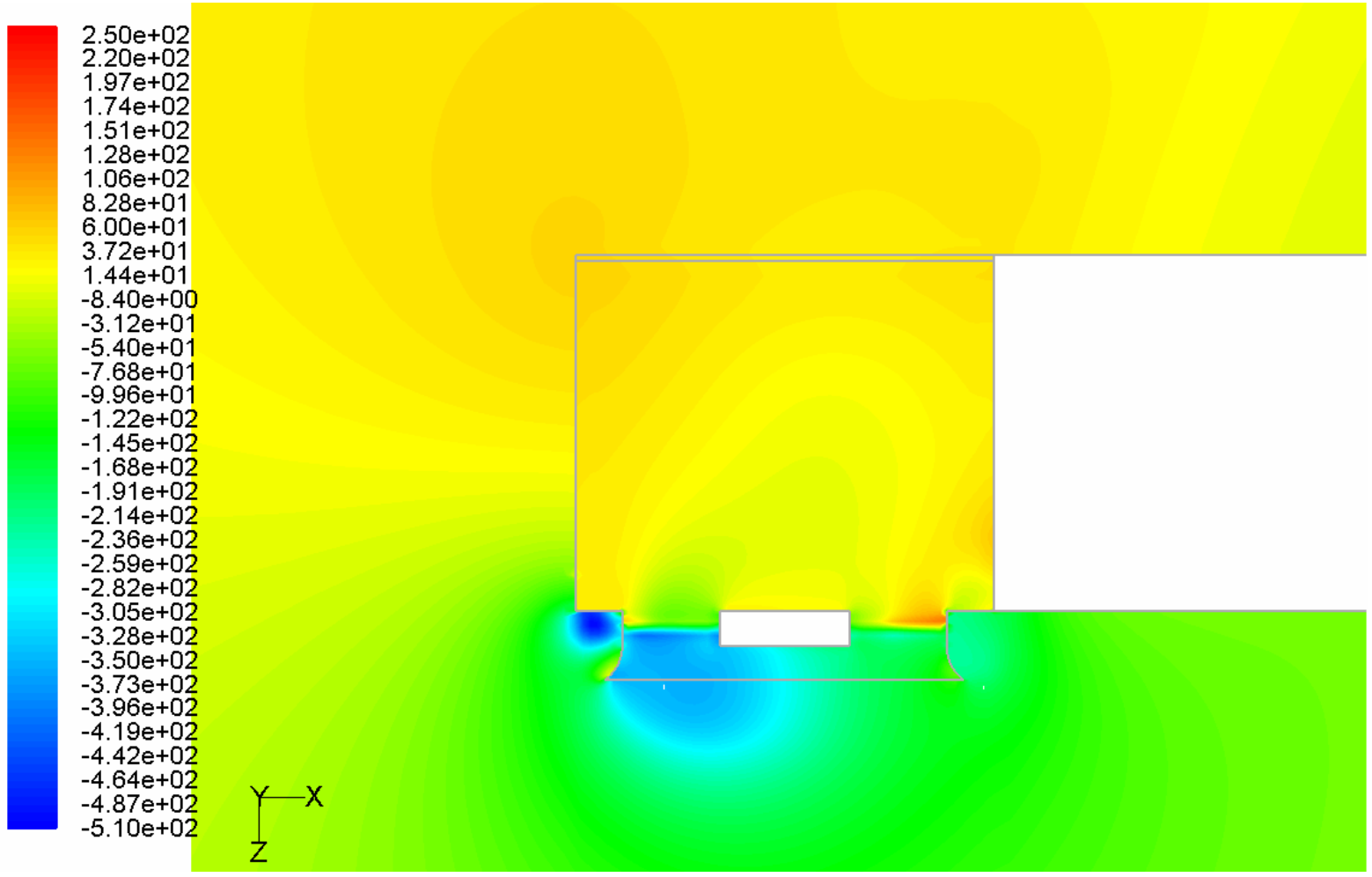

Figure 4.11: Static pressure, $p_{\text {stat }} N / \mathrm{m}^{2}$, fan $(4,1)$ at a wind speed of $9 \mathrm{~m} / \mathrm{s}$.

|Section view F-F (refer to figure 3.6).

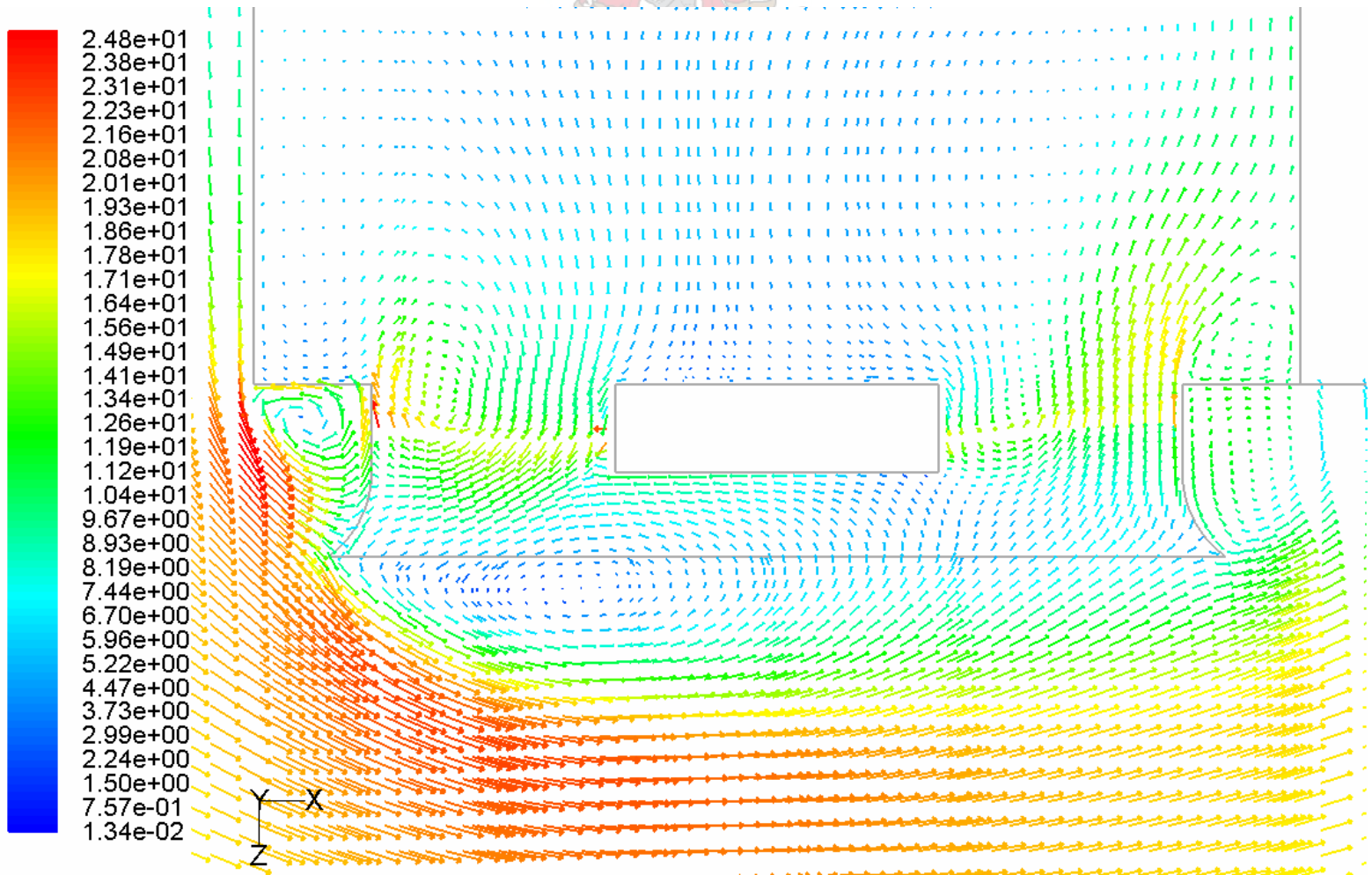

Figure 4.12: Vector plot, v, m/s, fan(4,1) at a wind speed of $9 \mathrm{~m} / \mathrm{s}$.

Section view F-F (refer to figure 3.6). 


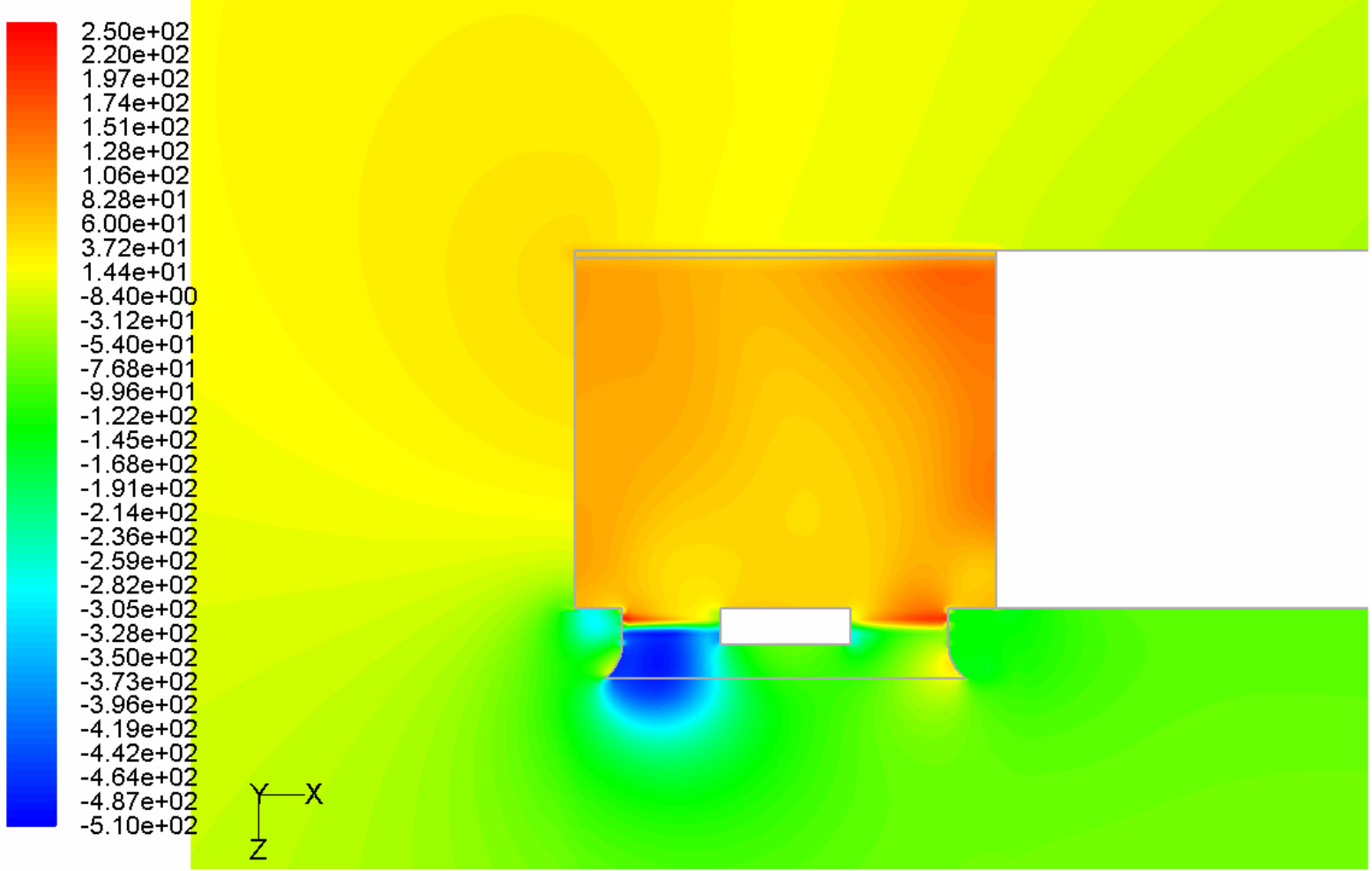

Figure 4.13: Static pressure, $p_{\text {stat }} N / \mathrm{m}^{2}$, fan $(6,1)$ at a wind speed of $9 \mathrm{~m} / \mathrm{s}$.

Section view F-F (refer to figure 3.6).

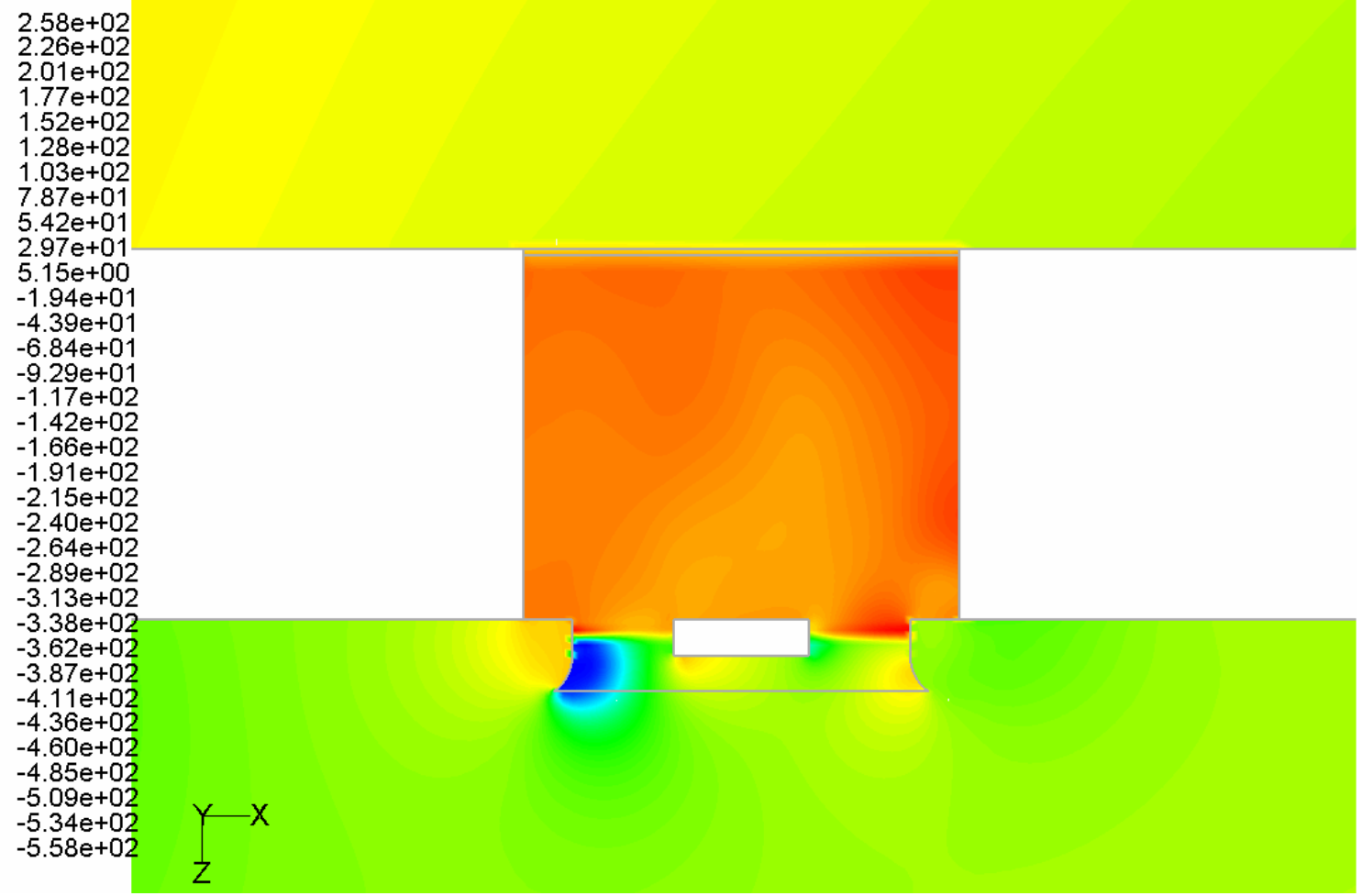

Figure 4.14: Static pressure, $p_{\text {stat }}, \mathrm{N} / \mathrm{m}^{2}$, fan $(4,3)$ at a wind speed of $9 \mathrm{~m} / \mathrm{s}$. Section view F-F (refer to figure 3.6). 
An example of the latter effect is illustrated in figure 4.15 which shows a swirling flow (vortex) containing entrained hot plume air along the sides of the ACSC. Ambient air is drawn upwards by the rising plume along the periphery of the ACSC. Due to the low pressure under the fan platform some of this air, after entraining hot plume air, is increasingly drawn into the fans in the down wind direction.

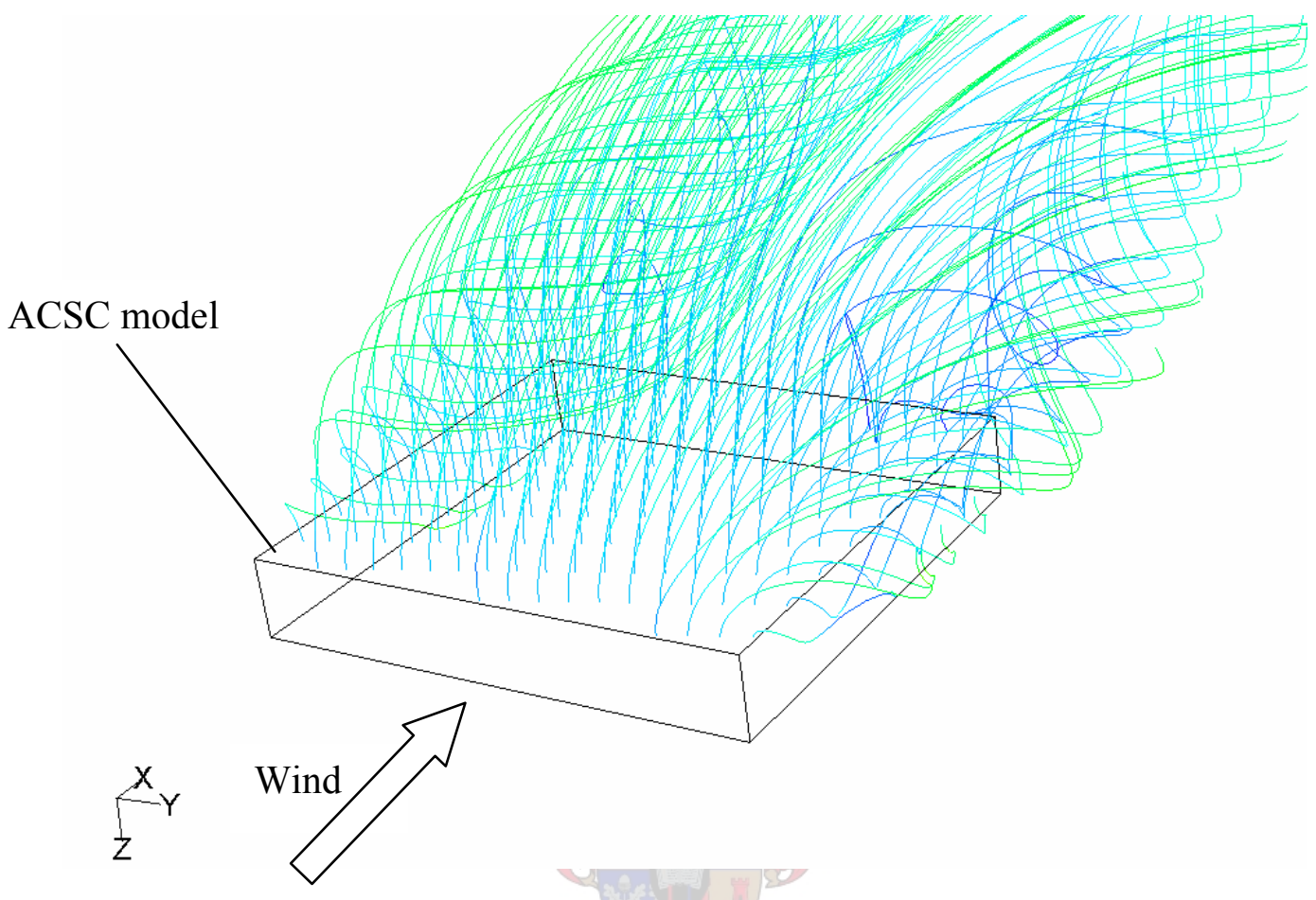

Figure 4.15: Streamline plot: Global flow field showing plume vortices of increasing magnitude in the downstream direction at a wind speed of $9 \mathrm{~m} / \mathrm{s}$.

The magnitude of the vortex increases in the downstream direction with a corresponding increased entrainment of hot plume air. This trend is clearly shown in figures 4.16 to 4.18. Due to the small upstream vortex, fan $(6,1)$ hardly experiences any increase in its inlet temperature (essentially ambient temperature) while fan $(6,5)$ experiences a measurable increase in inlet air temperature.

Figure 4.19 shows the air inlet temperature at each fan in row 6 where the hot air recirculation is present. Interpolation scheme 1 (Appendix C) is used to determine the air inlet temperature of the edge fans. 


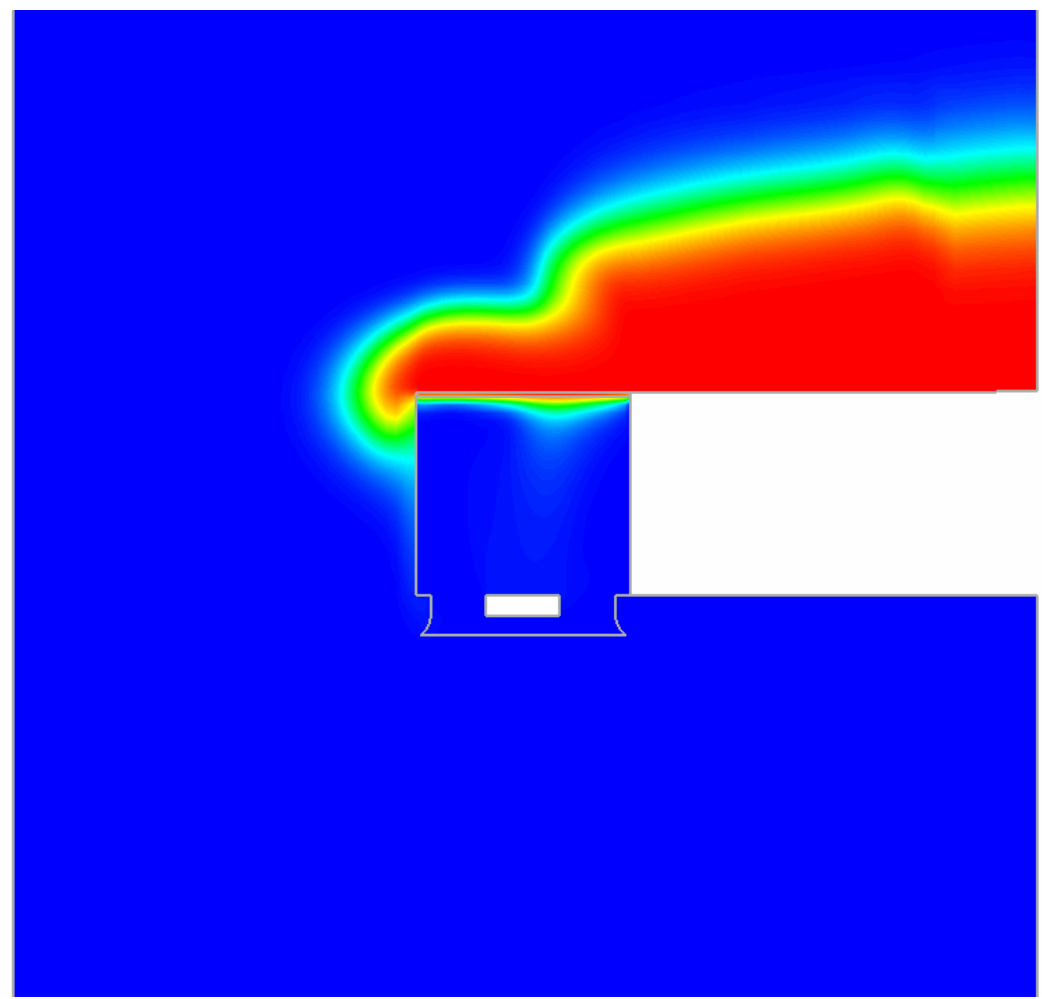

Figure 4.16: Temperature, $K$, fan(6,1) at a wind speed of $9 \mathrm{~m} / \mathrm{s}$.

|Section view D-D (refer to figure 3.6).

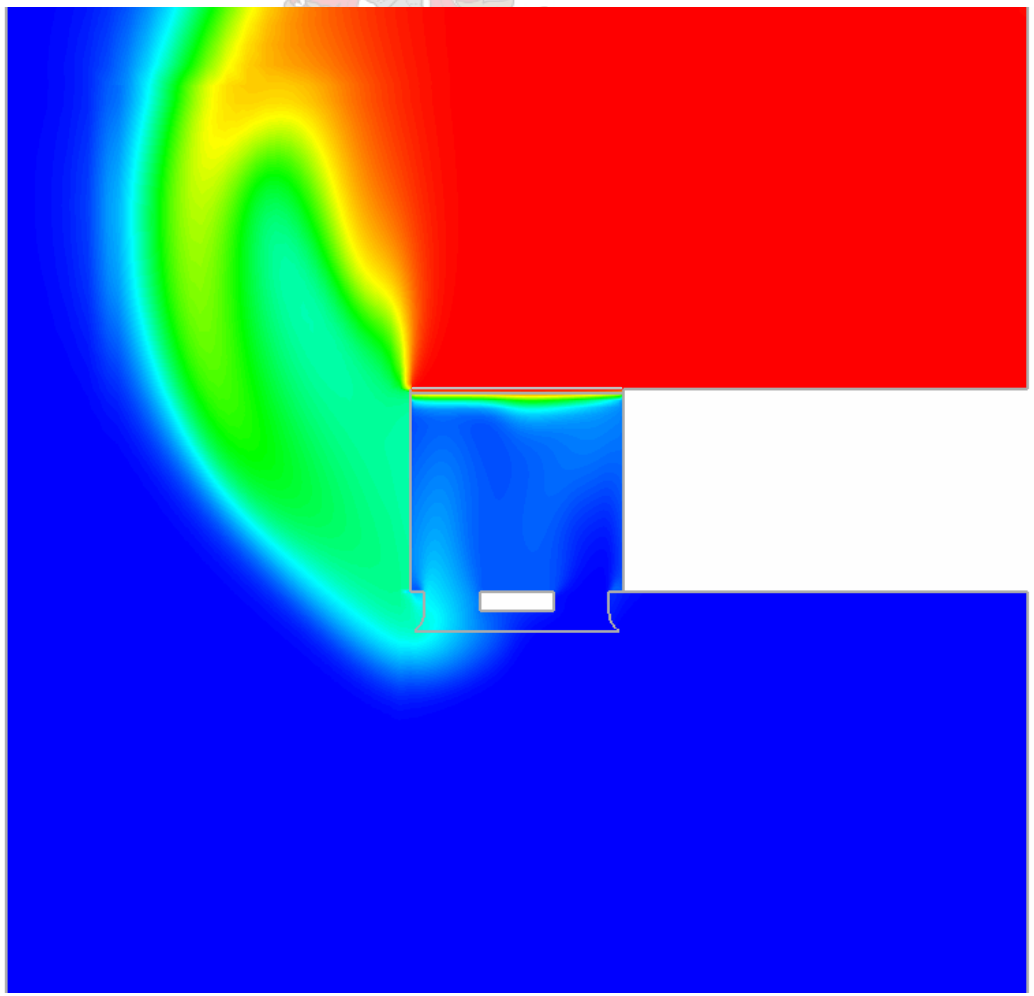

Figure 4.17: Temperature, $K$, fan(6,3) at a wind speed of $9 \mathrm{~m} / \mathrm{s}$.

Section view D-D (refer to figure 3.6). 


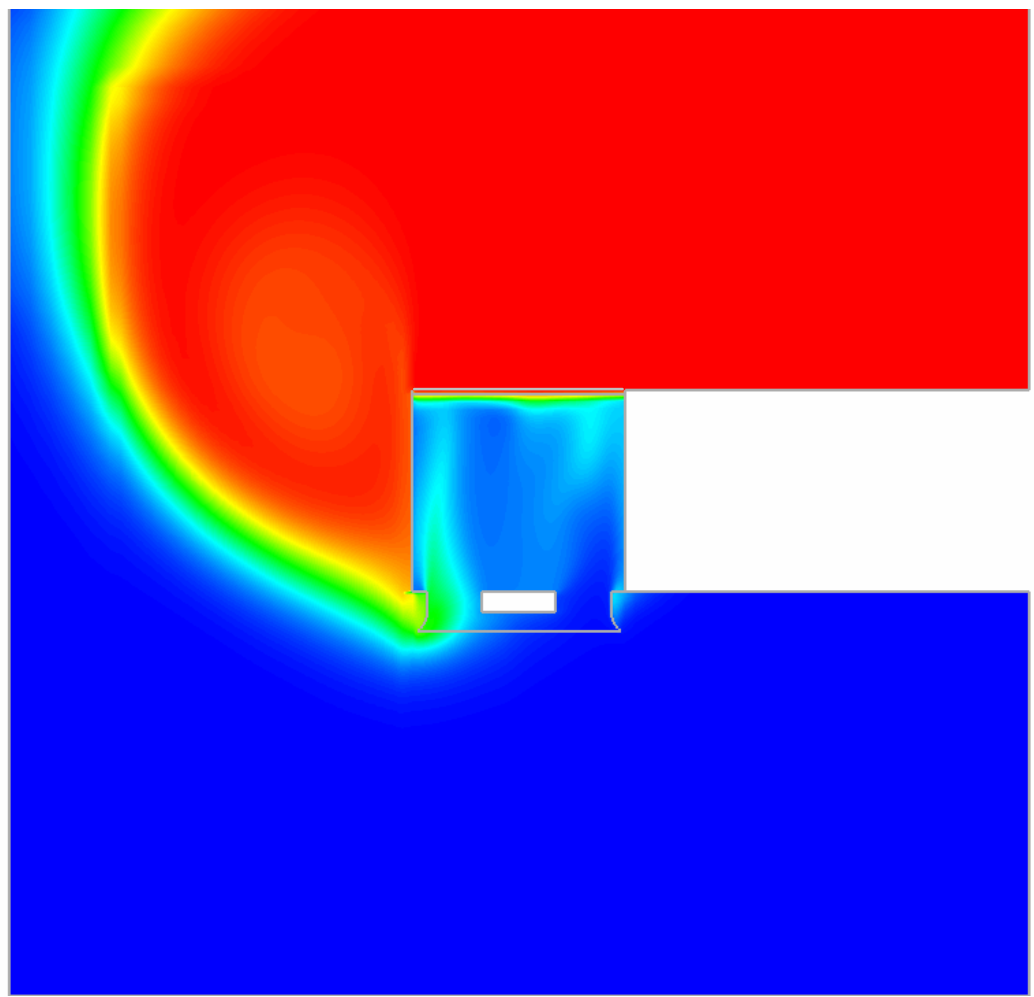

Figure 4.18: Temperature, $K$, fan(6,5) at a wind speed of $9 \mathrm{~m} / \mathrm{s}$.

Section view D-D (refer to figure 3.6).

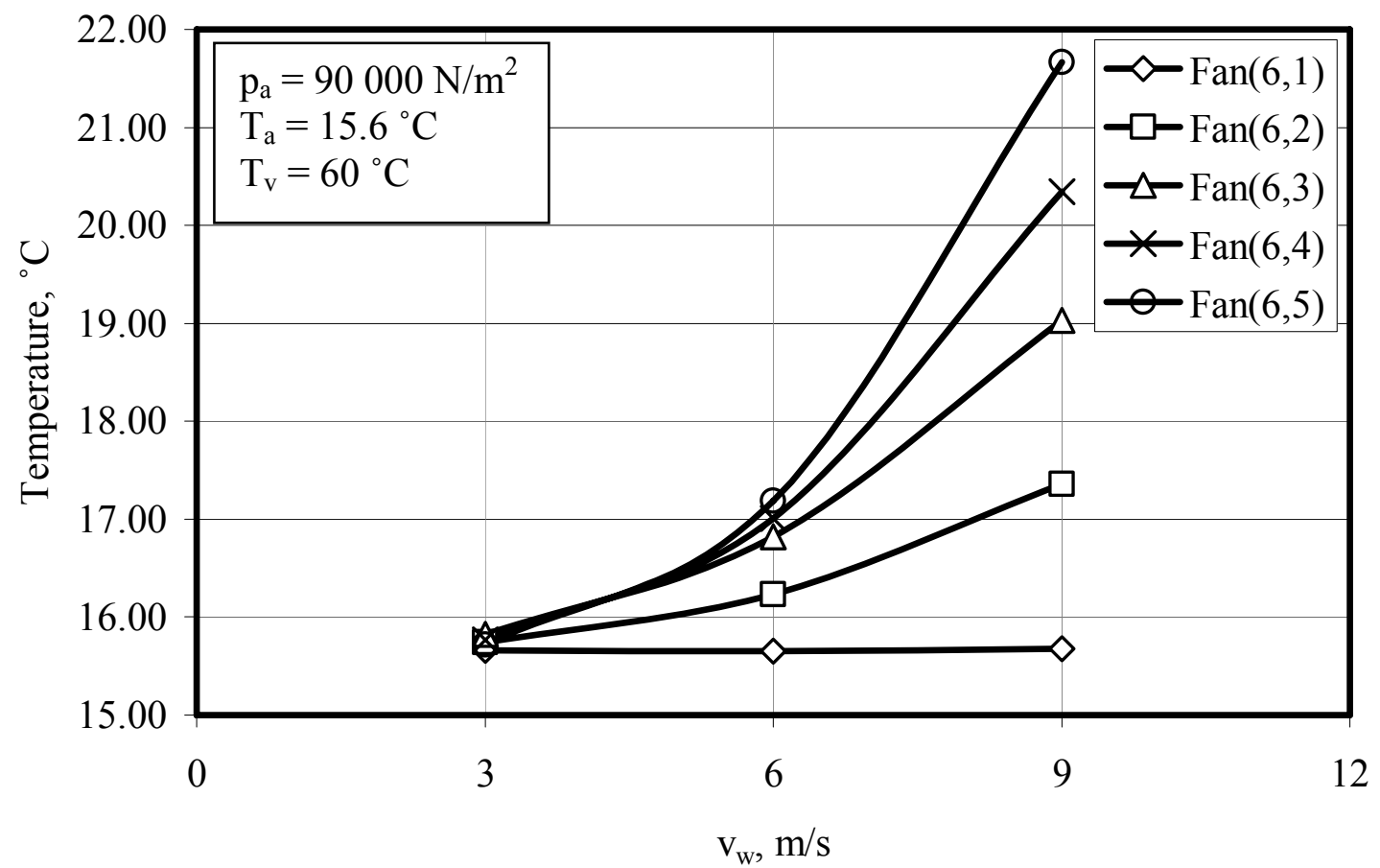

Figure 4.19: Air inlet temperature of the fans in row 6, and the wind in the $x$-direction. 


\subsection{System performance}

To find the volumetric effectiveness of the ACSC (under non-adiabatic conditions), the volumetric effectiveness of each of the thirty fans has to be determined. Due to time constraints, only some of the fans are analyzed and an interpolation scheme (combination of interpolation and extrapolation) is used to determine the volumetric effectiveness of the remaining fans (refer to Appendix $\mathrm{C}$ for the volumetric effectiveness of each fan). Different interpolation schemes are evaluated in Appendix C.

As shown in figure 4.20 the volumetric effectiveness of the ACSC decreases measurably with increasing wind speed.

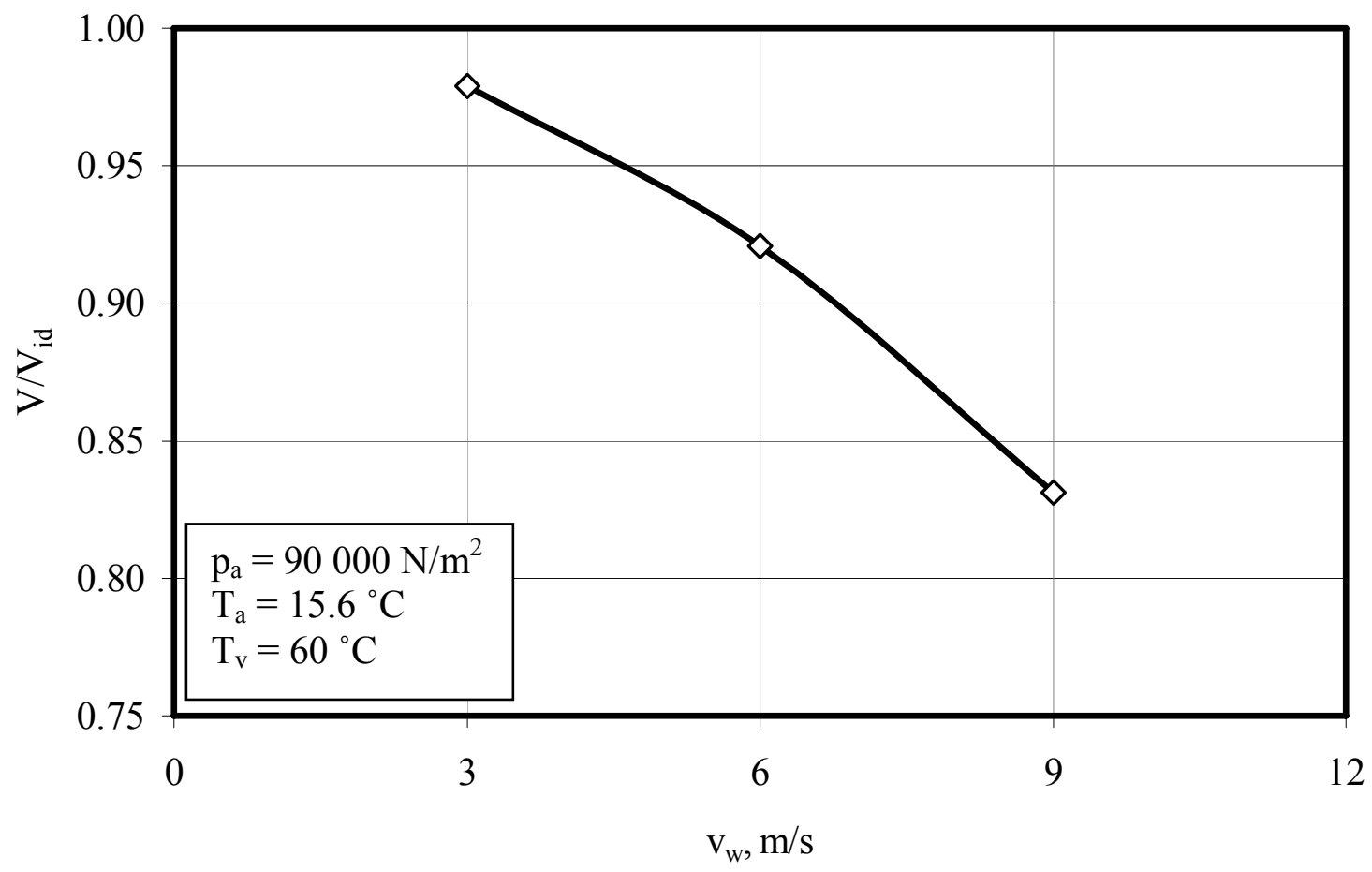

Figure 4.20: Volumetric effectiveness of ACSC.

Under non-adiabatic conditions the thermal effectiveness (this includes changes in volume flow and inlet air temperature) of the ACSC is defined as:

$\mathrm{e}_{\mathrm{t}}=\mathrm{Q} / \mathrm{Q}_{\mathrm{id}}$ 
The effectiveness of a cell or fan unit is according to equation (A.1) (see Appendix A):

$\mathrm{e}=1-\exp \left(-\mathrm{U}_{\mathrm{ij}} \mathrm{A} / \mathrm{m}_{\mathrm{afij}} \mathrm{c}_{\mathrm{pa}}\right)$

For the ACSC consisting of thirty fan units operating under ideal conditions (no inlet flow distortions) with an ideal air flow rate of $m_{\text {afid }}=717.65 \mathrm{~kg} / \mathrm{s}$ per fan unit, the total heat transfer from the steam to the air is:

$$
\begin{aligned}
\mathrm{Q}_{\text {id }} & =30 \mathrm{~m}_{\text {afid }} \mathrm{c}_{\mathrm{pa}}\left(\mathrm{T}_{\mathrm{v}}-\mathrm{T}_{\mathrm{a}}\right) \mathrm{e} \\
& =30 \mathrm{~m}_{\text {afid }} \mathrm{c}_{\mathrm{pa}}\left(\mathrm{T}_{\mathrm{v}}-\mathrm{T}_{\mathrm{a}}\right)\left[1-\exp \left(-\mathrm{UA} / \mathrm{m}_{\text {afid }} \mathrm{c}_{\mathrm{pa}}\right)\right] \\
& =30 \times 717.65 \times 1006.609 \times(333.15-288.75) \times\left[1-\exp \left(-44.41 / 717.65^{0.5443}\right)\right] \\
& =683.445 \times 10^{6} \mathrm{~W}
\end{aligned}
$$

During windy periods:

$$
\begin{aligned}
\mathrm{Q}=\sum_{\mathrm{i}=1}^{6} \sum_{\mathrm{j}=1}^{5} \mathrm{Q}_{\mathrm{fij}} & =\sum_{\mathrm{i}=1}^{6} \sum_{\mathrm{j}=1}^{5} \mathrm{~m}_{\mathrm{afij}} \mathrm{c}_{\mathrm{pa}}\left(\mathrm{T}_{\mathrm{v}}-\mathrm{T}_{\text {aij }}\right)\left[1-\exp \left(-\mathrm{U}_{\mathrm{ij}} \mathrm{A} / \mathrm{m}_{\mathrm{afij}} \mathrm{c}_{\mathrm{pa}}\right)\right] \\
& =\sum_{\mathrm{i}=1}^{6} \sum_{\mathrm{j}=1}^{5} \mathrm{~m}_{\mathrm{afij}} \mathrm{c}_{\mathrm{pa}}\left(\mathrm{T}_{\mathrm{v}}-\mathrm{T}_{\mathrm{aij}}\right)\left[1-\exp \left(-44.41 / \mathrm{m}_{\mathrm{afij}}{ }^{0.5443}\right)\right]
\end{aligned}
$$

where:

$$
\mathrm{m}_{\mathrm{afij}}=\rho_{\mathrm{a}} \mathrm{V}_{\mathrm{fij}}, \mathrm{kg} / \mathrm{s}
$$

The thermal effectiveness of the ACSC decreases with increasing wind speed as shown in figure 4.21. The dotted line shows the thermal effectiveness when only reduced fan air mass flow rates are considered (ambient air temperature assumed at the inlet to each fan i.e. hot air recirculation is ignored). Due to the relatively high windwall the effect of plume air recirculation is shown to have a small influence on the thermal effectiveness. 


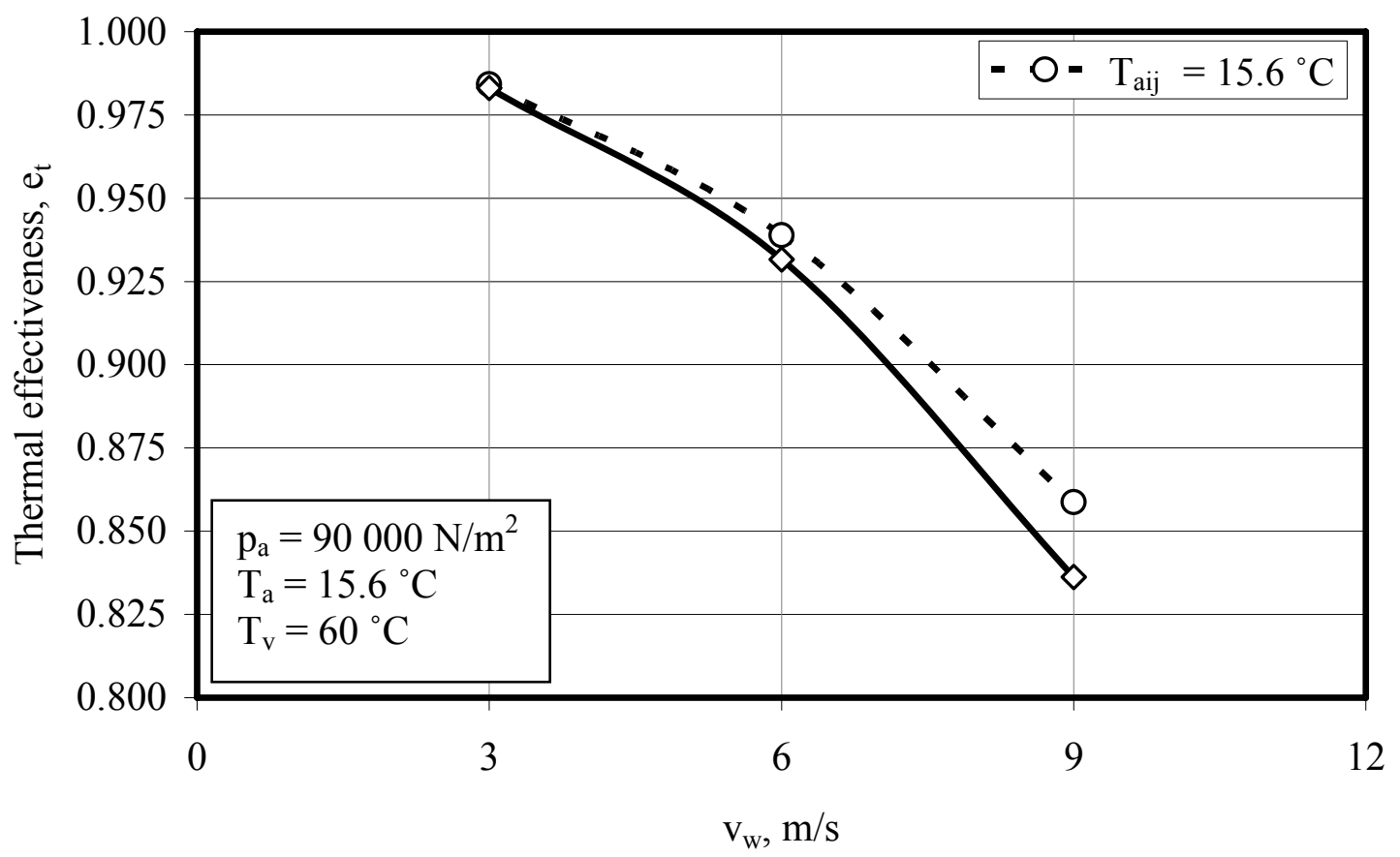

Figure 4.21: Thermal effectiveness of ACSC.

In a steam turbine power generating plant (during steady state or base load operation) the heat that is to be rejected by the ACSC is approximately constant at all ambient temperatures. When the ambient temperature rises or during windy periods when the ACSC thermal effectiveness is reduced there will be a rise in steam temperature and a corresponding turbine back pressure rise in order to reject the same amount of heat. Figure 4.23 shows how the turbine back pressure increases with increasing wind speed. The following equations were employed to determine the rise in steam temperature (figure 4.22) and corresponding increase in turbine back pressure (figure 4.23):

$$
\begin{aligned}
\mathrm{Q} & =\mathrm{Q}_{\mathrm{id}}=30 \mathrm{~m}_{\mathrm{afid}} \mathrm{c}_{\mathrm{pa}}\left(\mathrm{T}_{\mathrm{v}}-\mathrm{T}_{\mathrm{a}}\right)\left[1-\exp \left(-\mathrm{UA} / \mathrm{m}_{\mathrm{afid}} \mathrm{c}_{\mathrm{pa}}\right)\right] \\
& =\sum_{\mathrm{i}=1}^{6} \sum_{\mathrm{j}=1}^{5} \mathrm{Q}_{\mathrm{fij}}=\sum_{\mathrm{i}=1}^{6} \sum_{\mathrm{j}=1}^{5} \mathrm{~m}_{\mathrm{afij}} \mathrm{c}_{\mathrm{pa}}\left(\mathrm{T}_{\mathrm{vw}}-\mathrm{T}_{\text {aij }}\right)\left[1-\exp \left(-\mathrm{U}_{\mathrm{ij}} \mathrm{A} / \mathrm{m}_{\mathrm{afij}} \mathrm{c}_{\mathrm{pa}}\right)\right] \\
& =\sum_{\mathrm{i}=1}^{6} \sum_{\mathrm{j}=1}^{5} \mathrm{~m}_{\text {afij }} \mathrm{c}_{\mathrm{pa}} \mathrm{T}_{\mathrm{vw}}\left[1-\exp \left(-\mathrm{U}_{\mathrm{ij}} \mathrm{A} / \mathrm{m}_{\text {afij }} \mathrm{c}_{\mathrm{pa}}\right)\right]-\sum_{\mathrm{i}=1}^{6} \sum_{\mathrm{j}=1}^{5} \mathrm{~m}_{\mathrm{afij}} \mathrm{c}_{\mathrm{pa}} \mathrm{T}_{\mathrm{aij}}\left[1-\exp \left(-\mathrm{U}_{\mathrm{ij}} \mathrm{A} / \mathrm{m}_{\mathrm{afij}} \mathrm{c}_{\mathrm{pa}}\right)\right]
\end{aligned}
$$

or

$$
\mathrm{T}_{\mathrm{vw}}=\frac{30 \mathrm{~m}_{\mathrm{afid}} \mathrm{c}_{\mathrm{pa}}\left(\mathrm{T}_{\mathrm{v}}-\mathrm{T}_{\mathrm{a}}\right)\left[1-\exp \left(-\mathrm{UA} / \mathrm{m}_{\mathrm{afid}} \mathrm{c}_{\mathrm{pa}}\right)\right]+\sum_{\mathrm{i}=1}^{6} \sum_{\mathrm{j}=1}^{5} \mathrm{~m}_{\mathrm{afij}} \mathrm{c}_{\mathrm{pa}} \mathrm{T}_{\text {aij }}\left[1-\exp \left(-\mathrm{U}_{\mathrm{ijj}} \mathrm{A} / \mathrm{m}_{\mathrm{afij}} \mathrm{c}_{\mathrm{pa}}\right)\right]}{\sum_{\mathrm{i}=1}^{6} \sum_{\mathrm{j}=1}^{5} \mathrm{~m}_{\mathrm{afij}} \mathrm{c}_{\mathrm{pa}}\left[1-\exp \left(-\mathrm{U}_{\mathrm{ij}} \mathrm{A} / \mathrm{m}_{\mathrm{afij}} \mathrm{c}_{\mathrm{pa}}\right)\right]}
$$




$$
=\frac{30 \mathrm{~m}_{\text {afid }} \mathrm{c}_{\mathrm{pa}}\left(\mathrm{T}_{\mathrm{v}}-\mathrm{T}_{\mathrm{a}}\right)\left[1-\exp \left(-44.41 / \mathrm{m}_{\text {afid }}{ }^{0.5443}\right)\right]+\sum_{\mathrm{i}=1}^{6} \sum_{\mathrm{j}=1}^{5} \mathrm{~m}_{\mathrm{afij}} \mathrm{c}_{\mathrm{pa}} \mathrm{T}_{\text {aij }}\left[1-\exp \left(-44.41 / \mathrm{m}_{\mathrm{afij}}{ }^{0.5443}\right)\right]}{\sum_{\mathrm{i}=1}^{6} \sum_{\mathrm{j}=1}^{5} \mathrm{~m}_{\mathrm{afij}} \mathrm{c}_{\mathrm{pa}}\left[1-\exp \left(-44.41 / \mathrm{m}_{\mathrm{afij}}{ }^{0.5443}\right)\right]}
$$

the temperatures are in ${ }^{\circ} \mathrm{C}$.

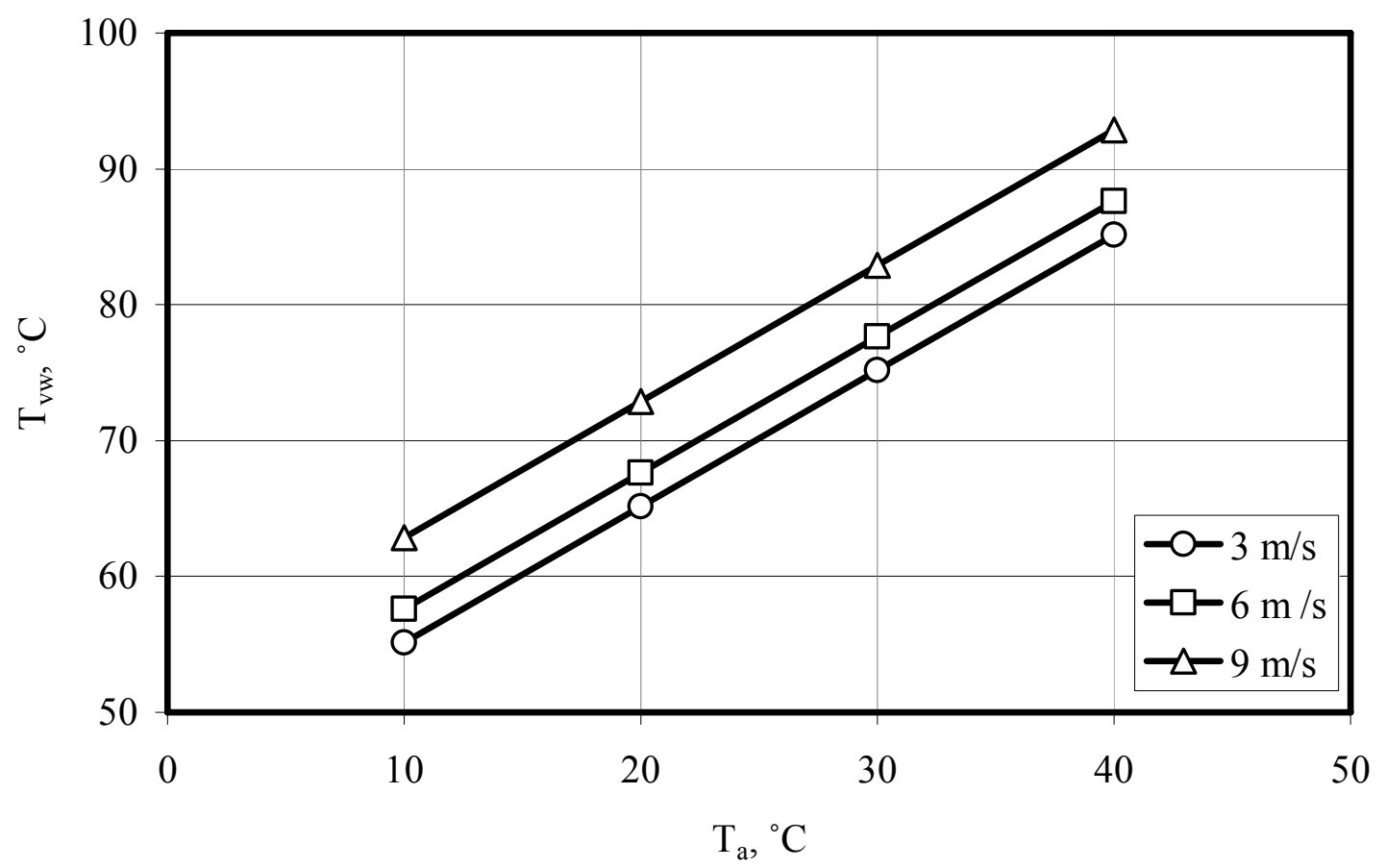

Figure 4.22: Ambient temperature and wind effect on saturation temperature of the turbine exhaust steam.

The saturation pressure of the steam corresponding to this temperature is given by (Kröger (2004)):

$\mathrm{p}_{\mathrm{vw}}=10^{\mathrm{z}}, \mathrm{N} / \mathrm{m}^{2}$

where:

$$
\begin{aligned}
\mathrm{Z} & =10.79586\left(1-273.16 / \mathrm{T}_{\mathrm{vw}}\right)+5.02808 \log _{10}\left(273.16 / \mathrm{T}_{\mathrm{vw}}\right) \\
& +1.50474 \times 10^{-4}\left[1-10^{-8.29692\left\{\left(\mathrm{~T}_{\mathrm{vw}} / 273.16\right)-1\right\}}\right] \\
& +4.2873 \times 10^{-4}\left[10^{4.76955\left(1-273.16 / \mathrm{T}_{\mathrm{vw}}\right)}-1\right]+2.786118312
\end{aligned}
$$

where $\mathrm{T}_{\mathrm{vw}}$ is in $\mathrm{K}$. 


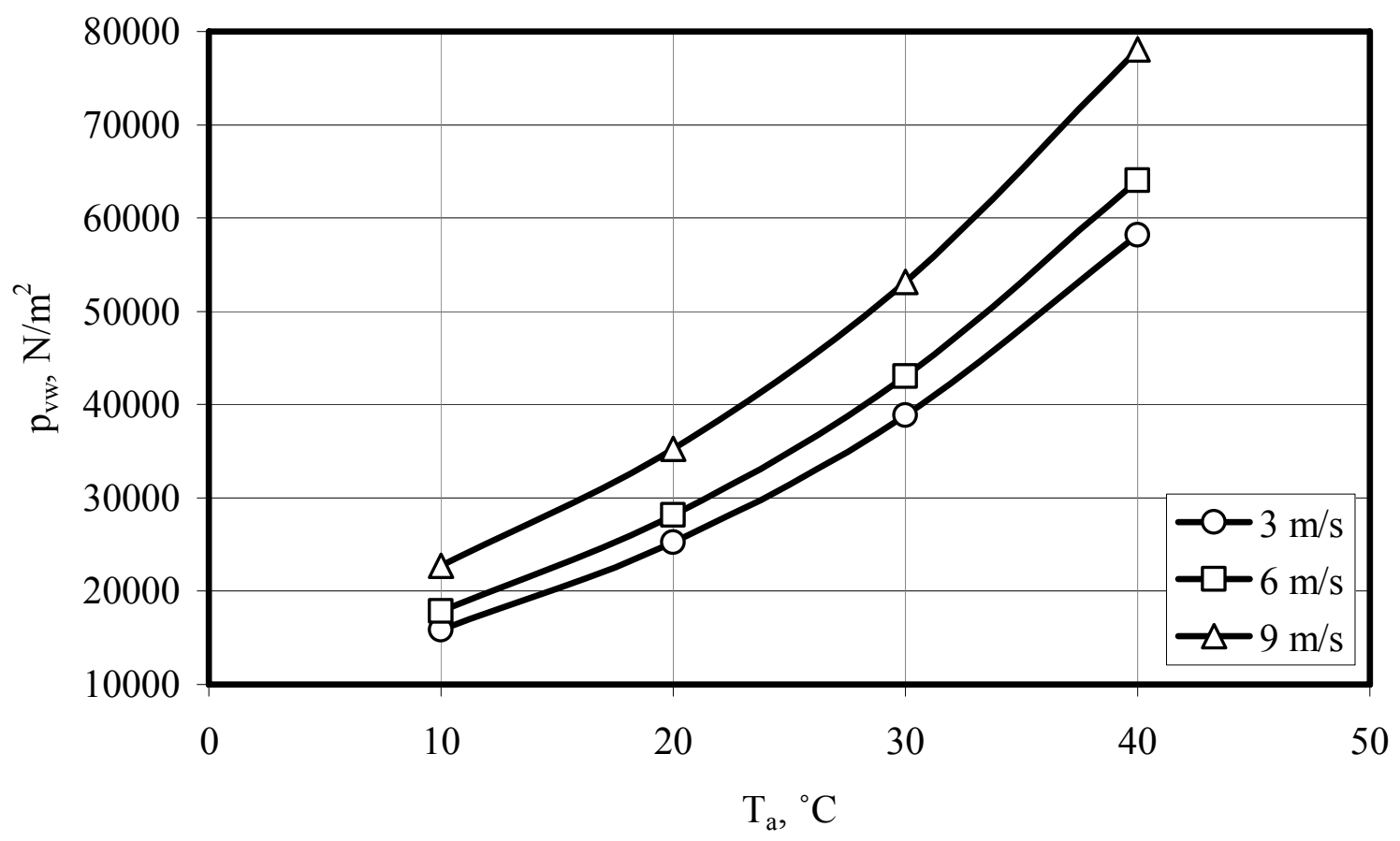

Figure 4.23: Ambient temperature and wind effect on turbine back pressure.

The trend of turbine back pressure as shown in figure 4.23 is in line with recently measured proprietary results at a plant similar to the present. 


\section{ACSC PERFORMANCE UNDER WINDY CONDITIONS (WIND AT $45^{\circ}$ WITH RESPECT TO X-DIRECTION)}

This chapter presents the results of the numerical analysis and shows the flow field about an ACSC and its performance when the wind blows in the positive $\mathrm{x}$-y-direction $\left(45^{\circ}\right.$ with respect to the $\mathrm{x}$-and y-directions) at speeds of $3 \mathrm{~m} / \mathrm{s}, 6 \mathrm{~m} / \mathrm{s}$ and $9 \mathrm{~m} / \mathrm{s}$ at an elevation corresponding to the fan platform height above ground level (20 m).

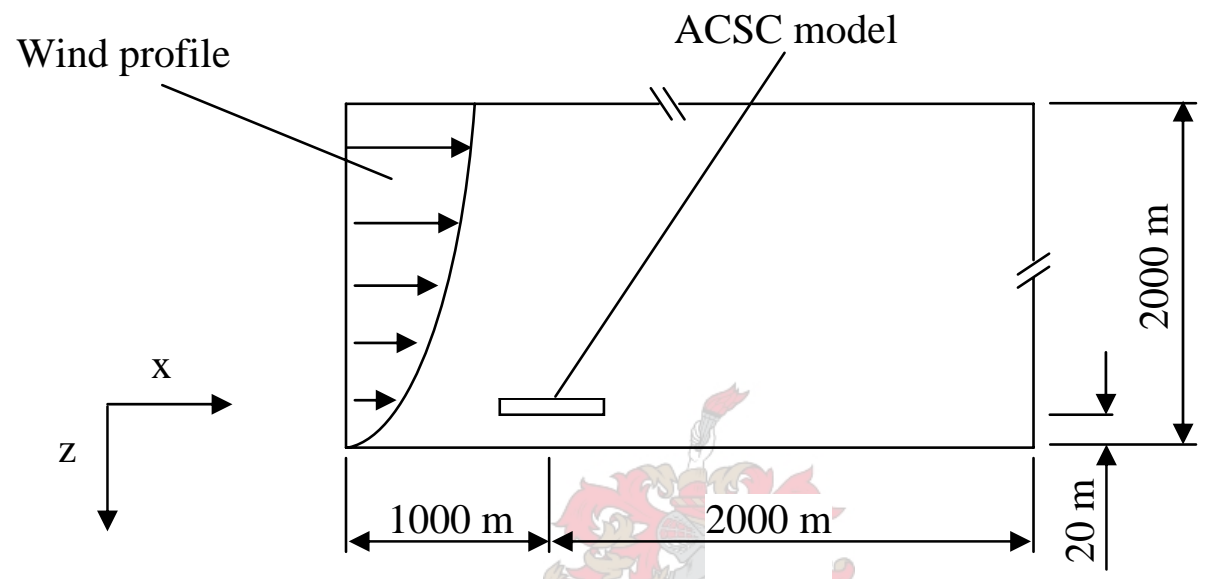

Side elevation

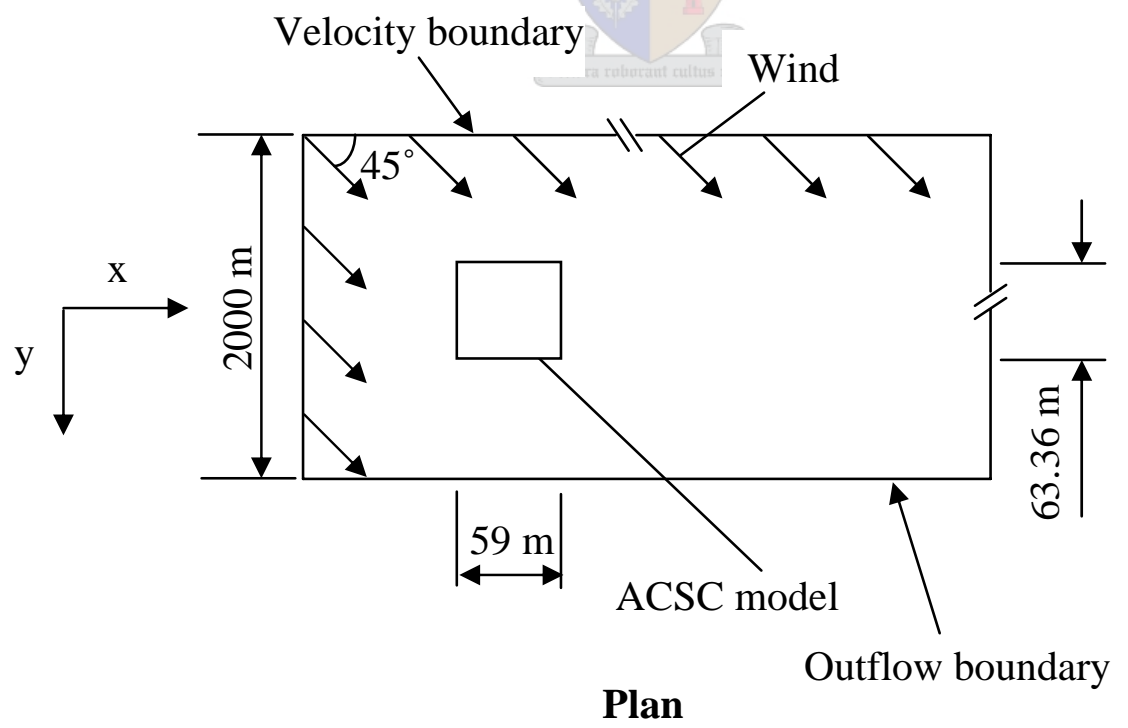

Figure 5.1: Global flow field. 
Figure 5.1 shows that for the case where the wind blows in the positive $x-y$-direction the two slip-walls in the global flow field numerical model (plan view in figure 3.2) are changed to a velocity boundary and an outflow boundary.

The following procedure will be followed:

- Solve the global flow field (refer to figure 3.2).

- Solve the flow field for specified fans (refer to figure 3.6) and determine their volumetric effectiveness.

- Determine the volumetric effectiveness of the remaining fans by interpolation and extrapolation.

- Calculate the volumetric effectiveness of the ACSC.

- Calculate the thermal effectiveness of the ACSC.

\subsection{Global flow field}

The global flow field model with the wind at an angle of $45^{\circ}$ with respect to $\mathrm{x}$ - and $\mathrm{y}$-directions does react as expected, when the wind speed is increased (plume rise angle changes). At a wind speed of $3 \mathrm{~m} / \mathrm{s}$ the plume rise angle is about $30^{\circ}$, at $6 \mathrm{~m} / \mathrm{s}$ the plume rise angle is about $45^{\circ}$ and at $9 \mathrm{~m} / \mathrm{s}$ the plume rise angle is about $60^{\circ}$ immediately downstream of the ACSC (refer to figures 5.2 to 5.4).

Figures 5.5 and 5.6 show that a low pressure region exists at the leading edge, underneath the ACSC. Figure 5.7 shows that this low pressure region is more evident at rows 3 and 4 and column 3 (refer to figure 5.8). 


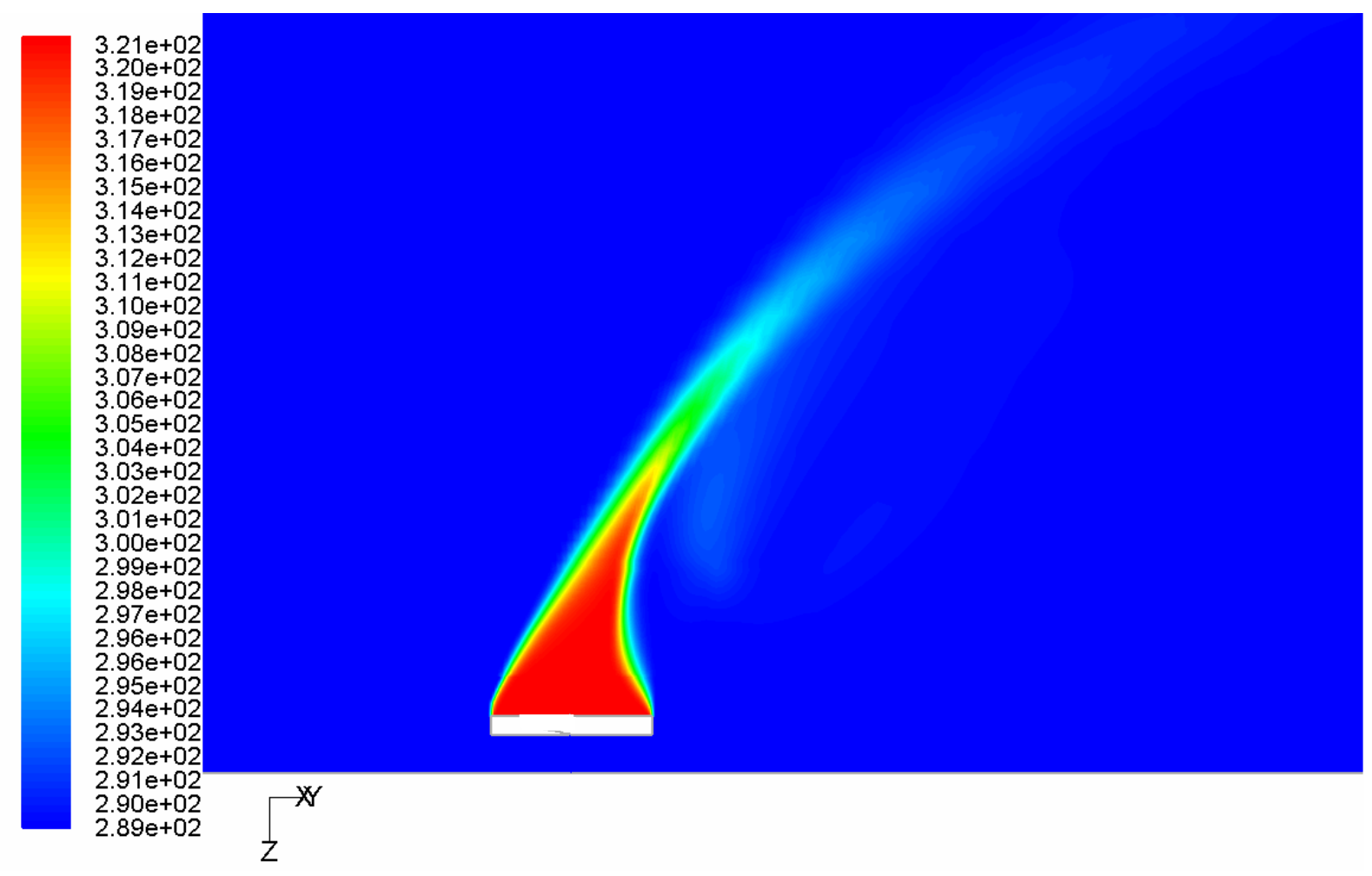

Figure 5.2: Temperature, $K$, global flow field at a wind speed of $3 \mathrm{~m} / \mathrm{s}$.

Section view G-G (refer to figure 3.2).

$3.15 \mathrm{e}+02$

$3.14 \mathrm{e}+02$

$3.13 \mathrm{e}+02$

$3.12 \mathrm{e}+02$

$3.11 \mathrm{e}+02$

$3.10 \mathrm{e}+02$

$3.09 \mathrm{e}+02$

$3.08 \mathrm{e}+02$

$3.07 \mathrm{e}+02$

$3.06 \mathrm{e}+02$

$3.05 \mathrm{e}+02$

$3.04 \mathrm{e}+02$

$3.03 \mathrm{e}+02$

$3.02 \mathrm{e}+02$

$3.01 \mathrm{e}+02$

$3.00 \mathrm{e}+02$

$2.99 \mathrm{e}+02$

$2.98 \mathrm{e}+02$

$2.97 \mathrm{e}+02$

$2.96 \mathrm{e}+02$

$2.96 \mathrm{e}+02$

$2.95 \mathrm{e}+02$

$2.94 \mathrm{e}+02$

$2.93 e+02$

$2.92 \mathrm{e}+02$

$2.91 \mathrm{e}+02$

$2.90 \mathrm{e}+02$

$2.89 \mathrm{e}+02$

Z
$X Y$

Figure 5.3: Temperature, K, global flow field at a wind speed of $6 \mathrm{~m} / \mathrm{s}$. Section view G-G (refer to figure 3.2). 


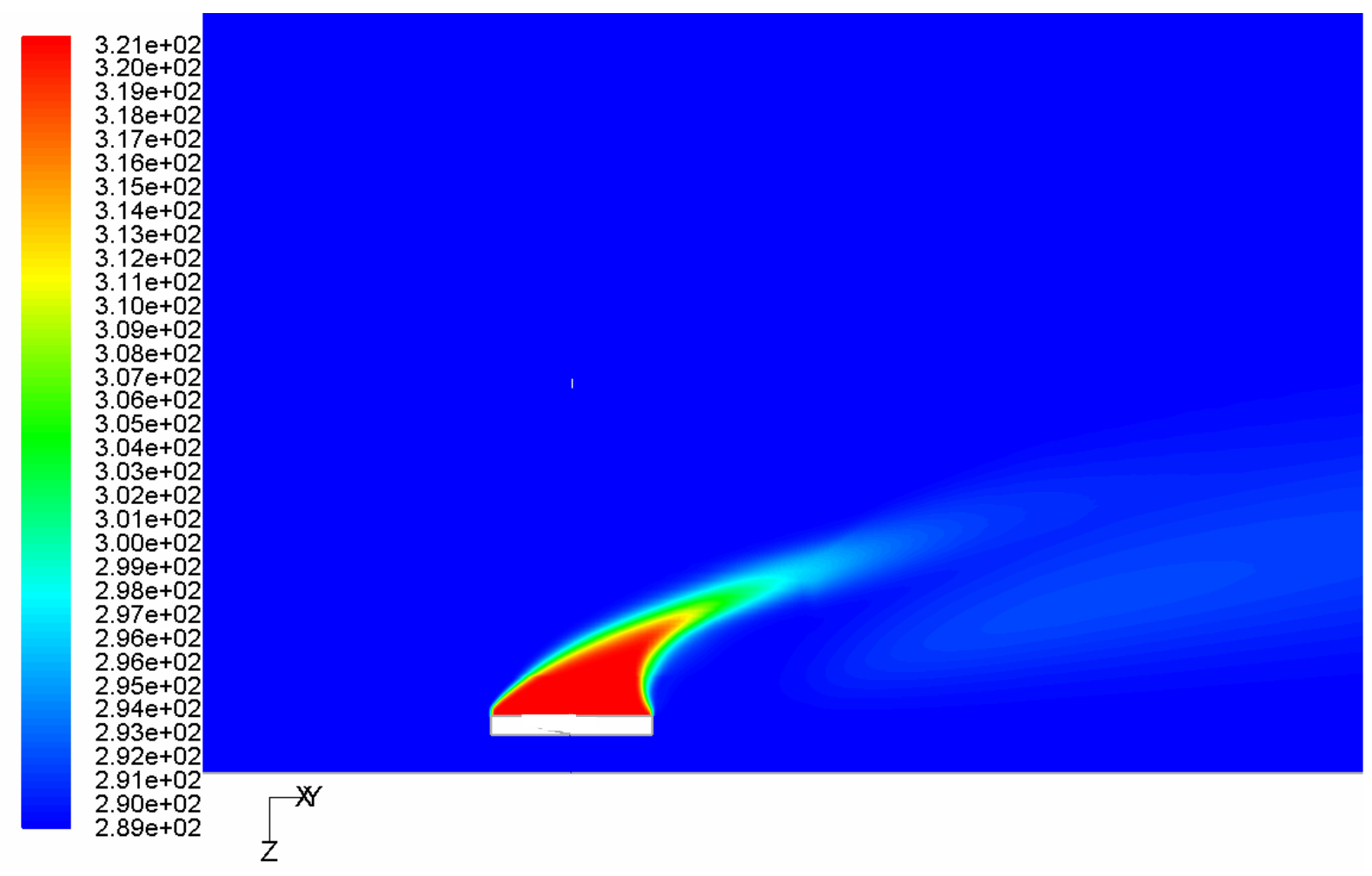

Figure 5.4: Temperature, $K$, global flow field at a wind speed of $9 \mathrm{~m} / \mathrm{s}$.

Section view G-G (refer to figure 3.2).

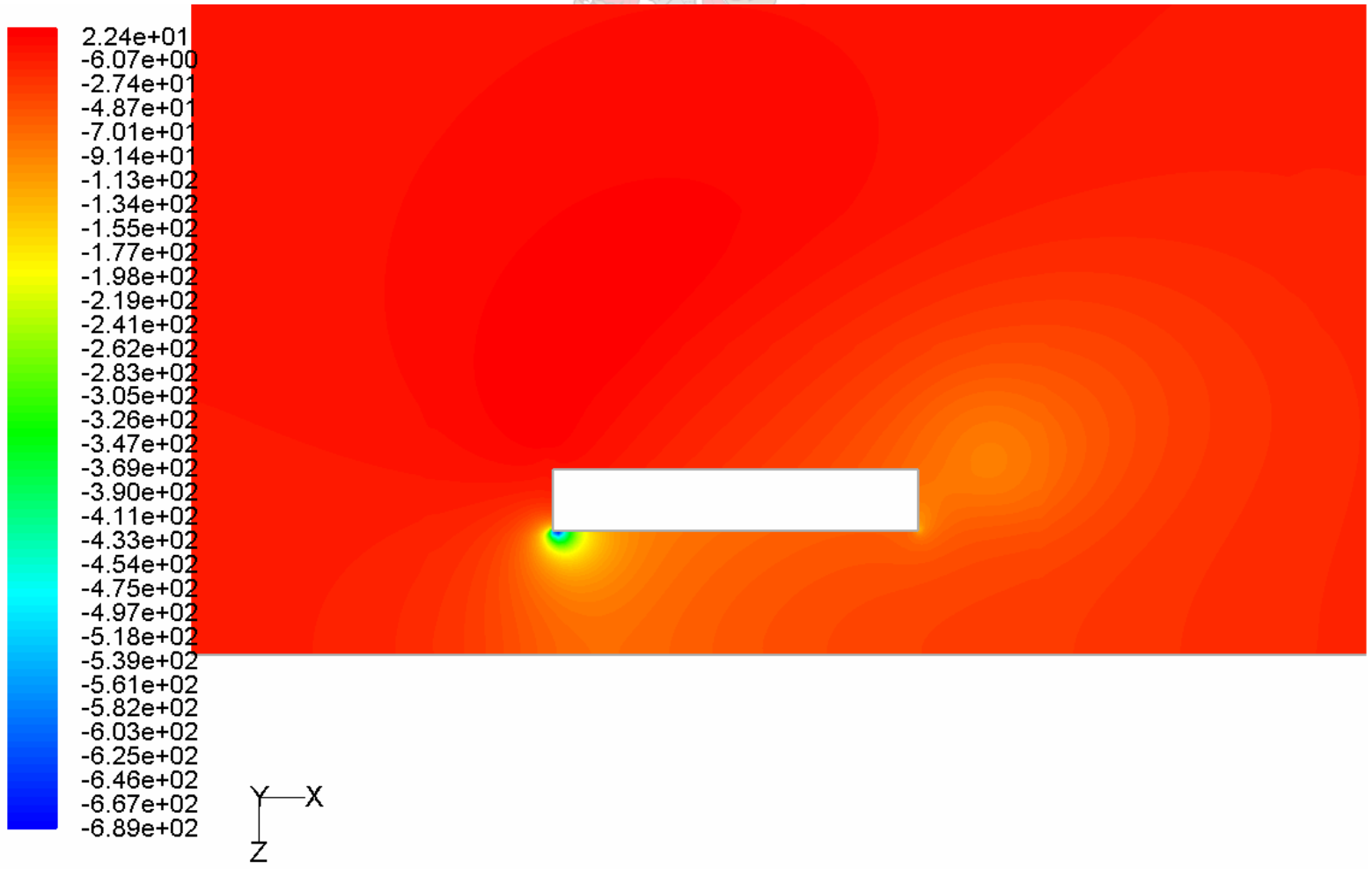

Figure 5.5: Static pressure, $p_{\text {stat }}, \mathrm{N} / \mathrm{m}^{2}$, global flow field at a wind speed of $9 \mathrm{~m} / \mathrm{s}$. Section view B-B (refer to figure 3.2). 


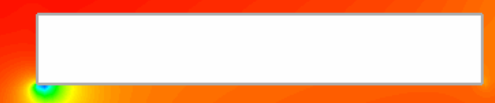

Figure 5.6: Static pressure, $p_{\text {stat }} \mathrm{N} / \mathrm{m}^{2}$, global flow field at a wind speed of $9 \mathrm{~m} / \mathrm{s}$.

Section view H-H (refer to figure 3.2).

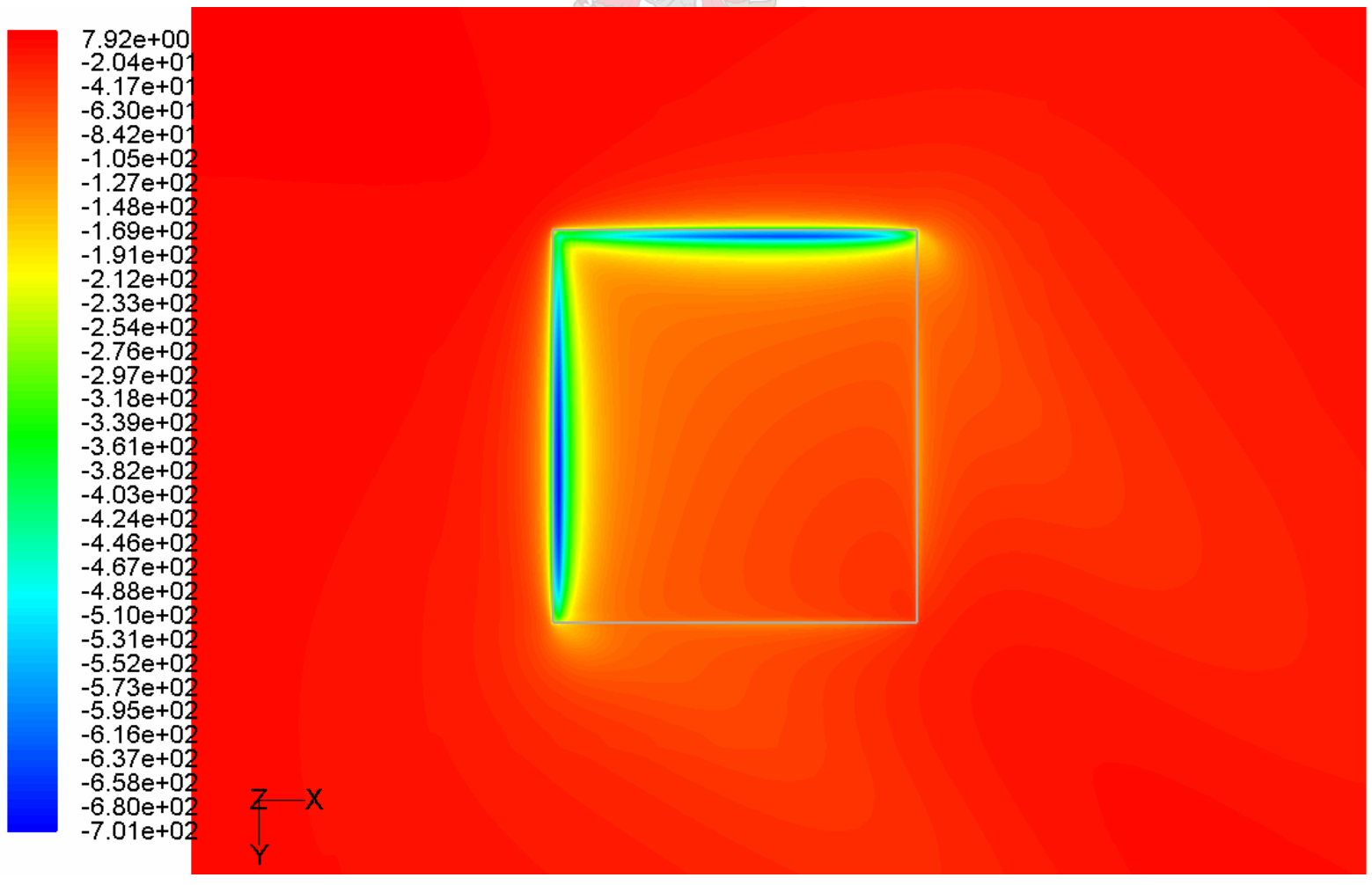

Figure 5.7: Static pressure, $p_{\text {stat, }}, \mathrm{N} / \mathrm{m}^{2}$, global flow field at a wind speed of $9 \mathrm{~m} / \mathrm{s}$. Section view A-A (refer to figure 3.2). 


\subsection{Fan performance}

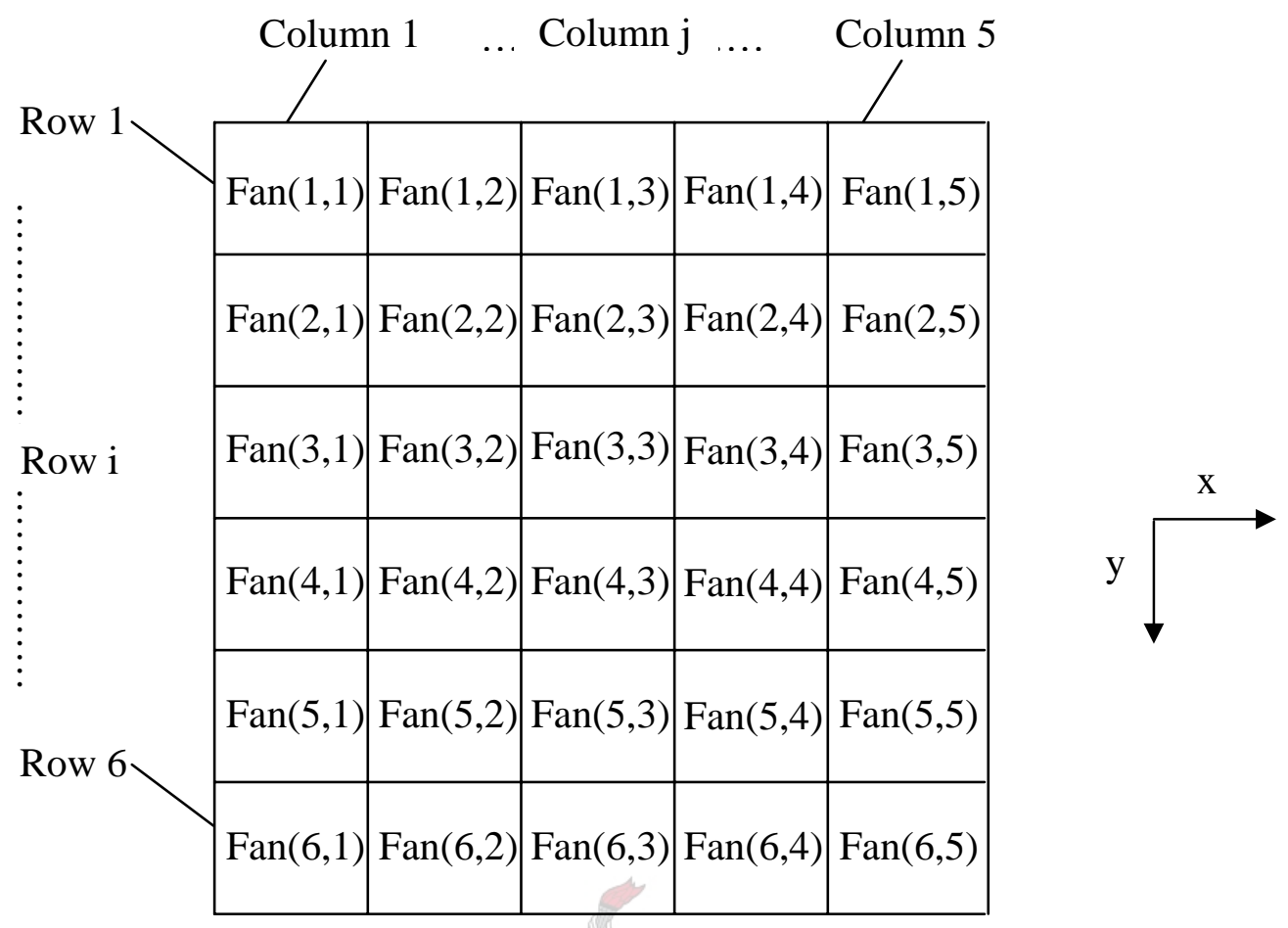

Figure 5.8: Numerical model (ACSC) with fan location.

The volumetric effectiveness of fan(1,1), fan(1,3), fan(1,5), fan(2,3), fan(3,1), fan(3,3) fan(3,5), fan(4,1), fan(4,3), fan(4,5), fan(5,3), fan(6,1), fan(6,3) and fan(6,5) is determined numerically at wind speeds of $3 \mathrm{~m} / \mathrm{s}, 6 \mathrm{~m} / \mathrm{s}$ and $9 \mathrm{~m} / \mathrm{s}$.

The wind has a significant effect on the volumetric effectiveness of the upstream edge fans, but a lesser effect on the volumetric effectiveness of the remaining fans. Figure 5.9 shows that the wind has the greatest negative effect on fans( 3,1$),(4,1)$ and $(1,3)$.

Due to the reduced component of wind speed in the direction of the main axes of the ACSC the reduction in upstream fan performance is not as dramatic as in the case of the flow in the $\mathrm{x}$-direction. 


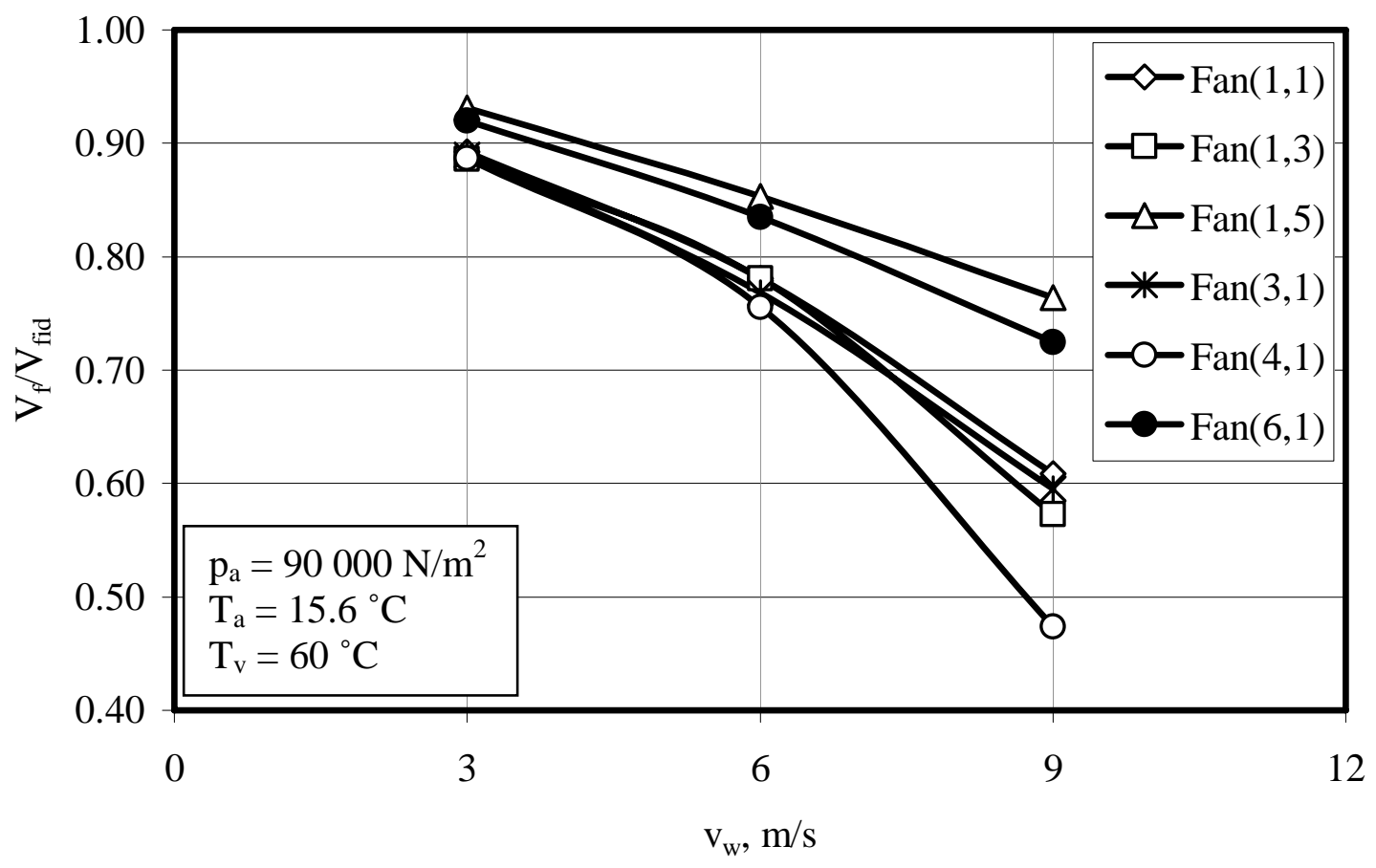

Figure 5.9: Volumetric effectiveness of fans.

As the wind speed increases, inlet flow distortions and low pressure regions are experienced similar to the case where the wind was blowing in the positive $\mathrm{x}$-direction. Regarding the hot air recirculation, the inlet air temperature of fan $(1,1)$ is at ambient temperature while the remaining fans in column one and row one experiences an inlet air temperature increase of about $1^{\circ} \mathrm{C}$.

Figure 5.10 shows that a swirling flow (vortex) arises as the hot air exits the ACSC, and it develops in the $x-y$-direction. 
$1.65 \mathrm{e}+01$

$1.57 \mathrm{e}+01$

$1.49 \mathrm{e}+01$

$1.42 \mathrm{e}+01$

$1.34 \mathrm{e}+01$

$1.26 \mathrm{e}+01$

$1.18 \mathrm{e}+01$

$1.10 \mathrm{e}+01$

$1.02 \mathrm{e}+01$

$9.44 \mathrm{e}+00$

$8.65 \mathrm{e}+00$

$7.87 \mathrm{e}+00$

$7.08 \mathrm{e}+00$

$6.29 \mathrm{e}+00$

$5.51 \mathrm{e}+00$

$4.72 \mathrm{e}+00$

$3.93 \mathrm{e}+00$

$3.15 \mathrm{e}+00$

$2.36 \mathrm{e}+00$

$1.57 \mathrm{e}+00$

$7.87 \mathrm{e}-01$

$0.00 \mathrm{e}+00$
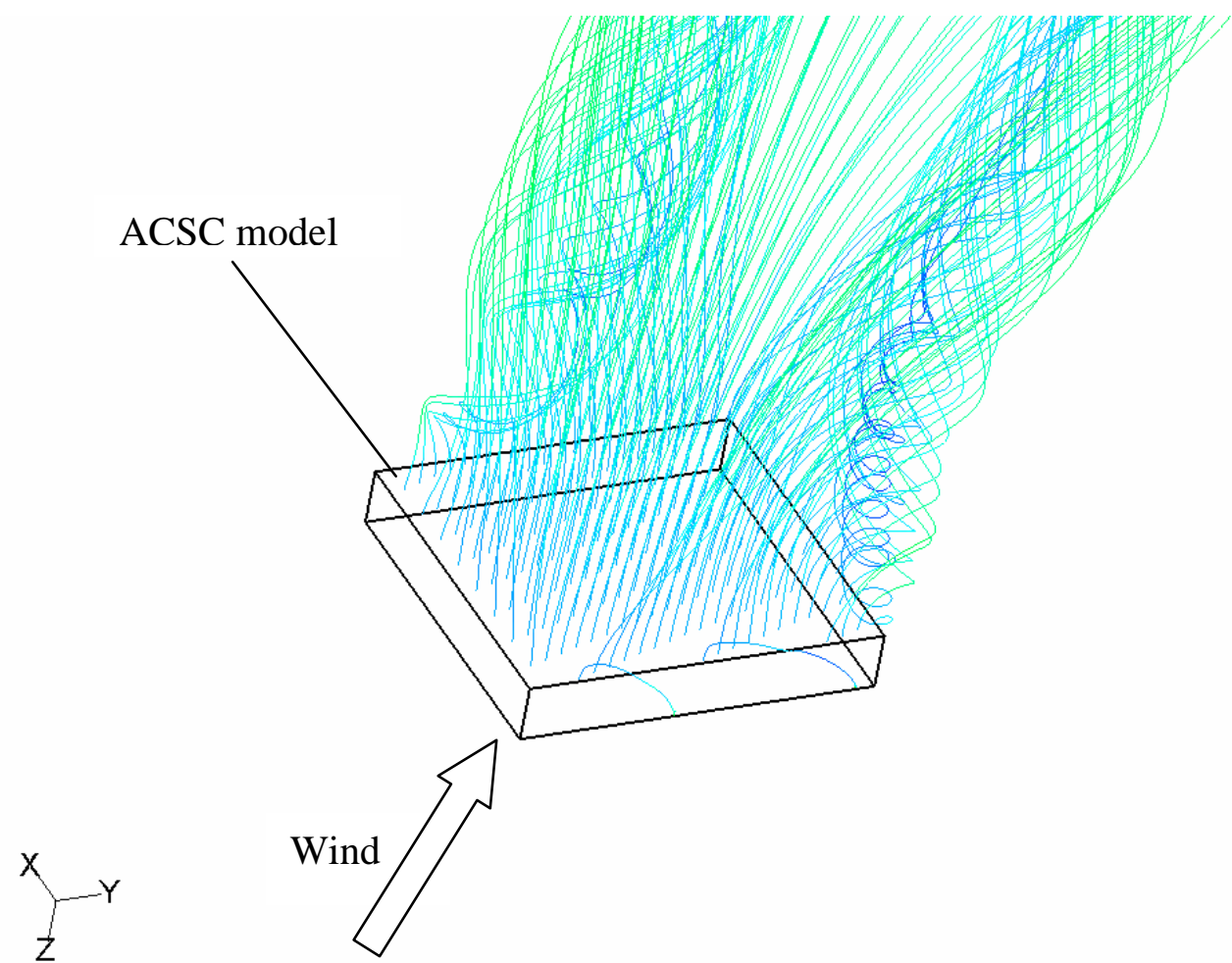

Figure 5.10: Streamline plot, global flow field showing plume vortices of increasing magnitude in the downstream direction at a wind speed of $9 \mathrm{~m} / \mathrm{s}$.

\subsection{System performance}

Due to time constraints, only some of the fans are numerically analyzed, and an interpolation scheme (interpolation scheme 3 ) is used to determine the volumetric effectiveness of the remaining fans (refer to Appendix C). Figure 5.11 indicates that the wind does have a significant negative effect on the volumetric effectiveness of the ACSC.

The thermal effectiveness of the ACSC decreases with increasing wind speed as shown in figure 5.12. The dotted line shows the thermal effectiveness when only reduced fan air mass flow rates are considered (ambient air temperature assumed at the inlet to each fan i.e. hot air recirculation is ignored). Due to the relatively high wind wall the effect of plume air recirculation is shown to have a small influence on the thermal effectiveness.

Figure 5.13 and figure 5.14 show how the steam temperature and turbine back pressure increases with increasing wind speed. 


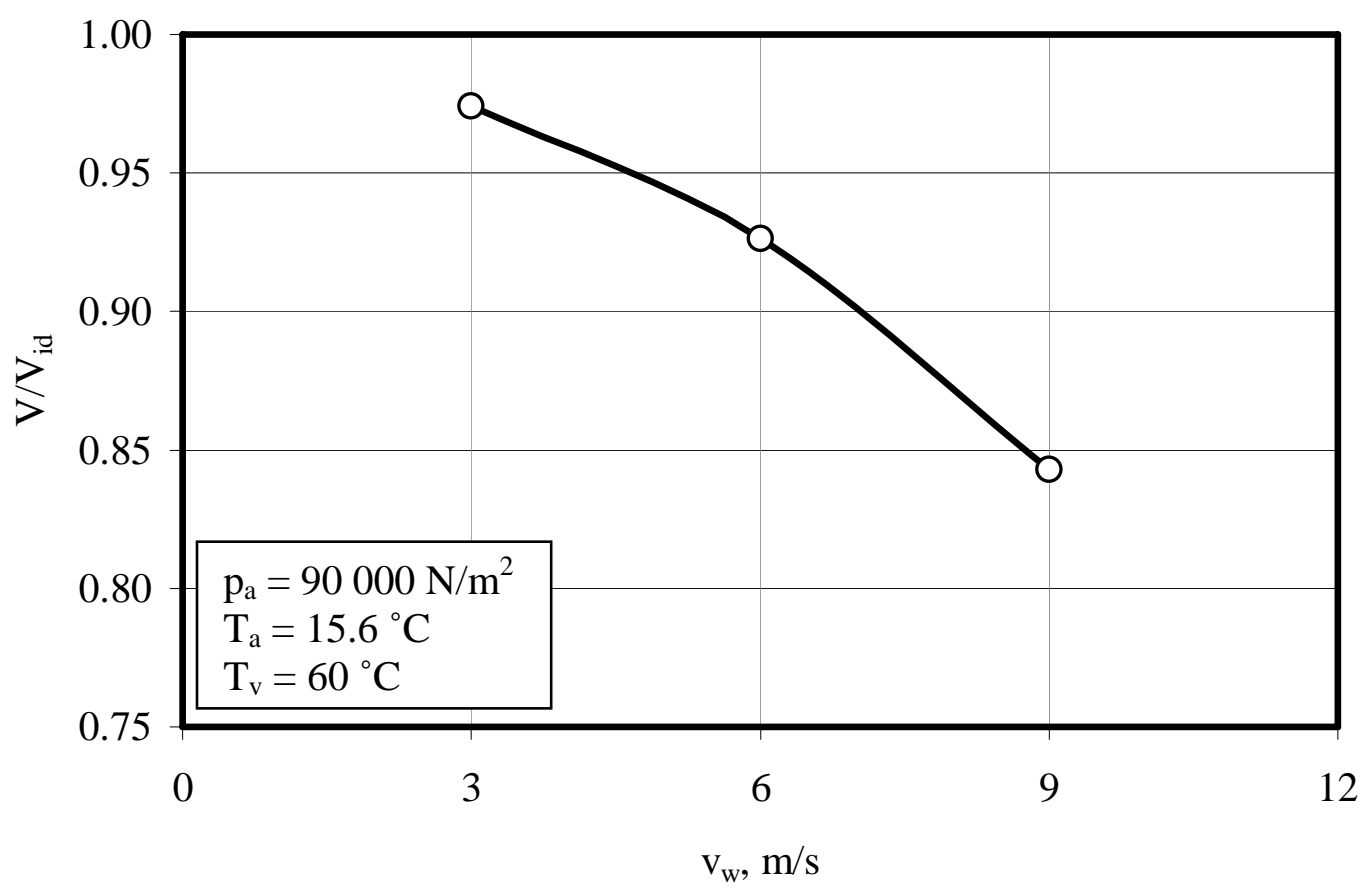

Figure 5.11: Volumetric effectiveness of ACSC.

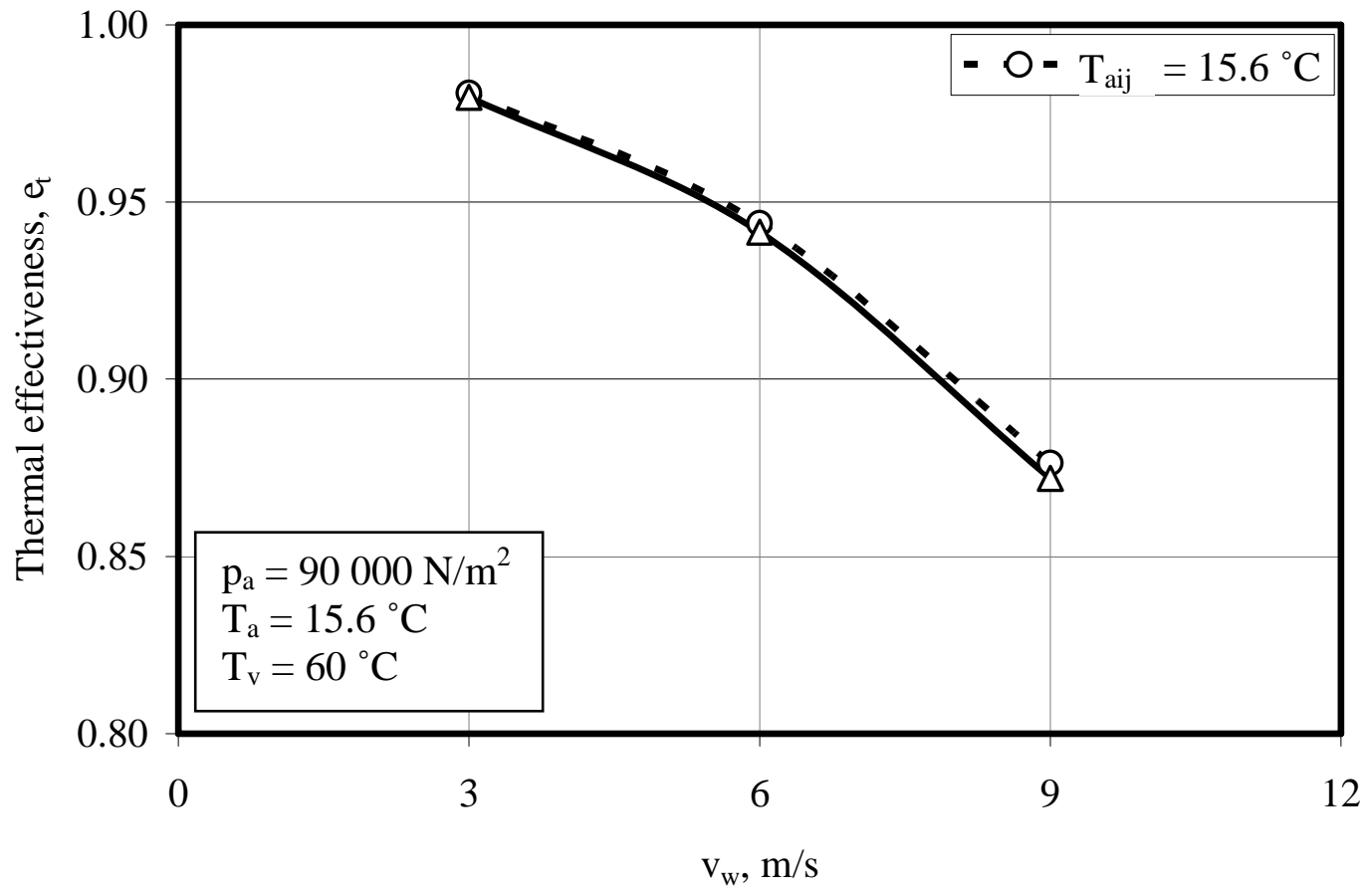

Figure 5.12: Thermal effectiveness of ACSC. 


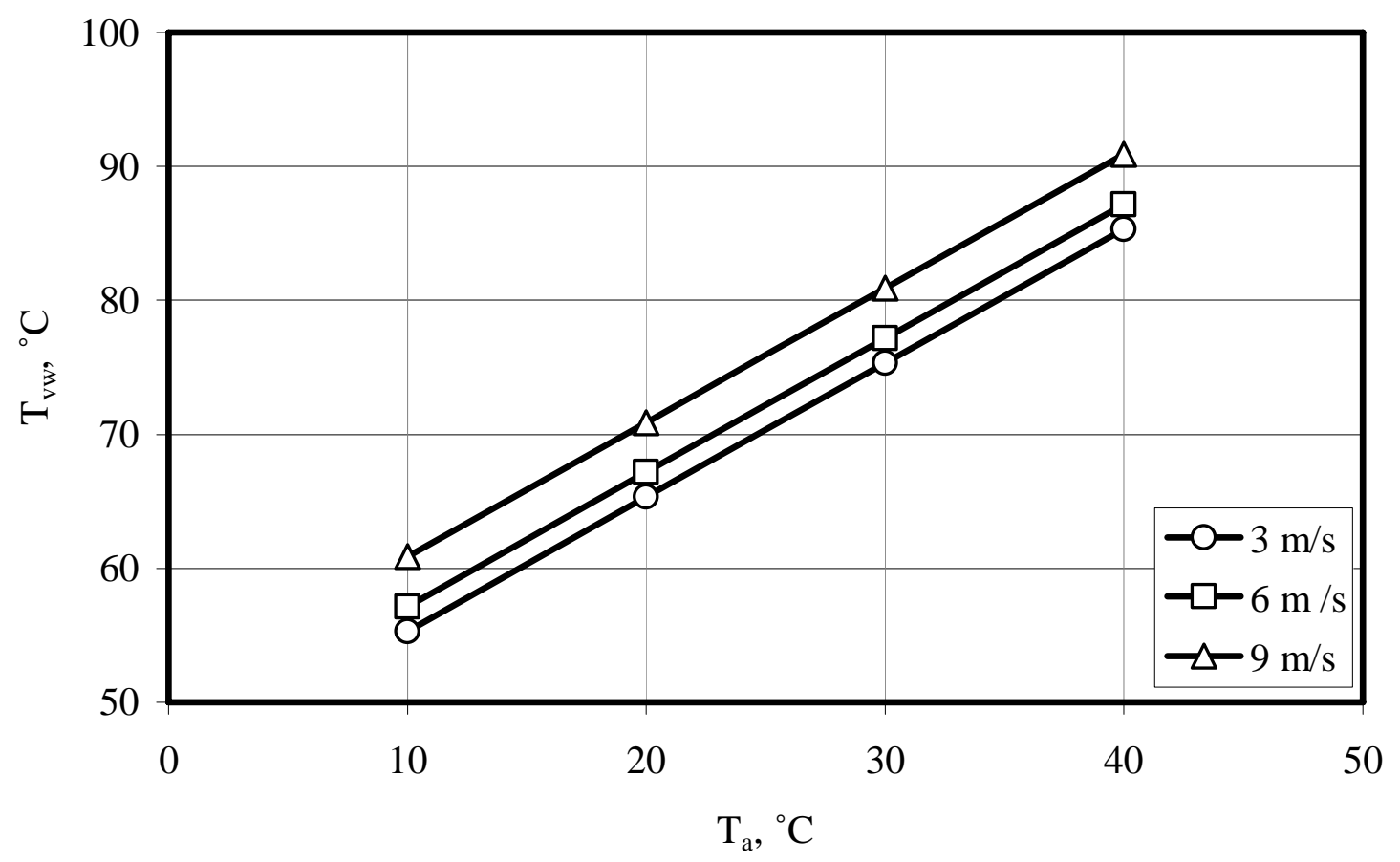

Figure 5.13: Ambient temperature and wind effect on saturation temperature of the turbine exhaust steam.

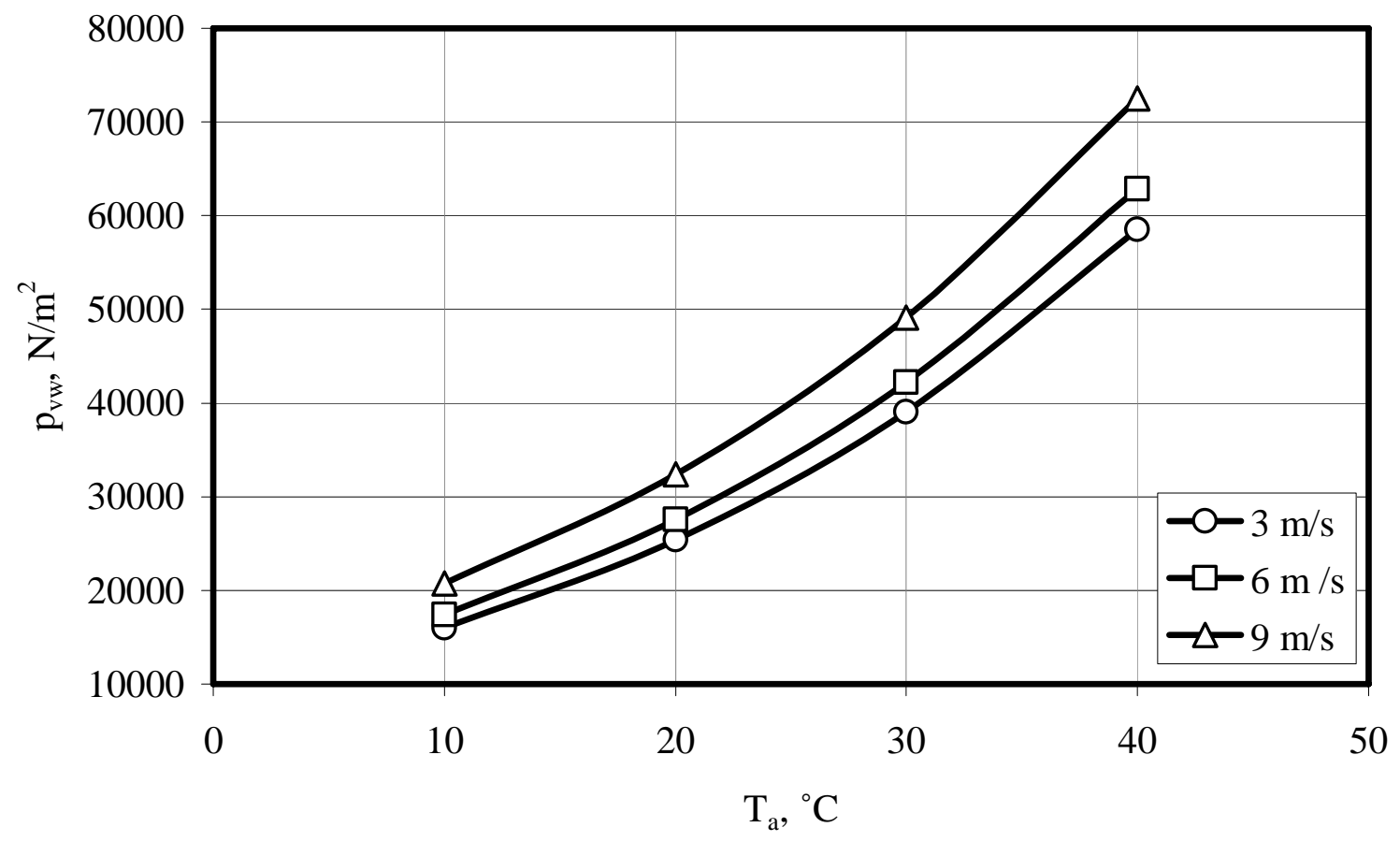

Figure 5.14: Ambient temperature and wind effect on turbine back pressure. 


\section{EFFECT OF SKIRT AND SCREEN}

The objective of this chapter is to show how the performance of the ACSC is improved with the addition of a solid walkway or skirt along the periphery of the fan platform or deck or a screen under the ACSC, while being subjected to winds of $3 \mathrm{~m} / \mathrm{s}, 6 \mathrm{~m} / \mathrm{s}$ and $9 \mathrm{~m} / \mathrm{s}$ in the $\mathrm{x}$-direction and $\mathrm{x}$-y-direction at an elevation corresponding to the fan platform height above ground level $(20 \mathrm{~m})$.

\subsection{Effect of skirt width on the upstream fan performance}

The negative impact of the wind (non-adiabatic case) is most evident at the edge fan fan $(4,1)$ in figure 2.2. At a wind speed of $9 \mathrm{~m} / \mathrm{s}$ in the $\mathrm{x}$-direction, the volumetric effectiveness of fan $(4,1)$ decreases to $14 \%$. By extending the fan platform or adding a walkway or a skirt as shown in figure 6.1 the volumetric effectiveness of this fan increases as is illustrated in figures 6.2 and 6.3 .

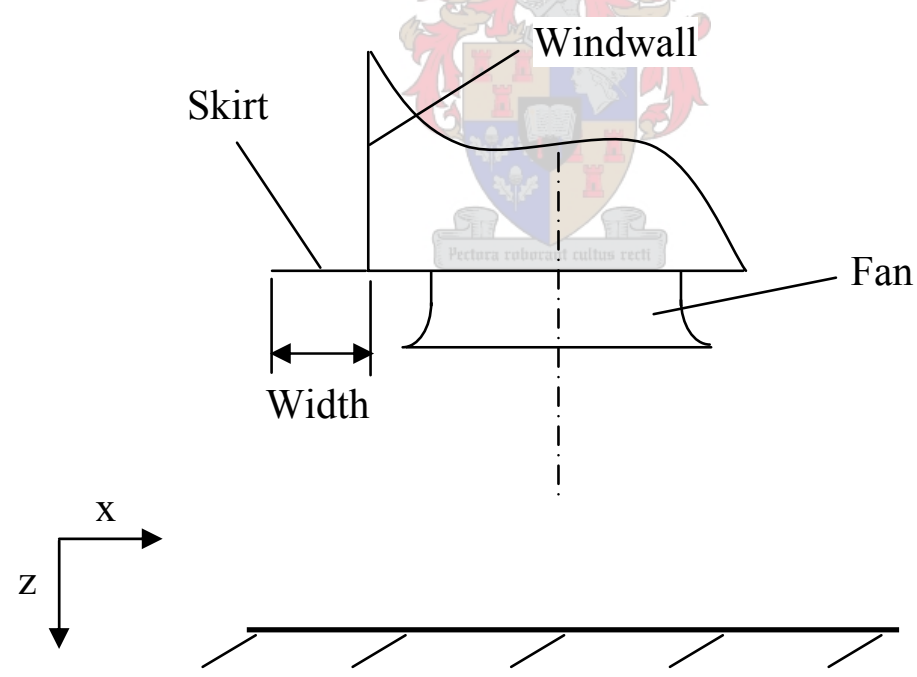

Figure 6.1: Location of skirt.

Figure 6.4 and figure 6.5 show that there is a low pressure region as well as a corresponding distorted flow at the inlet of fan $(4,1)$. Figure 6.6 shows the distorted flow in more detail. This low pressure region and the corresponding distorted flow pattern contribute to the decreases in the volume flow rate through the fan. Figure 6.7 to figure 6.9 show how the different skirt widths affect the low pressure region under fan $(4,1)$. Figure 6.10 and figure 6.11 show how the addition of the $3 \mathrm{~m}$ walkway affects (displaces) the distorted inlet flow condition. 


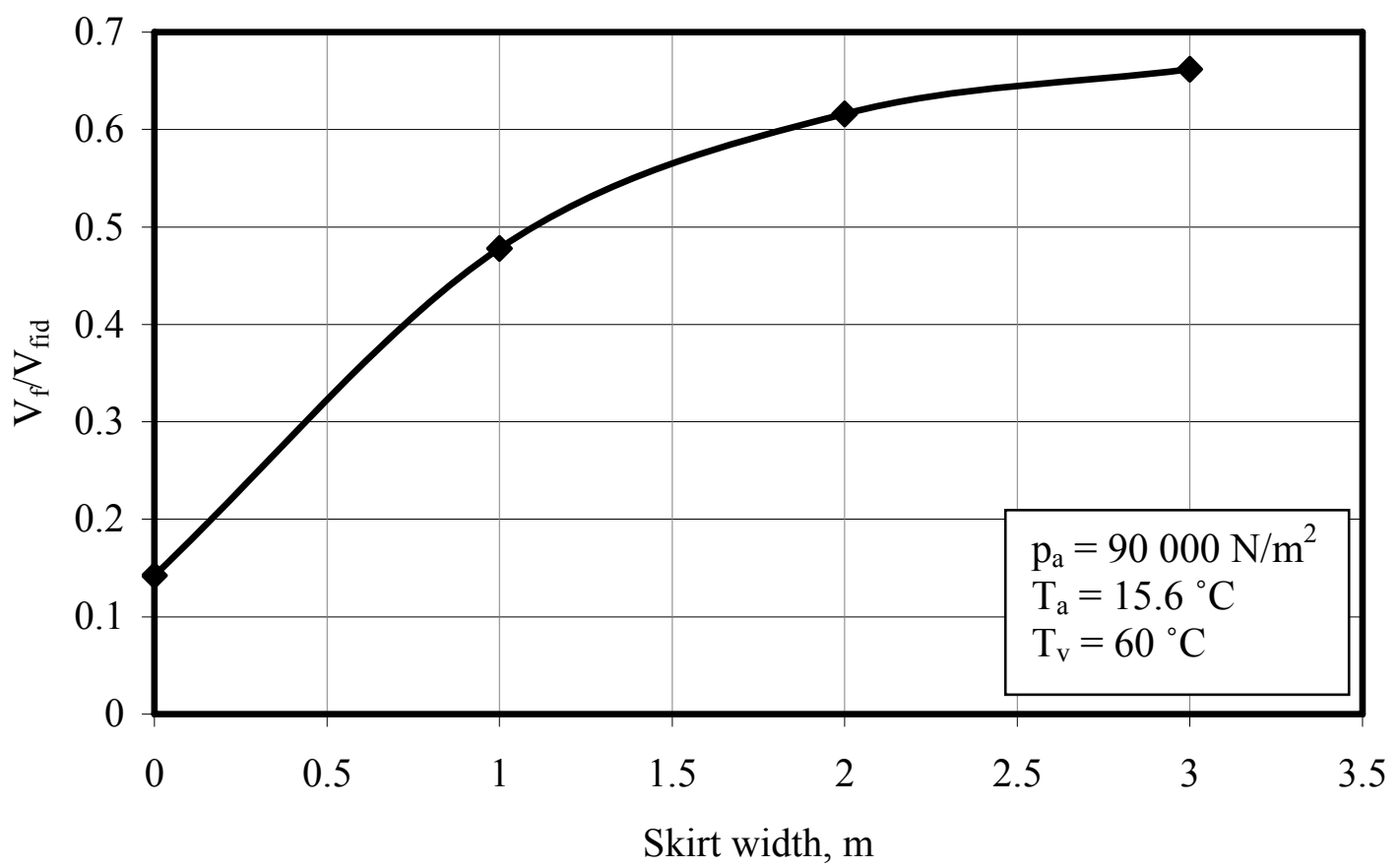

Figure 6.2: Volumetric effectiveness, fan(4,1) at a wind speed of $9 \mathrm{~m} / \mathrm{s}$.

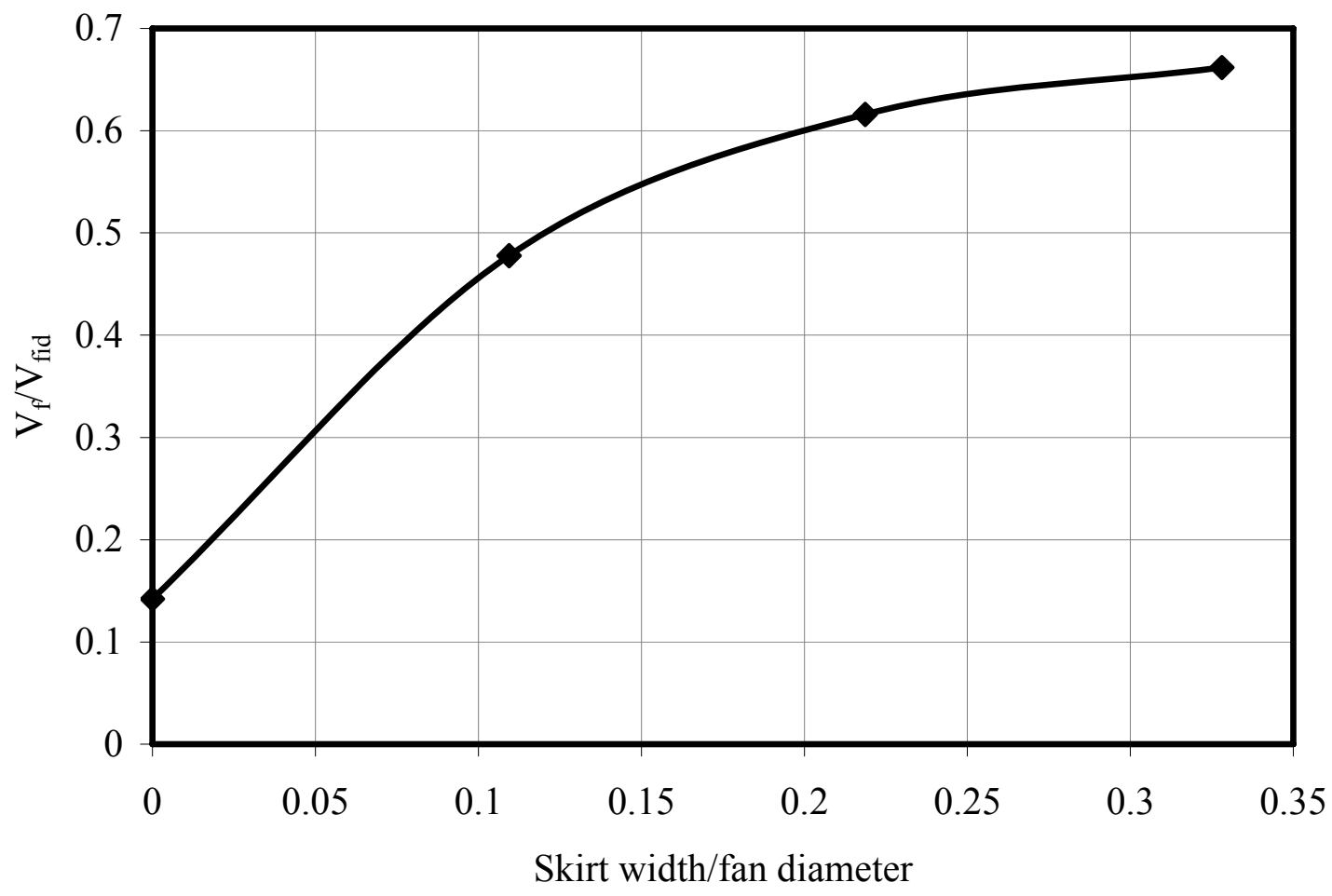

Figure 6.3: Volumetric effectiveness, fan $(4,1)$ at a wind speed of $9 \mathrm{~m} / \mathrm{s}$. 


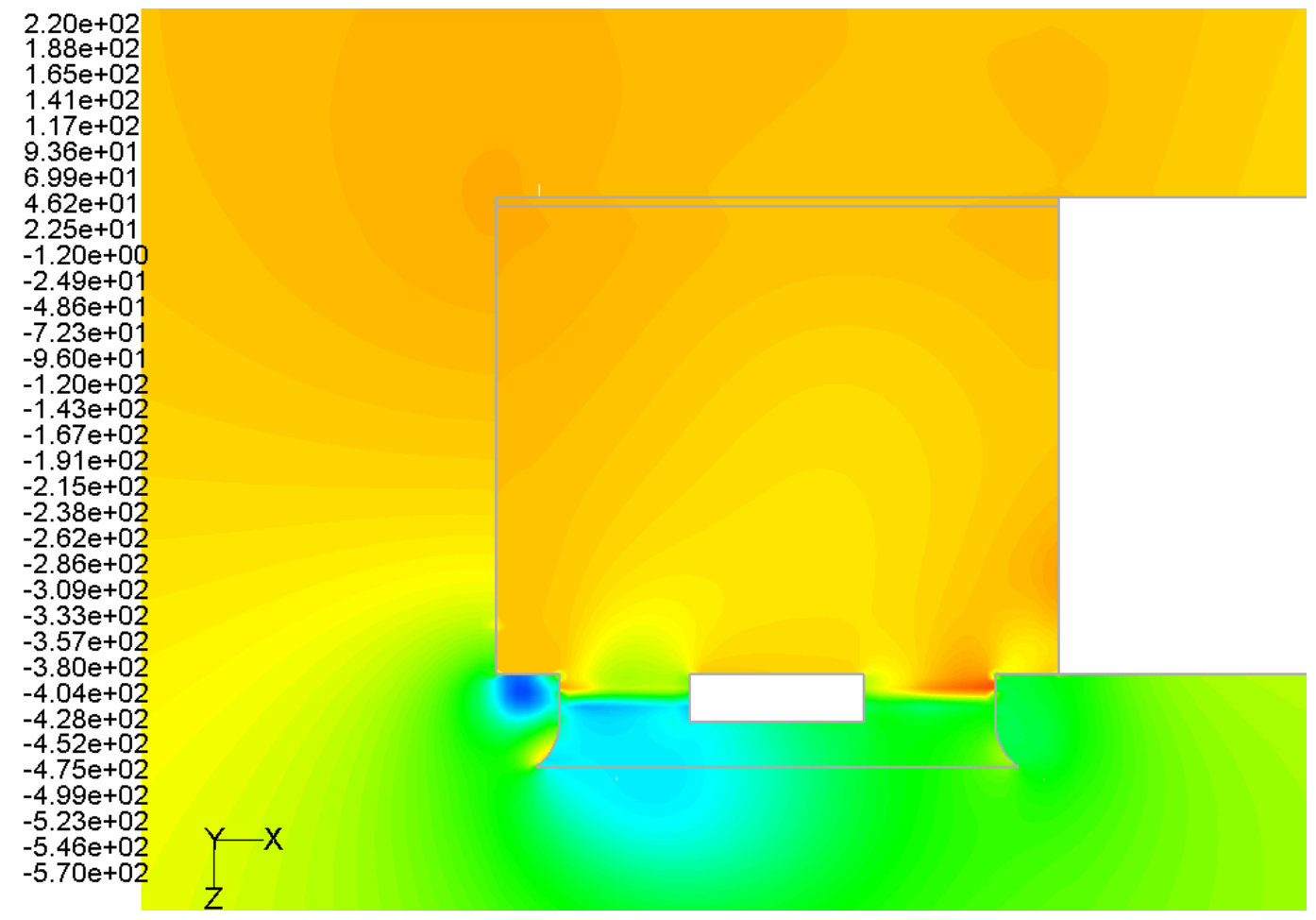

Figure 6.4: Static pressure, $p_{\text {stat }}, \mathrm{N} / \mathrm{m}^{2}$, fan $(4,1)$ at a wind speed of $9 \mathrm{~m} / \mathrm{s}$ and a skirt width of $0 \mathrm{~m}$. Section view F-F (refer to figure 3.5).

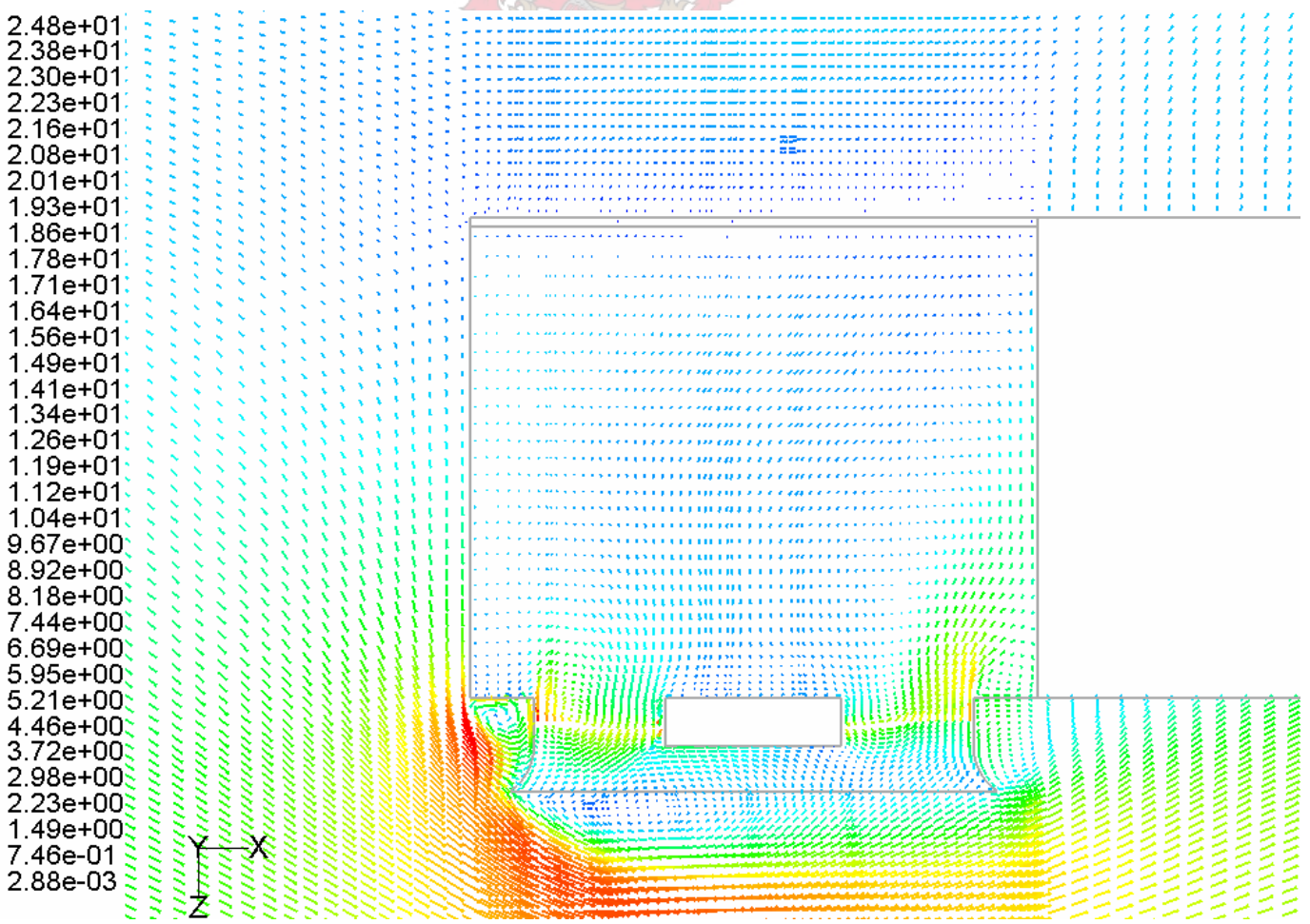

Figure 6.5: Vector plot, $v, \mathrm{~m} / \mathrm{s}$, fan $(4,1)$ at a wind speed of $9 \mathrm{~m} / \mathrm{s}$ and a skirt width of $0 \mathrm{~m}$. Section view F-F (refer to figure 3.5). 


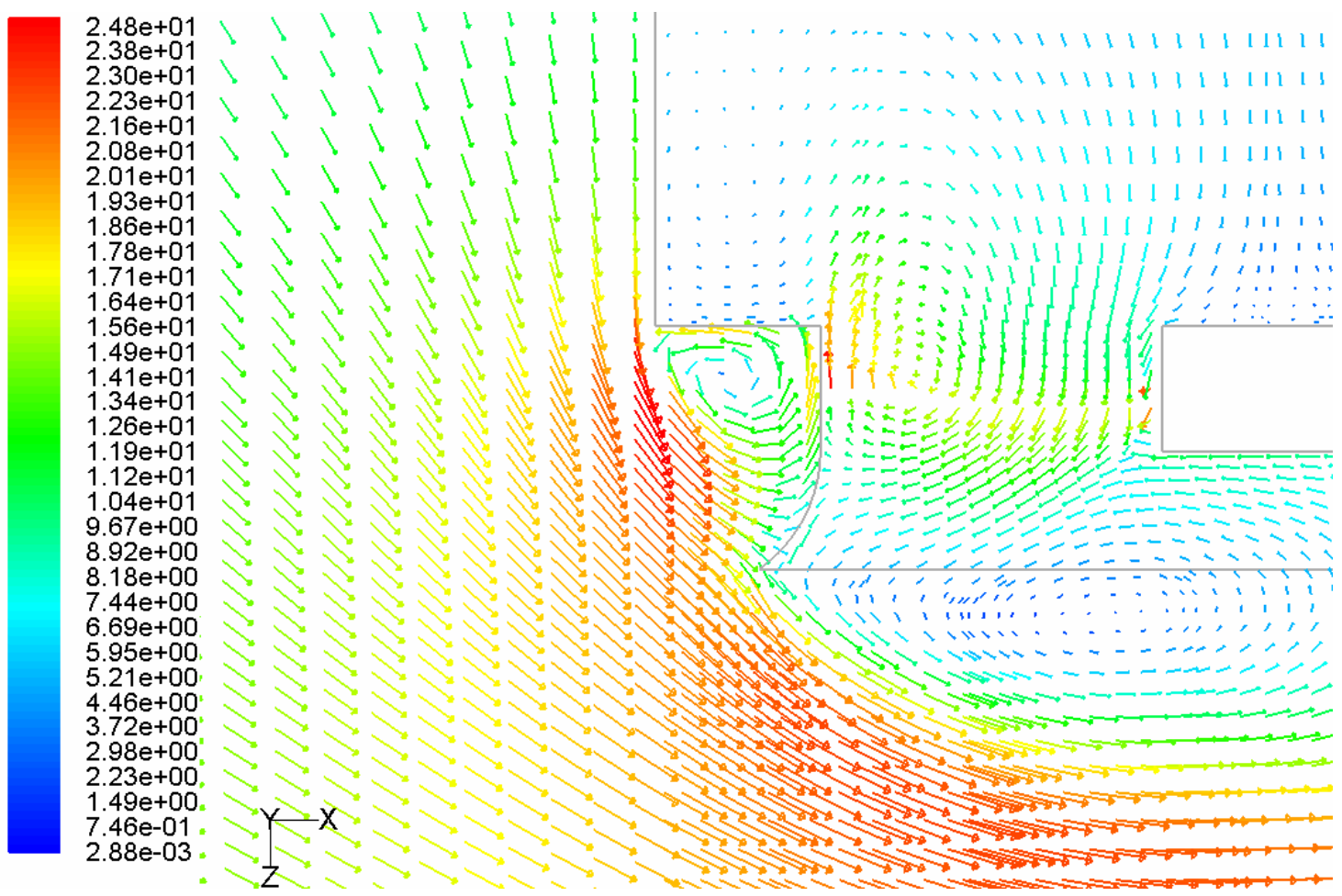

Figure 6.6: vector plot, $v, \mathrm{~m} / \mathrm{s}$, close-up of fan(4,1) at a wind speed of $9 \mathrm{~m} / \mathrm{s}$ and a skirt width of $0 \mathrm{~m}$. Section view F-F (refer to figure 3.5).

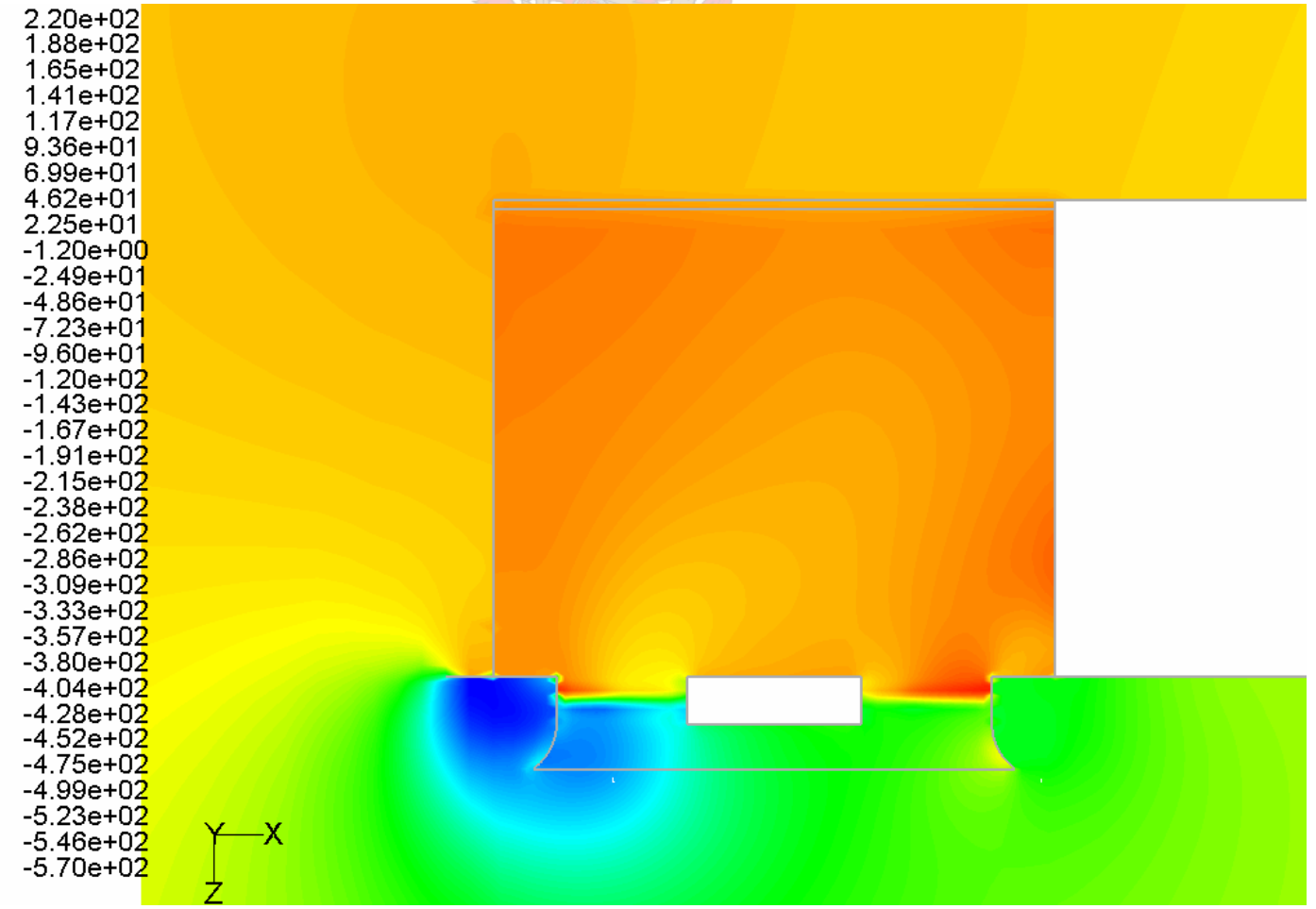

Figure 6.7: Static pressure, $p_{\text {stat }} N / \mathrm{m}^{2}$, fan $(4,1)$ at a wind speed of $9 \mathrm{~m} / \mathrm{s}$ and a skirt width of $1 \mathrm{~m}$. Section view F-F (refer to figure 3.5). 


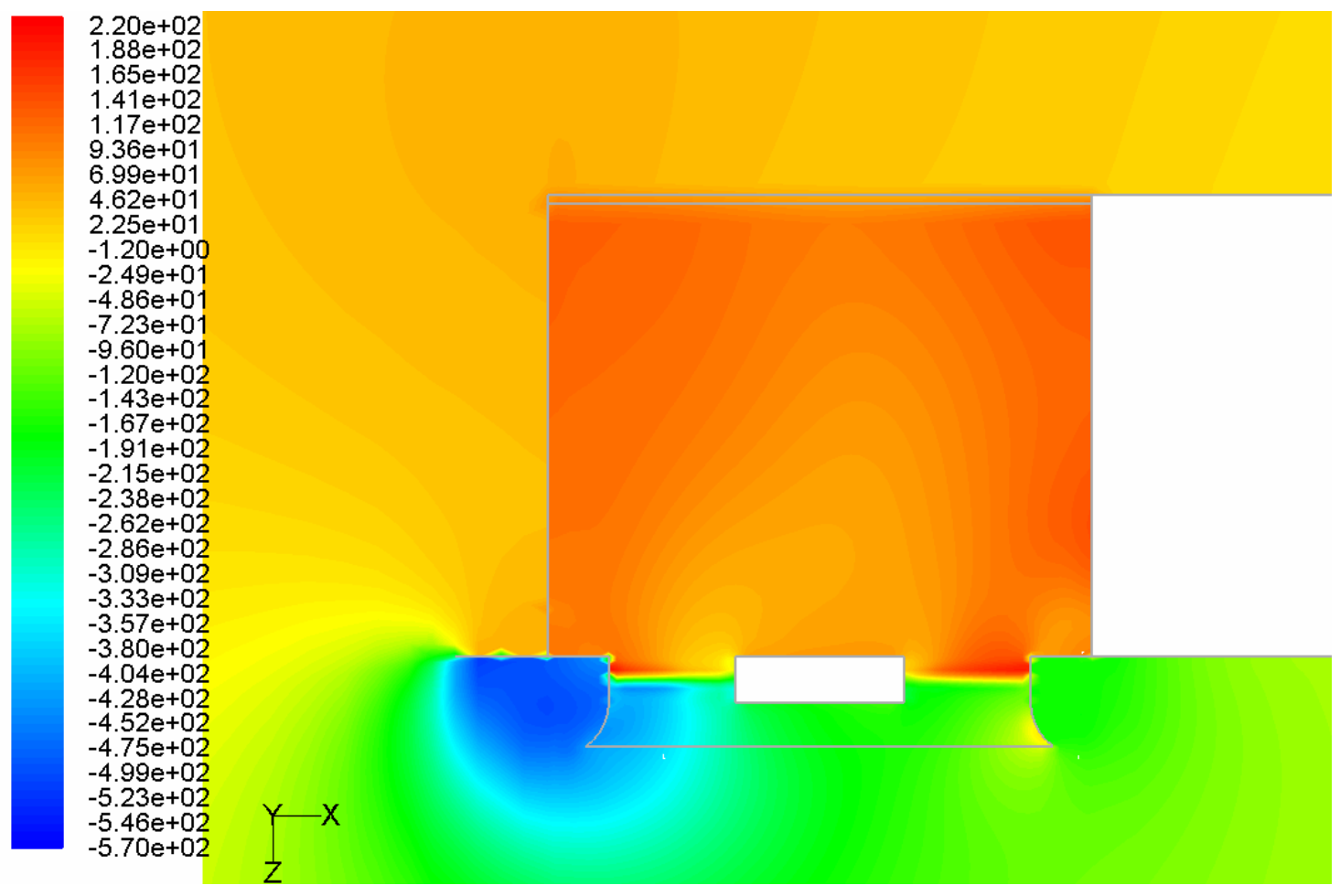

Figure 6.8: Static pressure, $p_{\text {stat }} N / \mathrm{m}^{2}$, fan $(4,1)$ at a wind speed of $9 \mathrm{~m} / \mathrm{s}$ and a skirt width of $2 \mathrm{~m}$. Section view F-F (refer to figure 3.5).

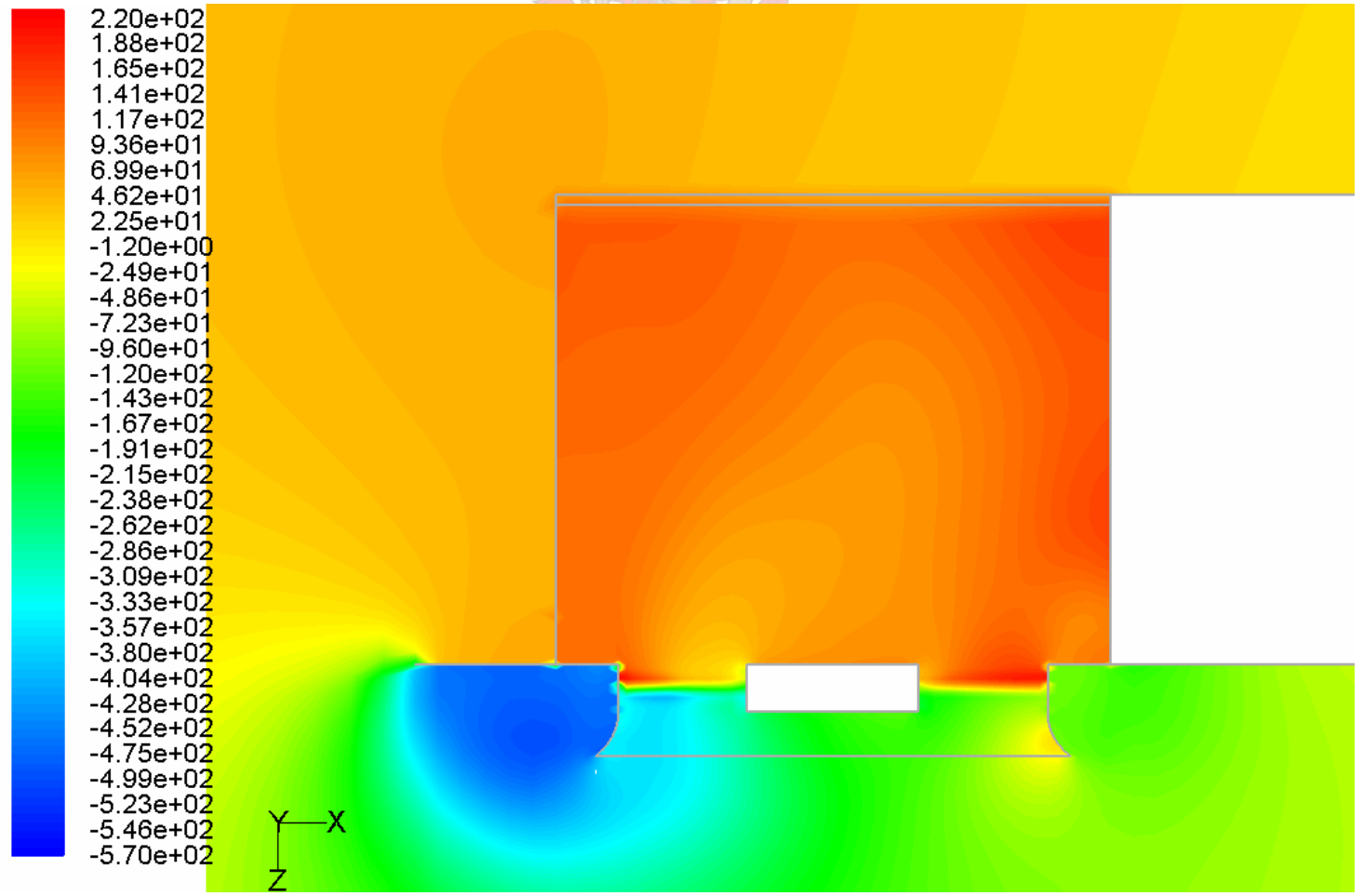

Figure 6.9: Static pressure, $p_{\text {stat, }} N / \mathrm{m}^{2}$, fan $(4,1)$ at a wind speed of $9 \mathrm{~m} / \mathrm{s}$ and a skirt width of $3 \mathrm{~m}$. Section view F-F (refer to figure 3.5). 


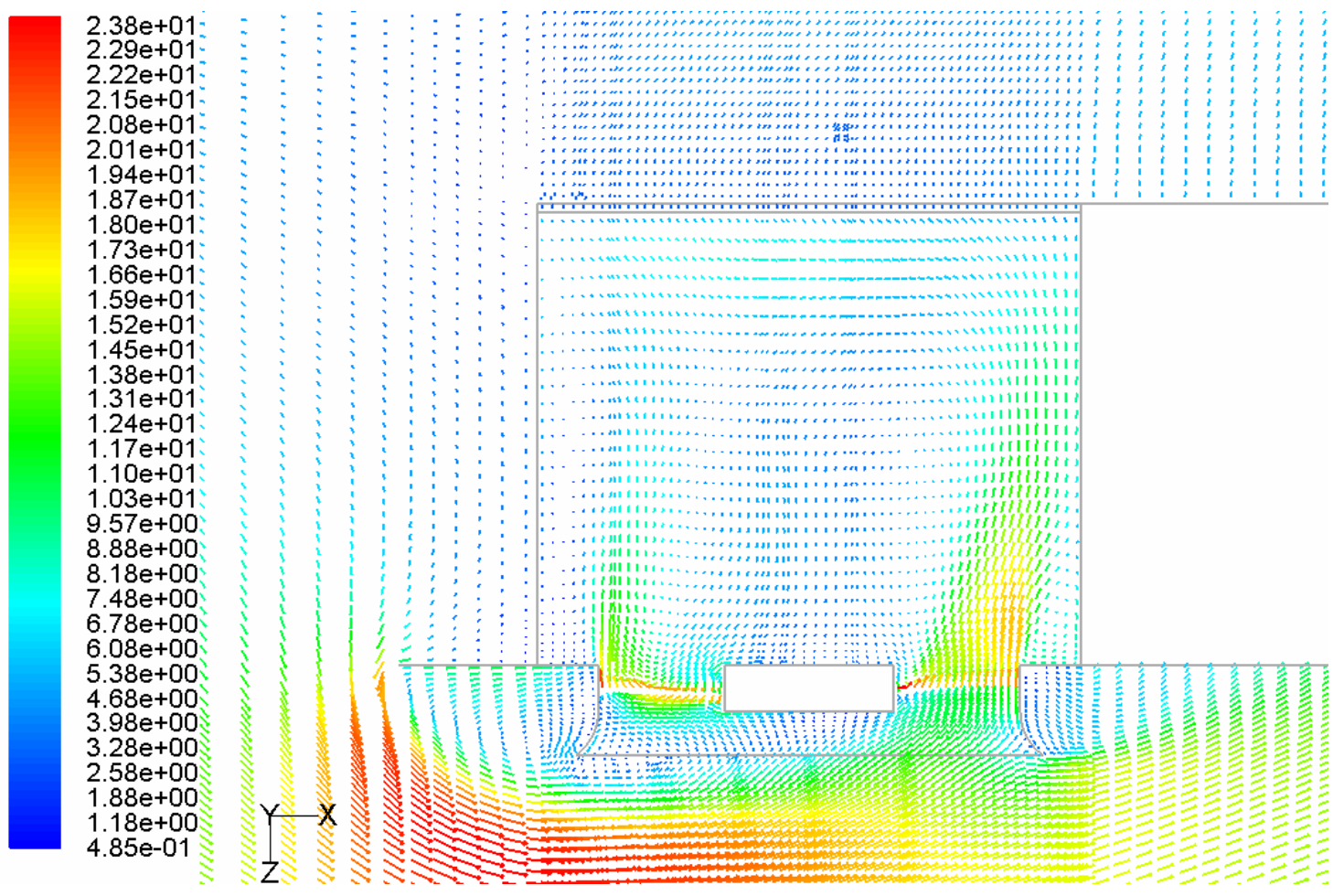

Figure 6.10: vector plot, $v, \mathrm{~m} / \mathrm{s}, \mathrm{fan}(4,1)$ at a wind speed of $9 \mathrm{~m} / \mathrm{s}$ and a skirt width of $3 \mathrm{~m}$. Section view F-F (refer to figure 3.5 ).
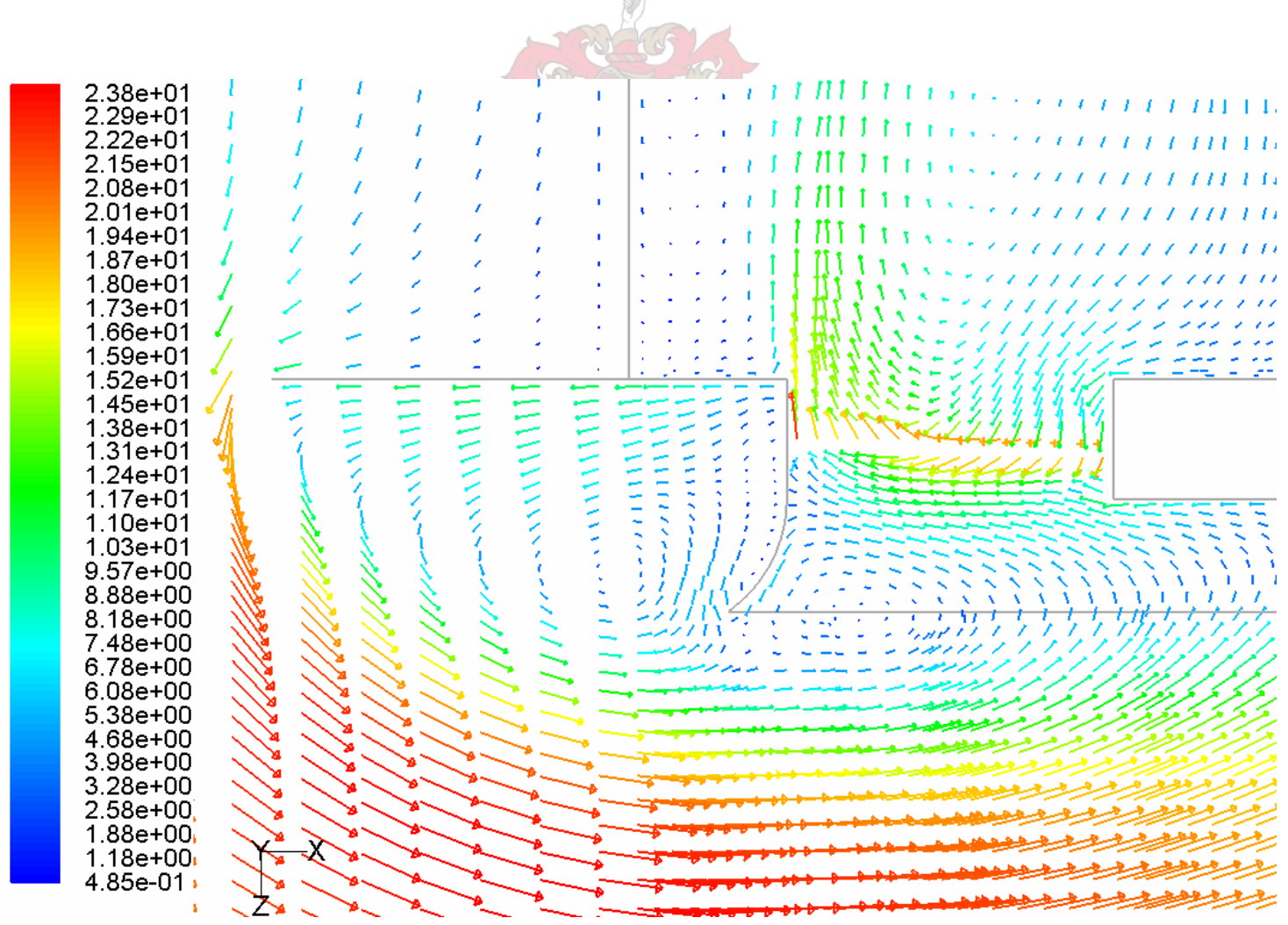

Figure 6.11: Vector plot, $v, \mathrm{~m} / \mathrm{s}$, close-up of fan $(4,1)$ at a wind speed of $9 \mathrm{~m} / \mathrm{s}$ and a skirt width of $3 \mathrm{~m}$. Section view F-F (refer to figure 3.5). 


\subsection{Effect of skirt on global flow field}

According to the above results, the addition of a $3 \mathrm{~m}$ walkway or skirt to the ACSC will result in a significant performance improvement. The performance improvement of this ACSC (3 m walkway or skirt added) will be analyzed while being subjected to wind (in the x-direction and in the $\mathrm{x}$-y-direction).

\subsubsection{Global flow field with skirt}

The flow trajectory of the hot plume air that exits the ACSC is similar to that shown in the previous two chapters under similar wind conditions. The plume angle increases as the wind speed increases.

The addition of the walkway or skirt affects the low pressure region at the upstream edge fan region. Figures $6.10,6.11,6.12,6.13$ and 6.14 show the effect of the walkway or skirt on this low pressure region with the wind in the $\mathrm{x}$-direction and in the $\mathrm{x}$-y-direction. The low pressure region at the upstream edge fan is displaced in an upstream direction, compared with figures $4.7,4.8,5.5,5.6$ and 5.7 respectively. 


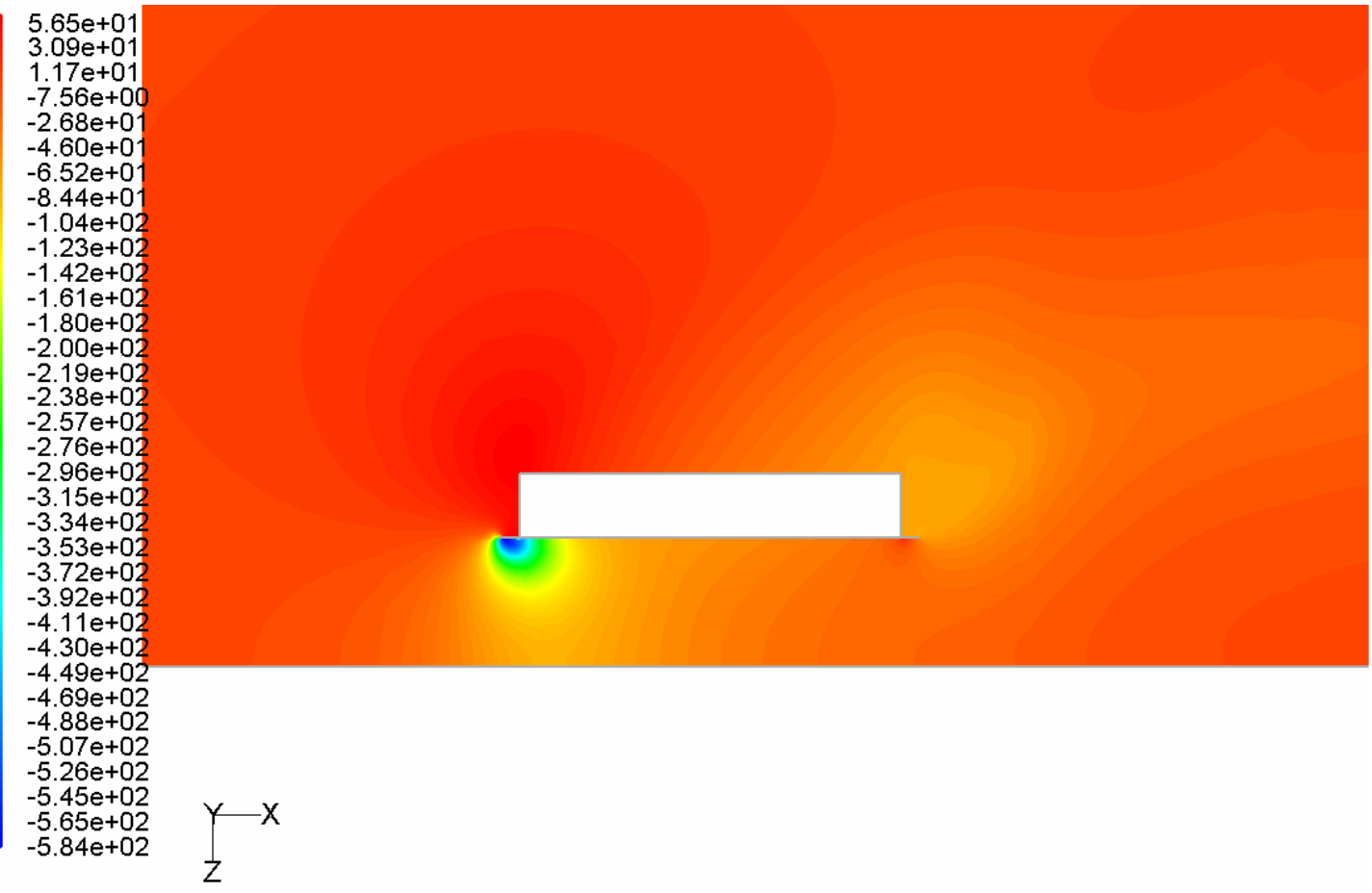

Figure 6.10: Static pressure, $p_{\text {stat }}, \mathrm{N} / \mathrm{m}^{2}$, global flow field at a wind speed of $9 \mathrm{~m} / \mathrm{s}$ (x-direction) and a skirt width of $3 \mathrm{~m}$. Section view B-B (refer to figure 3.2).

$5.64 e+01$
$3.69 \mathrm{e}+01$
$2.23 \mathrm{e}+01$
$7.64 \mathrm{e}+00$
$-6.98 \mathrm{e}+00$
$-2.16 \mathrm{e}+01$
$-3.62 \mathrm{e}+01$
$-5.08 \mathrm{e}+01$
$-6.55 \mathrm{e}+01$
$-8.01 \mathrm{e}+01$
$-9.47 \mathrm{e}+01$
$-1.09 \mathrm{e}+02$
$-1.24 \mathrm{e}+02$
$-1.39 \mathrm{e}+02$
$-1.53 \mathrm{e}+02$
$-1.68 \mathrm{e}+02$
$-1.82 \mathrm{e}+02$
$-1.97 \mathrm{e}+02$
$-2.12 \mathrm{e}+02$
$-2.26 \mathrm{e}+02$
$-2.41 \mathrm{e}+02$
$-2.56 \mathrm{e}+02$
$-2.70 \mathrm{e}+02$
$-2.85 \mathrm{e}+02$
$-2.99 \mathrm{e}+02$
$-3.14 \mathrm{e}+02$
$-3.29 \mathrm{e}+02$
$-3.43 \mathrm{e}+02$
$-3.58 \mathrm{e}+02$
$-3.73 \mathrm{e}+02$
$-3.87 \mathrm{e}+02$
$-4.02 \mathrm{e}+02$
$-4.16 \mathrm{e}+02$
$-4.31 \mathrm{e}+02$

$-4.31 \mathrm{e}+02$

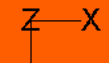

Figure 6.11: Static pressure, $p_{\text {stat }}, \mathrm{N} / \mathrm{m}^{2}$, global flow field at a wind speed of $9 \mathrm{~m} / \mathrm{s}$ (x-direction) and a skirt width of $3 \mathrm{~m}$. Section view A-A (refer to figure 3.2). 


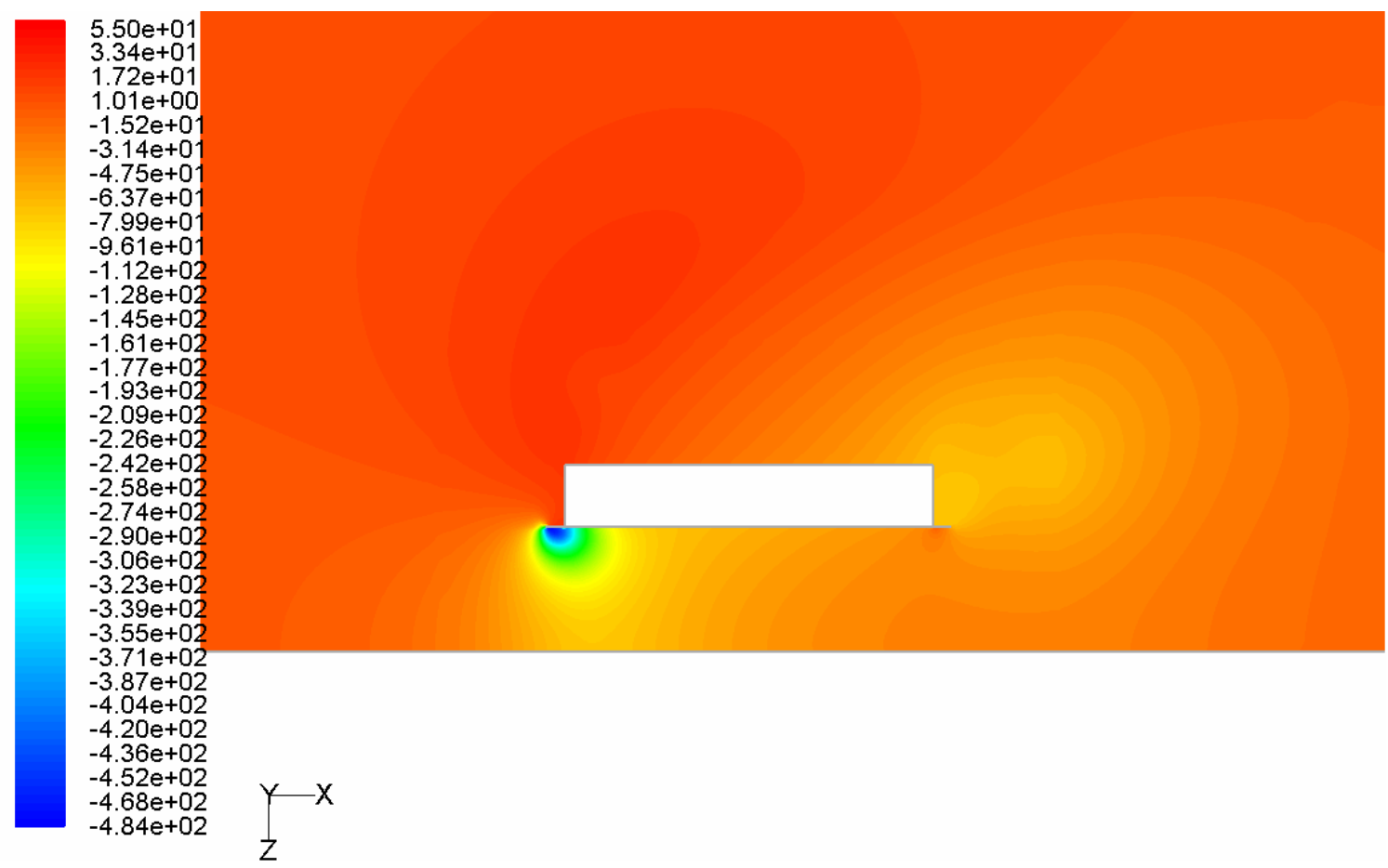

Figure 6.12: Static pressure, $p_{\text {stat, }} N / \mathrm{m}^{2}$, global flow field at a wind speed of $9 \mathrm{~m} / \mathrm{s}$ (x-y-direction) and a skirt width of $3 \mathrm{~m}$. Section view B-B (refer to figure 3.2).

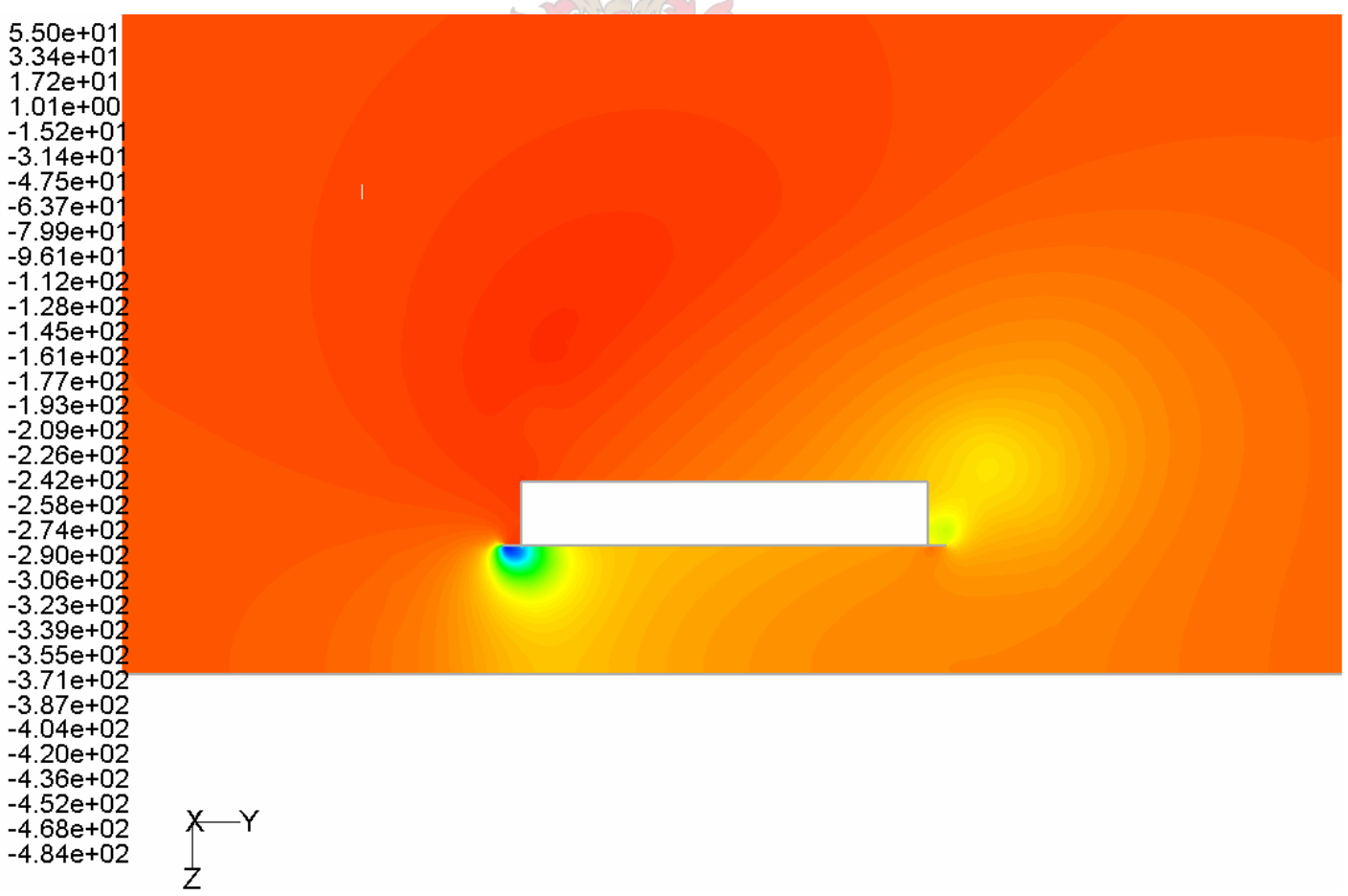

Figure 6.13: Static pressure, $p_{\text {stat, }} N / \mathrm{m}^{2}$, global flow field at a wind speed of $9 \mathrm{~m} / \mathrm{s}$ (x-y-direction) and a skirt width of $3 \mathrm{~m}$. Section view $\mathrm{H}-\mathrm{H}$ (refer to figure 3.2). 


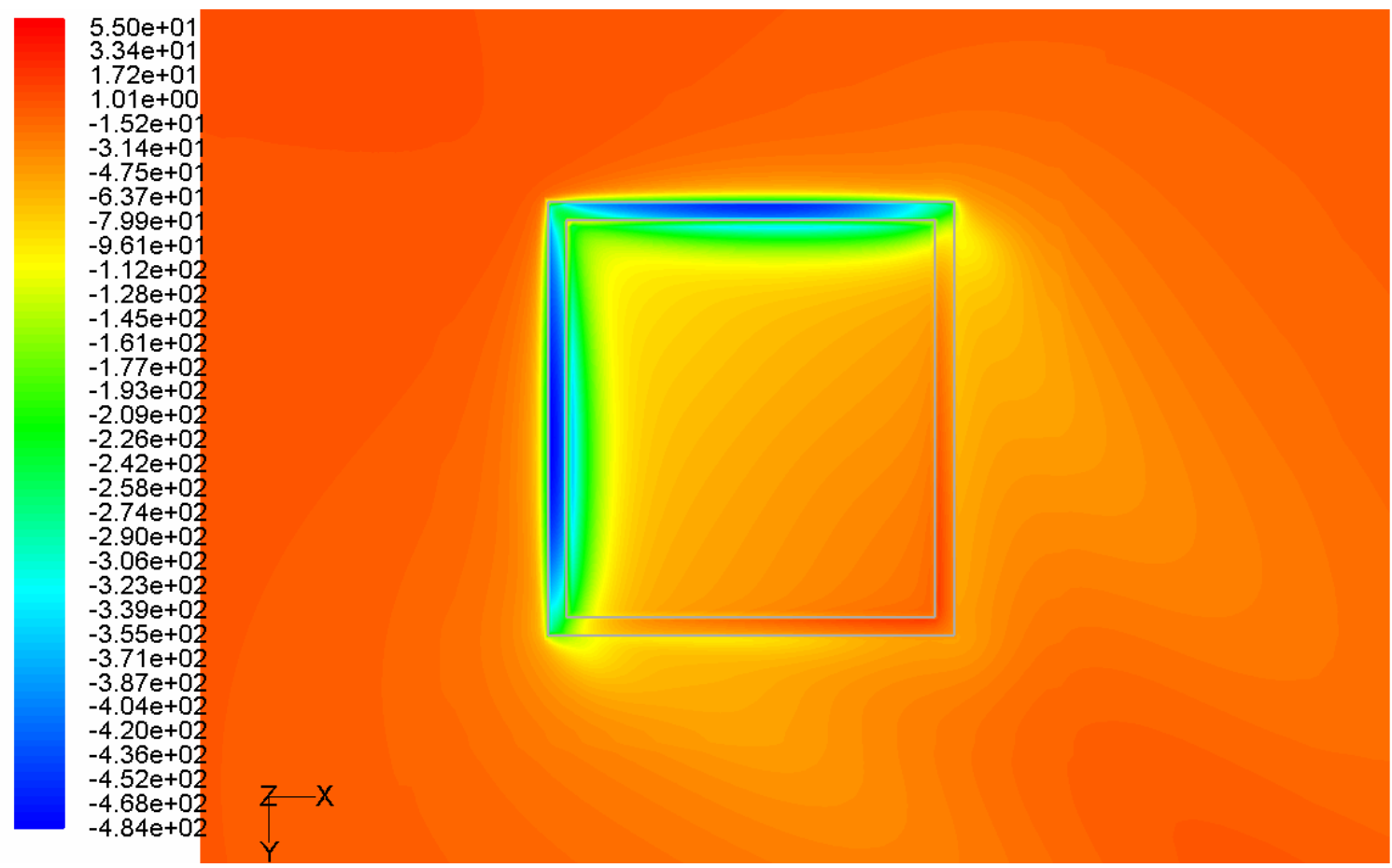

Figure 6.14: Static pressure, $p_{\text {stat, }} N / \mathrm{m}^{2}$, global flow field at a wind speed of $9 \mathrm{~m} / \mathrm{s}$ (x-y-direction) and a skirt width of $3 \mathrm{~m}$. Section view A-A (refer to figure 3.2).

\subsubsection{Fan performance with skirt}

The wind has a lesser effect on the volumetric effectiveness of the upstream edge fans compared to the case where there is no walkway or skirt. Compare figure 6.15 with figure 4.10 and figure 6.16 with figure 5.9.

In the case where the wind blows in the $\mathrm{x}$-direction at $9 \mathrm{~m} / \mathrm{s}$, hot air recirculation is present at $\operatorname{fan}(6,1), \operatorname{fan}(6,3)$ and $\operatorname{fan}(6,5)$. However, the addition of the skirt decreased the hot air recirculation. The air inlet temperature of $\operatorname{fan}(6,3)$ and $\operatorname{fan}(6,5)$ is $0.8{ }^{\circ} \mathrm{C}$ and $5{ }^{\circ} \mathrm{C}$ respectively higher than ambient and there is no increase in the air inlet temperature of fan(6,1). Figures 6.17 and 6.18 show the hot air circulation at fan(6,3) and fan(6,5).

In the case where the wind blows in the $x-y$-direction at $9 \mathrm{~m} / \mathrm{s}$, hot air recirculation is approximately of the same magnitude as for the case where there is no skirt. 


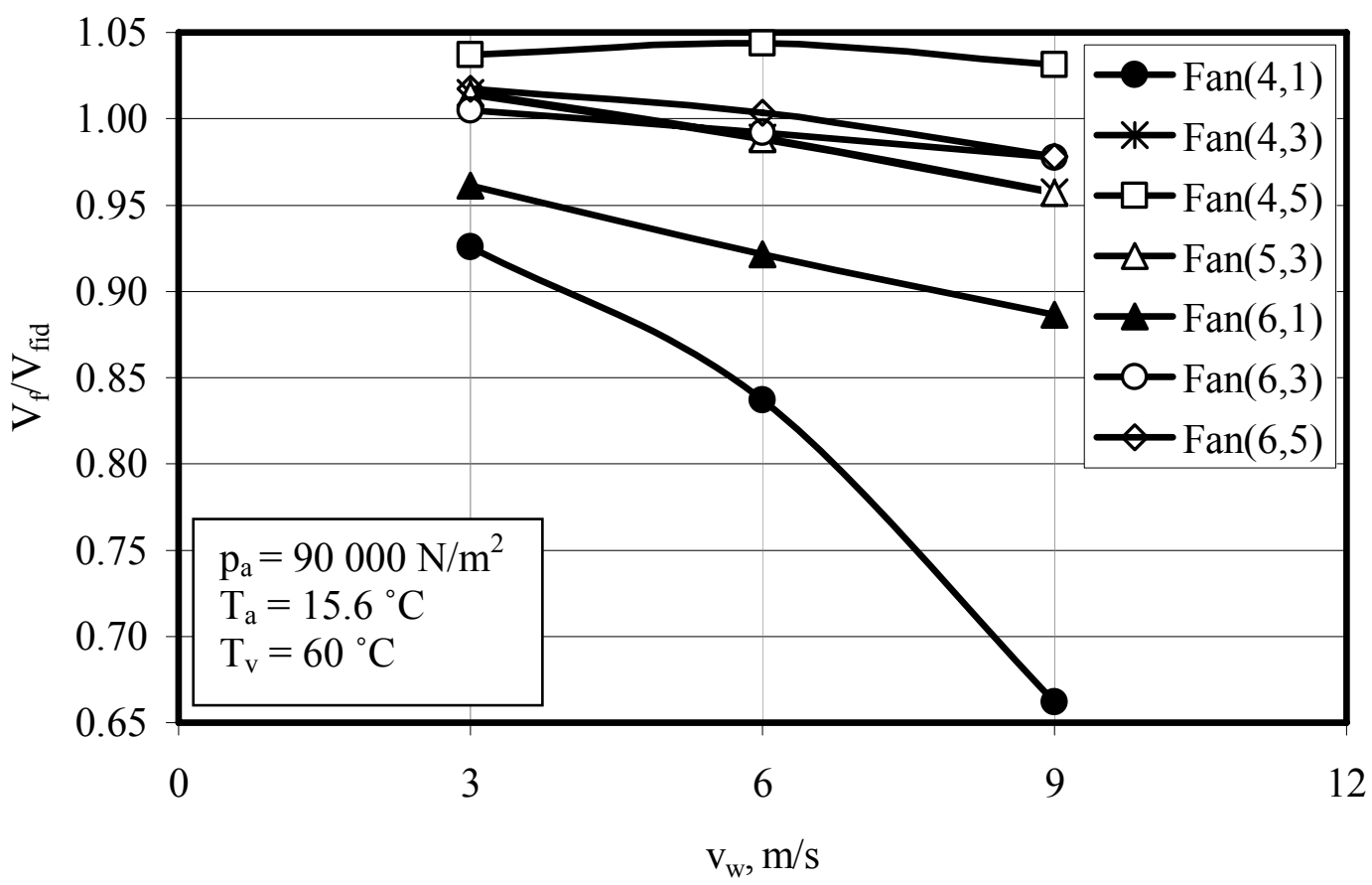

Figure 6.15: Volumetric effectiveness of fans with a $3 \mathbf{m}$ walkway (wind in the in $\mathrm{x}$-direction).

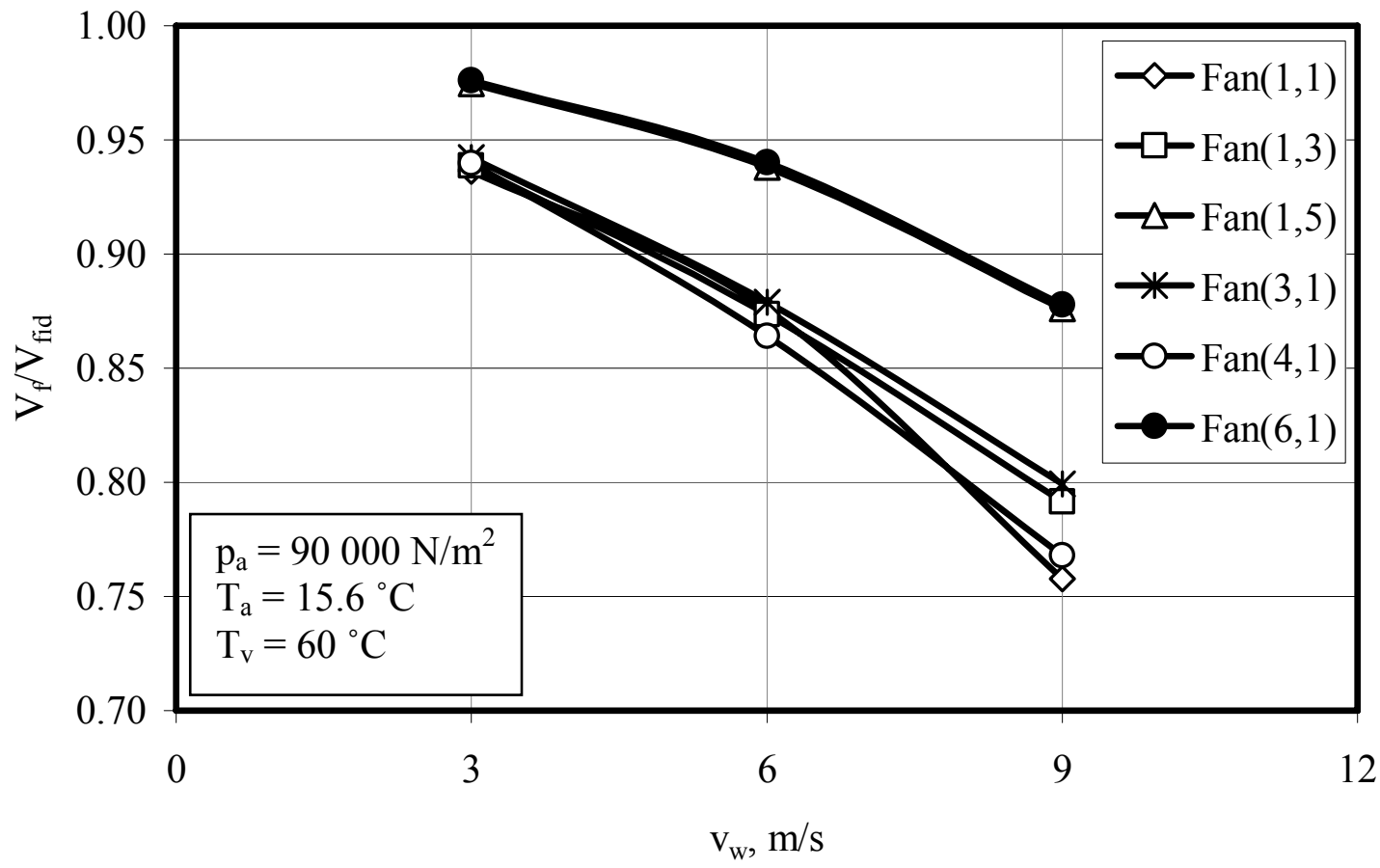

Figure 6.16: Volumetric effectiveness of fans with a $3 \mathbf{m}$ walkway (wind in $\mathrm{x}$-y-direction). 

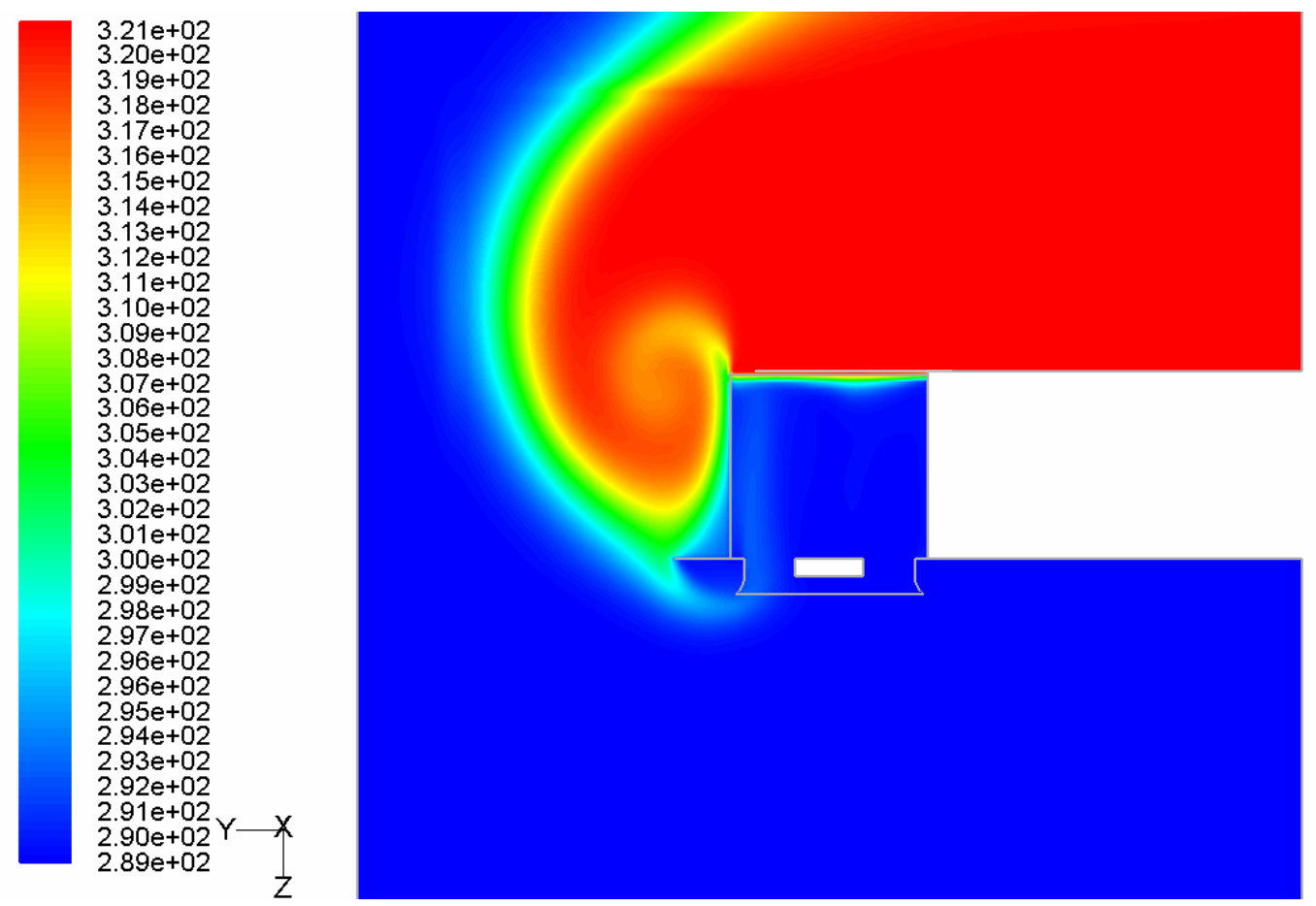

Figure 6.17: Temperature, $K$, fan(6,3) at a wind speed of $9 \mathrm{~m} / \mathrm{s}$ (x-direction).

Section view D-D (refer to figure 3.6).

$3.21 e+02$
$3.20 \mathrm{e}+02$
$3.19 \mathrm{e}+02$
$3.18 \mathrm{e}+02$
$3.17 \mathrm{e}+02$
$3.16 \mathrm{e}+02$
$3.15 \mathrm{e}+02$
$3.14 \mathrm{e}+02$
$3.13 \mathrm{e}+02$
$3.12 \mathrm{e}+02$
$3.11 \mathrm{e}+02$
$3.10 \mathrm{e}+02$
$3.09 \mathrm{e}+02$
$3.08 \mathrm{e}+02$
$3.07 \mathrm{e}+02$
$3.06 \mathrm{e}+02$
$3.05 \mathrm{e}+02$
$3.04 \mathrm{e}+02$
$3.03 \mathrm{e}+02$
$3.02 \mathrm{e}+02$
$3.01 \mathrm{e}+02$
$3.00 \mathrm{e}+02$
$2.99 \mathrm{e}+02$
$2.98 \mathrm{e}+02$
$2.97 \mathrm{e}+02$
$2.96 \mathrm{e}+02$
$2.96 \mathrm{e}+02$
$2.95 \mathrm{e}+02$
$2.94 \mathrm{e}+02$
$2.93 \mathrm{e}+02$
$2.92 \mathrm{e}+02$
$2.91 \mathrm{e}+02$
$2.90 \mathrm{e}+02 \mathrm{Y}-\mathrm{X}$
$2.89 \mathrm{e}+02$

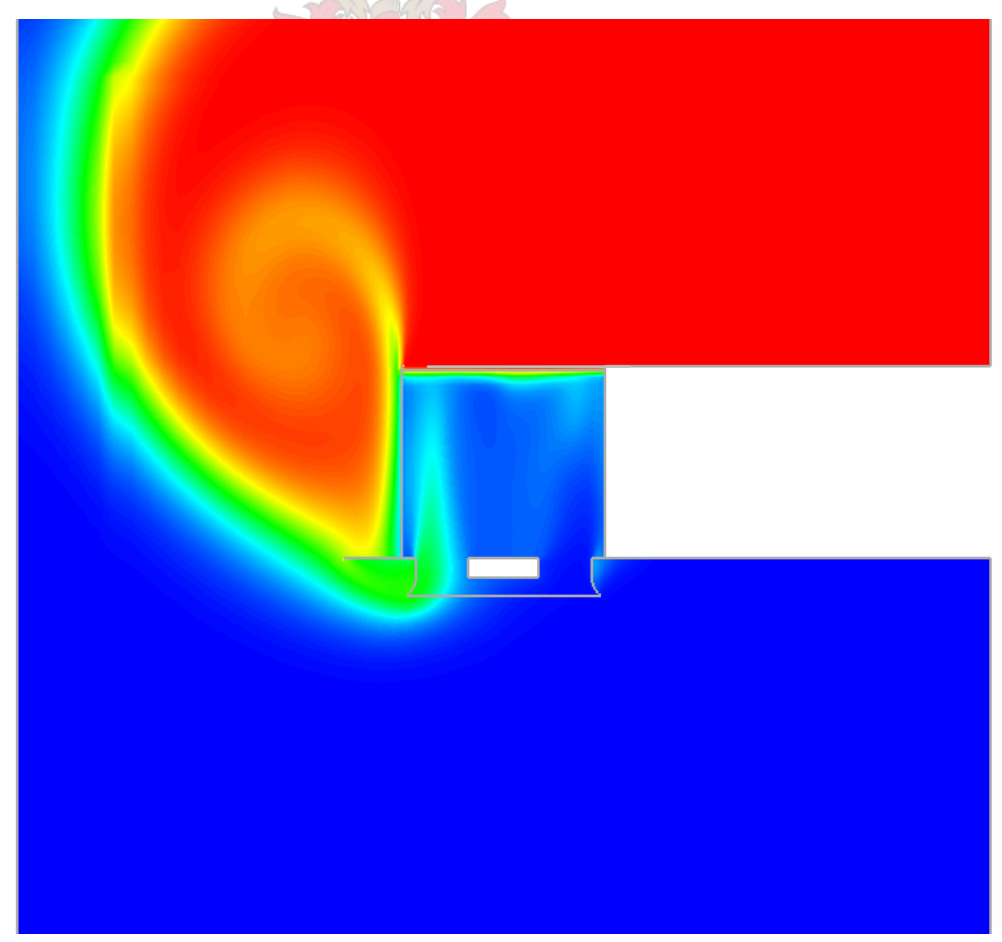

Figure 6.18: Temperature, $K$, fan(6,5) at a wind speed of $9 \mathrm{~m} / \mathrm{s}$ (x-direction). Section view D-D (refer to figure 3.6). 


\subsubsection{System performance with skirt}

Due to time constraints, only some of the fans are numerically analyzed, and an interpolation scheme (interpolation scheme 2) is used to determine the volumetric effectiveness of the remaining fans (refer to Appendix C). Figures 6.19 and 6.21 indicate that the addition of the skirt does result in the significant improvement of the volumetric effectiveness of the ACSC.

The thermal effectiveness of the ACSC is also improved with the addition of the skirt as shown in figures 6.20 and 6.22. The dotted line shows the thermal effectiveness when only reduced fan air mass flow rates are considered (ambient air temperature assumed at the inlet to each fan i.e. hot air recirculation is ignored). Due to the relatively high wind wall the effect of plume air recirculation is shown to have a small influence on the thermal effectiveness.

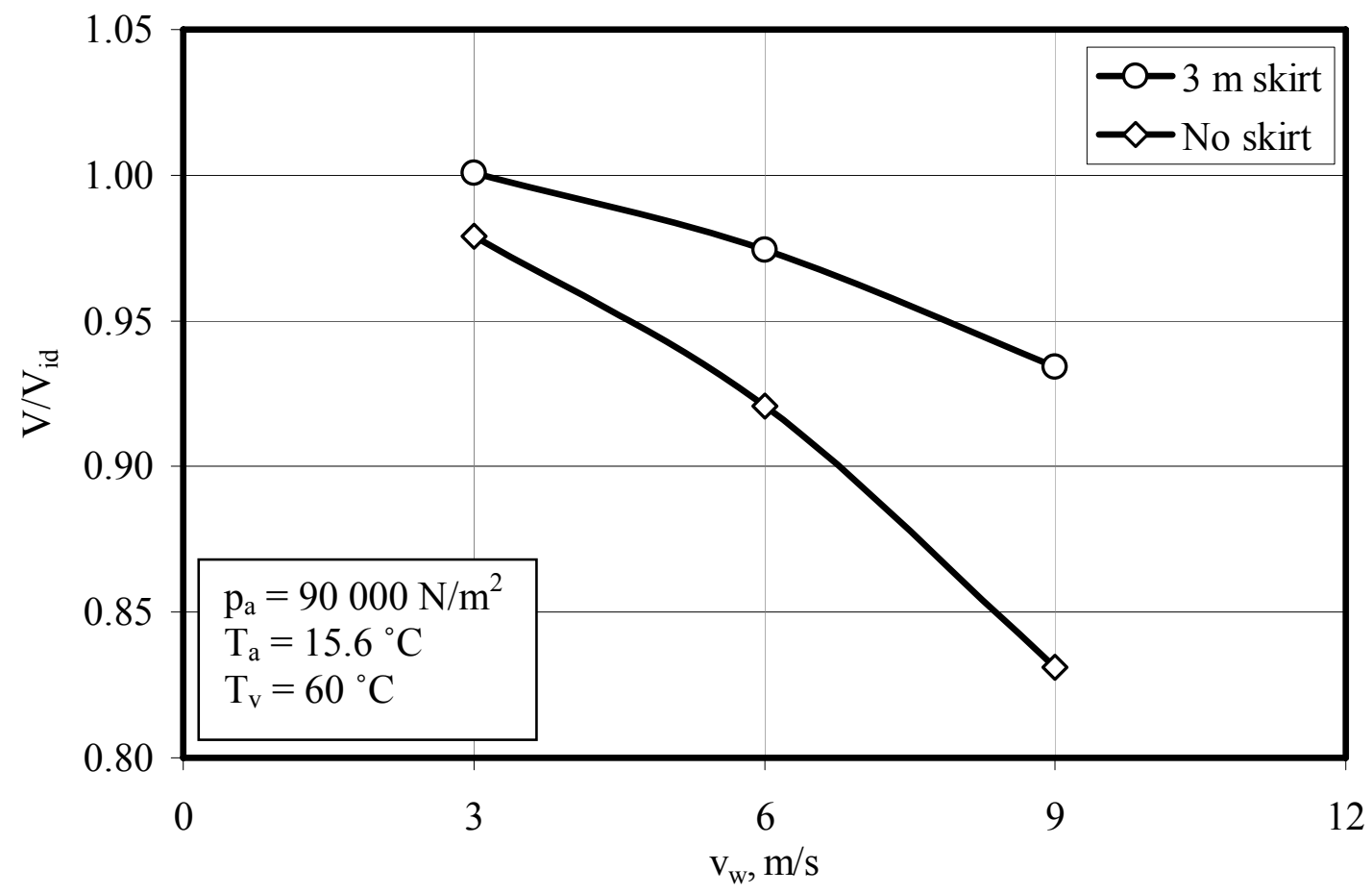

Figure 6.19: Volumetric effectiveness of ACSC with

a $3 \mathbf{m}$ skirt (wind in the $\mathrm{x}$-direction). 


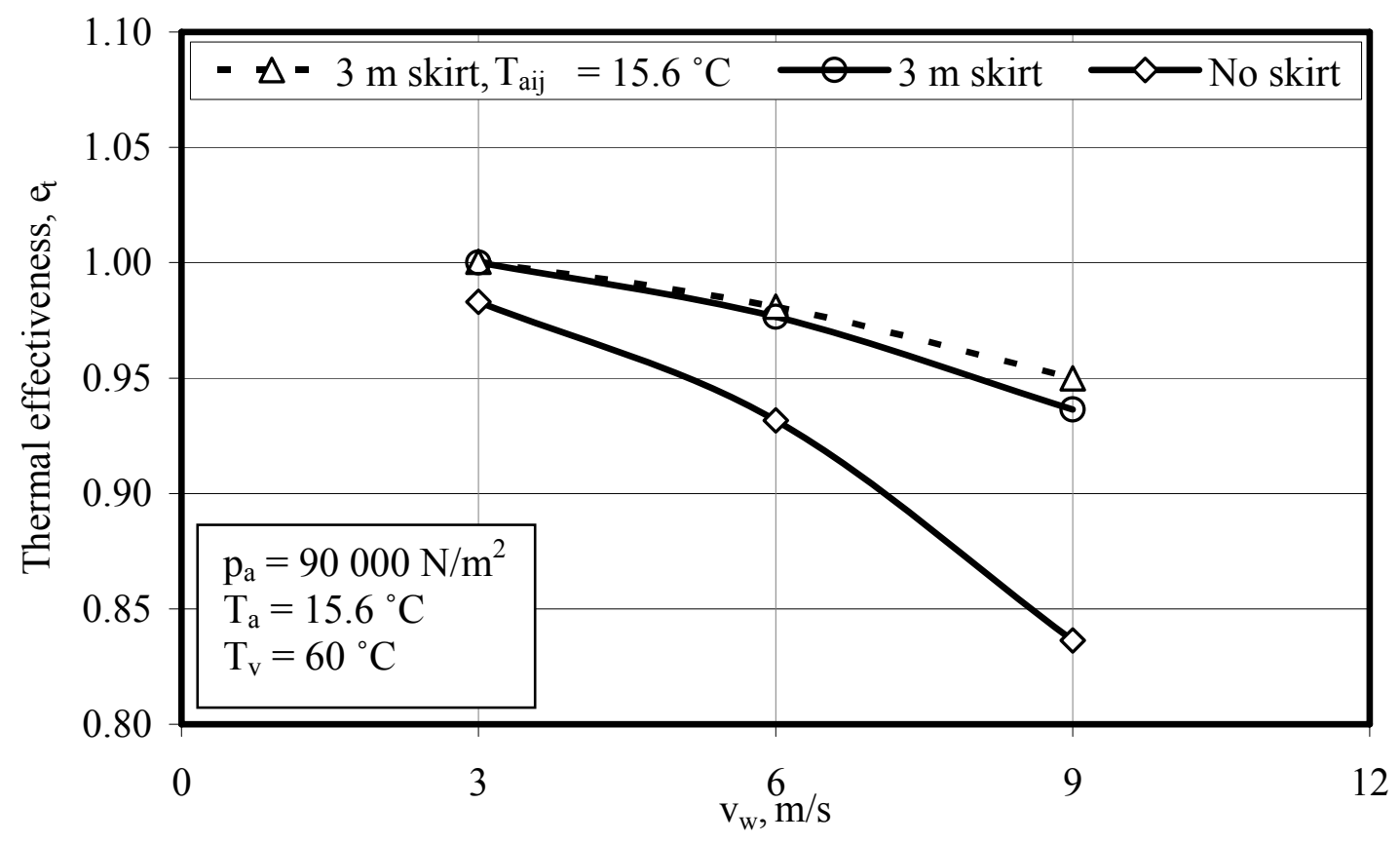

Figure 6.20: Thermal effectiveness of ACSC with a $3 \mathbf{m}$ skirt (wind in the $\mathrm{x}$-direction).

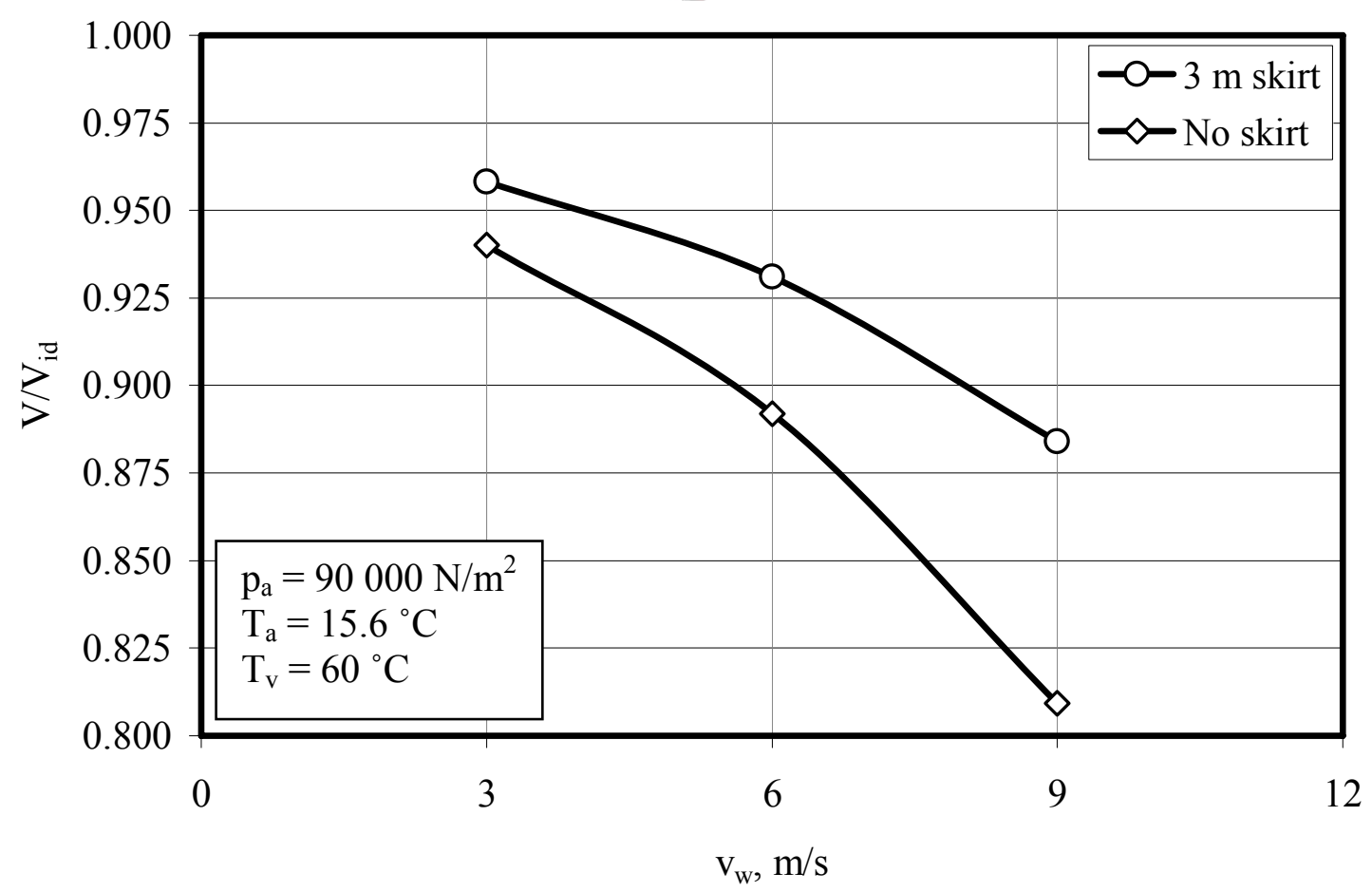

Figure 6.21: Volumetric effectiveness of ACSC with a $3 \mathrm{~m}$ skirt (wind in the $x-y$-direction). 


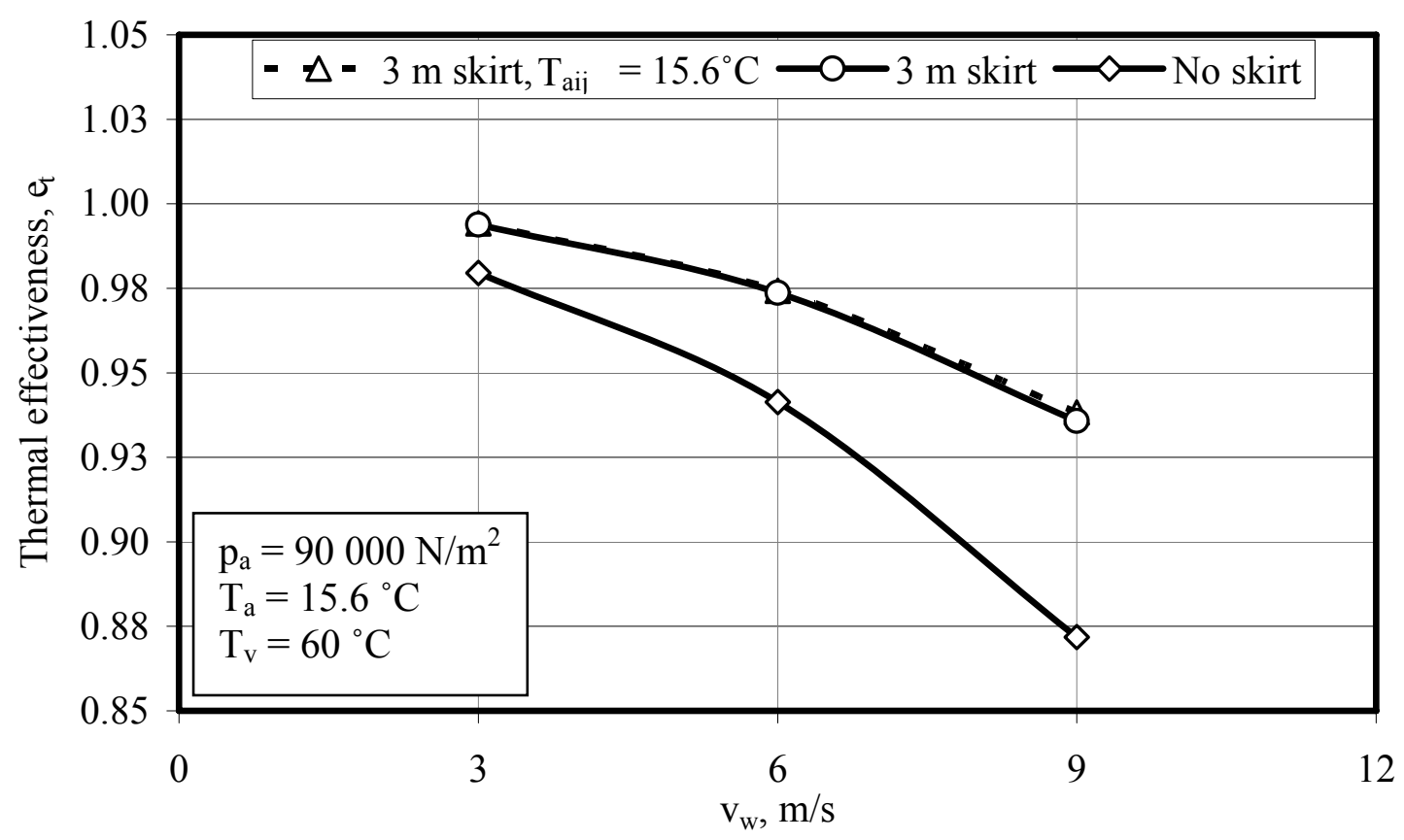

Figure 6.22: Thermal effectiveness of ACSC with a $3 \mathrm{~m}$ skirt (wind in the $\mathrm{x}$-y-direction).

\subsection{Effect of screen on the global flow field}
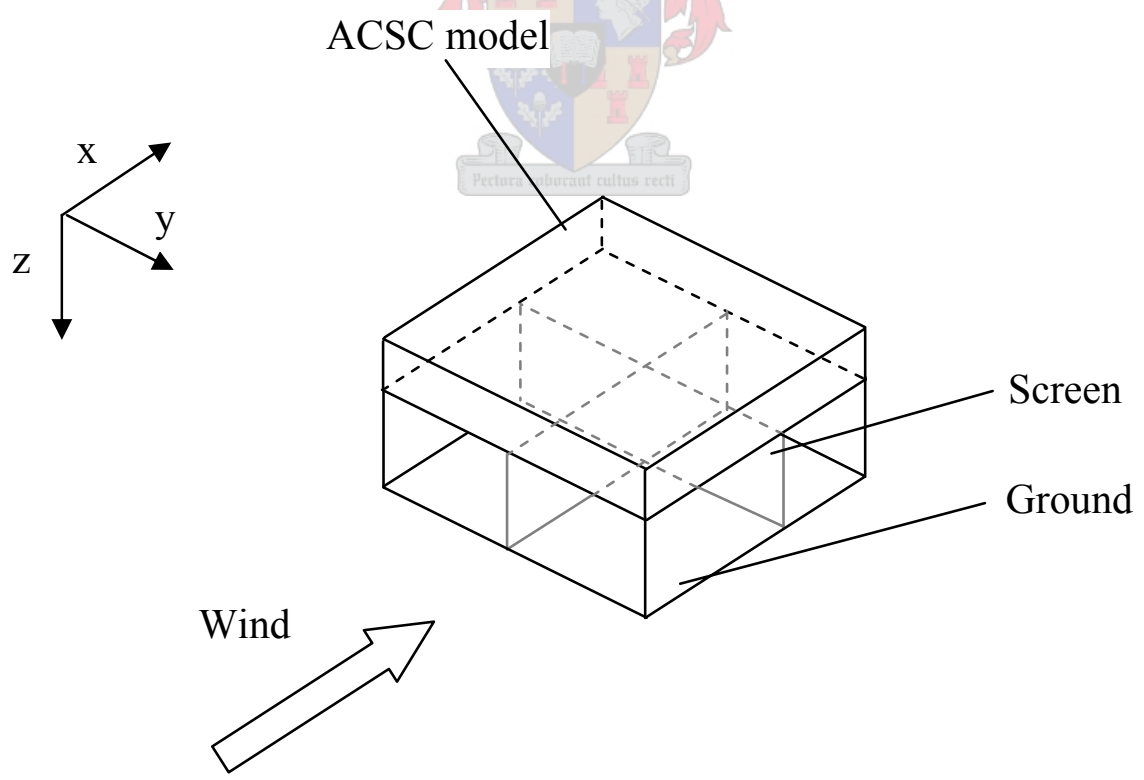

Figure 6.23: Location of screen. 
To reduce the amount of air that flow through underneath the ACSC a screen (e.g. shade net, slats or similar) may be installed under the fan platform as shown schematically in figures 6.23 and figure 6.24. The screen covers the area between the ground and the ACSC platform.

The screen was numerically modeled in FLUENT using the porous jump boundary condition. This condition calculates a pressure drop across a face in the flow domain, based on the normal velocity and a prescribed loss coefficient, i.e. $\Delta \mathrm{p}=\mathrm{K}_{\mathrm{sc}} \rho \mathrm{v}^{2}$ where a loss coefficient of $\mathrm{K}_{\mathrm{sc}}=1$ is assumed for the screen.
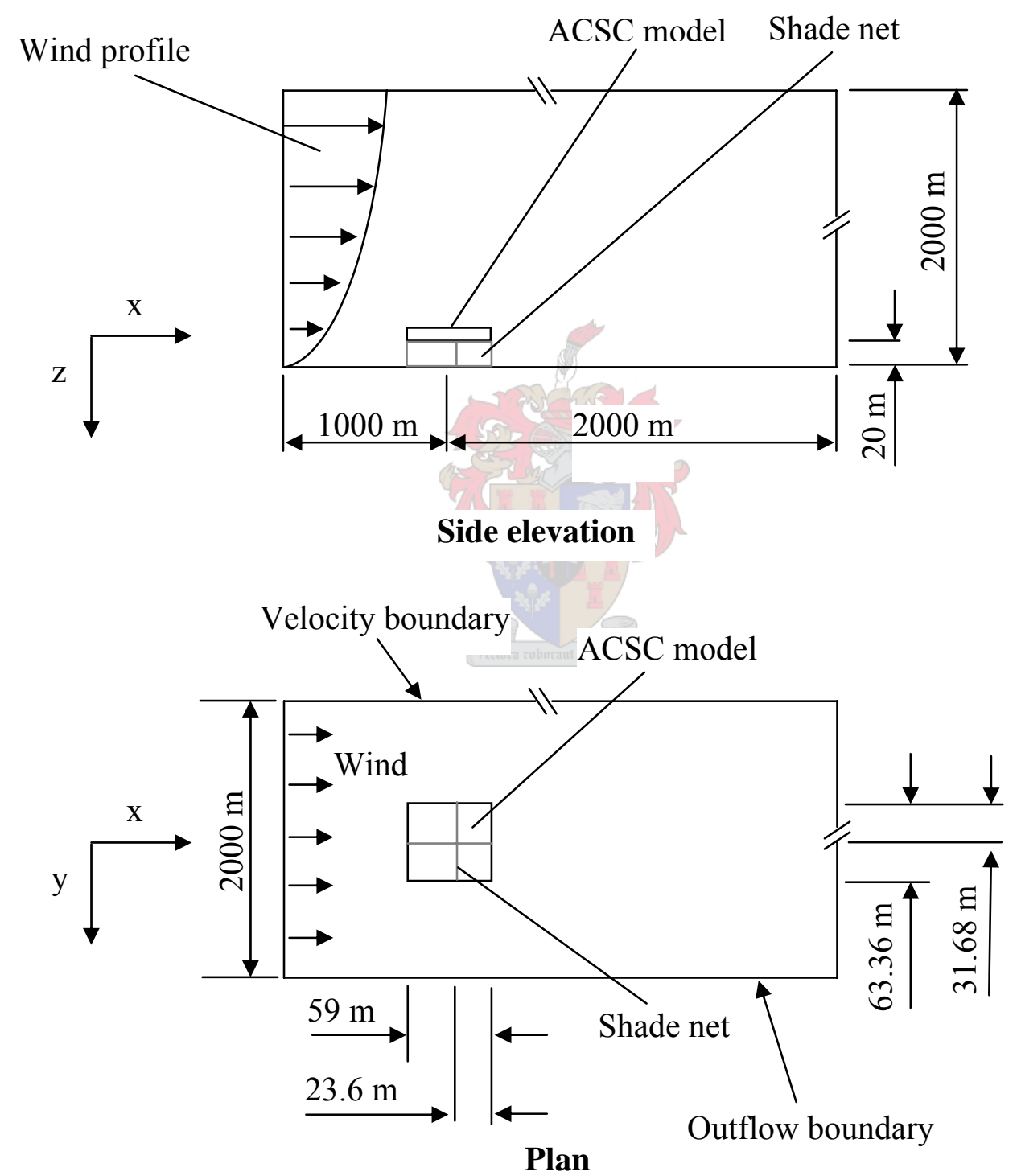

Figure 6.24: Global flow field.

The performance improvement of the ACSC shown in figures 6.23 and 6.24 (with skirt) will be analyzed while being subjected to wind that blows in the x-direction. The purpose of the 
screen is not only to reduce the flow passing through under the ACSC but also to increase the pressure under the upstream edge fan.

\subsubsection{Global flow field with screen}

Figures 6.25 and 6.26 show that the screen does not affect the low pressure region at the upstream edge fans measurably.

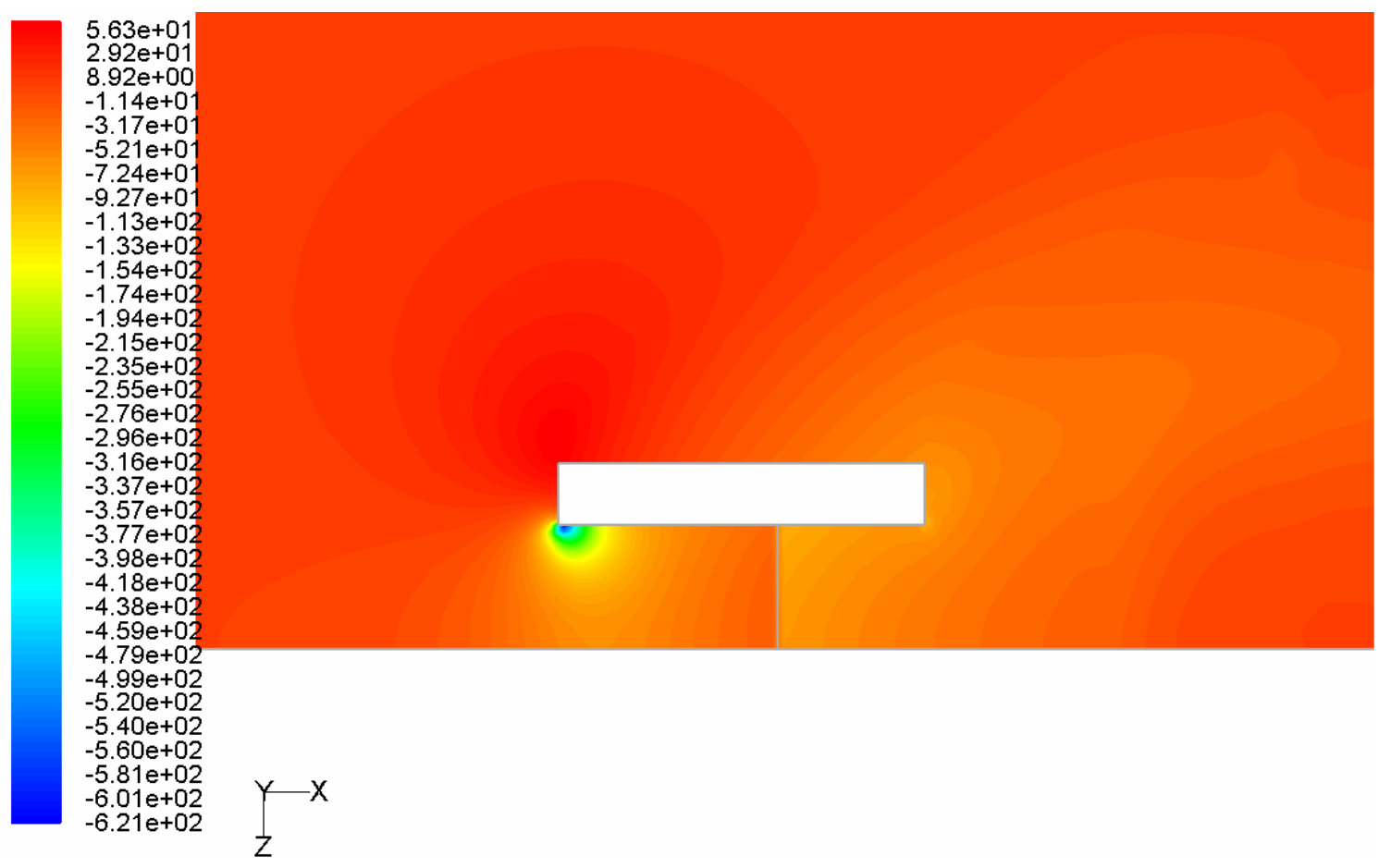

Figure 6.25: Static pressure, $p_{\text {stat }} \mathrm{N} / \mathrm{m}^{2}$, global flow field at a wind speed of $9 \mathrm{~m} / \mathrm{s}$. Section view B-B (refer to figure 3.2). 


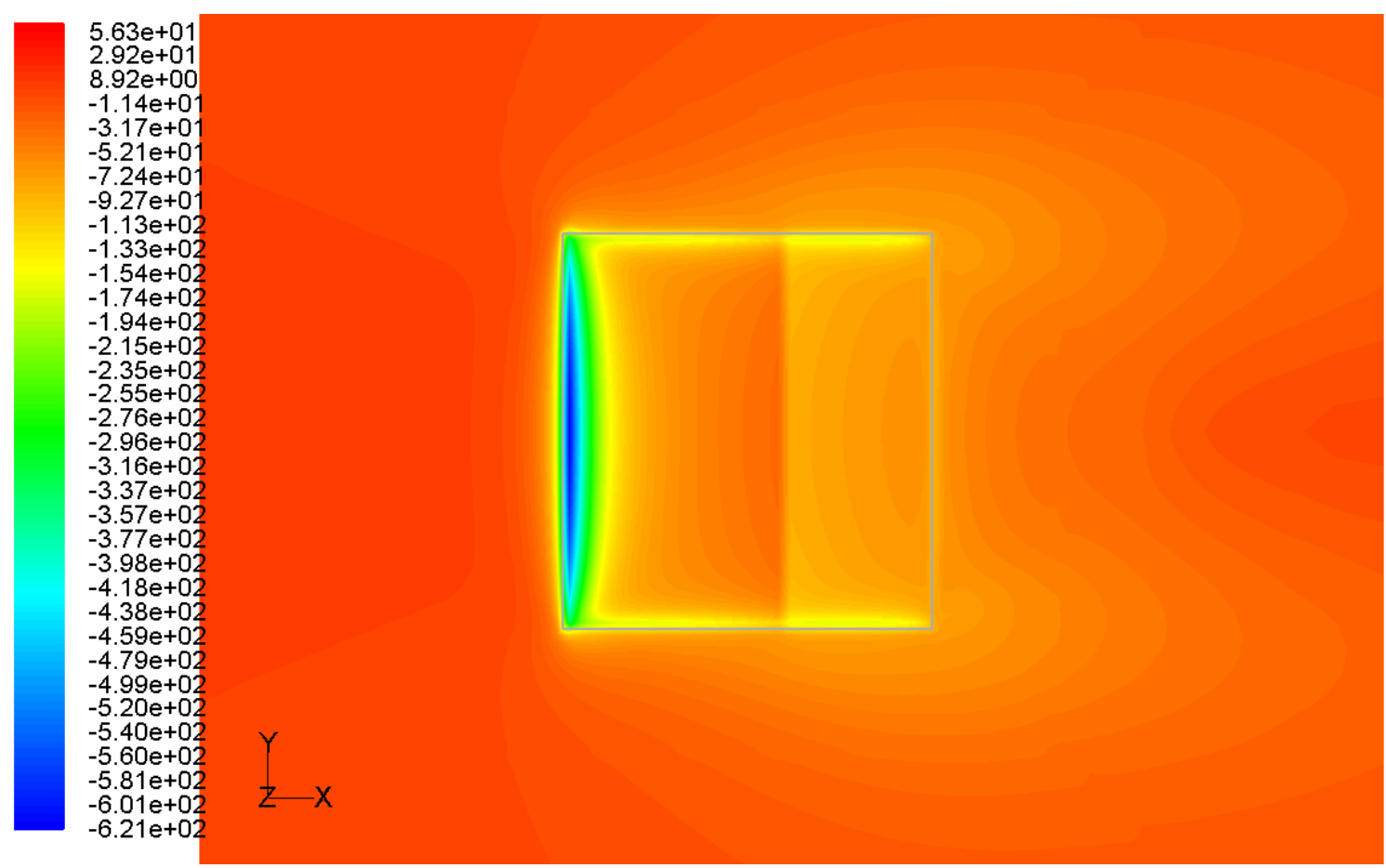

Figure 6.26: Static pressure, $p_{\text {stat }} \mathrm{N} / \mathrm{m}^{2}$, global flow field at a wind speed of $9 \mathrm{~m} / \mathrm{s}$. Section view A-A (refer to figure 3.2).

\subsubsection{Fan performance with screen}

The volumetric effectiveness of $\operatorname{fan}(4,1), \operatorname{fan}(4,3)$, $\operatorname{fan}(4,4), \operatorname{fan}(4,5), \operatorname{fan}(5,3), \operatorname{fan}(6,1)$, fan $(6,3)$ and $f a n(6,5)$ are numerically determined at wind speeds of $3 \mathrm{~m} / \mathrm{s}, 6 \mathrm{~m} / \mathrm{s}$ and $9 \mathrm{~m} / \mathrm{s}$ in the $\mathrm{x}$-direction (specified at the fan platform height of $20 \mathrm{~m}$ above the ground).

Figure 6.27 shows that the volumetric effectiveness of the fans, except for fan $(4,1)$, are not measurably changed by the addition of the screen (see figure 4.10 for comparison). 


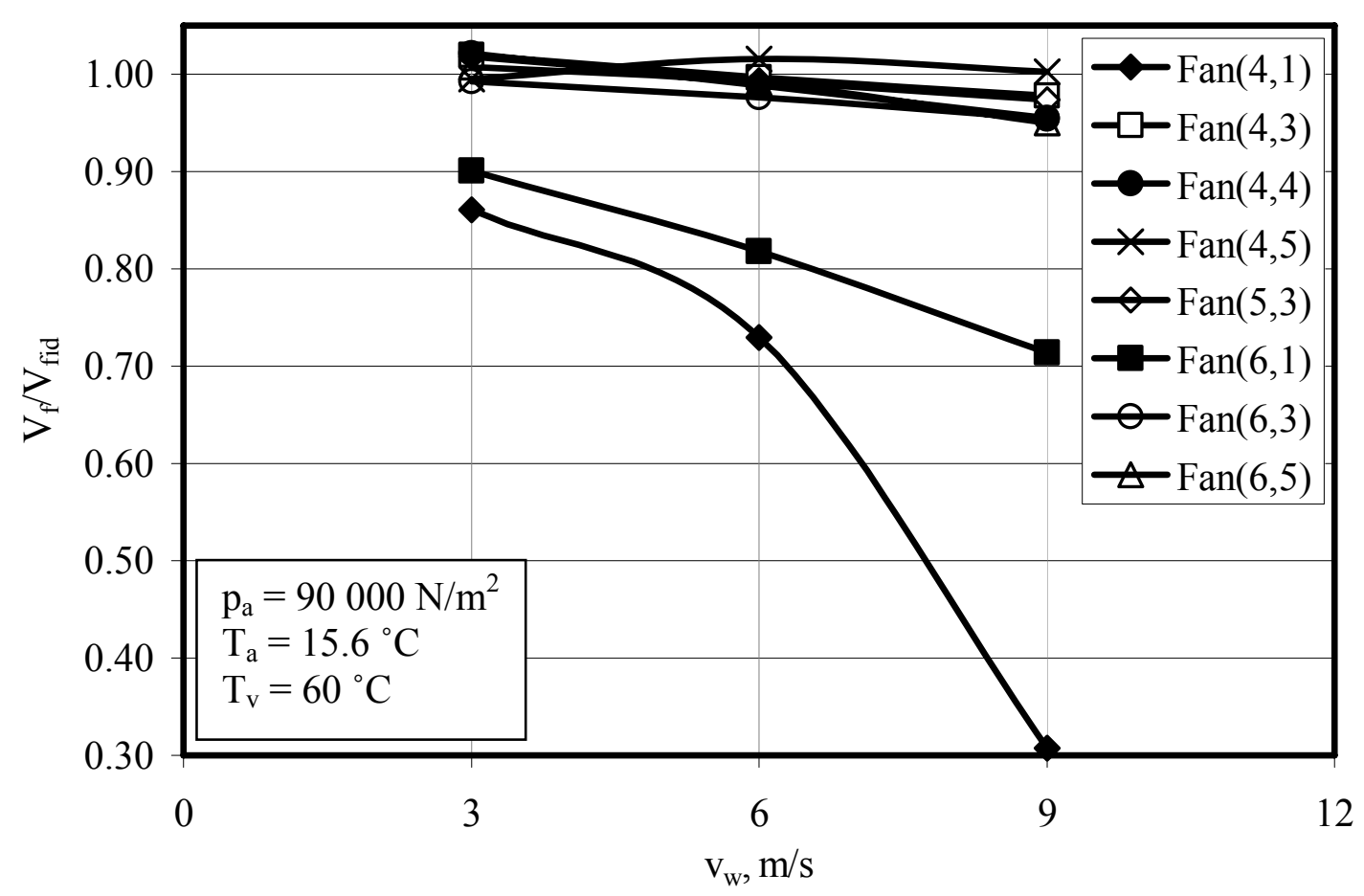

Figure 6.27: Volumetric effectiveness of fans.

Figure 6.28 shows that the low pressure region at fan $(4,1)$ is still present.

The hot air recirculation is still present at $\operatorname{fan}(6,1), \operatorname{fan}(6,3)$ and $\operatorname{fan}(6,5)$. However the addition of the screen slightly reduces recirculation. The air inlet temperature of fan $(6,3)$ and fan $(6,5)$ is respectively approximately $1{ }^{\circ} \mathrm{C}$ and $4{ }^{\circ} \mathrm{C}$ higher than ambient. The screen has no effect on the air inlet temperature of fan(6,1). Figures 6.28 and 6.29 show the hot air circulation at fan $(6,3)$ and fan $(6,5)$. 


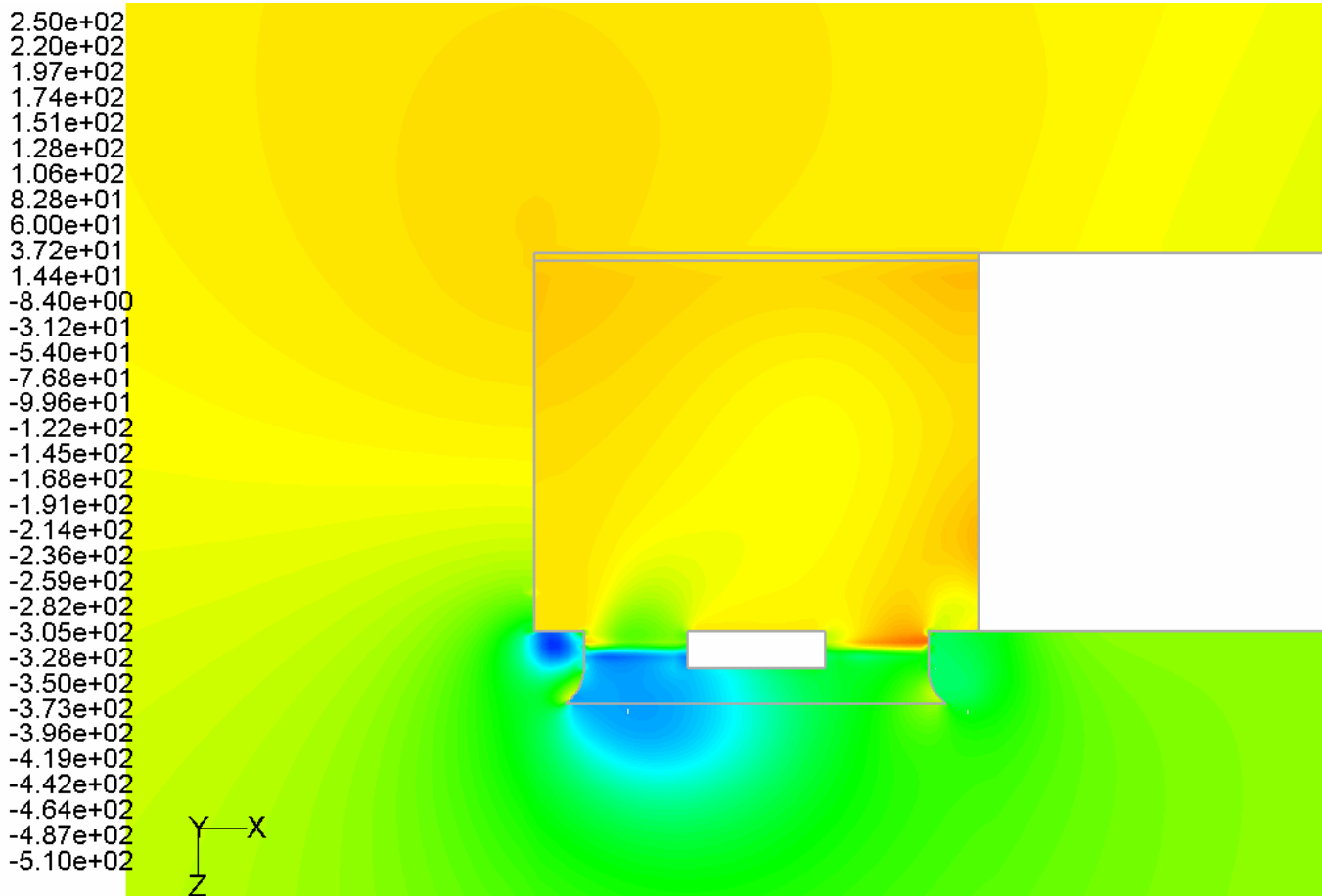

Figure 6.28: Static pressure, $p_{\text {stat, }} N / \mathrm{m}^{2}$, fan $(4,1)$ at a wind speed of $9 \mathrm{~m} / \mathrm{s}$.

Section view F-F (refer to figure 3.6).
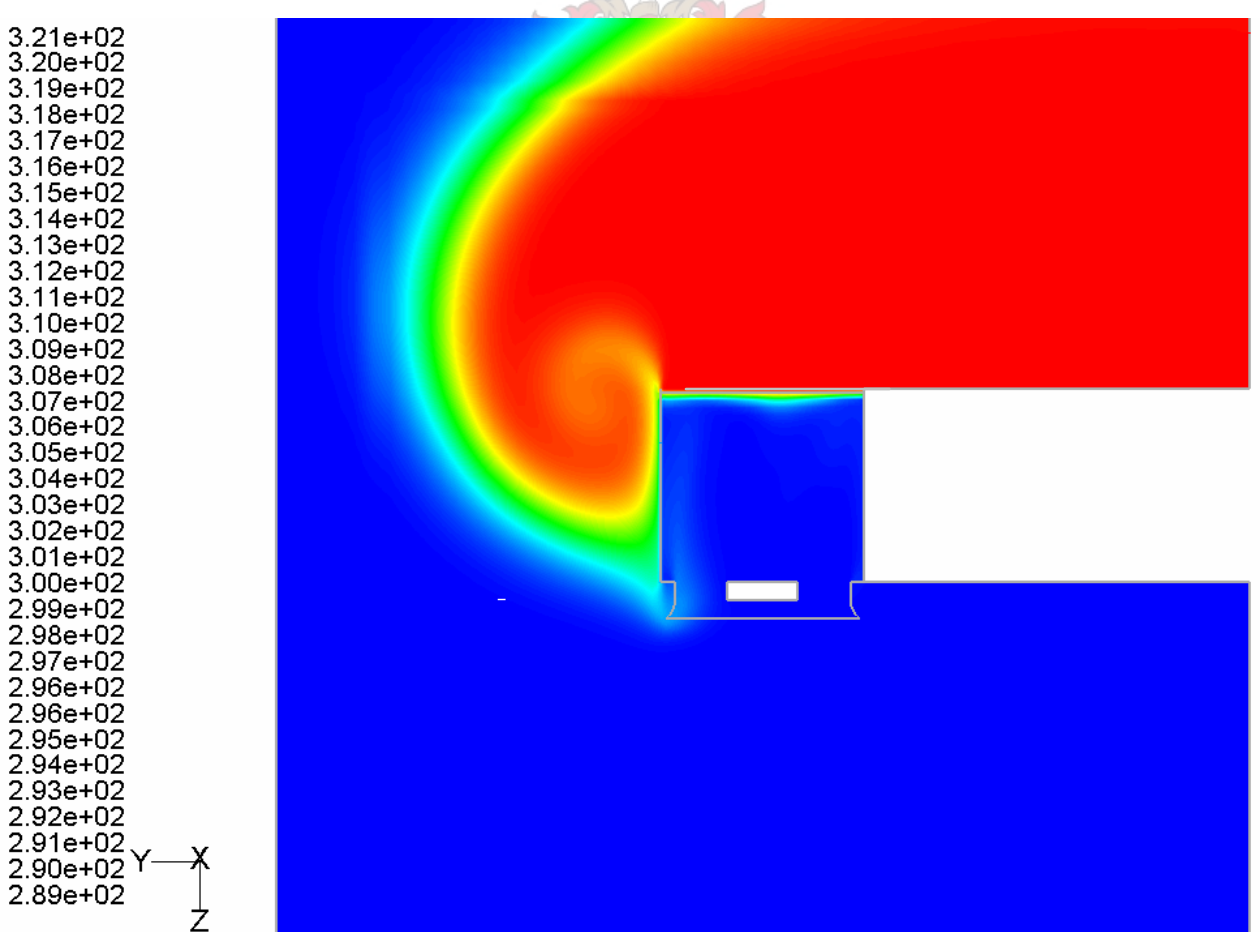

Figure 6.29: Temperature, $K, \operatorname{fan}(6,3)$ at a wind speed of $9 \mathrm{~m} / \mathrm{s}$.

Section view D-D (refer to figure 3.6). 

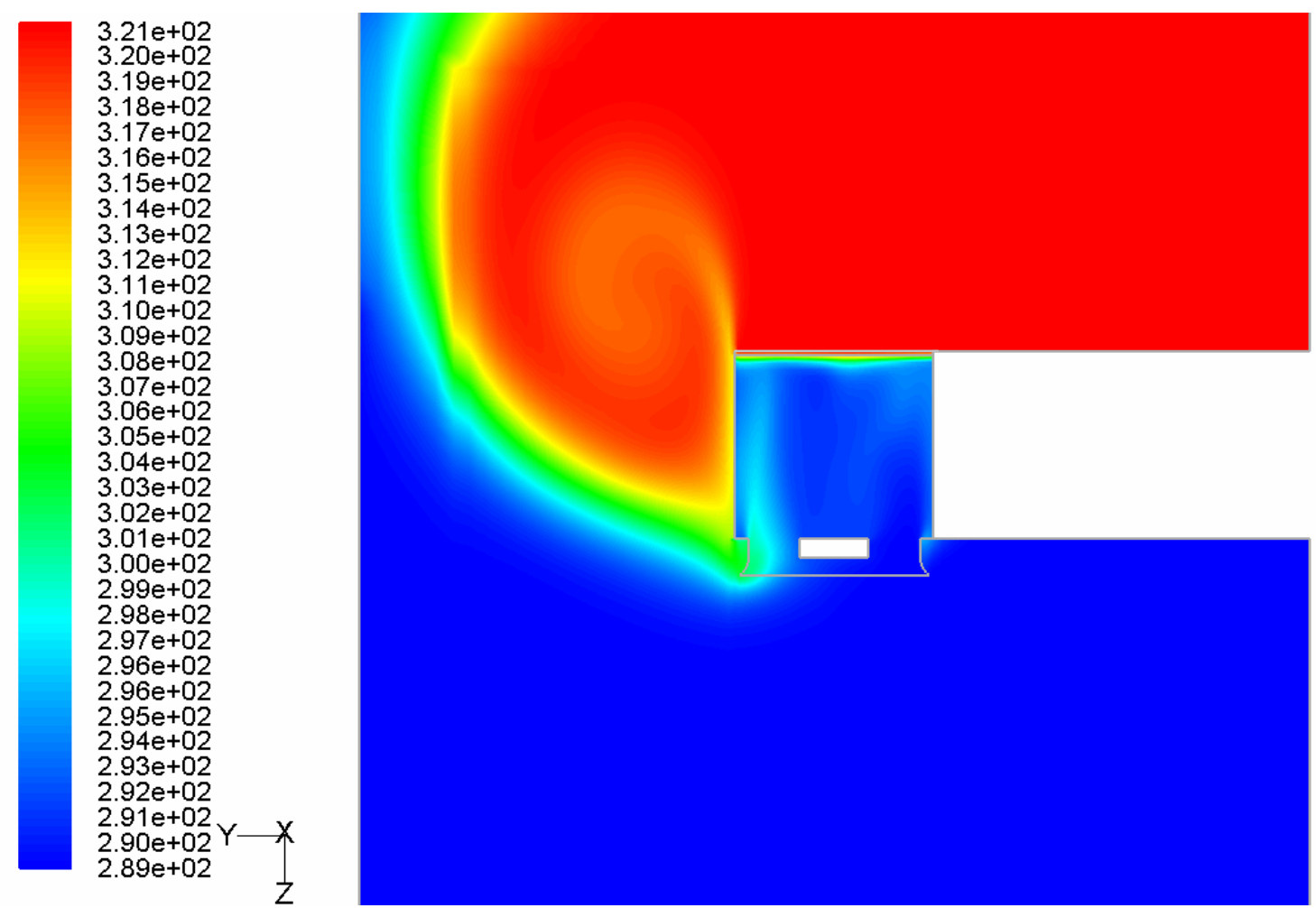

Figure 6.30: Temperature, $K, \operatorname{fan}(6,5)$ at a wind speed of $9 \mathrm{~m} / \mathrm{s}$.

Section view D-D (refer to figure 3.6).

\subsubsection{System performance with screen}

Due to time constraints, only some of the fans are analyzed numerically, and an interpolation scheme (interpolation scheme 4) is used to determine the volumetric effectiveness of the remaining fans (refer to Appendix C). Figure 6.31 indicates that the addition of the screen does not have a significant effect on the improvement of the volumetric effectiveness of the ACSC.

The thermal effectiveness of the ACSC decreases with increasing wind speed as shown in figure 6.32. The dotted line shows the thermal effectiveness when only reduced fan air mass flow rates are considered (ambient air temperature assumed at the inlet to each fan i.e. hot air recirculation is ignored).

Due to the relatively high wind wall the effect of plume air recirculation is shown to have a small influence on the thermal effectiveness. 


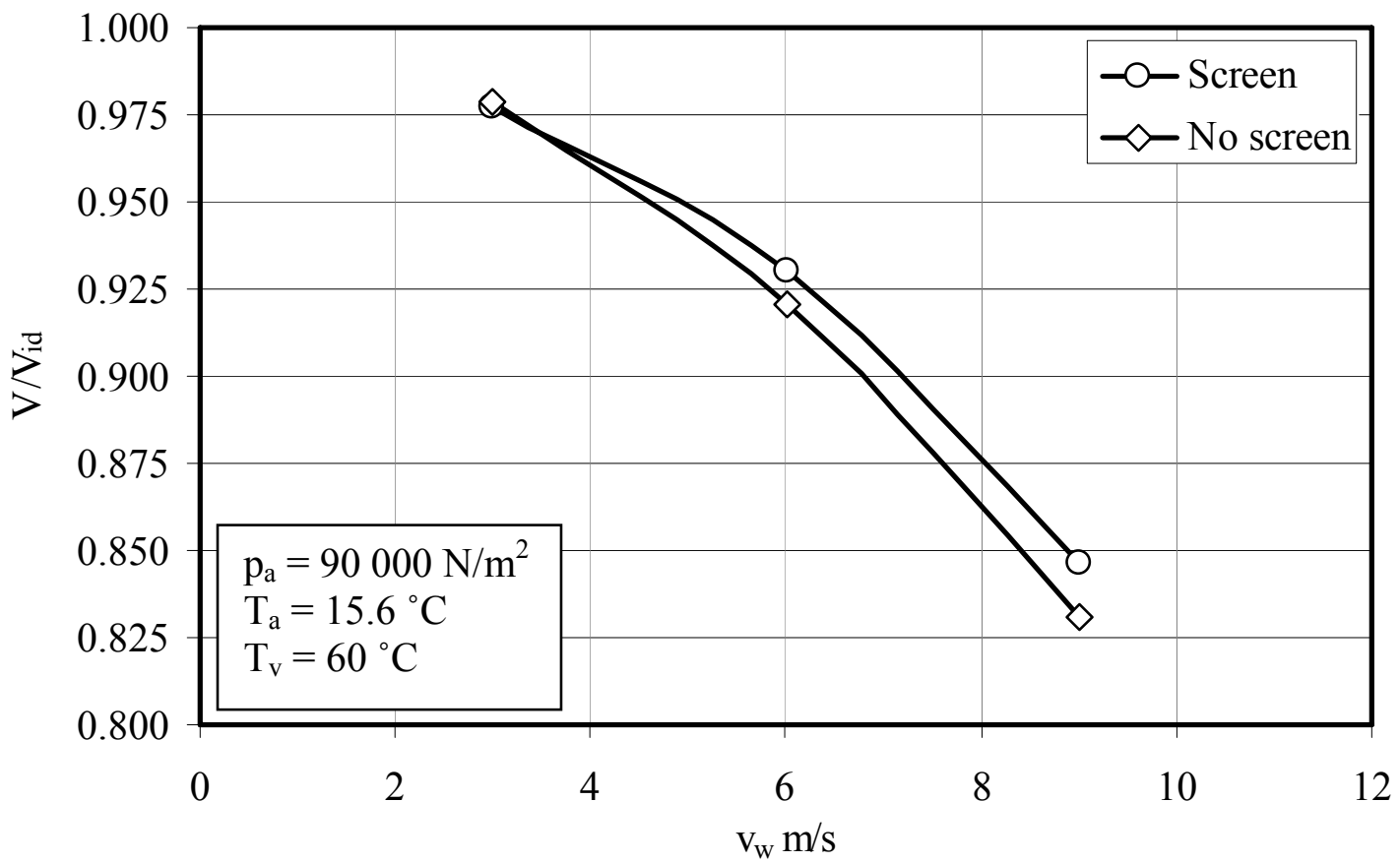

Figure 6.31: Volumetric effectiveness of ACSC with a screen (wind in the $x$-direction).

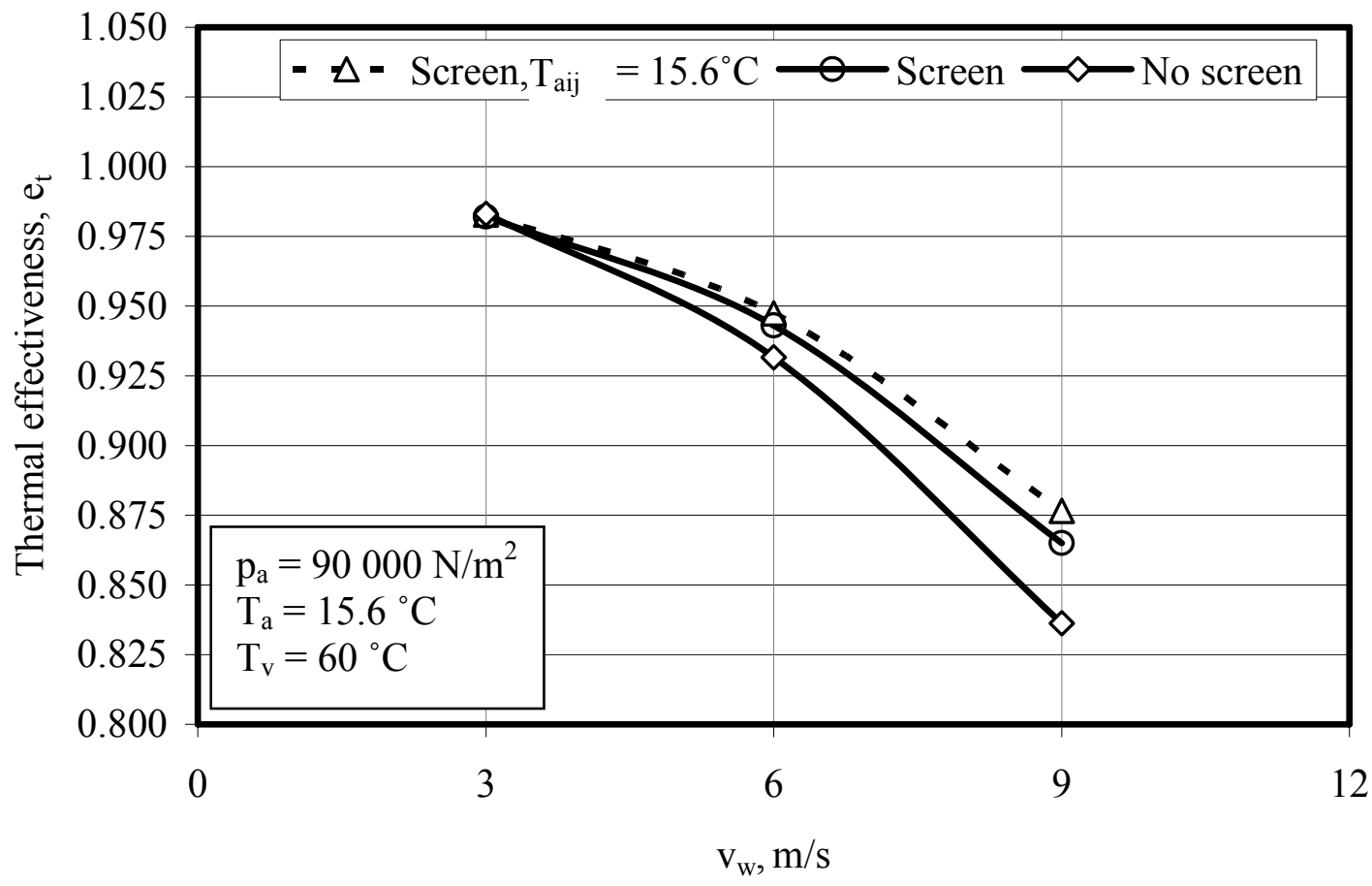

Figure 6.32: Thermal effectiveness of ACSC with a screen (wind in the $x$-direction). 


\section{CONCLUSIONS AND RECOMMENDATIONS}

The purpose of this study was to numerically (CFD) determine the performance trend and airflow pattern about and through the ACSC shown in figures 2.1 and 2.2, under windy conditions. An attempt was also made to improve the performance of an ACSC under windy conditions.

\subsection{Effect of wind on the ACSC performance}

The model analyzed in this study shows that wind does influence the performance of an ACSC significantly. The flow distortions and corresponding low pressure region at the upstream edge fans contributes mainly to the net decrease in the ACSC performance as the wind speed is increased, but the wind does have a positive influence on certain fans. The volumetric effectiveness of certain downstream fans is increased to above $100 \%$.

Figure 7.1 shows influence of the wind as well as the wind direction on the thermal effectiveness of the ACSC.

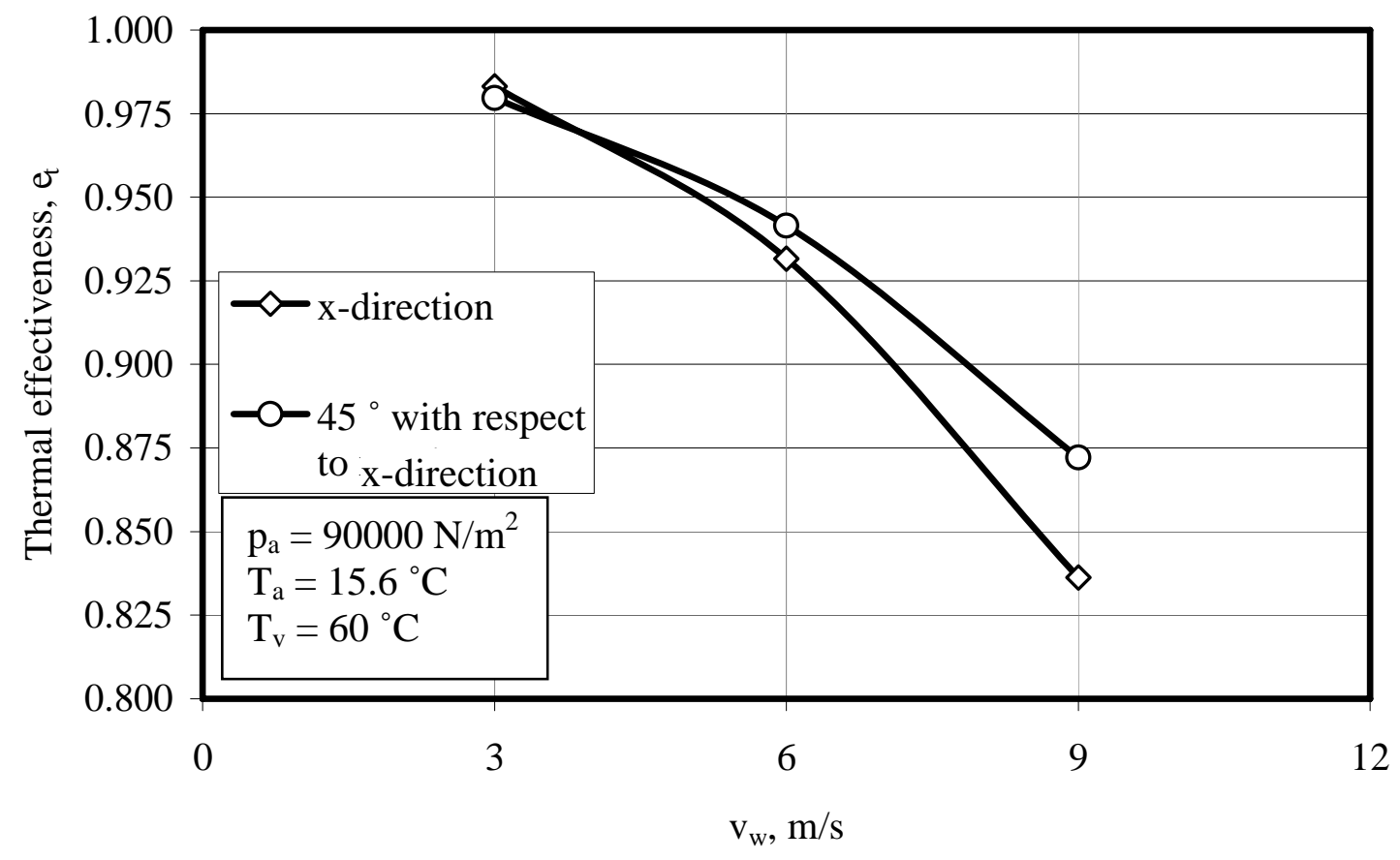

Figure 7.1: Thermal effectiveness of ACSC under windy conditions (various directions). 


\subsection{Effect of skirt on the ACSC performance}

The addition of a skirt does increase the performance of an ACSC measurably (12 \% increase in thermal effectiveness at a wind speed of $9 \mathrm{~m} / \mathrm{s}$ ) under windy conditions, as shown in figure 7.2, by modifying the flow into the ACSC and by reducing the hot air recirculation that exists at the downstream edge fans. The low pressure region at the inlet of the upstream edge fans is displaced away from the fan inlet, resulting in an increase in the volumetric effectiveness of the upstream edge fans and a corresponding increase in the volumetric effectiveness of the ACSC.

At a relatively low wind speed $(3 \mathrm{~m} / \mathrm{s})$ the volumetric effectiveness of the ACSC with a $3 \mathrm{~m}$ skirt is approximately $100 \%$. Even though the volumetric flow rate of the upstream edge fans are below the ideal volumetric flow rate $\left(661 \mathrm{~m}^{3} / \mathrm{s}\right)$, the volumetric effectiveness of the downstream fans are increased to above $100 \%$ due to the windy conditions.

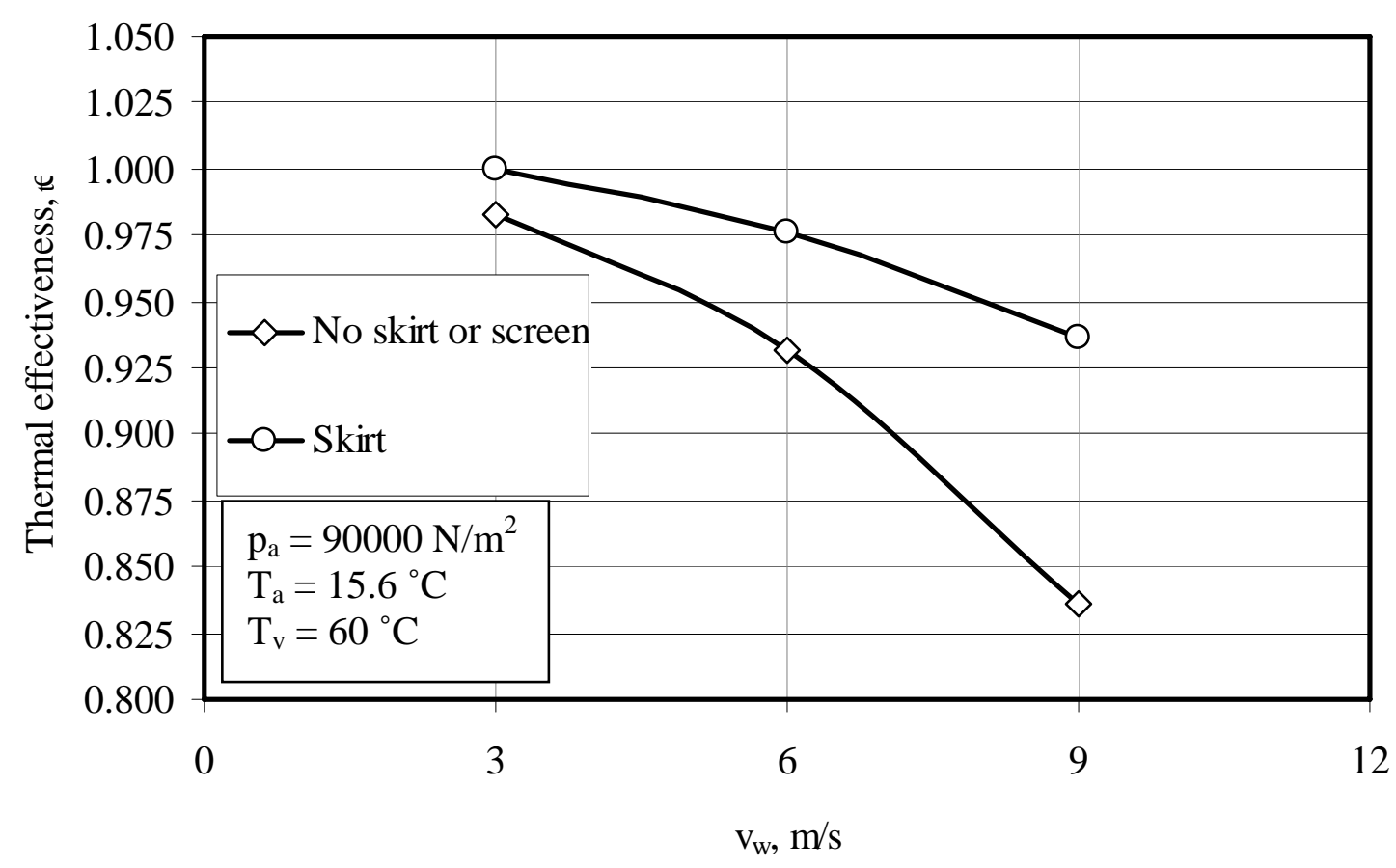

Figure 7.2: Thermal effectiveness of ACSC (wind in the x-direction).

The addition of the $3 \mathrm{~m}$ skirt does affect the steam temperature and the turbine back pressure measurably as shown in figures 7.3 and 7.4. Approximate empirical fits to the data in figures 7.3 and 7.4 for the wind in the $\mathrm{x}$-direction and with the addition of a $3 \mathrm{~m}$ skirt are: 
$\mathrm{T}_{\mathrm{VW}}=0.0134\left(74.1+0.028 \mathrm{v}_{\mathrm{w}}^{2.16}\right)\left(44.41+\mathrm{T}_{\mathrm{a}}\right),{ }^{\circ} \mathrm{C}$

$\mathrm{p}_{\mathrm{vw}}=0.107 \mathrm{~T}_{\mathrm{vw}}^{2.97}, \mathrm{~N} / \mathrm{m}^{2}$

where all temperatures are in ${ }^{\circ} \mathrm{C}$.

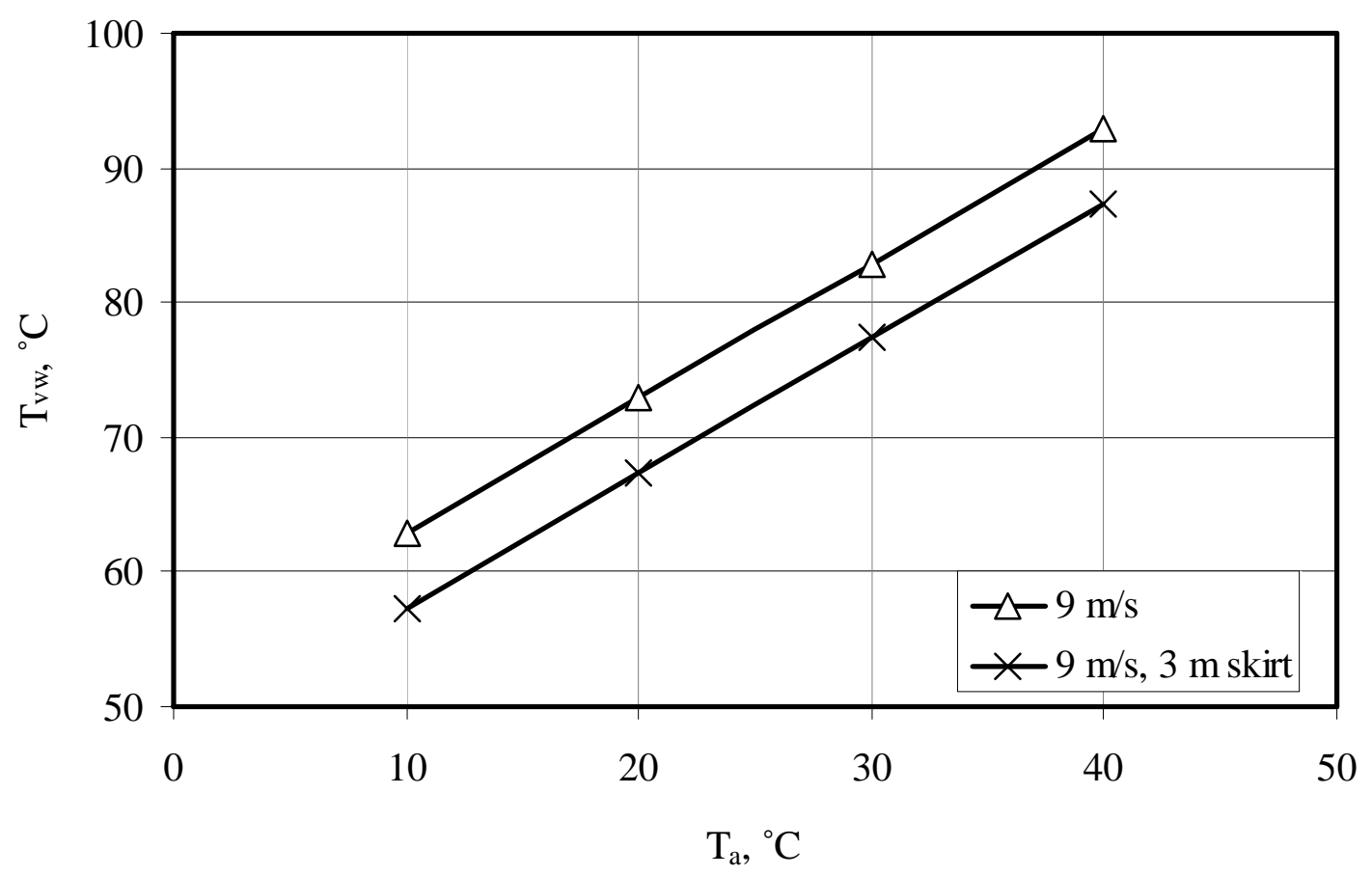

Figure 7.3: Ambient temperature and wind effect on saturation temperature of the turbine exhaust steam.

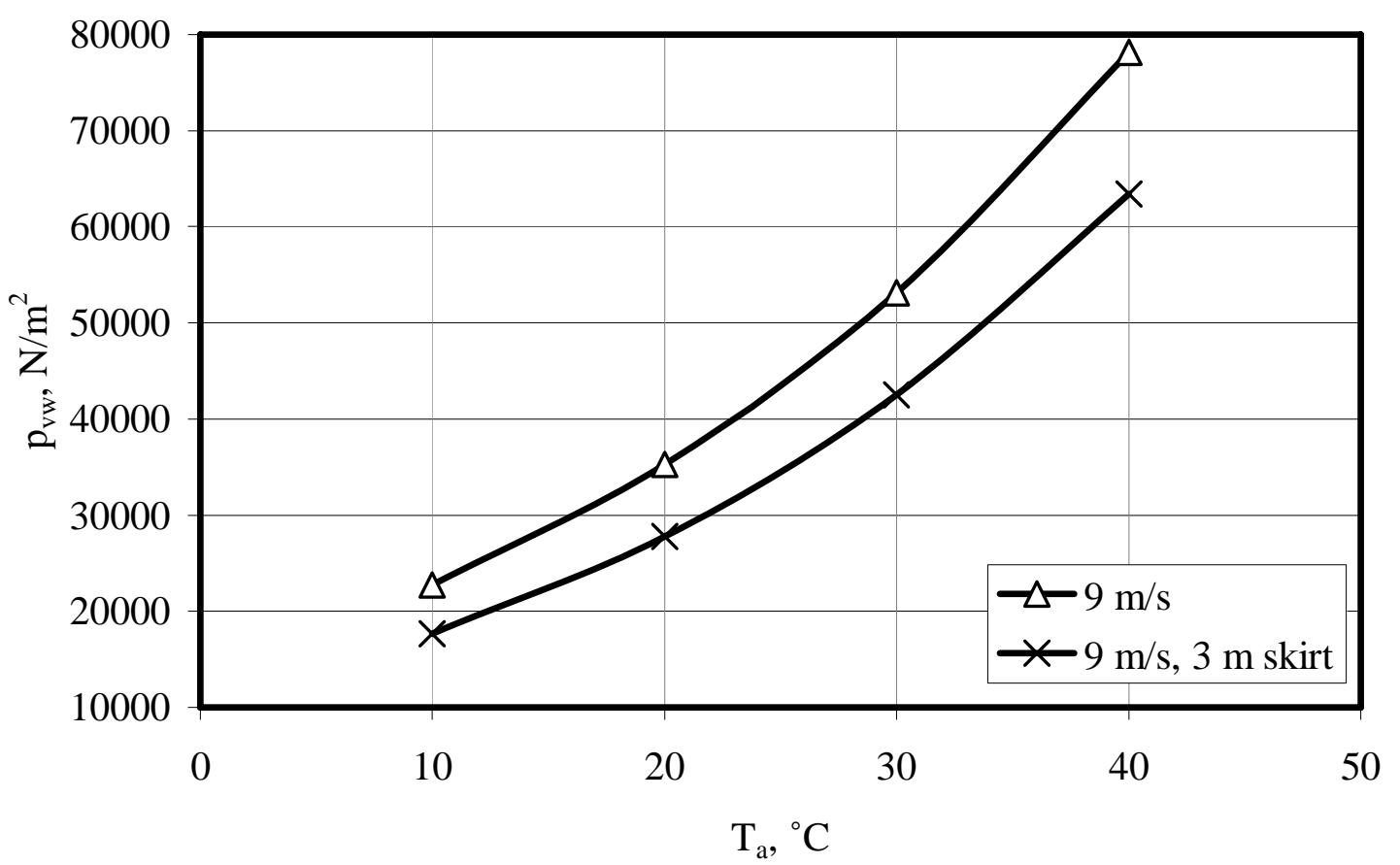

Figure 7.4: Ambient temperature and wind effect on turbine back pressure. 


\subsection{Effect of screen on the ACSC performance}

The use of a screen at a specific location underneath the ACSC is evaluated with a view to improving the performance of an ACSC. The screen does improve the performance of ACSC but not nearly to the same extent as the skirt does, as is shown in figure 7.5.

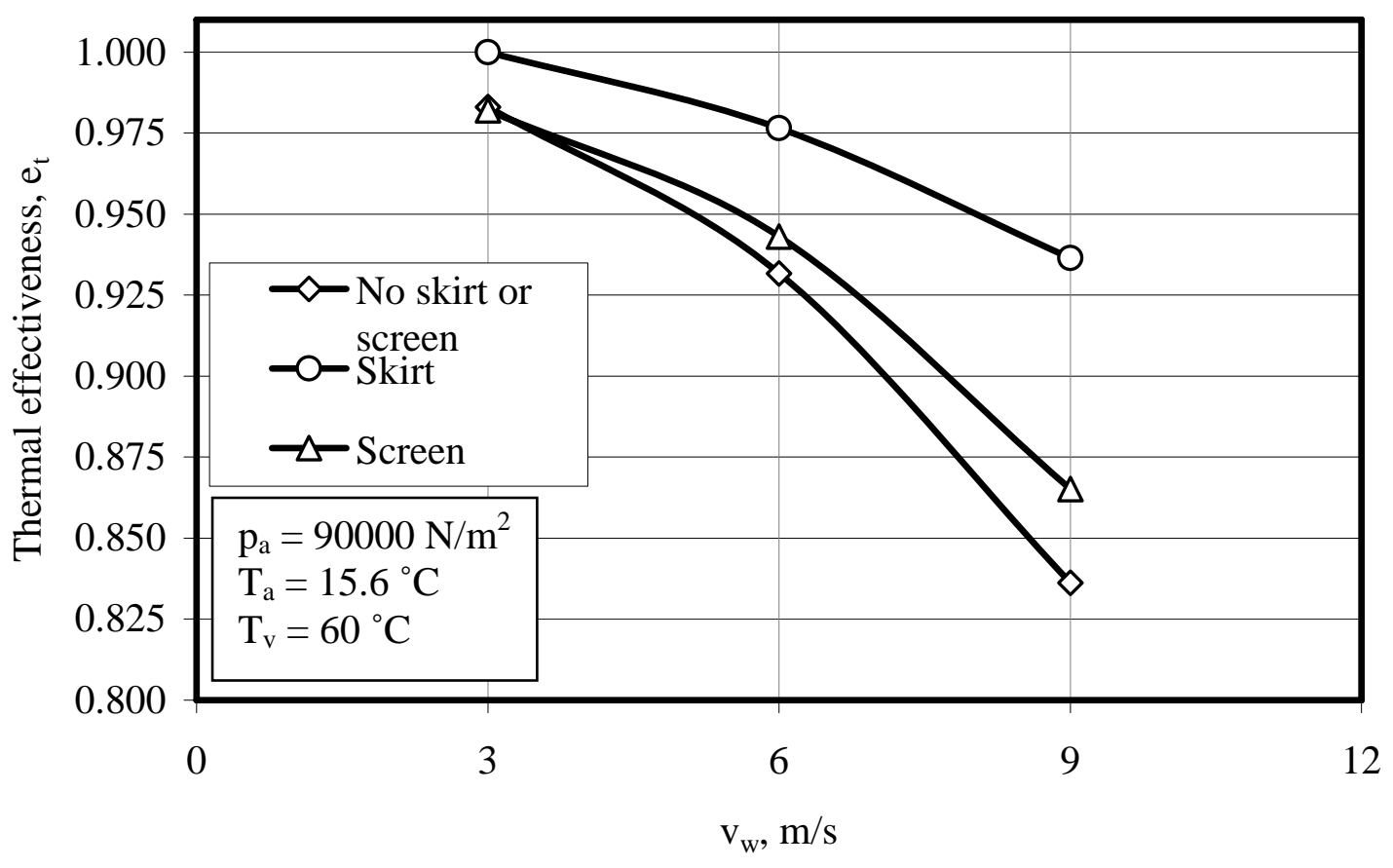

Figure 7.5: Thermal effectiveness of ACSC (wind in the x-direction).

\subsection{Effect of wind on turbine back pressure}

If the particular ACSC is connected to the outlet of a steam turbine the latter's outlet steam temperature and corresponding back pressure is found to change as function of wind speed and ambient air temperature. Approximate empirical fits to the data in figures 4.22 and 4.23 for wind in the $\mathrm{x}$-direction and figures 5.13 and 5.14 for wind at $45^{\circ}$ with respect to the $\mathrm{x}$ direction are respectively:

$$
\begin{aligned}
& \mathrm{T}_{\mathrm{vw}}=0.013\left(75.63+0.035 \mathrm{v}_{\mathrm{w}}{ }^{2.49}\right)\left(45.17+\mathrm{T}_{\mathrm{a}}\right),{ }^{\circ} \mathrm{C} \\
& \mathrm{p}_{\mathrm{vw}}=0.094 \mathrm{~T}_{\mathrm{vw}}{ }^{3}, \mathrm{~N} / \mathrm{m}^{2} \\
& \mathrm{~T}_{\mathrm{vw}}=0.0133\left(74.89+0.031 \mathrm{v}_{\mathrm{w}}{ }^{2.4}\right)\left(45.33+\mathrm{T}_{\mathrm{a}}\right),{ }^{\circ} \mathrm{C}
\end{aligned}
$$


$\mathrm{p}_{\mathrm{vw}}=0.094 \mathrm{~T}_{\mathrm{vw}}{ }^{3}, \mathrm{~N} / \mathrm{m}^{2}$

where all temperatures are in ${ }^{\circ} \mathrm{C}$.

Since $T_{v w}$ is a linear function of $T_{a}$ the results of this study can be applied to determine the change in the turbine back pressure where the design temperature difference differs from $\left(\mathrm{T}_{\mathrm{v}}-\mathrm{T}_{\mathrm{a}}\right)_{\mathrm{d}}=(60-15.6)=44.4{ }^{\circ} \mathrm{C}$. For instance equation 7.3 can be written as:

$$
\begin{aligned}
\mathrm{T}_{\mathrm{Vw}} & =0.013\left(75.63+0.035 \mathrm{v}_{\mathrm{w}}^{2.49}\right)\left(45.17\left(\mathrm{~T}_{\mathrm{v}}-\mathrm{T}_{\mathrm{a}}\right)_{\mathrm{d}} /(60-15.6)+\mathrm{T}_{\mathrm{a}}\right) \\
& =0.013\left(75.63+0.035 \mathrm{v}_{\mathrm{w}}{ }^{2.49}\right)\left(1.0173\left(\mathrm{~T}_{\mathrm{v}}-\mathrm{T}_{\mathrm{a}}\right)_{\mathrm{d}}+\mathrm{T}_{\mathrm{a}}\right)
\end{aligned}
$$

\subsection{Recommendations}

The primary focus of this study was to determine performance trends of an ACSC under windy conditions. The performance was measurably improved by the addition of a skirt, for an ACSC that has 30 fan units located $20 \mathrm{~m}$ above the ground with a windwall that is $10 \mathrm{~m}$ high.

The following recommendations are made:

- The performance of other air-cooled condensers having more or fewer fan units differently arranged and at various heights above ground level with different windwall heights should be determined.

- Further improvements in performance may possibly be achieved under windy conditions by different screen arrangements and geometries, guide vanes etc.

- Modifications of the fan inlets (rounded, conical and cylindrical) will also influence performance and should be studied.

- The influence of temperature inversions on the performance should be investigated since this will influence air inlet temperatures to fans.

- At high ambient temperatures a suitable evaporative cooling system should be included in the ACSC to improve turbine performance. 
- The method used to analyze the ACSC flow pattern was essentially a manual parallel solving method. To analyze the flow more time efficiently and accurately, a more powerful computer system should be used. 


\section{REFERENCES}

Bredell, J.R., Kröger, D.G and Thiart, G.D., Numerical Investigation of Fan Performance in a Forced Draft Air-Cooled Steam Condenser, MScEng Thesis, Department of Mechanical Engineering, University of Stellenbosch, 2005.

Bredell, J.R., Kröger, D.G and Thiart, G.D., Numerical Investigation of Fan Performance in a Forced Draft Air-Cooled Steam Condenser, Applied Thermal Engineering, Vol. 26, pp. 846-852, 2006.

Coetzee, R.V. and du Toit, C., Numerical Simulation of an Air-Cooled Heat Exchanger, B.Eng. Thesis, Department of Mechanical Engineering, Potchefstroom University for Christian Higher Education, 2000.

Coetzee, R.V. and du Toit, C., Numerical Modeling of an Air-Cooled Heat Exchanger: Influence of End-Effects on Results, R\&D Journal of the South African Institution of Mechanical Engineering, Vol. 20, No. 1, 2004.

Duvenhage, K., and Kröger, D.G., The Influence of Wind on the Performance of Forced Draft Air-Cooled Heat Exchangers, Journal of Wind Engineering and Industrial Aerodynamics, Vol. 62, 259-277, 1996.

Goldschagg, H.B., Lessons Learned from the World's Largest Air Cooled Condenser, Paper presented at the EPRI Int. Symp. on Improved Technology for Fossil Power Plants - New and Retrofit Applications, Washington, March 1993

Goldschagg, H.B., Vogt, F., du Toit, C.G., Thiart, G.D. and Kröger, D.G., Air-cooled Steam Condenser Performance in the Presence of Crosswinds, EPRI TR-108483 2113, Proceedings: Cooling Tower Technology Conference, pp. 1.61-1.77, July 1997.

Kröger, D.G., Air-cooled Heat Exchanger and Cooling Towers, Penwell Corp., Tulsa, 2004. 
Mehrotra, V., Berkoe, J., Messersmith, D., Evaluating Performance of Air Cooled Heat Exchangers in LNG Plants, Prepared for Presentation at the AIChE Spring National Meeting, LNG Equipment Design, New Orleans, April 2003.

Meyer, C.J., Numerical Investigation of the Effect of Inlet Flow Distortions on Forced Draught Air-Cooled Heat Exchanger Performance, Applied Thermal Engineering, Vol. 25, Issues 11-12, pp. 1634-1649, 2005.

Salta, C.A. and Kröger, D.G., Effect of Inlet Flow Distortions on Fan Performance in Forced Draught Air-Cooled Heat Exchangers, Heat Recovery Systems \& CHP, Vol. 15, No. 6, pp. 555-561, 1995.

Van Aarde, D.J. and Kröger, D.G., Vloeiverliese deur 'n A-Raam Vinbuisbundel in 'n Lugverkoelde Kondensator, MScEng Thesis, Department of Mechanical Engineering, University of Stellenbosch, 1990.

Van Staden, M.P. and Pretorius, L., An Integrated Approach to Transient Simulation of Large Air-Cooled Condensers using Computational Fluid Dynamics, Proceedings of the $1^{\text {st }}$ South African Conference on Applied Mechanics (SACAM), Midrand, South Africa, 1996.

Van Staden, M.P. and Pretorius, L., An Integrated Approach to Transient Simulation of Large Air-Cooled Condensers using Computational Fluid Dynamics, PhD Thesis, Department of Mechanical Engineering, Rand Afrikaans University, 2000. 


\section{APPENDIX A \\ DESIGN SPECIFICATIONS}

A.1. The thermo-physical properties of the ambient dry air surrounding the ACSC are given below:

Density

Thermal conductivity

Specific heat

Molecular (dynamic) viscosity

Air temperature

Barometric pressure

$$
\begin{aligned}
\rho_{\mathrm{a}} & =1.0857 \mathrm{~kg} / \mathrm{m}^{3} \\
\mathrm{k}_{\mathrm{a}} & =0.02535 \mathrm{~W} / \mathrm{mK} \\
\mathrm{c}_{\mathrm{pa}} & =1006.609 \mathrm{~J} / \mathrm{kgK} \\
\mu_{\mathrm{a}} & =1.7948 \times 10^{-5} \mathrm{~kg} / \mathrm{sm} \\
\mathrm{T}_{\mathrm{a}} & =15.6^{\circ} \mathrm{C} \text { or } 288.75 \mathrm{~K} \\
\mathrm{p}_{\mathrm{a}} & =90000 \mathrm{~N} / \mathrm{m}^{2}
\end{aligned}
$$

\section{A.2. Steam condition:}

Saturated steam temperature

$\mathrm{T}_{\mathrm{v}}=60{ }^{\circ} \mathrm{C}$

\section{A.3. Effectiveness of A-frame condenser unit:}

$\mathrm{e}=1-\exp \left(-\mathrm{U}_{\mathrm{ij}} \mathrm{A} / \mathrm{m}_{\mathrm{afij}} \mathrm{c}_{\mathrm{pa}}\right)=1-\exp \left(-44.41 / \mathrm{m}_{\mathrm{afij}}{ }^{0.5443}\right)$

\section{A.4. Effective system resistance:}

$\Delta p_{e}=-\left(4.132315 \times 10^{-4} V_{f}^{2}+5.629484 \times 10^{-2} V_{f}^{2}\right), N / m^{2}$ 


\section{APPENDIX B}

\section{FAN SPECIFICATIONS}

\section{B.1. Fan dimensions}

The fan (referred to as B-fan) dimensions and specifications in the ACSC under consideration are as follows:

Fan diameter

$\mathrm{d}_{\mathrm{f}} \quad=9.145 \mathrm{~m}$

Hub-tip-ratio

$\mathrm{d}_{\mathrm{h}} / \mathrm{d}_{\mathrm{f}}=0.4$

Ratio of hub thickness to fan diameter

$\mathrm{H}_{\mathrm{h}} / \mathrm{d}_{\mathrm{h}}=0.1$

Height of the bellmouth fan inlet from platform

$\mathrm{H}_{\mathrm{b}} \quad=1.92 \mathrm{~m}$

Bellmouth inlet radius

$\mathrm{r}_{\mathrm{b}} \quad=1.16 \mathrm{~m}$

Number of blades

$\mathrm{n}_{\mathrm{f}} \quad=8$

Rotational speed

$\mathrm{N}=125 \mathrm{rpm}$

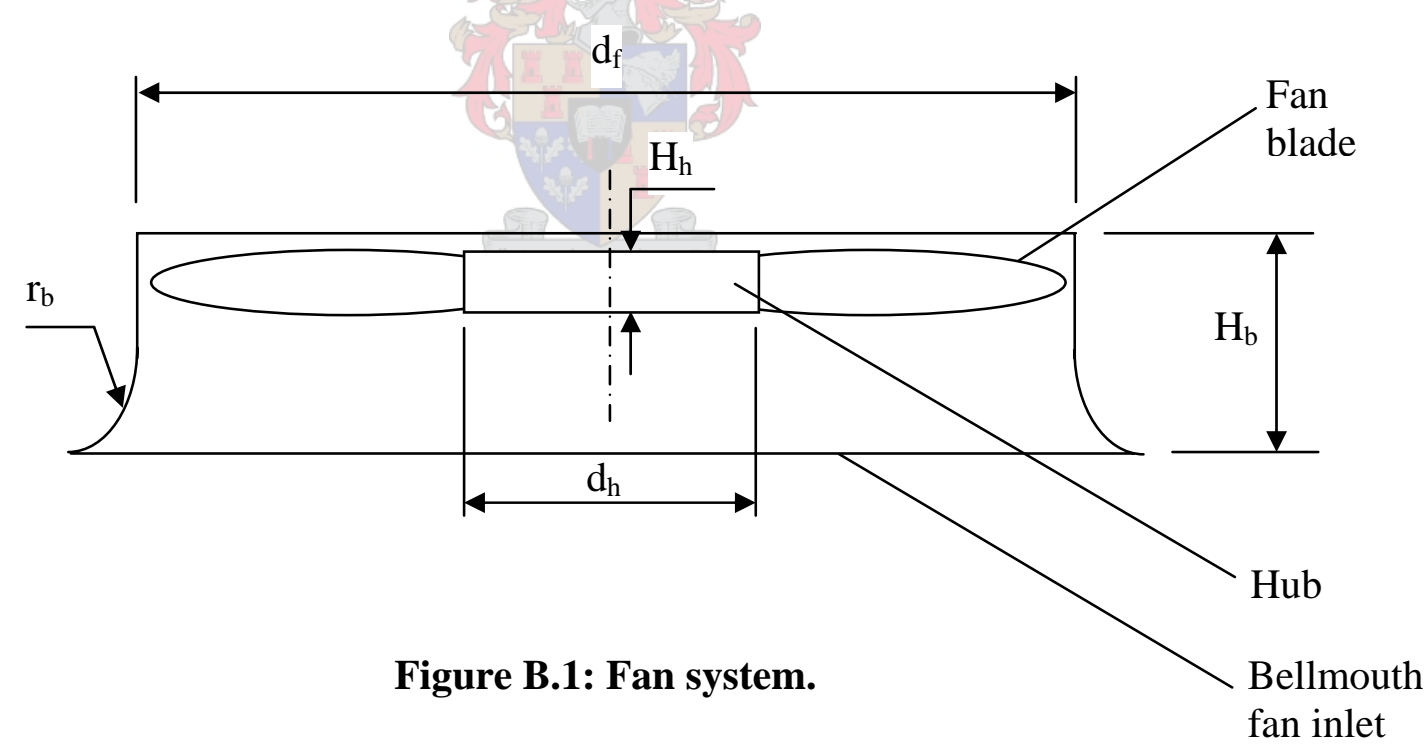

For a detailed description of the B-fan's blade properties and performance characteristics see Bredell et al. (2005). 


\section{APPENDIX C \\ INTERPOLATION SCHEMES}

The application of the actuator disc model in the evaluation of the performance of a large number of fans can be very time consuming. By reducing the number of fans actually analyzed in the ACSC model and employing the results to determine the appropriate performance of the remaining fans by means of interpolation and extrapolation, good results can be achieved in a greatly reduced period of time.

\section{C.1. Interpolation scheme 1}

Interpolation scheme 1 is indicated in figure C.1. The fan numbers which are underlined are the fans that are numerically analyzed (volumetric effectiveness). The volumetric effectiveness of the fans which are not underlined may be determined approximately by interpolation between adjacent fans (interpolation scheme 1). The arrows in figure C.1 indicate in which direction the interpolation is executed. For instance the arrow intersecting fan $(4,4)$ horizontally indicates the following interpolation:

$\mathrm{V}_{\mathrm{f}(4,4)} / \mathrm{V}_{\mathrm{fid}}=\left(\mathrm{V}_{\mathrm{f}(4,3)}+\mathrm{V}_{\mathrm{f}(4,5)}\right) / 2 \mathrm{~V}_{\text {fid }}$ 


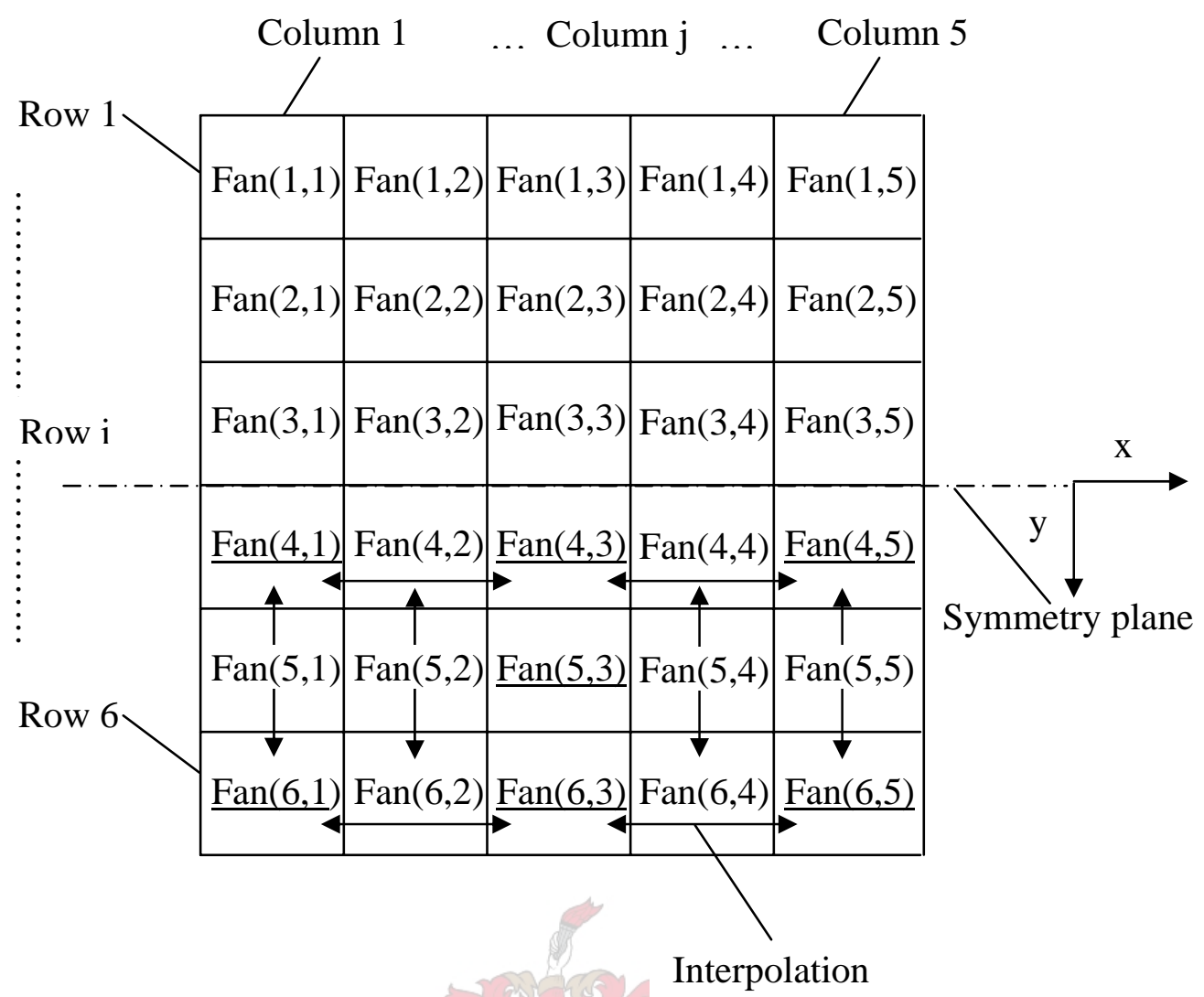

Figure C.1: Interpolation scheme 1.

\section{C.2. Interpolation scheme 2}

The interpolation scheme 2 is indicated in figure C.2 to obtain more realistic values for fans not analyzed. The fan numbers which are underlined are the fans that are analyzed numerically (volumetric effectiveness). The volumetric effectiveness of the fans which are not underlined has to be determined by an interpolation or an extrapolation scheme (refer to figures C.3 to C.5). The volumetric effectiveness of fan $(4,4)$ is, as in scheme 1 , found by interpolation:

$\mathrm{V}_{\mathrm{f}(4,4)} / \mathrm{V}_{\text {fid }}=\left(\mathrm{V}_{\mathrm{f}(4,3)}+\mathrm{V}_{\mathrm{f}(4,5)}\right) / 2 \mathrm{~V}_{\text {fid }}$

More realistic values of volumetric effectiveness of fan(4,2), fan(5,2) and fan(6,2) are obtained by extrapolation from downstream fans. In the case of fan $(4,2)$ :

$\mathrm{V}_{\mathrm{f}(4,2)} / \mathrm{V}_{\text {fid }}=\left\{\mathrm{V}_{\mathrm{f}(4,3)}+\left(\mathrm{V}_{\mathrm{f}(4,3)}-\mathrm{V}_{\mathrm{f}(4,4)}\right)\right\} / \mathrm{V}_{\text {fid }}$ 


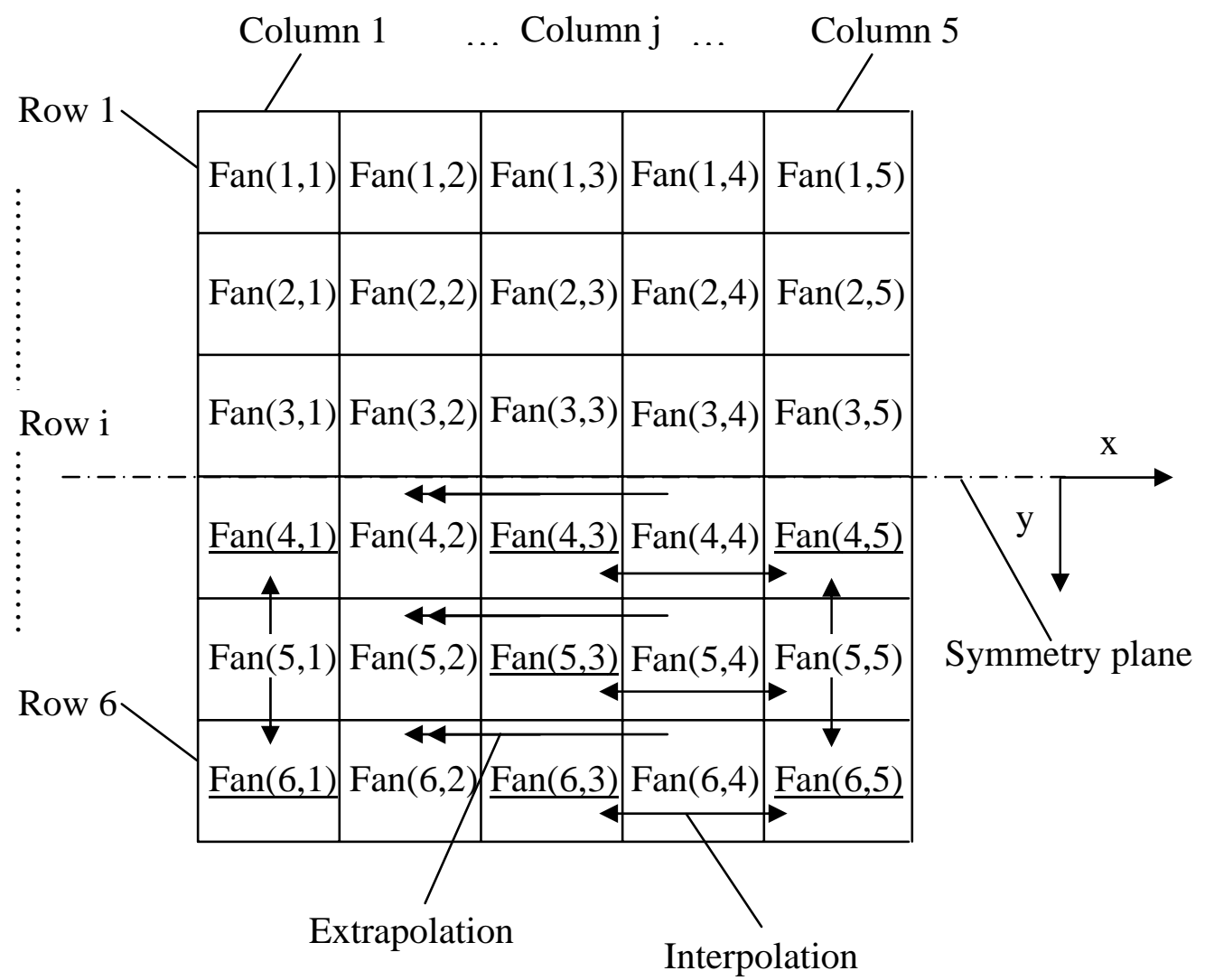

Figure C.2: Interpolation scheme 2.

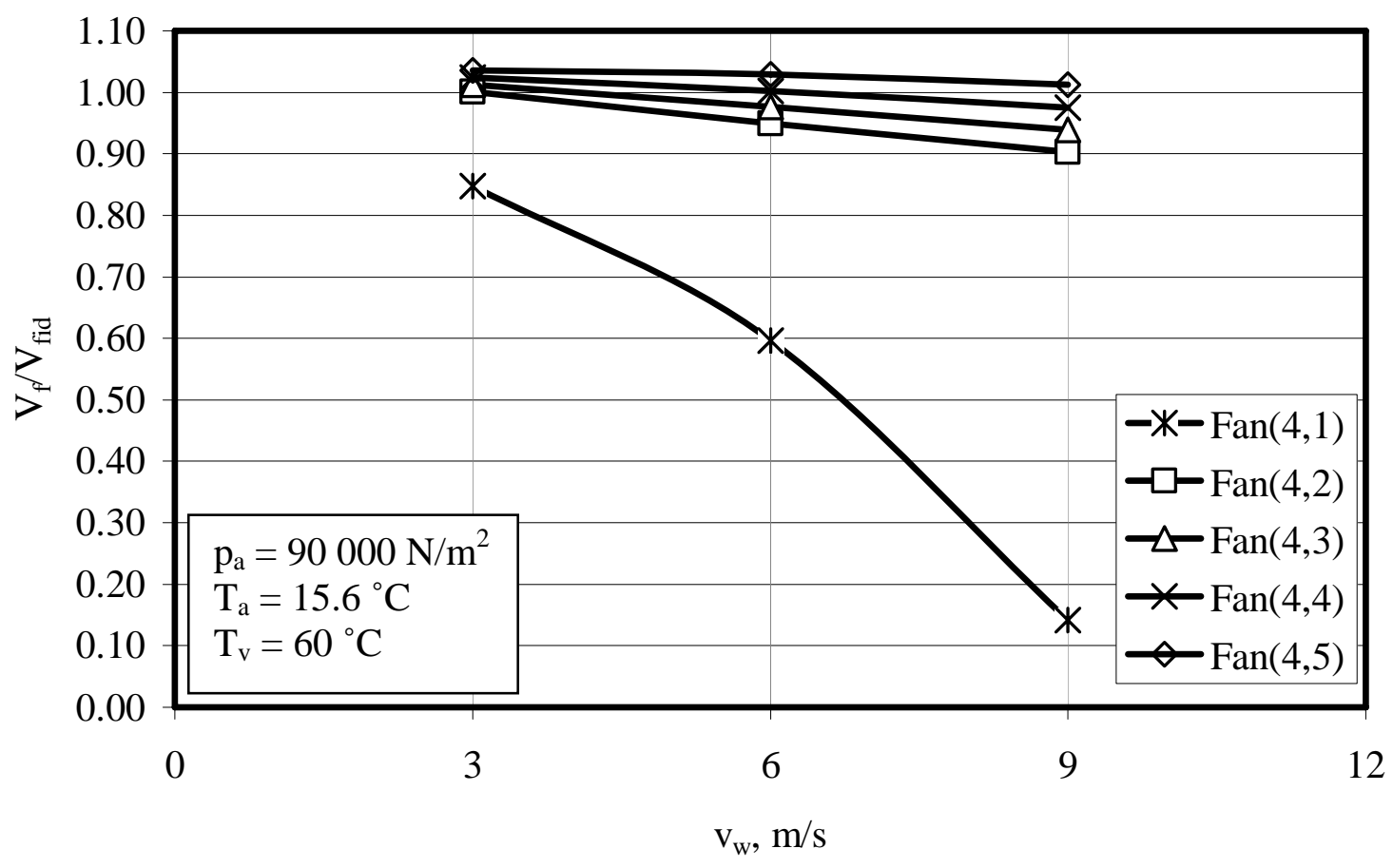

Figure C.3: Volumetric effectiveness of the fans in row 4. 


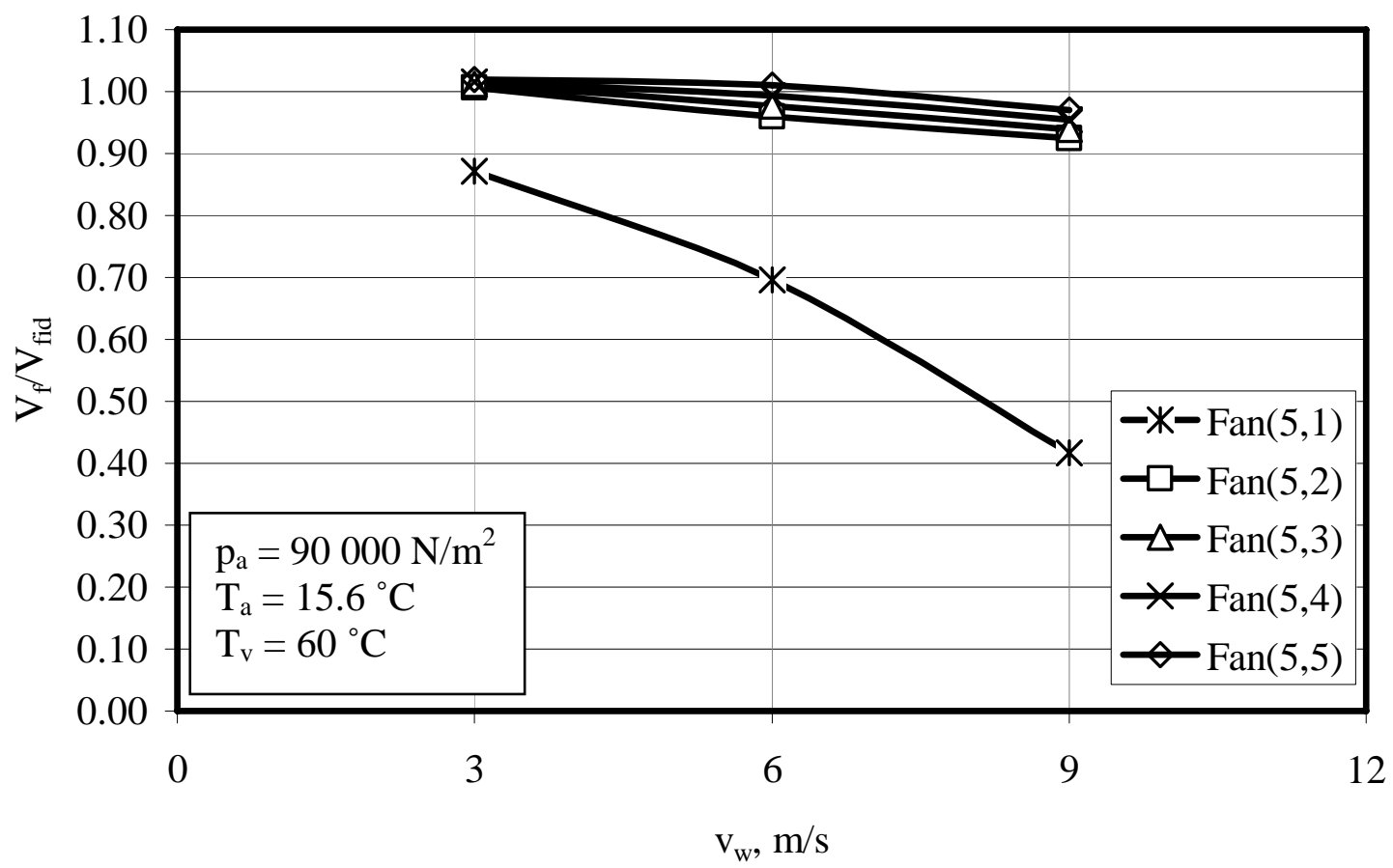

Figure C.4: Volumetric effectiveness of the fans in row 5.

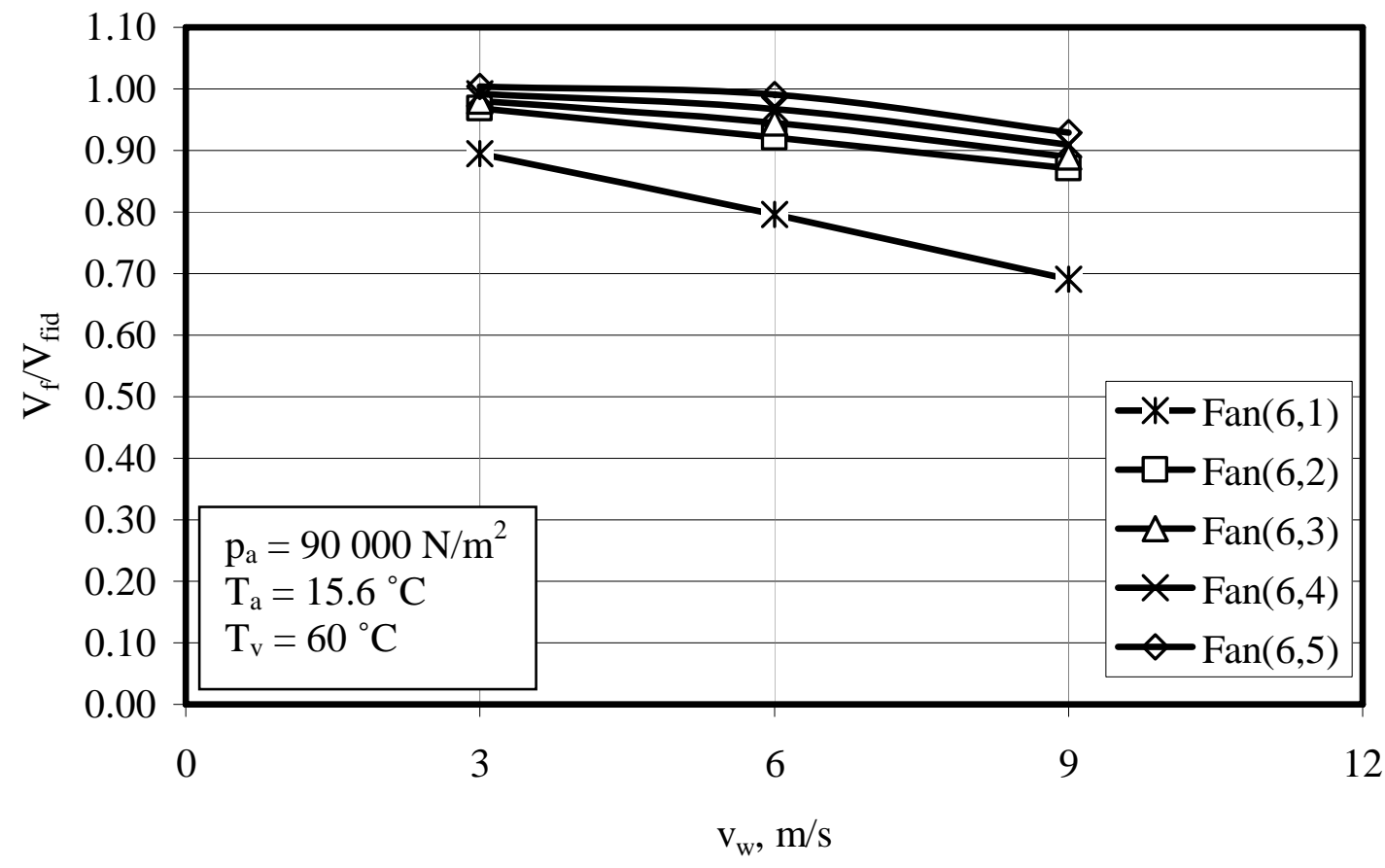

Figure C.5: Volumetric effectiveness of the fans in row 6. 


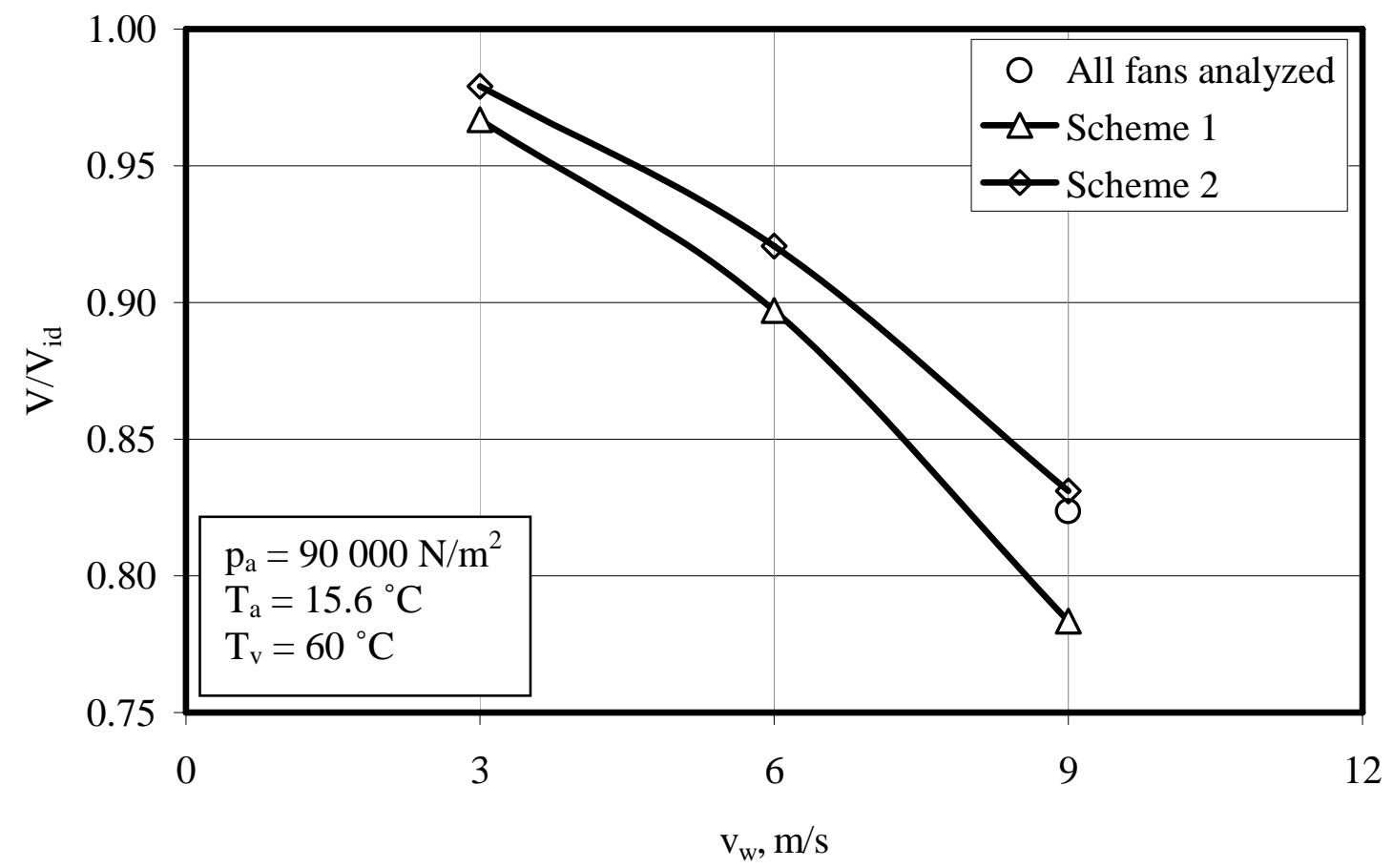

Figure C.6: Volumetric effectiveness of ACSC.

The two interpolation schemes are compared in figure C.6. Interpolation scheme 2 is found to be in better agreement with the one case where all the fans were analyzed (see tables C.1 and C.2).

Table C.1: Volumetric effectiveness of each fan at a wind speed of 9 m/s.

\begin{tabular}{|c|c|c|c|c|}
\hline Fan(4,1) & Fan(4,2) & Fan(4,3) & Fan(4,4) & Fan(4,5) \\
0.1423 & 0.8617 & 0.9390 & 0.9792 & 1.012 \\
\hline Fan(5,1) & Fan(5,2) & Fan(5,3) & Fan(5,4) & Fan(5,5) \\
0.3433 & 0.8724 & 0.9395 & 0.9750 & 1.007 \\
\hline Fan(6,1) & Fan(6,2) & Fan(6,3) & Fan(6,4) & Fan(6,5) \\
0.6907 & 0.8565 & 0.89 & 0.9176 & 0.9286 \\
\hline
\end{tabular}


Table C.2: Air inlet temperature, ${ }^{\circ} \mathrm{C}$, at each fan at a wind speed of $9 \mathrm{~m} / \mathrm{s}$.

\begin{tabular}{|c|c|c|c|c|}
\hline $\begin{array}{c}\text { Fan(4,1) } \\
15.6{ }^{\circ} \mathrm{C}\end{array}$ & $\begin{array}{c}\operatorname{Fan}(4,2) \\
15.6{ }^{\circ} \mathrm{C}\end{array}$ & $\begin{array}{c}\text { Fan(4,3) } \\
15.6{ }^{\circ} \mathrm{C}\end{array}$ & $\begin{array}{c}\text { Fan }(4,4) \\
15.6{ }^{\circ} \mathrm{C}\end{array}$ & $\begin{array}{c}\text { Fan }(4,5) \\
15.6{ }^{\circ} \mathrm{C}\end{array}$ \\
\hline $\operatorname{Fan}(5,1)$ & $\operatorname{Fan}(5,2)$ & $\operatorname{Fan}(5,3)$ & $\operatorname{Fan}(5,4)$ & $\operatorname{Fan}(5,5)$ \\
$15.6{ }^{\circ} \mathrm{C}$ & $15.6{ }^{\circ} \mathrm{C}$ & $15.6{ }^{\circ} \mathrm{C}$ & $15.6{ }^{\circ} \mathrm{C}$ & $15.63{ }^{\circ} \mathrm{C}$ \\
\hline $\operatorname{Fan}(6,1)$ & $\operatorname{Fan}(6,2)$ & $\operatorname{Fan}(6,3)$ & $\operatorname{Fan}(6,4)$ & $\operatorname{Fan}(6,5)$ \\
$15.68{ }^{\circ} \mathrm{C}$ & $15.94{ }^{\circ} \mathrm{C}$ & $19.03{ }^{\circ} \mathrm{C}$ & $21.5^{\circ} \mathrm{C}$ & $21.67{ }^{\circ} \mathrm{C}$ \\
\hline
\end{tabular}

\section{C.3. Interpolation scheme 3}

The interpolation scheme 3 is indicated in figure C.7. The fan numbers which are underlined are the fans that are analyzed numerically (volumetric effectiveness). In interpolation scheme 3 the volumetric effectiveness of the unsolved fans (numerically not analyzed) are calculated by extrapolating as well as interpolating (equations C. 2 and C.3 are used). Figures C.8 to C.13 show the volumetric effectiveness of each fan.

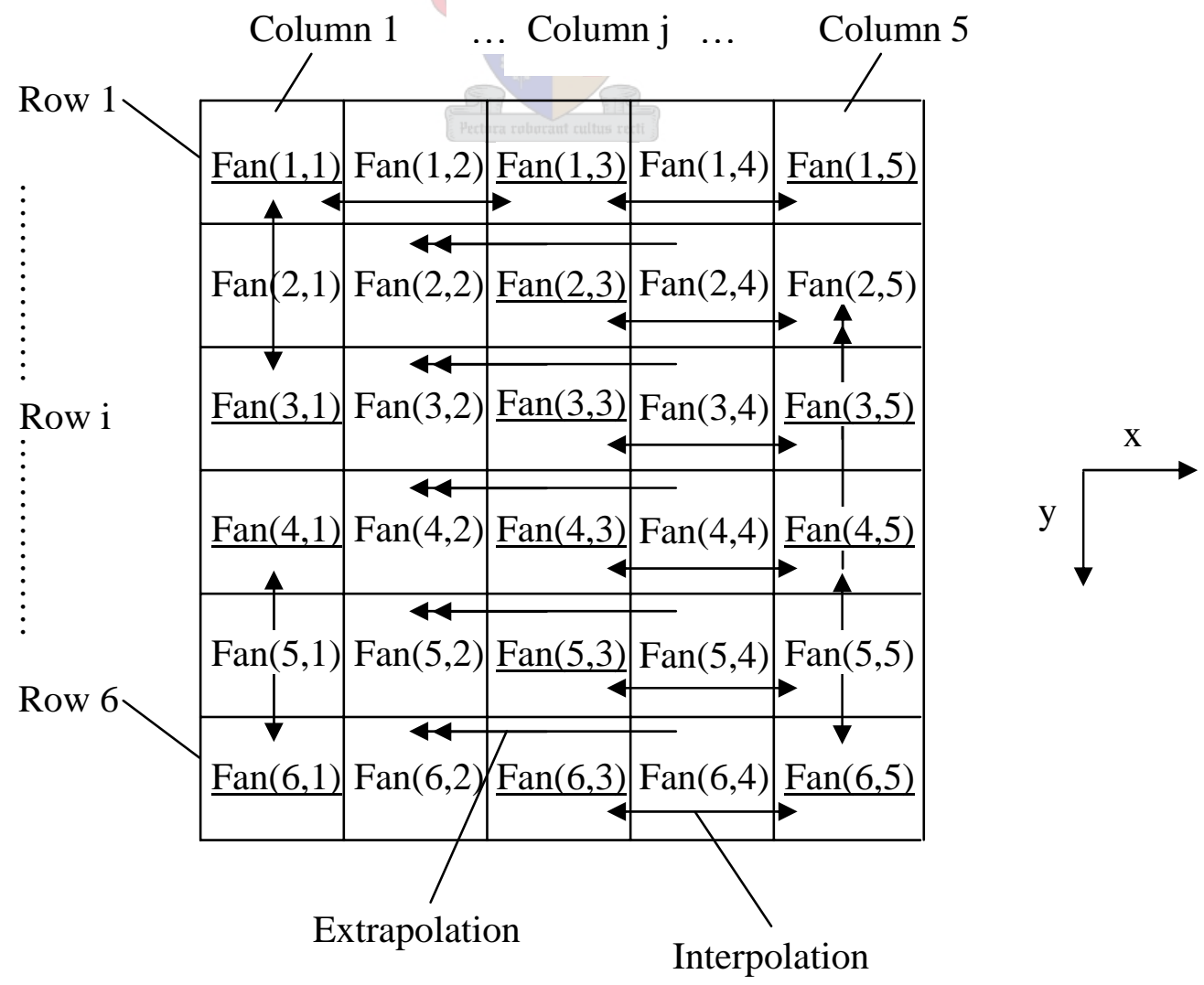

Figure C.7: Interpolation scheme 3. 


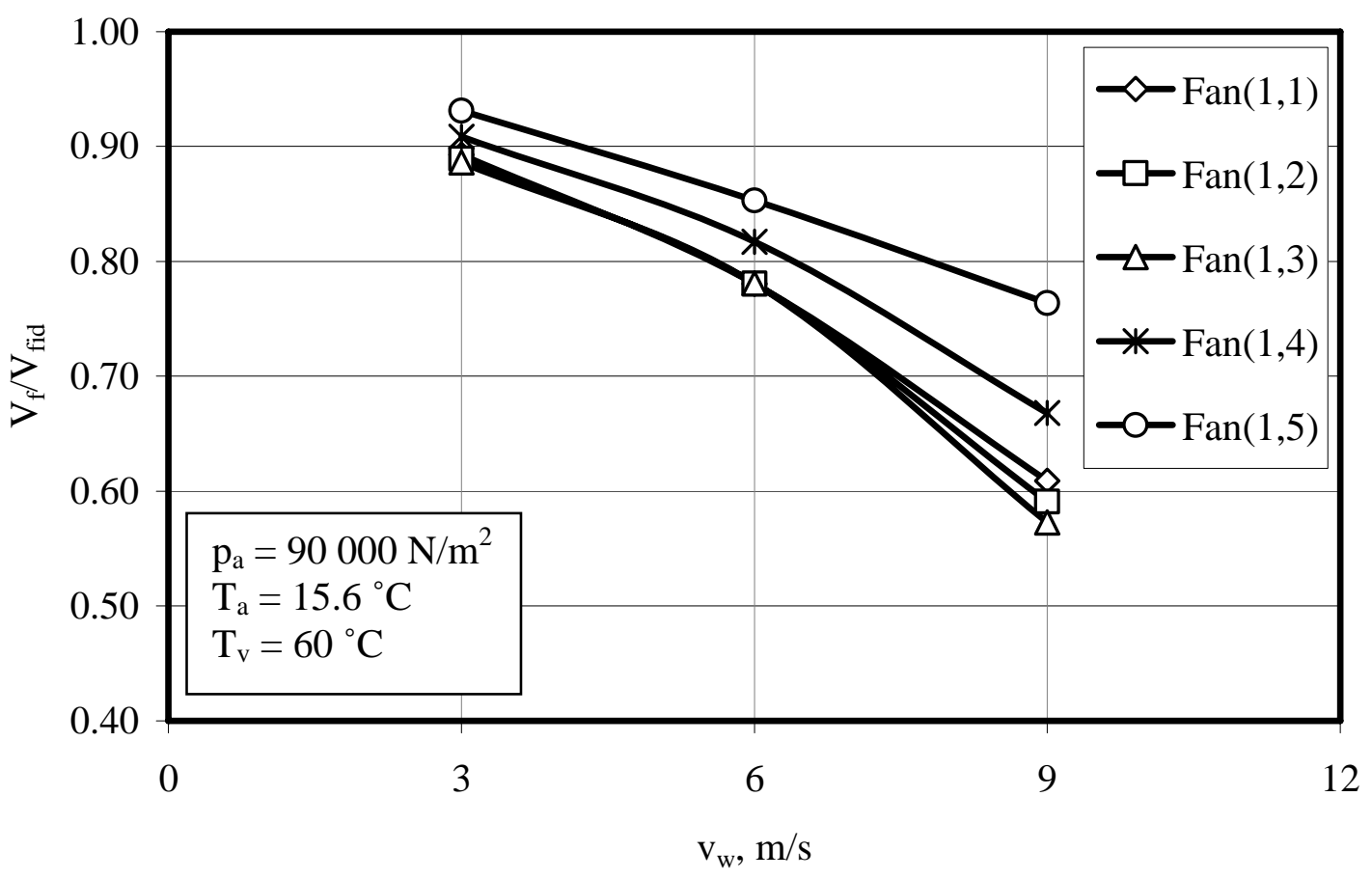

Figure C.8: Volumetric effectiveness of the fans in row 1.

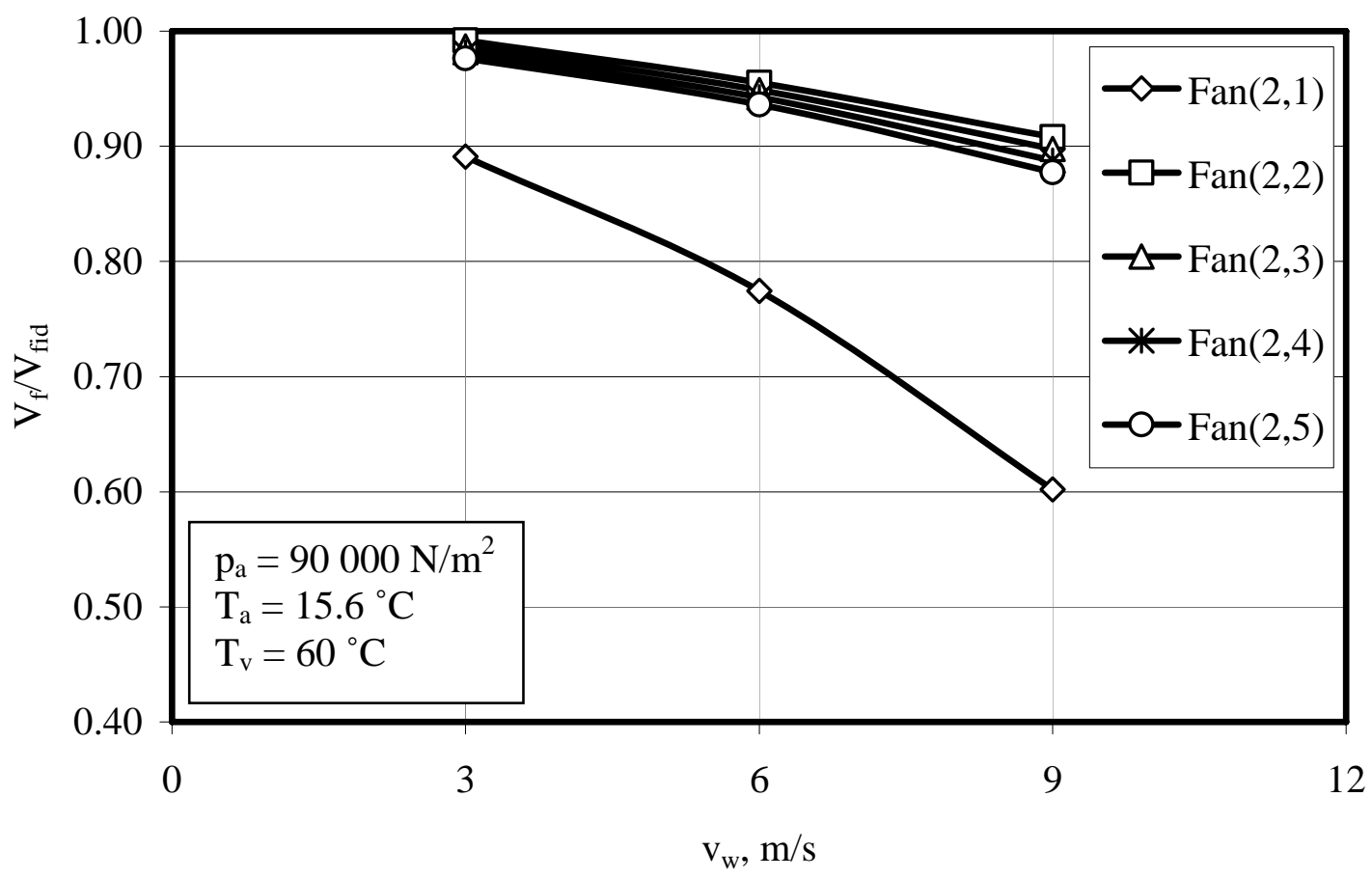

Figure C.9: Volumetric effectiveness of the fans in row 2. 


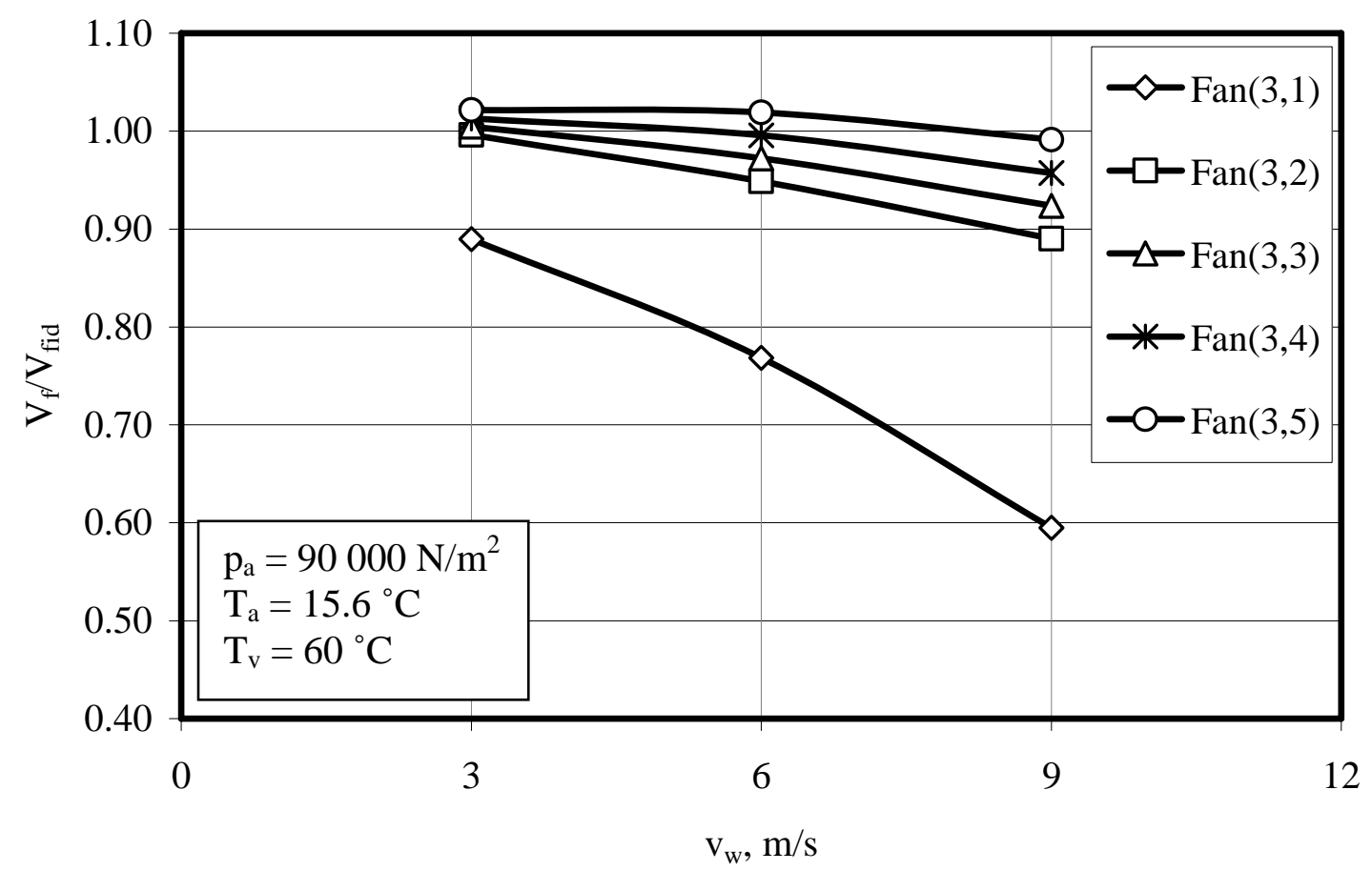

Figure C.10: Volumetric effectiveness of the fans in row 3.

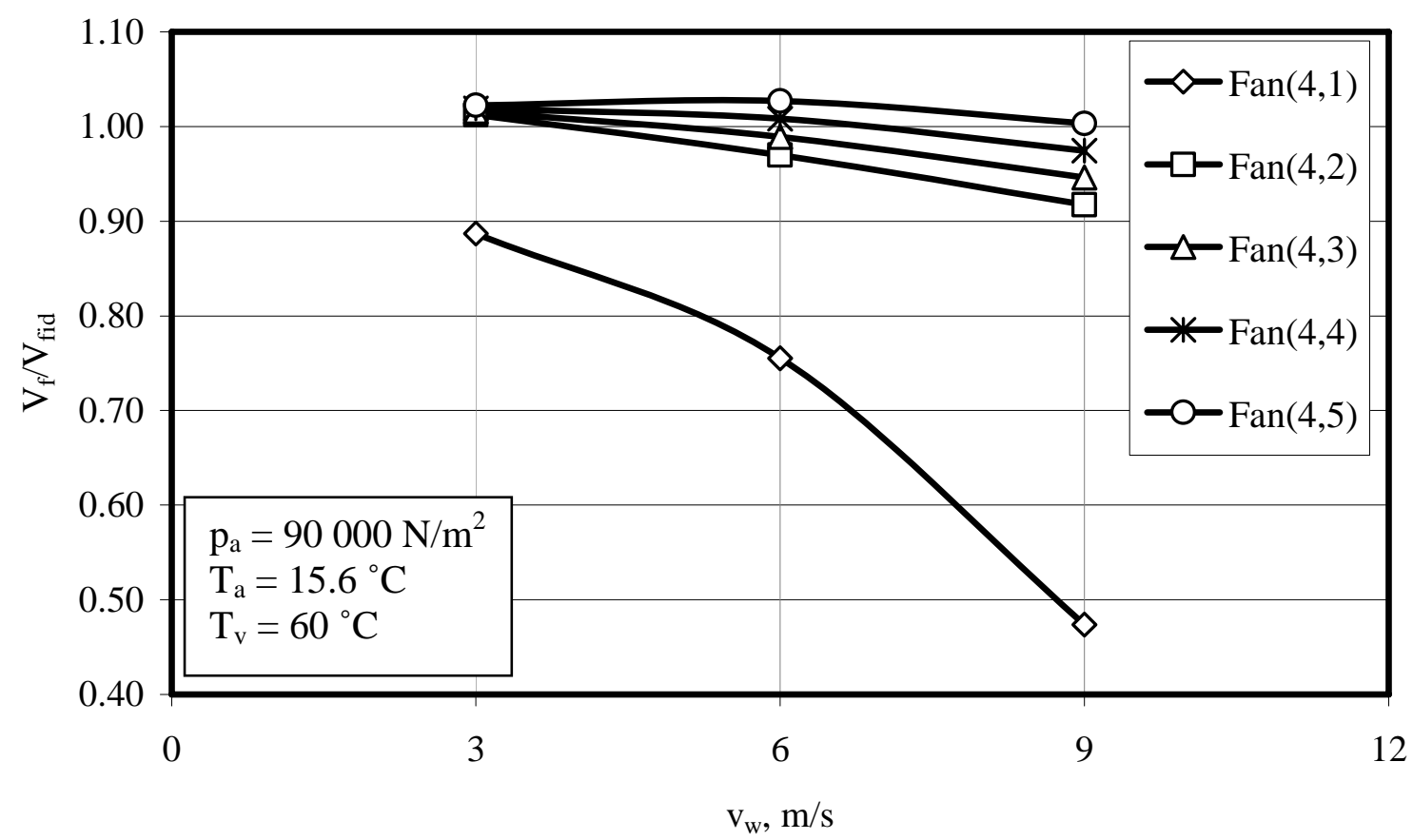

Figure C.11: Volumetric effectiveness of the fans in row 4. 


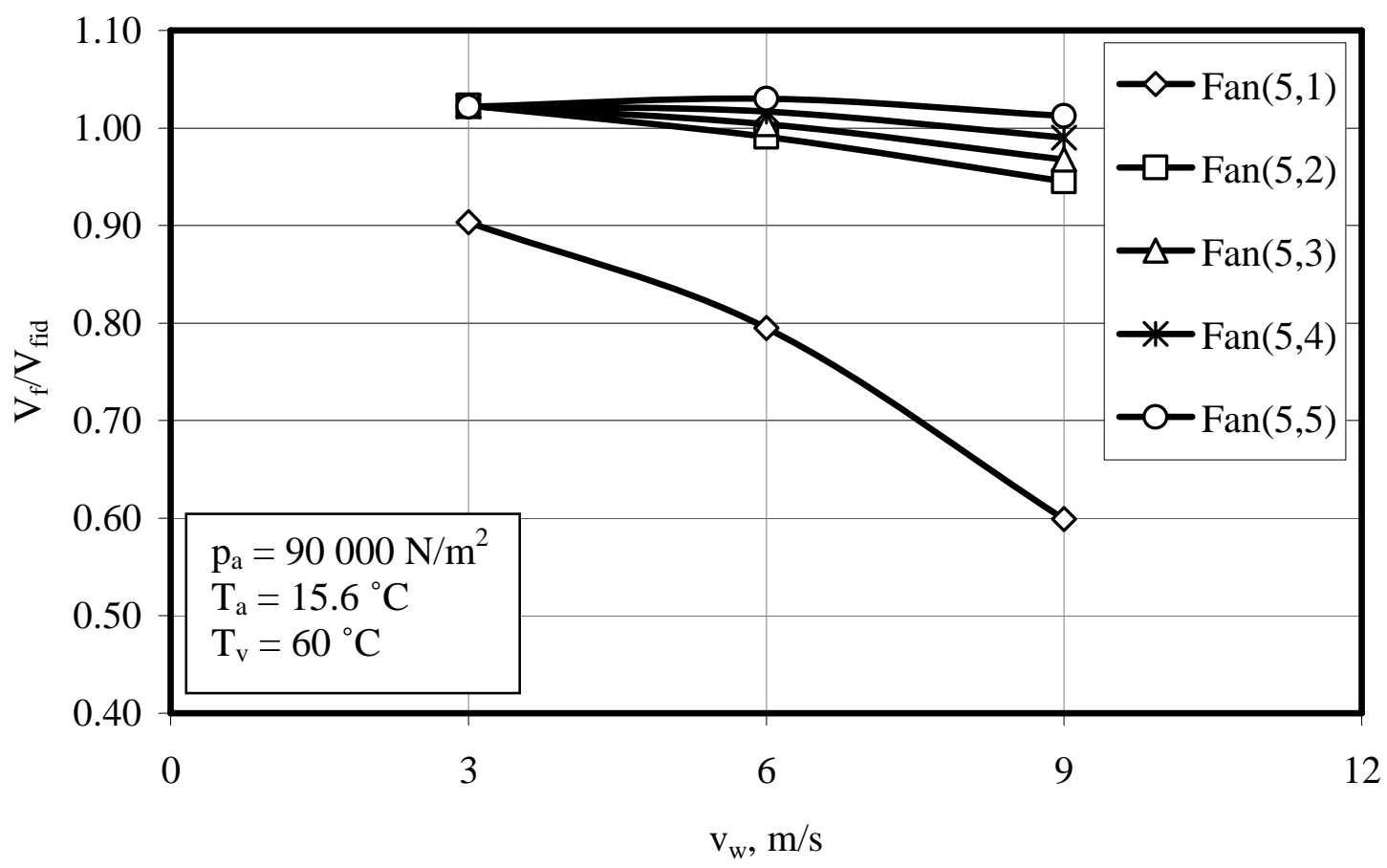

Figure C.12: Volumetric effectiveness of the fans in row 5.

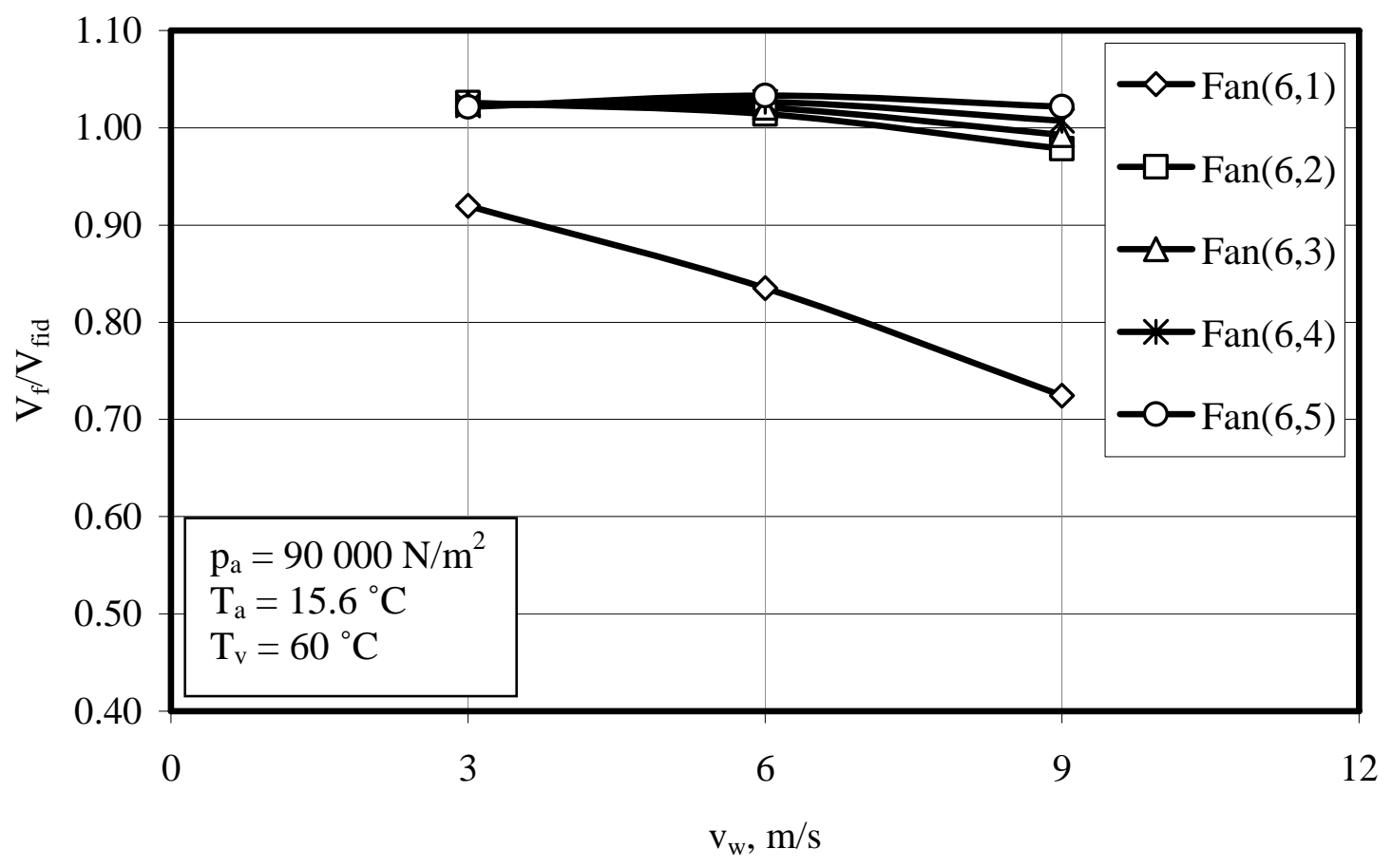

Figure C.13: Volumetric effectiveness of the fans in row 6. 


\section{C.4. Interpolation scheme 4}

The interpolation scheme 4 is indicated in figure C.14. The fan numbers which are underlined are the fans that are analyzed numerically (volumetric effectiveness). In interpolation scheme 4 the volumetric effectiveness of the unsolved fans (numerically not analyzed) are calculated by extrapolating as well as interpolating (equations C.4 to C.8 are used). Figures C.15 to C.17 show the volumetric effectiveness of each fan.

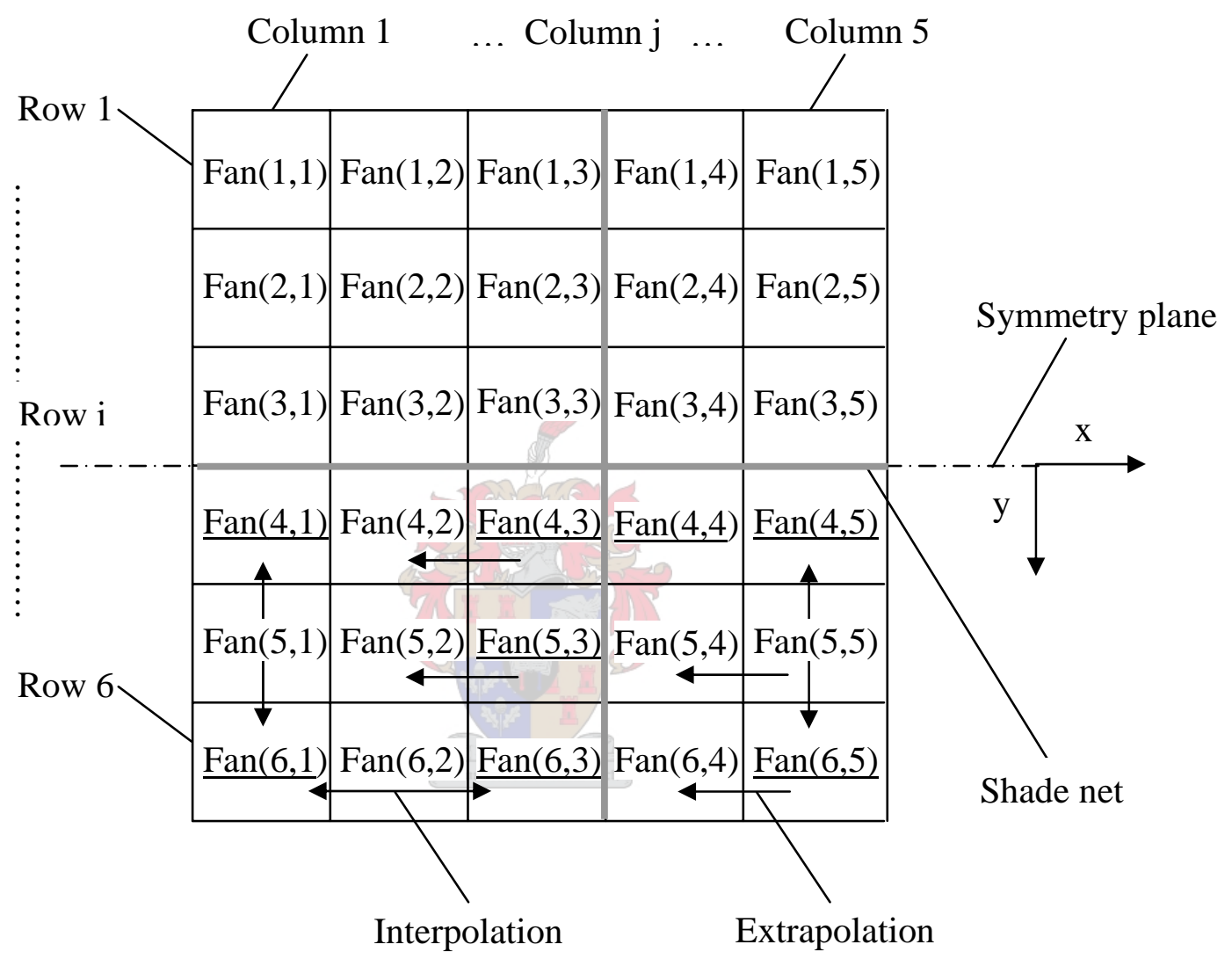

Figure C.14: Interpolation scheme 4.

The volumetric effectiveness of fan $(5,1)$ is, as in scheme 1 , scheme 2 and scheme 3 , found by interpolation:

$\mathrm{V}_{\mathrm{f}(5,1)} / \mathrm{V}_{\mathrm{fid}}=\left(\mathrm{V}_{\mathrm{f}(6,1)}+\mathrm{V}_{\mathrm{f}(4,1)}\right) / 2 \mathrm{~V}_{\text {fid }}$

The extrapolation method used in this scheme differs from the previous schemes:

$\mathrm{V}_{\mathrm{f}(4,2)} / \mathrm{V}_{\mathrm{fid}}=\left\{\mathrm{V}_{\mathrm{f}(4,3)}+\left(\mathrm{V}_{\mathrm{f}(6,2)}-\mathrm{V}_{\mathrm{f}(6,3)}\right)\right\} / \mathrm{V}_{\text {fid }}$ 
$\mathrm{V}_{\mathrm{f}(5,2)} / \mathrm{V}_{\text {fid }}=\left\{\mathrm{V}_{\mathrm{f}(5,3)}+\left(\mathrm{V}_{\mathrm{f}(6,2)}-\mathrm{V}_{\mathrm{f}(6,3)}\right)\right\} / \mathrm{V}_{\text {fid }}$

$\mathrm{V}_{\mathrm{f}(5,4)} / \mathrm{V}_{\text {fid }}=\left\{\mathrm{V}_{\mathrm{f}(5,5)}+\left(\mathrm{V}_{\mathrm{f}(4,4)}-\mathrm{V}_{\mathrm{f}(4,5))\} / \mathrm{V}_{\text {fid }}}\right.\right.$

$\mathrm{V}_{\mathrm{f}(6,4)} / \mathrm{V}_{\text {fid }}=\left\{\mathrm{V}_{\mathrm{f}(6,5)}+\left(\mathrm{V}_{\mathrm{f}(4,4)}-\mathrm{V}_{\mathrm{f}(4,5)}\right)\right\} / \mathrm{V}_{\text {fid }}$

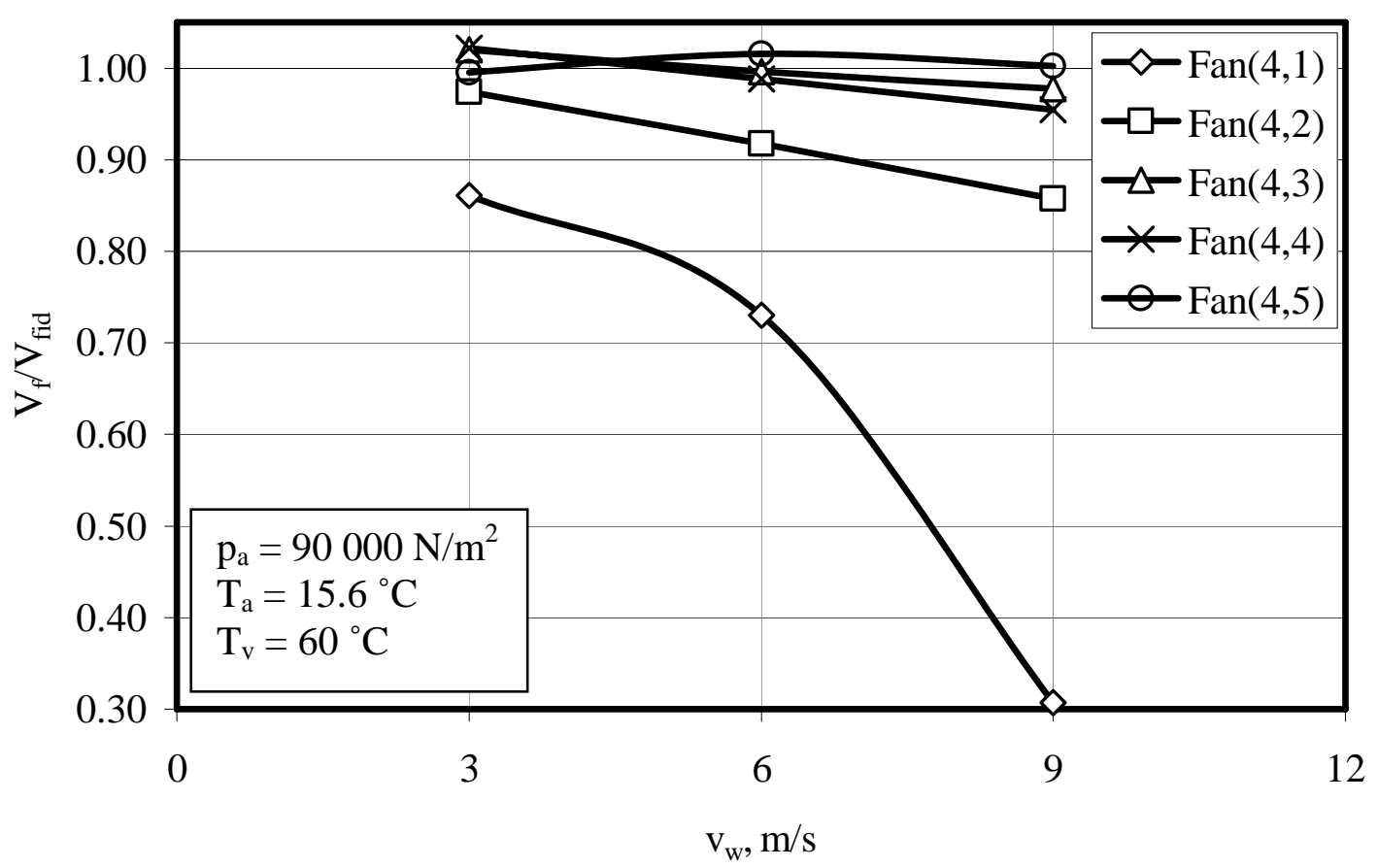

Figure C.15: Volumetric effectiveness of the fans in row 4.

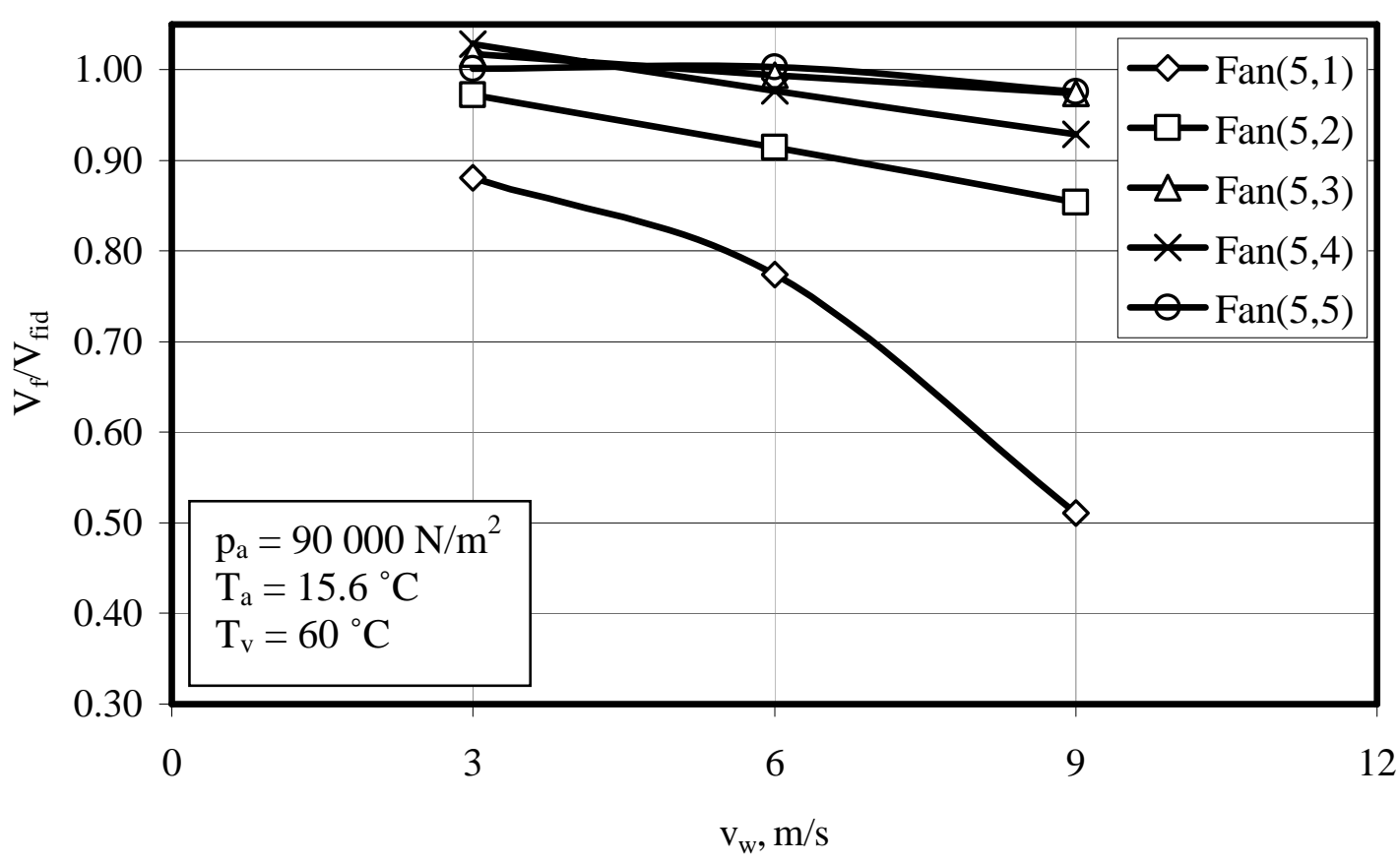

Figure C.16: Volumetric effectiveness of the fans in row 5. 


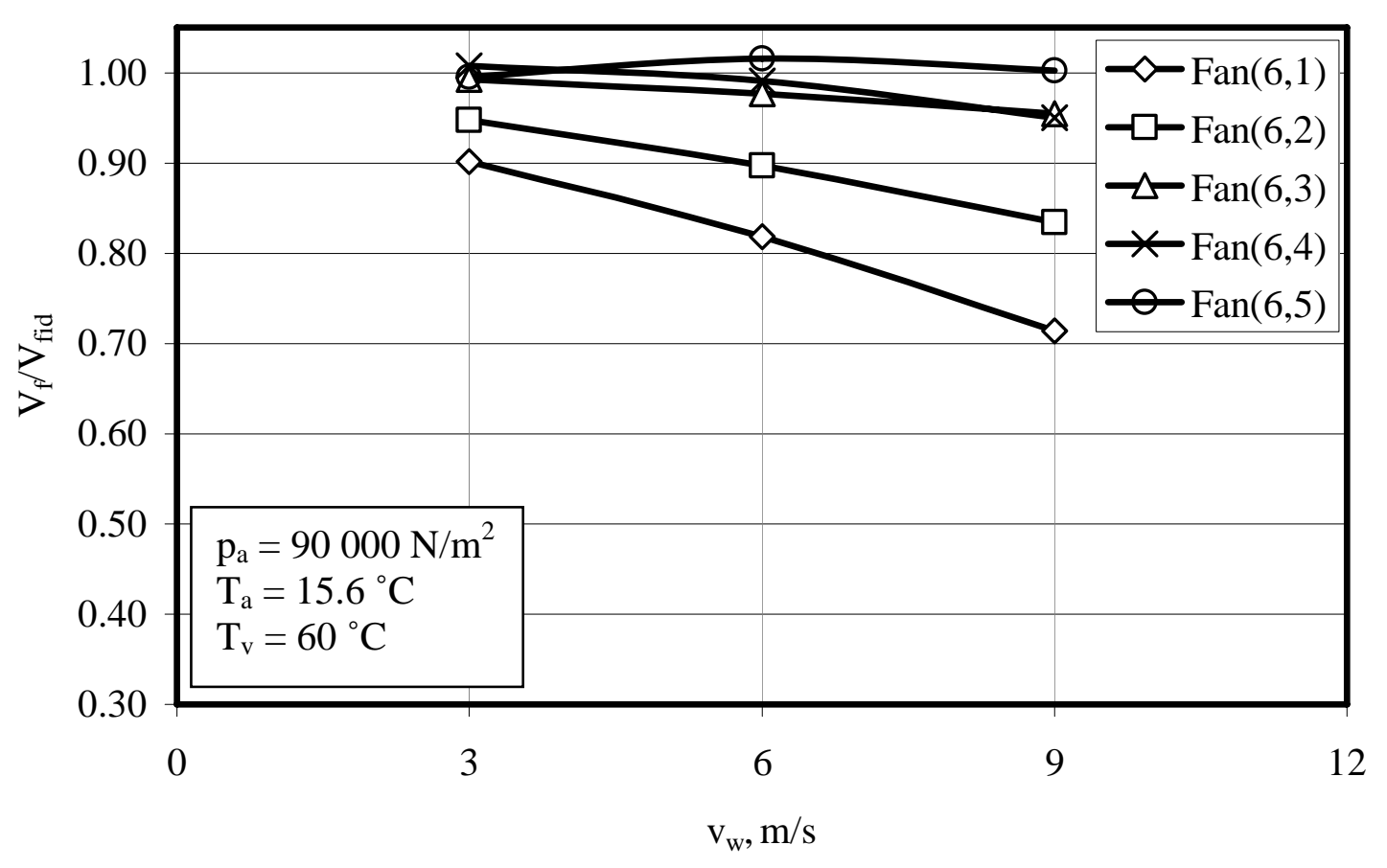

Figure C.17: Volumetric effectiveness of the fans in row 6. 


\section{APPENDIX D \\ SENSITIVITY ANALYSIS}

The objective of this chapter is to determine the effect that wind profile, buoyancy and fan inlet shape have on the global flow field and the resultant ACSC volumetric effectiveness when the wind blows in the x-direction at speeds of 3, 6 and $9 \mathrm{~m} / \mathrm{s}$.

Case 1: Uniform wind profile, rectangular uniform fan inlet and adiabatic conditions (no heat transfer).

Case 2: Uniform wind profile, rectangular uniform fan inlet and non-adiabatic conditions (heat transfer).

Case 3: Non-uniform wind profile, rectangular uniform fan inlet and adiabatic conditions (no heat transfer).

Case 4: Non-uniform wind profile, rectangular uniform fan inlet and non-adiabatic conditions (heat transfer).

Case 5: Non-uniform wind profile and non-adiabatic conditions (heat transfer). Replacing the rectangular uniform fan inlets in the global flow field with circular uniform fan inlets.

\section{D.1. Effect of buoyancy}

Compare case 1 with 2 and case 3 with 4 in figure E.1.

Case 1 assumes a uniform wind velocity distribution and no buoyancy effects. The resultant volumetric effectiveness is shown in figure D.1. When buoyancy effects are considered (case 2) the volumetric effectiveness is approximately $2 \%$ higher at a speed of $3 \mathrm{~m} / \mathrm{s}$ and less than $1 \%$ lower at a speed of $9 \mathrm{~m} / \mathrm{s}$.

Buoyancy effects are similar in the case (case 3 and 4) of a non-uniform wind profile $\left(\mathrm{v}_{\mathrm{H}}=\mathrm{v}_{\mathrm{ref}}\left(\mathrm{H} / \mathrm{H}_{\mathrm{ref}}\right)^{1 / 7}\right)$. 


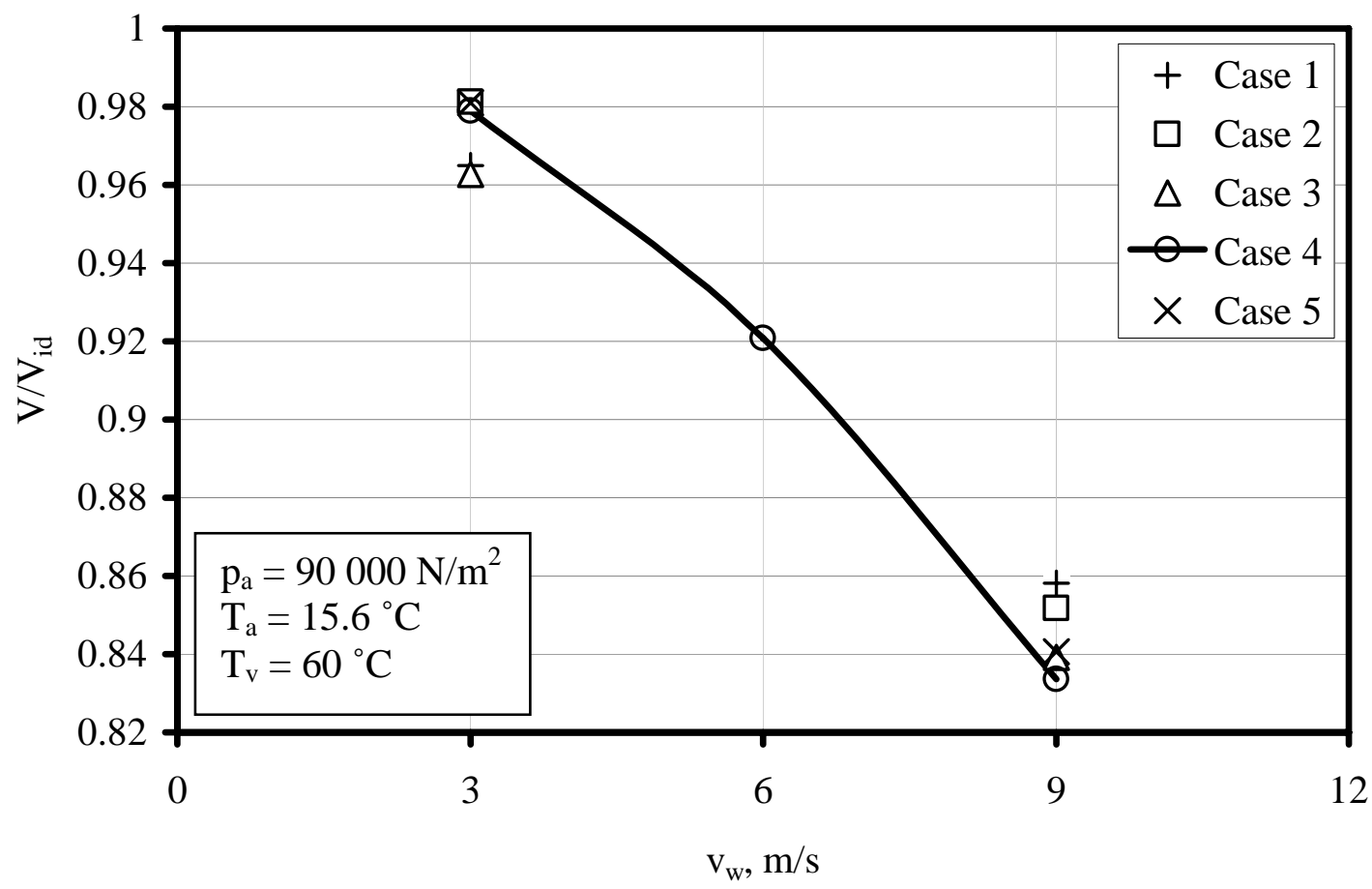

Figure D.1: System volumetric effectiveness.

\section{D.2. Effect of wind profile}

Compare case 1 with case 3 and case 2 with case 4 in figure E.1.

At a wind speed of $3 \mathrm{~m} / \mathrm{s}$, the volumetric effectiveness hardly changes when the wind profile is altered from uniform to non-uniform, but at $9 \mathrm{~m} / \mathrm{s}$ it decreases by about $2 \%$ when the wind profile is altered from uniform to non-uniform. The same trend is observed when cases 2 and 4 are compared.

From the above results it may be concluded that the volumetric effectiveness is little affected by differences in upstream wind velocity distributions.

\section{D.3. Effect of fan inlet shape}

Compare case 4 with 5 in figure D.1.

In case 4 the boundary condition at the inlet to the ACSC is simply assumed to be an area across which the flow is uniform (see figure D.2). In a more realistic model this area should be replaced by the round or circular inlets of the individual fans as assumed in case 5 and 
shown schematically in figure D.3. When comparing the results of these two cases as shown in figure D.1 it is noted that the difference between the two cases is negligible.
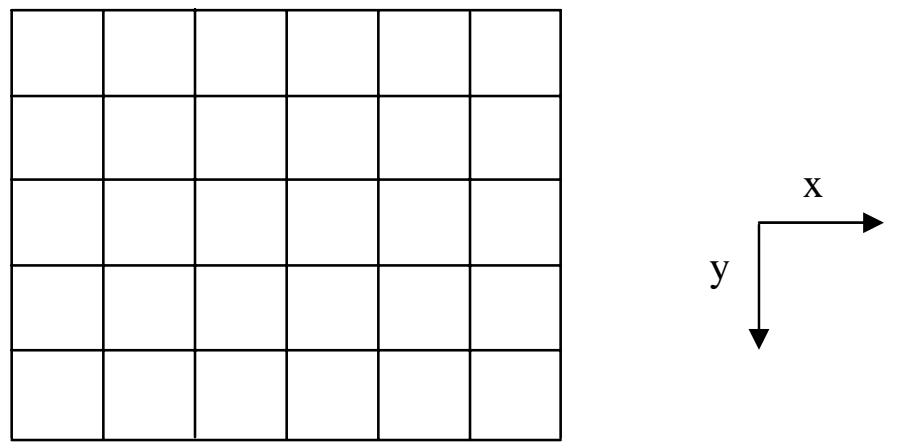

Figure D.2: Case 4, Global flow field with rectangular fan inlets (uniform inlet velocity distribution).
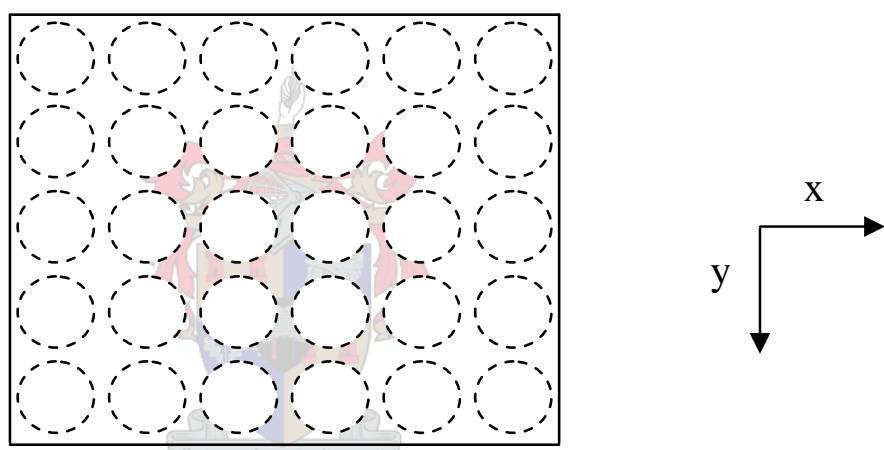

Figure D.3: Case 5, Global flow field with circular fan inlets (uniform inlet velocity distribution). 